\title{
Optimizing intersectoral collaboration in school health promotion : creating win-win situations and a systematic implementation based on the diagnosis of sustainable collaboration model
}

Citation for published version (APA):

Pucher, K. K. (2015). Optimizing intersectoral collaboration in school health promotion : creating win-win situations and a systematic implementation based on the diagnosis of sustainable collaboration model. [Doctoral Thesis, Maastricht University]. Datawyse / Universitaire Pers Maastricht. https://doi.org/10.26481/dis.20151214kp

Document status and date:

Published: 01/01/2015

DOI:

10.26481/dis.20151214kp

Document Version:

Publisher's PDF, also known as Version of record

Please check the document version of this publication:

- A submitted manuscript is the version of the article upon submission and before peer-review. There can be important differences between the submitted version and the official published version of record. People interested in the research are advised to contact the author for the final version of the publication, or visit the DOI to the publisher's website.

- The final author version and the galley proof are versions of the publication after peer review.

- The final published version features the final layout of the paper including the volume, issue and page numbers.

Link to publication

\footnotetext{
General rights rights.

- You may freely distribute the URL identifying the publication in the public portal. please follow below link for the End User Agreement:

www.umlib.nl/taverne-license

Take down policy

If you believe that this document breaches copyright please contact us at:

repository@maastrichtuniversity.nl

providing details and we will investigate your claim.
}

Copyright and moral rights for the publications made accessible in the public portal are retained by the authors and/or other copyright owners and it is a condition of accessing publications that users recognise and abide by the legal requirements associated with these

- Users may download and print one copy of any publication from the public portal for the purpose of private study or research.

- You may not further distribute the material or use it for any profit-making activity or commercial gain

If the publication is distributed under the terms of Article 25fa of the Dutch Copyright Act, indicated by the "Taverne" license above, 


\section{Optimizing intersectoral collaboration in school health promotion}

Creating win-win situations and a systematic implementation based on the Diagnosis of Sustainable Collaboration model

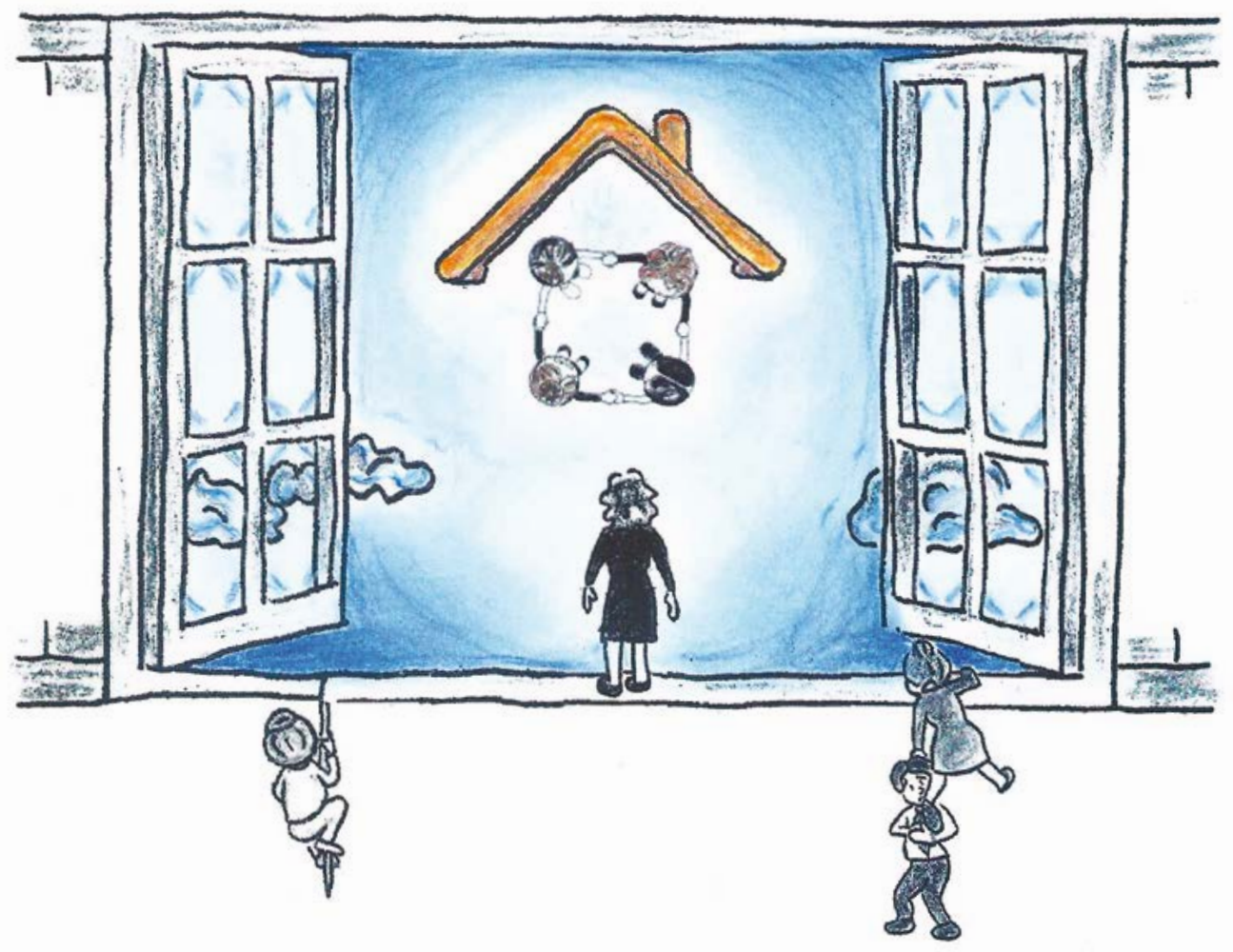

Katharina K. Pucher 


\section{Colophon}

Cover design and lay-out: Derya Sayin | Katharina K. Pucher

Production: Datawyse | Universitaire Pers Maastricht, The Netherlands

(C) Katharina K. Pucher, 2015

ISBN: 9789461595041

The research presented in this thesis was conducted at the School for Public Health and Primary Care (CAPHRI), Department of Health Promotion, Maastricht University. CAPHRI participates in the Netherlands School of Primary Care Research (CaRe). CAPHRI was classified as "excellent" by the external evaluation committee of leading international experts that reviewed CAPHRI in December 2010. The research presented in this dissertation was funded by the Netherlands Organization for Health Research and Development (ZonMW, Grant no. 63300019).

All rights are reserved. No part of this book may be reproduced or transmitted in any form or by any means, without the written permission from the author or, where appropriate, the publisher of the article. 


\section{Optimizing intersectoral collaboration in school health promotion}

Creating win-win situations and a systematic implementation based on the Diagnosis of Sustainable Collaboration model

\section{Proefschrift}

ter verkrijging van de graad van doctor aan de Universiteit Maastricht, op gezag van de Rector Magnificus, Prof. L.L.G. Soete, volgens het besluit van het College van Decanen, in het openbaar te verdedigen op maandag 14 december 2015 om 14:00 uur

$$
\text { door }
$$

Katharina Karolina Pucher

geboren op 4 december 1984 te Zabrze (Polen)

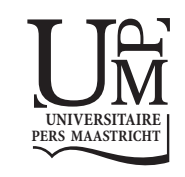




\section{Promotor}

Prof. dr. N.K. De Vries

\section{Copromotoren}

Dr. M.J.J.M. Candel

Dr. N.M.W.M. Boot

\section{Beoordelingscommissie}

Prof. dr. S.P.J. Kremers (voorzitter)

Dr. V. Bos, Rijksinstituut voor Volksgezondheid en Milieu, Bilthoven

Dr. K. Dadaczynski, Leuphana University, Lueneburg

Prof. dr. ir. M.W.J. Jansen

Prof. dr. G. Kok 


\section{Contents}

Chapter 1

General introduction

Part I Benefits of health promotion for the educational sector

Chapter 2

School health promotion interventions targeting physical activity and nutrition

can improve academic performance in primary- and middle school children

Part II A systematic approach to the establishment of

intersectoral collaboration in CSHP

Chapter 3

A multiple-case study of intersectoral collaboration in comprehensive school health

promotion using the Diagnosis of Sustainable Collaboration model

Chapter 4

Effectiveness of a systematic approach to promote intersectoral collaboration

in comprehensive school health promotion - a multiple-case study using

quantitative and qualitative data

Chapter 5

Predictors and mediators of sustainable collaboration and implementation

in comprehensive school health promotion

Chapter 6

General discussion

Valorization Addendum

Appendices

Summary

Samenvatting

Curriculum Vitae

Dankwoord

Publication list 

Chapter 1 General introduction

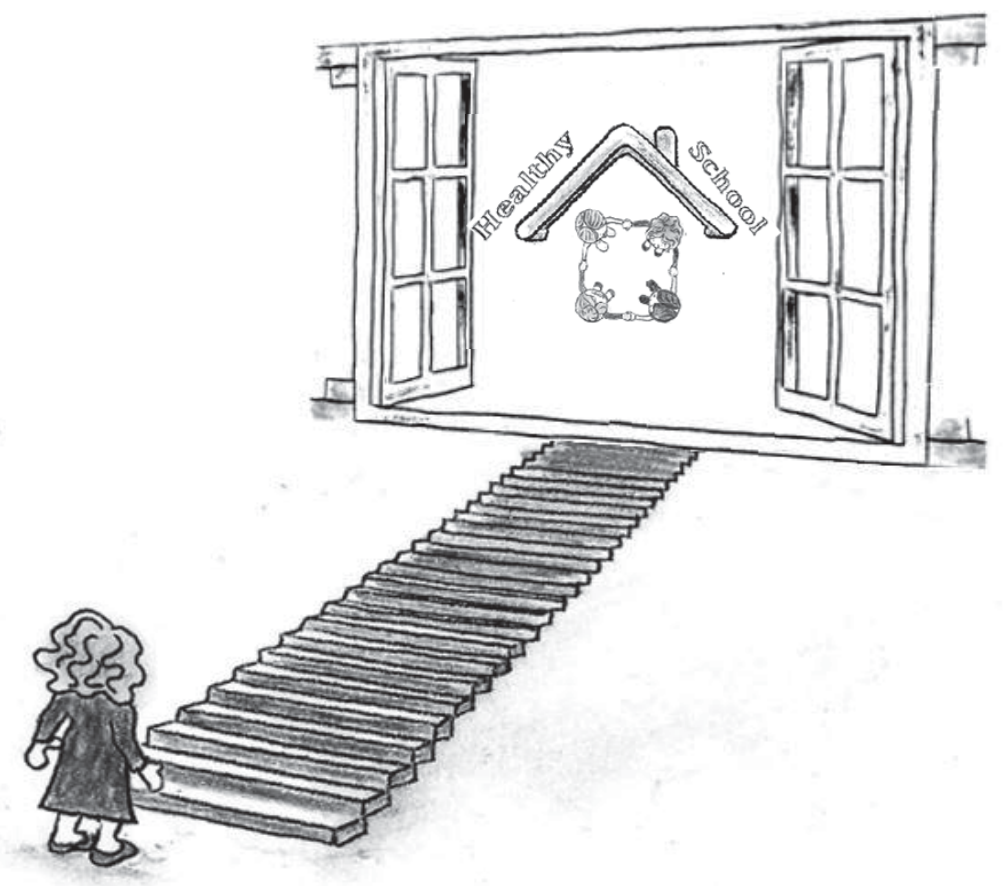



Interest in successful collaborations for health promotion is rising. Not only is there an increasing number of initiatives employing a comprehensive approach in which interdisciplinary teams have to work together (Stahl, Wismar, Ollila, Lahtinen, \& Leppo, 2006; Warner \& Gould, 2009), but the number of health professionals responsible for building and sustaining coalitions is also increasing (Barry et al., 2012).

The need for collaboration also applies to comprehensive school health promotion $(\mathrm{CSHP})^{1}$, a context in which teachers, school administrators and authorities combine forces with organizations working in the field of public health, addiction care, mental health, youth care and social welfare. Together they work to achieve improvements in students' health and health behavior as well as their physical and social environment. The CSHP approach is based on planned and sequential health promotion and education through the whole curriculum, participation of the whole school community and integrated multiple interventions of outstanding quality supplied by public organizations (Allensworth \& Kolbe, 1987; Marx, Wooley, \& Northrop, 1998). The range of parties involved (e.g. schools, prevention agencies and health authorities), the tasks to be accomplished (e.g. at individual (students and teachers), school and public stakeholder levels) and preconditions to be met (e.g. funding and supporting local health policy) require know-how on intersectoral collaboration and its systematic development.

Although the World Health Organization (WHO) has recognized CSHP as an effective means of improving children's wellbeing and health (IUHPE, 2009), its introduction is hampered by ongoing debates about schools' social responsibility to implement health promotion (WHO, 2014). In the Netherlands, debates are fueled by the lack of policies obliging schools to implement health promotion, and their inability to handle the overwhelming range of programs being offered (Boot, van Assema, Hesdahl, \& de Vries, 2010a; Boot, van Assema, Hesdahl, Leurs, \& de Vries, 2010b). Studies among Dutch schools showed that the lack of binding policies results in health promotion not being included in the general workload (i.e. the task description and budgets for personnel) and not being supported by all organizational tiers. The studies also showed that schools feel overloaded with health promotion programs and find it difficult to choose (Boot, 2011). However, there are also schools that are starting to recognize that CSHP addresses health and social issues, which can in turn help to achieve educational targets. It seems that evidence supporting the positive relation between health promotion and educational outcomes can help to implement health promotion in schools, by providing a persuasive argument in line with the primary academic goals (St Leger, 2001).

\footnotetext{
${ }^{1}$ Comprehensive school health promotion is used as overarching term in this dissertation and refers to a wholeschool approach. It can be used interchangeably with the terms health promoting schools used in Europe and Australia and comprehensive school health promotion used in the USA and Canada.
} 
Just as important as schools for the implementation of CSHP at school are agencies that provide school-based programs and health promotion expertise at local and regional levels, and authorities that fund public health policy and youth health care. In the field of school health promotion, little is as yet known about ways to establish a functional collaborative structure between these sectors (Samdal \& Rowling, 2013). A first attempt to achieve this was made in 2008 by Leurs et al. (2008). When the first comprehensive approach to school health promotion was introduced in the Netherlands, and an appropriate collaborative structure had to be developed, Leurs et al. (2008) summarized their experiences with the establishment of this structure in the Dlagnosis of sustainable Collaboration (DISC) model. This model categorizes factors at individual, organizational and policy level into six main clusters: collaborative support, change management, project management, context, external factors, and sustainable collaboration. Leurs et al. (2008) found that that the DISC model can be used as a diagnostic instrument to study facilitators and barriers for CSHP collaborations. They also suggested that the results of the analysis can be used to make strategic choices about the future direction of the collaboration. The effectiveness of a systematic approach based on DISC analysis and appropriate strategies to improve intersectoral collaboration was never studied, however.

Both topics - the benefits of school health promotion for the educational sector and the systematic establishment of intersectoral collaboration in CSHP - are discussed in this dissertation. 


\section{Benefits of health promotion for the educational sector}

Health promotion in schools is regarded as a powerful and cost-effective global prevention strategy (WHO, 2015). The first reason is that the majority of young children are enrolled in schools, making schools an optimal place to reach many children at a young age, in order to intervene to promote healthy lifestyles. Secondly, schools are staffed with professional and nonprofessional workers, who have the capacity to teach children the skills and knowledge they need to make healthy choices later in their lives. In many countries (including the Netherlands), health is not included in the primary educational goals. A school's core business is limited to academic goals, such as mathematics and language. Given the recurrent debates about the school's responsibility to implement health promotion, strong and appealing arguments are called for to make the educational sector feel more committed and responsible for the implementation of health promotion initiatives in schools, despite all of the implications. Kolbe (1986) visualized the rationale for such arguments (Figure 1.1).

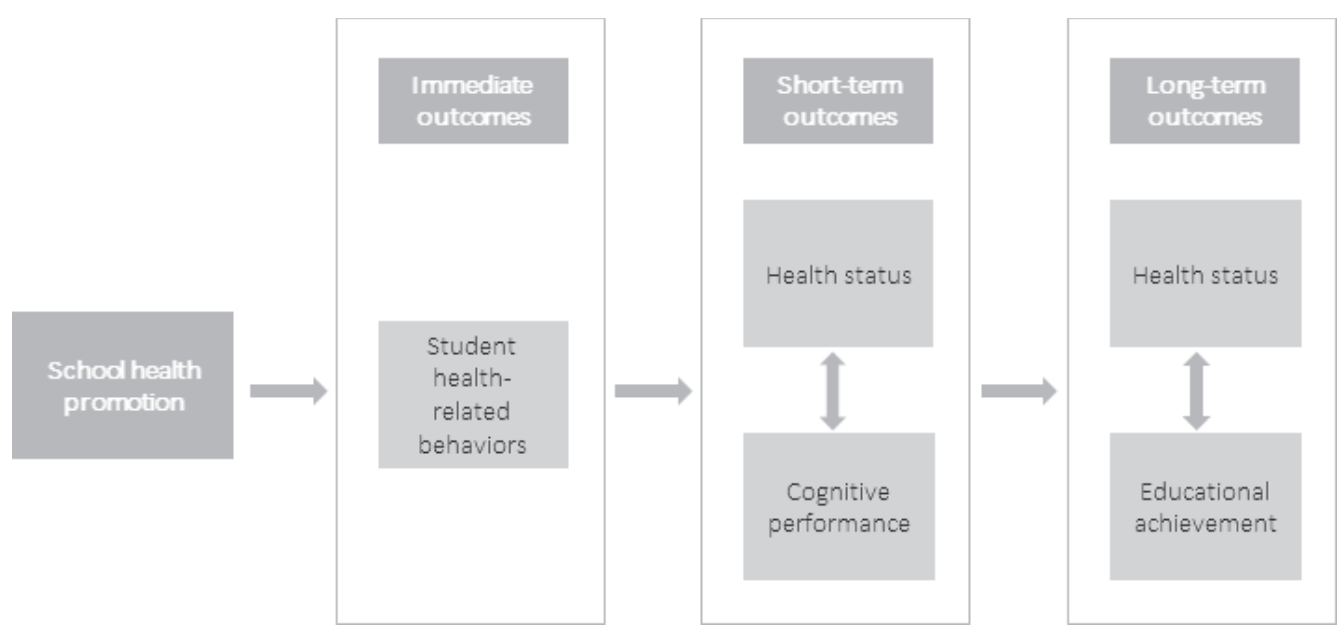

Figure 1.1: Simplified version of school health promotion and outcomes (adapted from Kolbe, (1986))

Figure 1.1 suggests that school health promotion creates win-win situations for the health and educational sectors. School health promotion can favorably influence students' healthrelated behavior, which can result in short-term improvements in their health status and cognitive performance. In the long run, this can further improve students' health and their educational achievement. According to Kolbe (1986), even greater effects can be expected when school health promotion is embedded in a broader framework, like the CHSP. CHSP not only educates children about their health and health determinants, but also targets the physical and social environment in and around schools, supported by community activities and health services (Allensworth, Wyche, Lawson, \& Nicholson, 1995; IUHPE, 2009). The CSHP 
components are assumed to interact with each other, making a unique contribution to health and education outcomes compared to single-issue health promotion interventions (i.e. those including only one CHSP component). For example, an intervention addressing the physical environment of a school can promote an active lifestyle among children, which is known to contribute to cognitive well-being and cognitive performance. Such an intervention could include changes to buildings, grounds, and equipment in and around a school which invite children to be physically active. Including a health education intervention in the general school curriculum can also be effective. It could teach children about active lifestyles and their determinants, and provide them with skills to shape their lives in an active way, which again would enhance cognitive well-being and cognitive performance. It is plausible that stronger effects on health-related behaviors and cognitive performance can be expected in an integrated intervention combining physical environment and health education elements, or even more elements, as is the case in CSHP. The positive relation between school health promotion and academic performance illustrated in Figure 1.1 offers opportunities for health promotion in schools, since it clearly indicates benefits for educational goals. It is therefore worthwhile to study the relationship between school health promotion interventions and academic performance.

Published reviews support the view that single-issue health promotion interventions (St Leger \& Nutbeam, 2000; Stewart-Brown, 2006) and interventions embedded in a broader framework, such as CSHP (Lister-Sharp, Chapman, Stewart-Brown, \& Sowden, 1999; St Leger, 1999; Stewart-Brown, 2006), have positive health outcomes. There is also evidence that students' health status influences the most important outcome for the educational sector: students' academic performance (Davis \& Cooke, 2007; Resnick et al., 1997), but less evidence regarding the specific benefits of school-based programs for students' academic performance. Particularly limited is the evidence on the effects and mechanisms of general school health promotion programs, such as those targeting physical activity and a healthy diet. Such programs have a less obvious relationship with teaching and learning than selective programs (i.e. those targeting children at risk) or indicated programs (i.e. those targeting children with specific symptoms) (DeSocio \& Hootman, 2004; Greenberg et al., 2003a; Zins, Weissberg, Wang, \& Walberg, 2004). In 2010, when we became interested in this subject, only one review had studied the relationship between physical activity interventions and academic performance (Trudeau \& Shephard, 2008). Two other empirical reviews suggested some mediating mechanisms for the relationship between physical activity and academic performance (Trudeau \& Shephard, 2010) and between nutrition and academic performance (Taras, 2005). However, some studies in the reviews were methodologically weak, the outcome measures of academic performance varied widely, and some studies had focused on groups at risk (e.g. students with nutritional deficiencies or special educational needs and hyperactive or impulsive students) rather than general school populations. There was no 
comprehensive review available of methodologically sound studies (i.e. randomized controlled trials (RCTs), cross-over controlled trials, or quasi-experimental designs with preand posttest) on general school health promotion interventions using a standardized measure of academic performance, whereas such evidence would reveal the purest effects of health promotion on academic performance, offering opportunities for generalization. Similarly, no review study had compared a comprehensive with a limited approach to school health promotion, to evaluate their effects on academic performance.

\section{Objectives of Part I of this dissertation}

Part I of this dissertation addresses the aspects of academic performance described above by providing a systematic review of general school-based programs, whether part of a broad or limited initiative, and their effects on standardized measures of students' academic performance. The following research questions are addressed: (1) What is the evidence for effects of general lifestyle interventions on children's academic performance? (2) What are the mechanisms that authors of original studies have proposed to account for these effects? (3) Are there any differences in outcomes between the studies that used a broad framework for school health promotion, such as the HPS initiative, and studies that used a more limited approach?

\section{Intersectoral collaboration in CSHP}

Working together with various actors to realize CSHP has been argued to reduce fragmentation and overlap in school health promotion (Deschesnes, Martin, \& Hill, 2003; Leurs et al., 2005b; WHO, 1995) and to improve the effectiveness and efficiency of school health promotion in the long run (Lister-Sharp et al., 1999; St Leger, 1999; Stewart-Brown, 2006). However, the holistic approach to health is complex and difficult to implement, and establishing a functional collaborative structure between the relevant sectors is one of the challenges of its implementation. The development of such an intersectoral collaboration is the subject of the investigations reported on in this dissertation, which were based on the Dutch context.

\section{CHSP and intersectoral collaboration in the Dutch context}

The first Dutch variant of CSHP, called SchoolBeat, was introduced in secondary education in 2002 in the southern parts of the Netherlands. SchoolBeat was modeled on the American Healthy School model (Allensworth \& Kolbe, 1987; Kolbe, 1986; Marx et al., 1998) and was based on four principles: (1) creation of demand-driven practices in school health promotion, with schools implementing only health promotion programs that fit their specific health problems, (2) application of a systematic approach to school health promotion, ideally 
formalized in a school health plan covering four years, (3) integration of the health promotion efforts in the existing infrastructure for individual health care and (4) implementation through systematic collaboration with relevant regional and local partners in the field of health promotion, welfare and health care. Compliance with the school-level principles is facilitated through a six-step plan (the SchoolBeat steps in Box 1.1), which schools can follow when becoming a 'Healthy School' (Leurs, Jansen, Schaalma, Mur-Veeman, \& De Vries, 2005a).

1. Determining health needs based on epidemiological data of the school community

2. Setting health promotion priorities

3. Assessing the important and modifiable determinants

4. Compiling a school health plan

5. Realizing the school health plan

6. Conducting a school-based evaluation

Box 1.1: SchoolBeat steps (from Leurs, Jansen, Mur-Veeman, \& De Vries (2005a))

SchoolBeat developed as a bottom-up initiative by relevant stakeholders in the field of addiction care, mental health, public health and social welfare in the Southern Limburg region, in response to the fragmentation and overlap in school health promotion regarding youth, health, and education. Together with schools, these stakeholders formed the collaborative structure in SchoolBeat, which is illustrated in Figure 1.2. This structure included four sectors: public health service (PHS), public service stakeholders (PSSs), the educational sector (i.e. health care coordinators, school management), and health authorities (e.g. municipalities). In this structure, each sector fulfills a particular role, which evolved from their daily activities and legal obligations. At regional and local levels, the PHS functions as a linkingpin between the education sector, health authorities and PSSs, as is illustrated by the narrowest point of the funnel in Figure 1.2. The PHS facilitates demand-driven practices by maintaining a single service point for health promotion programs and expertise. This is where all available health promotion initiatives come together, as illustrated by the top of the funnel, and are disseminated to schools according to their health demands, as illustrated by the bottom of the funnel. At school level, the 'SchoolBeat advisor' functions as an extension of the single service point toward schools. (S)he assists schools with the implementation of SchoolBeat through individual contacts with schools, and represents different public services and providers (e.g. from the welfare, health, prevention and safety sectors) (Buijs, 2005; Leurs, Steenbakkers, \& Jansen, 2006; RIVM Centre for Healthy Living, 2015b). Contacts with PSSs are maintained by the coordinator from the PHS. The coordinating role of the PHS

\footnotetext{
${ }^{2}$ In Figure 1.2 the term 'health promoting school advisor' is used for 'SchoolBeat advisor'. The former is the name used in the national model.
} 
derived from its statutory responsibility for the implementation of local public health policy and youth health care, which are funded by the municipal authorities (Hirsch Ballin, 2008). Taken together, participating schools represent the clients in the collaboration, whereas the municipal government is the main funding body. The PHS and PSSs are the coordinator and providers of topic-specific expertise, educational materials and health promotion programs (Leurs et al., 2008).

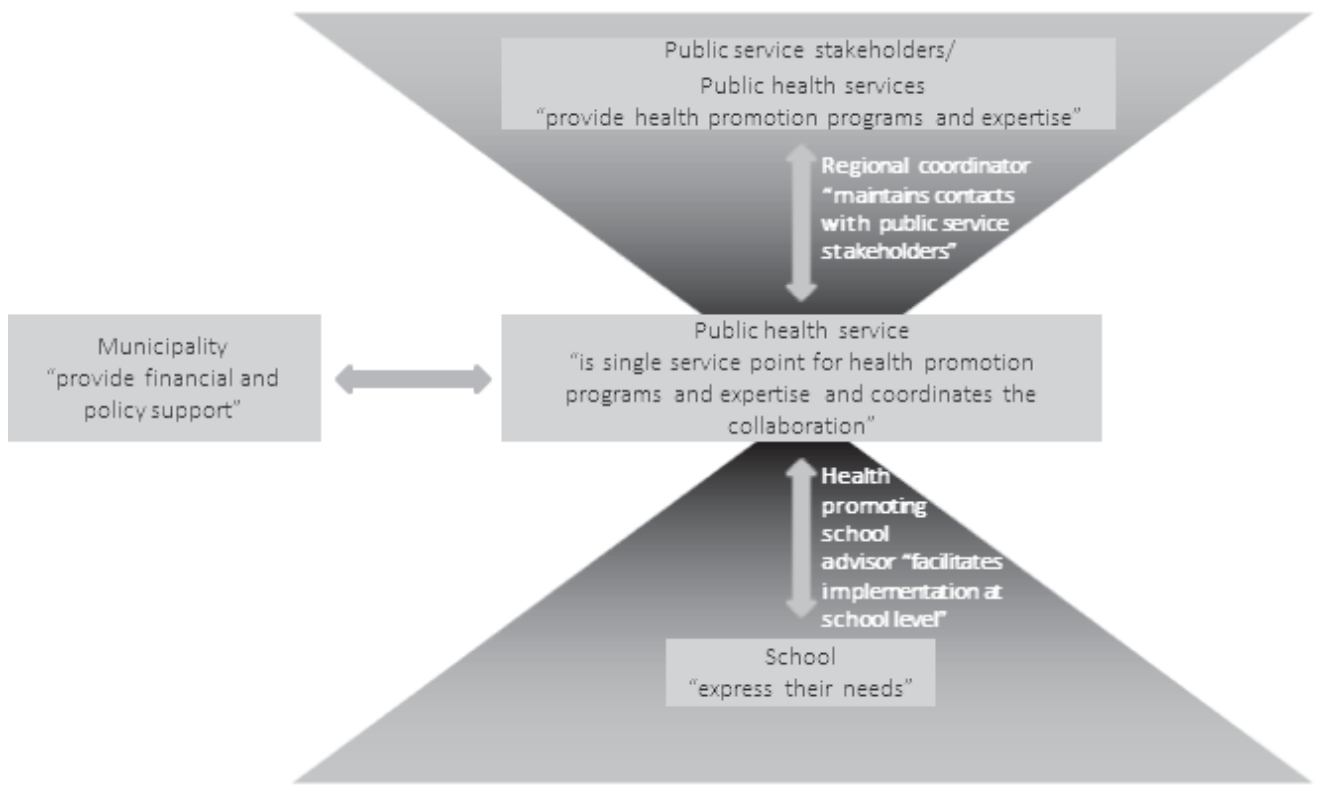

Figure 1.2: Collaborative structure of SchoolBeat / the Dutch variant of CSHP and its demand-driven practices

In parallel with this bottom-up initiative in Southern Limburg, school health promotion received attention nationally in the 'National Action Program on School Health Policy' in 2002 (Buijs, De Jong, Paulussen, \& Van Wijngaarden, 2002). This act recognizes the fragmentation of school health promotion and related policies as a national problem and advocates more cohesion between local, regional and national health promotion agencies and the establishment of a task group on healthy schools, to improve the situation. In 2003, commissioned by the Ministry of Health, nine national institutes from the health and education sectors formed the national task force coordinated by the Netherlands Institute for Health Promotion and Disease Prevention (NIGZ). At the time, the NIGZ also represented the Netherlands in the Schools for Health in Europe (SHE) network ${ }^{3}$ (CBO, 2015) and, at the same

\footnotetext{
${ }^{3}$ SHE is a network of National Coordinators from 43 countries in the European Region. It aims to support organizations and professionals to develop and sustain school health promotion in each country (CBO, 2015).
} 
time, coordinated this network. In 2005, the task group translated the 'National Action Program on School Health Policy' into a working document on Health Promoting Schools for primary and secondary education. The SchoolBeat project in Southern Limburg was used as the starting point for the national healthy school model (Buijs, 2005). Since then, several Dutch regions have adopted this national model, each using it so as to fit in with regional characteristics (Bos, De Jongh, \& Paulussen, 2010). The collaborative structure between the four sectors depicted in Figure 1.2 is representative of intersectoral collaboration in other Dutch regions. The specific tasks fulfilled by the various sectors may vary across Dutch regions.

Since 2007, the Ministry of Public Health has delegated the responsibility for further development of the healthy school model in primary education to the Centre for Healthy Living a department of the National Institute for Public Health and the Environment (RIVM). The RIVM Centre for Healthy Living is a platform for the exchange of expertise on available lifestyle interventions, planning instruments, and communication materials. It monitors the quality, efficiency, and coherence of these interventions and makes them accessible to the general public (Ministry of Health of the Netherlands, 2013). In 2008, when our investigation of intersectoral collaboration for CSHP started, the RIVM Centre for Healthy Living conducted a study among PHSs about the current school health promotion practices in the Netherlands (Bos et al., 2010). Results showed that the national implementation was in its very early stages then, and practitioners perceived the national healthy school model (i.e. the SchoolBeat steps) as not flexible enough and too linear, and needed more assistance for its implementation. With regard to collaboration, PHSs reported that more professional assistance was required for the implementation at school level. Collaboration with health services was desirable but was so far limited to referrals, and more support was needed for this as well. The findings were supported by a later study into the role of assistance from professionals in the implementation of SchoolBeat (Boot et al., 2010a). The authors found that this implementation is so complex that specific professional knowledge and organizational skills are required for successful implementation and collaboration. In the following years, several national initiatives followed to support both.

The national healthy school model was further developed into a modular system, including four independent modules: (1) orientation and organization, (2) needs assessment, (3) planning and organization, and (4) evaluation (RIVM Centre for Healthy Living, 2010). It comprised all activities from the old model, but gave users more freedom to start with CSHP at any time and at any step. For example, schools could start with a health promotion activity prior to the needs assessment of students' health, which would not have been possible in the old healthy school model. In addition, a practitioners' guide was published to assist health professionals in working with the model in the local context (RIVM Centre for Healthy Living, 2010). It devotes one chapter to each module and in addition includes a supplement on 
intersectoral collaboration which is based on the insights from Boot's (2011) dissertation on the implementation of CHSP in the Netherlands and the present dissertation on intersectoral collaboration. The first practitioners' guide was developed for primary education. This was followed by a manual for secondary education and vocational education (2011), a newsletter for the three school types (2013) and a certification system that was introduced for schools in the process of becoming a healthy school (for primary schools in 2012, for vocational schools in 2013, and for secondary schools in 2014). Moreover, since 2013, schools can apply annually for funding from the Ministry of Health to assist them in the implementation of the healthy school model. Extending the HS model to kindergartens is currently under consideration. The numbers of applicants for funding from the Ministry and for the healthy school certificate are promising. In 2014, about 500 schools applied for additional funding by the Ministry of Health. Currently, 290 primary schools, 37 secondary and 33 vocational schools hold a healthy school certificate (RIVM Centre for Healthy Living, 2015a).

\section{The Diagnosis of Sustainable Collaboration (DISC) model}

In public health, there are a number of partnership models, each grounded in specific comprehensive initiatives (Clark et al., 2006; Crowley, Yu, \& Kaftarian, 2000; Feinberg, Greenberg, \& Osgood, 2004; Florin, Mitchell, Stevenson, \& Klein, 2000; Kegler \& Swan, 2011b). These models suggest more or less the same set of factors influencing collaboration at individual, organizational, and policy levels. The Dlagnosis of Sustainable $\underline{\text { Collaboration }}$ (DISC) model is a partnership model based on the literature on planned organizational change, organizational behavior and interorganizational work, advocating a systematic approach to the establishment of intersectoral collaboration in CSHP. It has specifically been developed to diagnose facilitators and barriers in the collaborative structure (Leurs et al., 2008). Leurs et al. (2008) suggested that the results of the diagnosis could also be used to determine strategies to further guide the collaboration; the latter was never investigated, however.

The DISC model distinguishes 26 factors, categorized into six main clusters, that impact on the collaborative process and its sustainability: change management, project management, collaborative support, external factors, context, and sustainable collaboration ${ }^{4}$ (Figure 1.3). According to the DISC model, the collaborative process and progress are determined by stakeholders' collaborative support, which can be assessed at the level of the perceptions, intentions, and actions of the parties involved. The collaboration makes progress when stakeholders succeed in translating their positive perceptions into positive intentions and actions. It stagnates when it fails to enter the performance stage. The collaborative process is also affected by factors in the wider context. On the one hand, there are contextual

\footnotetext{
${ }^{4}$ Adapted from Leurs et al. (2008). This construct was previously named comprehensive school health promotion.
} 
factors (e.g. characteristics of organizations) which influence the collaboration and can be controlled by the partners themselves. On the other hand, there are external factors (e.g. policy and regulations), which are rather beyond the control of the alliance itself. The collaborative structure varies across phases. During the developmental and initial implementation phases, the collaborative process takes place within a project management structure deciding who, what, when. This project management structure fades out when the subject of the collaborative process is integrated into the regular work of the partner organizations, and the alliance becomes self-supportive. This integration is captured in the sixth DISC cluster, sustainable collaboration. Sustainable collaboration in the model refers to a stable, self-supportive alliance. To facilitate the integration of a project-bound coalition (i.e. regarding a project with a project-management structure) into regular working routines (a self-supporting coalition without strict project management but embedded in normal routines), one leader or a small group of leaders need to implement the principles of change management (e.g. vision and change strategies). A more detailed description of the DISC constructs and factors is provided elsewhere (Pucher, Candel, Boot, Van Raak, \& De Vries, 2015a).

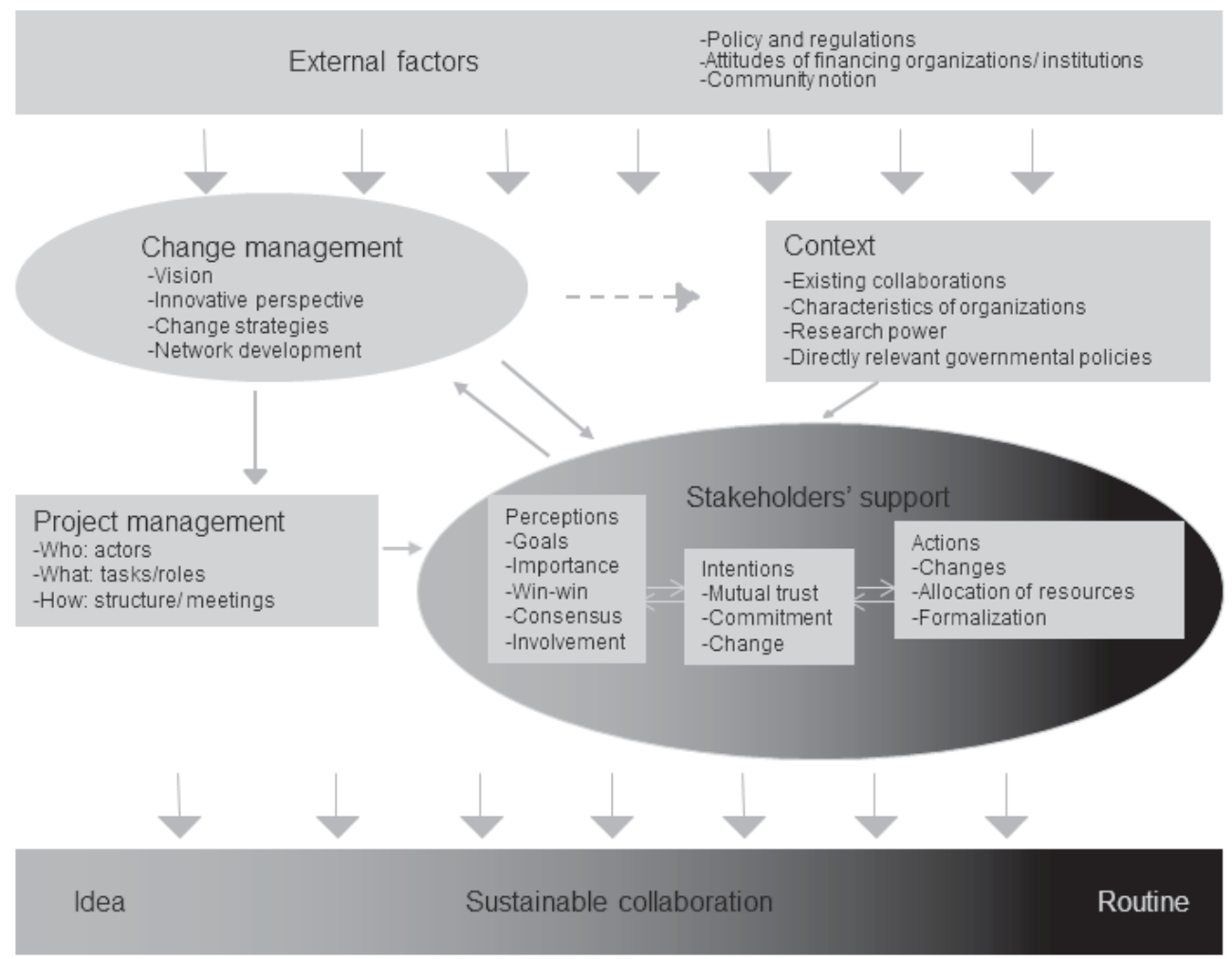

Figure 1.3: Diagnosis of Sustainable Collaboration (DISC) model (adapted from Leurs et al. (2008)) 
Leurs et al. (2008) developed the DISC questionnaire, which measures each DISC factor using a number of indicators. The DISC questionnaire can be used to assess the status quo of the collaboration, similar to a checklist. In their evaluation of the SchoolBeat collaboration in southern Limburg, Leurs et al. (2008) validated the results of the DISC questionnaire with semi-structured interviews. Their study showed that DISC factors do indeed influence the collaboration between health authorities, schools, and prevention organizations in CSHP. Based on the results, they formulated the first hypotheses about the relationships between the DISC constructs (Figure 1.3, see arrows).

The instrumental use of diagnostic results is frequently applied in managerial choices (Wholey, 1996). It is often referred to as 'systematic change' and has been reported to substantially increase the chances of success compared with managerial decisions taken on an ad-hoc basis (Cummings \& Worley, 2001; Daft \& Noe, 2001; De Caluwé \& Vermaak, 2003).

\section{Systematic development of intersectoral collaboration using the DISC model}

This dissertation reports on our research into the effects and processes of the systematic development of intersectoral collaboration in CSHP based on the DISC model. The study was embedded in a two-year DISC-based trajectory, which was developed to support Dutch health professionals engaged in CSHP. It was implemented from 2008 to 2011 in six PHS regions across the Netherlands (i.e. North-Holland, South-Holland, Drenthe, North-Limburg, MidHolland, and Brabant), and targeted regional CSHP coordinators based at PHSs. The trajectory included conducting DISC analyses of facilitators and barriers for CSHP collaborations, the formulation of a DISC-based strategy based on results of previous analyses, and professional support in the implementation of the DISC-based strategy. Professional support included monthly personal/telephone contacts with a central advisor involved in the trajectory. This advisor was a health educator working at the PHS where SchoolBeat and the DISC model had been developed and who was specialized in the implementation of Dutch healthy school model. Contacts basically comprised critical reflection on the collaborative process using a standard interview protocol, exchange of expertise between regions, occasional peer-review of documents and a joint training session for regional coordinators. In addition, a newsletter published every four months informed the regions about their progress. An overview of the DISC-based trajectory is provided in Figure 1.4. 

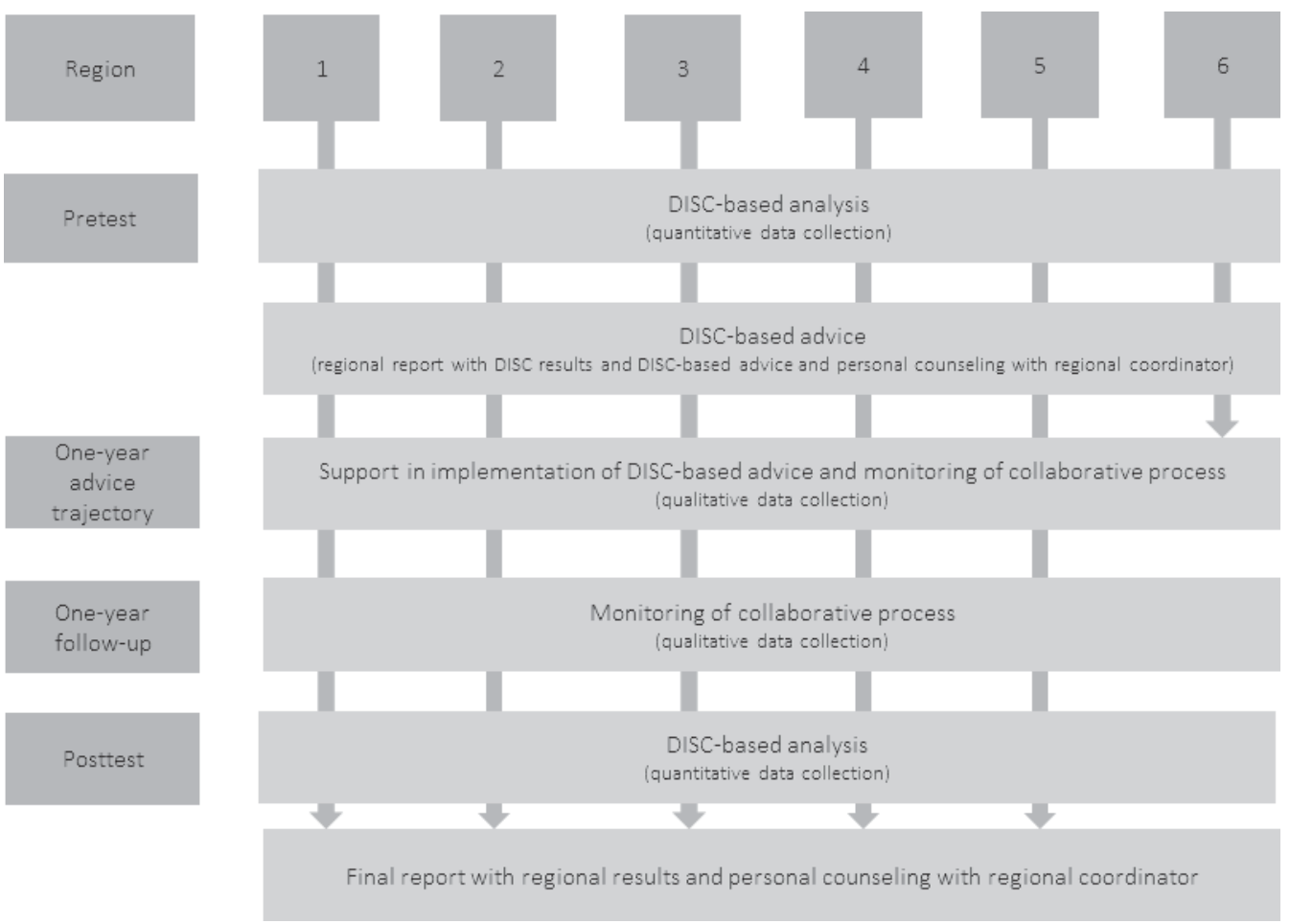

Figure 1.4: Design of the DISC-based trajectory ${ }^{5}$

\section{Study design and procedure}

The DISC-based trajectory was evaluated in a multiple-case design study using multiple data sources and methods (Table 1.1). Six Dutch PHS regions provided the cases for the DISC-based trajectory. Their characteristics and starting situations varied (Pucher et al., 2015a). Baseline DISC analyses were conducted at the end of 2008, using an adapted version of the DISC questionnaire developed by Leurs et al. (2008). Regional coordinators had to identify relevant stakeholders and distribute materials for the survey. The researcher (i.e. author of this dissertation) analyzed the results of the DISC questionnaires. Based on these results, the main advisor in the trajectory formulated initial recommendations concerning each DISC construct. The DISC results and recommendations were fed back to regional coordinators in a report in

\footnotetext{
${ }^{5}$ Because of different priorities, region 6 did not complete the trajectory. Pretests were performed in different periods due to different degrees of readiness of the regions, caused by practical issues (regions 1-4, 6: November 2008 - February 2009; region 5: October 2009 to November 2009). In two regions, additional DISC analyses were conducted on request. Region 2: A new analysis was conducted halfway through the advisory trajectory, in order to unify the CSHP working methods of the region's own PHS and a merger PHS. This analysis was not included in our study, since it had another goal than that pursued in the DISC-based trajectory. Region 4: A new baseline DISC analysis was considered in mid-2009, as the regions felt the need for an update. In the longitudinal studies, this new analysis was used as a baseline measurement for this particular region.
} 
the early months of 2009. A regional meeting followed where the regional coordinator, the main advisor and the researcher were present to further clarify the results. A DISC-based strategy to be implemented was formulated. From mid-2009 to mid-2010, the main advisor in the trajectory provided professional support to the regions for the implementation of the DISC-based strategy, using standardized interviews with regional coordinators during this period and documents received from the regions. The same interviews and documents were used to monitor the collaborative process to meet the research objectives. The collaborative process continued to be monitored during a one-year follow up, from mid-2010 to mid-2011, using the same methods. This time, the researcher held interviews with regional coordinators. Interviews were conducted bi-monthly by phone. At the end of 2011, a second DISC analysis was conducted in each region, which, together with the baseline DISC analysis, served as an effect evaluation. A detailed description of the measurement instruments and the study procedure is provided elsewhere (Pucher, Candel, Krumeich, Boot, \& De Vries, 2015b).

\section{Process of inquiry}

In the process of inquiry, we aimed to achieve instrumental and research aims (i.e. supporting health professionals in the systematic establishment of intersectoral collaboration vs. evaluating the effectiveness and process of the systematic approach). The DISC-based trajectory was set up accordingly. It was based on an approach similar to the steps of action research, which allow research to be combined with practice: observe/collect, reflect/review, plan, act. In action research, the researcher and the population that is the subject of the inquiry progress together through these steps on a cyclical basis (Kemmis \& Taggart, 1982; Sankara, Dick, \& Passfiedl, 2001). In the first two steps, a particular problem is diagnosed and the results of the diagnosis are shared and interpreted. Plans are made and implemented in the last two steps, after which the cycle starts again. Learning experiences in each step can be an argument for reconsidering actions and plans in the previous steps, making the process dynamic rather than linear. The cyclical nature of the process can be seen as an intervention in itself. Within our DISC-based trajectory, the observation and reflection steps included DISC analyses to raise awareness of perceived facilitators and barriers in the collaborations, and the formulation of recommendations to address identified barriers, followed by the operationalization and implementation of concrete actions during the advisory part of the DISC-based trajectory (i.e. planning and action steps). In addition, the observation and reflection steps included critical reflection during consultations with the main advisor in the trajectory, and the results of formative evaluations conducted at the organizations' own initiative, which could lead to reconsideration of plans and actions in previous steps.

The steps of action research and its interactive process bear close resemblance to various descriptions of the process of change within organizations (Cummings \& Worley, 2001). This makes the approach extremely suitable for interventions where factors at the 
1 organizational level must be equally considered with those at the individual level. This is also the case in the study of intersectoral collaboration.

\section{Objectives of Part II of this dissertation}

The research reported on in Part II of this dissertation had an instrumental and a scientific aim. The instrumental aim was to support health professionals in the systematic implementation of intersectoral collaboration in CSHP. The scientific aim was to evaluate the effects and the related processes of the systematic approach based on the DISC model. More specifically, the following two research questions guided the research.

(1) Can the DISC model be used to analyze facilitators and barriers for CSHP collaborations in different situations? (2) Can a systematic approach to intersectoral collaboration based on the DISC model enhance the collaboration among sectors involved in CSHP, as assessed in terms of improvements on the determinants of collaboration, implementation of CSHP, and sustainability of the collaboration? 


\section{Outline of the dissertation}

Part I of this dissertation reviews available studies using methodologically sound designs to evaluate the effects on students' academic performance of health promoting interventions targeting general health domains in general school populations (Chapter 2). Observed effects of interventions using a limited framework for school health promotion were compared with the effects of interventions using a broader framework, such as CSHP. The chapter also reports on mechanisms suggested by the researchers of original studies for observed effects (Chapter 2).

Part II of this dissertation reports on the analyses of facilitators and barriers in CSHP collaborations, based on the DISC analyses conducted at pretest. The results were compared between regions and sectors, and interpreted in the context of the specific characteristics of the collaborations and their starting situations. The results were also used to formulate a DISC-based strategy to improve the CSHP collaborations in each region (Chapter 3).

Next, the DISC-based trajectory was evaluated in terms of its effectiveness and related managerial processes. Effects on the determinants of collaboration were studied, as well as managerial activities implemented by regional coordinators in response to the DISC-based strategy. A mixed method approach was used, based on qualitative and quantitative data (Chapter 4).

In the next study, collaborative processes were quantitatively examined in greater depth. Predictors and mediators of the implementation of CSHP and sustainable collaboration in CSHP were assessed using path analysis. The chapter also reports on the effects of the DISC-based trajectory on short-term (DISC factors), intermediate (implementation of CSHP) and long-term outcomes (sustainable collaboration).

Table 1.1 gives an overview of the studies reported in Parts I and II of this dissertation.

The last part of this dissertation presents a review of the main findings and a discussion of practical and methodological considerations. Implications for research and practice are summarized and discussed (Chapter 6). 
Table 1.1: Main characteristics of the studies presented in this dissertation

Part I

2 Review of the effects of school health promotion interventions on academic performance and related mechanisms; comparison of effects between limited and broad approaches to school health promotion
Systematic review

Information on country, study Studies with methodologically purpose, research design, effects sound designs targeting the on academic performance, general health domains in outcome measures, components general school populations of CSHP and authors' published until 18 January 2012 explanations for observed effects

Part II

3

\section{Analysis and comparison} between region and sectors of facilitating and impeding factors in intersectoral collaborations in CSHP
Multiple case study

with cross-sectional design
Quantitative data on the determinants of collaboration collected with the DISC questionnaire at pretest
Representatives from schools, PHSs, municipalities and PSSs (regions 1, 2,4,5,6, Figure 5, Chapter 1)

4

Study of the effect of the DISCbased trajectory on intersectoral collaboration in CSHP

Study of the managerial activities employed during the DISC-based trajectory to stimulate intersectoral collaboration in CSHP
Multiple case study with pretest-posttest design
Quantitative data on the determinants of collaboration and sustainable collaboration collected with the DISC questionnaire at pretest and posttest

Qualitative data on managerial activities collected with standardized interviews and regional documents during the one-year advice trajectory and

the one-year follow-up period
Representatives from PHSs and PSSs (regions 1-5, Figure 5, Chapter 1)

Regional coordinators of CSHP (regions 1-5, Figure 5, Chapter 1 )
Study of mediators and

Multiple case study predictors of implementation with pretest-posttest and sustainable collaborations in design the DISC-based trajectory

\author{
Quantitative data on the Representatives from PHSs and \\ determinants of collaboration, PSSs (regions 1-5, Table 4, \\ the implementation of CSHP and Chapter 1) \\ sustainable collaboration \\ collected with the DISC \\ questionnaire during pretest and \\ posttest
}




\section{References}

Allensworth, D., \& Kolbe, L. J. (1987). The Comprehensive School Health Program: Exploring an Expanded Concept. Journal of School Health, 57(10), 409-412.

Allensworth, D. D., Wyche, J., Lawson, E., \& Nicholson, L. (1995). Defining a Comprehensive School Health Program: An Interim Statement. Washington, DC: Division of Health Sciences Policy, National Academy Press.

Barry, M. M., Battel-Kirk, B., Davison, H., Dempsey, C., Parish, R., Schipperen M., Speller, V., Van der Zanden, G., \& Zilnyk, A. (2012). The CompHP Project Handbooks. International Union for Health Promotion and Education (IUHPE). Paris.

Boot, N. M. W. M. (2011). Gezondheidsbevordering en voortgezet onderwijs, verstandshuwelijk of echte liefde? Een onderzoek naar de implementatie van schoolgezondheidsbeleid binnen scholen voor voortgezet onderwijs. Proefschrift. (Health promotion and secondary education: marriage of convenience or true love? A study about the implementation of school health promotion in secondary schools. Dissertation) Maastricht.

Boot, N. M. W. M., van Assema, P., Hesdahl, B., \& de Vries, N. K. (2010). Professional assistance in implementing school health policies. Health Education, 110(4), 294-308.

Boot, N. M. W. M., van Assema, P., Hesdahl, B., Leurs, M., \& de Vries, N. K. (2010). Gezondheidsbevordering en voortgezet onderwijs: verstandshuwelijk of echte liefde? (Health promotion and secondary education: marriage of convenience or true love?) Tijdschrift voor Gezondheidswetenschappen, 88(3), 127-135.

Bos, V., De Jongh, D., \& Paulussen, T. (2010). Gezondheidsbevordering en preventie in het onderwijs. Stand van zaken, effectiviteit en ervaringen van GGD'en en scholen (Health promotion and prevention in schools. Current state of affairs, effectiveness and experiences from public health services and schools.). Bilthoven: RIVM.

Buijs, G., De Jong, A., Paulussen, T., \& Van Wijngaarden, J. (2002). Actieprogramma Schoolgezondheidsbeleid Nederland (National Action Program on School Health Policy). Woerden: National Instituut voor Gezondheidsbevordering en Ziektepreventie (Netherlands Institute for Health Promotion and Disease Prevention).

Buijs, G. J. (2005). Werkdocument. De Gezonde School Methode in Nederland. (Work document. The Healthy School Approach in the Netherlands. Woerden: National Instituut voor Gezondheidsbevordering en Ziektepreventie (Netherlands Institute for Health Promotion and Disease Prevention).

CBO. (2015). SHE Schools for Europe Retrieved 8 January 2015, from http://www.schools-forhealth.eu/she-network. 
Clark, N., Doctor, L., Friedman, A., Lachance, L., Houle, C., Geng, X., \& Grisso, J. (2006). Community coalitions to control chronic disease: Allies against asthma as a model and case study. Health Promotion Practice, 7(2), 13S-22S.

Crowley, K., Yu, P., \& Kaftarian, S. (2000). Prevention actions and activities make a difference: A structural equation model of coalition building. Evaluation and Program Planning, 23(3), 381-388.

Cummings, T. G., \& Worley, C. G. (2001). Organizational Development and Change (7th edition). Mason, Ohio: Southern-Western College Publishing.

Daft, R. L., \& Noe, R. A. (2001). Organizational behavior. Orlando: Hartcourt Inc.

Davis, J. M., \& Cooke, S. M. (2007). Educating for a healthy, sustainable world: an argument for integrating Health Promoting Schools and Sustainable Schools. Health Promotion International, 22(4), 346-353.

De Caluwé, L., \& Vermaak, H. (2003). Learning to change: Thousand Oaks: Sage Publications.

Deschesnes, M., Martin, C., \& Hill, A. J. (2003). Comprehensive approaches to school health promotion: how to achieve broader implementation? Health Promotion International, 18(4), 387-396.

DeSocio, J., \& Hootman, J. (2004). Chilrden's Mental Health and School Success. The Journal of School Nursing, 20(4), 188-196.

Feinberg, M., Greenberg, M., \& Osgood, D. (2004). Readiness, functioning and perceived effectiveness in community prevention coalitions: A study of communities that care. American Journal of Community Psychology, 3/4(33), 163-176.

Florin, P., Mitchell, R., Stevenson, J., \& Klein, I. (2000). Predicting intermediate outcomes for prevention coalitions: A developmental perspective. Evaluation and Program Planning, 23(3), 341-346.

Greenberg, M. T., Weissberg, R. P., O'Brien, M. U., Zins, J. E., Fredericks, L., Resnik, H., \& Elias, M. J. (2003). Enhancing school-based prevention and youth development through coordinated social, emotional, and academic learning. American Psychologist, 58(6-7), 466-474.

Hirsch Ballin, E. M. H. (2008). Wet Publieke Gezondheid (Public Health Act). Overheid.nl (Government.nl). Retrieved 14 April 2015, from

http://wetten.overheid.nl/BWBR0024705/geldigheidsdatum_14-04-2015.

IUHPE. (2009). Achieving Health Promoting Schools: Guidelines for Promoting Health in Schools. Retrieved 15 January 2015, from http://www.dhhs.tas.gov.au/_data/assets/pdf_file/0011/115895/guidelines_for_heal th_promoting_schools1.pdf.

Kegler, M. C., \& Swan, D. W. (2011). An initial attempt at operationalizing and testing the Community Coalition Action Theory. Health Education \& Behavior, 38(3), 261-270. 
Kemmis, S., \& Taggart, R. (1982). The action research planner (3rd edition ed.). Geelong, Australia: Deakin University Press.

Kolbe, L. (1986). Increasing the impact of school health promotion programs: emerging research perspectives. Health Education, 17(5), 47-52.

Leurs, M., Jansen, M., Schaalma, H., Mur-Veeman, I., \& De Vries, N. (2005a). The Tailored SchoolBeat-approach: new concepts for health promotion in schools In S. Clift \& B. B. Jensen (Eds.), The Health Promoting School: International Advances in Theory, Evaluation and Practice (pp. 87 - 105). Copenhagen: Danish University of Education Press.

Leurs, M., Mur-Veeman, I., van der Sar, R., Schaalma, H., \& de Vries, N. (2008). Diagnosis of sustainable collaboration in health promotion - a case study. BMC Public Health, 8(382). doi: 10.1186/1471-2458-8-382

Leurs, M., Schaalma, H., Jansen, M., Mur-Veeman, I., St. Leger, L., \& De Vries, N. (2005b). Development of a collaborative model to improve school health promotion in the Netherlands. Health Promotion International, 20, 296 - 305.

Leurs, M., Steenbakkers, M., \& Jansen, M. (2006). Het schoolSlag-praktijkboek: samen werken aan preventie op maat in het onderwijs (The SchoolBeat manual: working together towards tailored prevention in education). Maastricht: GGD Zuid Limburg.

Lister-Sharp, D., Chapman, S., Stewart-Brown, S., \& Sowden, A. (1999). Health promoting schools and health promotion in schools: two systematic reviews. Health Technology Assessment, 3(22), 1-207.

Marx, E., Wooley, S. F., \& Northrop, D. (1998). Health is Academic - A Guide to Coordinated School Health Programs. New York: Teacher's College Press.

Ministry of Health of the Netherlands. (2013). Good Practice in the Field of Health Promotion and Primary Prevention. The Netherlands Country Review. Retrieved 15 April 2015, from http://www.loketgezondleven.nl/object_binary/o21294_141105-The-

Netherlands-Country-Review-PDF.pdf.

Pucher, K. K., Candel, M. J. J. M., Boot, N. M. W. M., Van Raak, A., \& De Vries, N. K. (2015a). A multiple-case study of intersectoral collaboration in the context of coordinated school health promotion using the Dlagnosis of Sustainable Collaboration (DISC) Model Health Education, 115(3/4), 301-321.

Pucher, K. K., Candel, M. J. J. M., Krumeich, A., Boot, N. M. W. M., \& De Vries, N. K. (2015b). Effectiveness of a systematic approach to promote intersectoral collaboration in comprehensive school health promotion-a multiple-case study using quantitative and qualitative data. BMC Public Health, 15(613), 1-14.

Resnick, M. D., Bearman, P. S., Blum, R. W., Bauman, K. E., Harris, K. M., Jones, J., Tabor, J., Beuhring, T., Sieving, R. E., Shew, M., Ireland, M., Bearinger, L. H., \& Udry, J. R. (1997). Protecting adolescents from harm: Findings From the National Longitudinal Study on 
Adolescent Health. Journal of the American Medical Association, 278(10), 823-832. doi: 10.1001/jama.1997.03550100049038

RIVM Centre for Healthy Living. (2010). Handleiding Gezonde School (Healthy School Guide). Bilthoven: National Institute for Public Health and the Environment - Centre for Healthy Living,

RIVM Centre for Healthy Living. (2015a, 11 May 2015). Gezondeschool.nl

from http://www.gezondeschool.nl

RIVM Centre for Healthy Living. (2015b). Vignetscholen (Certified Schools) Gezondeschool.nl (HealthySchool.nl). Retrieved 13 april 2015, from

http://www.gezondeschool.nl/po/vignet-gezonde-school-po/vignetscholen/.

Samdal, O., \& Rowling, L. (2013). The Implementation of Health Promoting Schools. Exploring theories of what, why and how. Canada: Routledge.

Sankara, S., Dick, B., \& Passfiedl, R. (2001). Effective change management through action research and action learning: Concepts, perspectives, processes and applications. Lismore, Australia: Southern Cross University Press.

St Leger, L. (2001). Schools, health literacy and public health: possibilities and challenges. Health Promotion International, 16(2), 197-205. doi: 10.1093/heapro/16.2.197

St Leger, L., \& Nutbeam, D. (2000). Research into Health Promoting Schools. Journal of School Health, 70(6), 257.

St Leger, L. H. (1999). The opportunities and effectiveness of the health promoting primary school in improving child health - a review of the claims and evidence. Health Education Reserach, 14(1), 51-69. doi: 10.1093/her/14.1.51

Stahl, T., Wismar, M., Ollila, E., Lahtinen, E., \& Leppo, K. (2006). Health in All Policies. Prospects and potentials. Finland: Ministry of Social Affairs and Health.

Stewart-Brown, S. (2006). What is the evidence on school health promotion in improving health or preventing disease and, specifically, what is the effectiveness of the health promoting schools approach? . Copenhagen: WHO Regional Office for Europe.

Taras, H. (2005). Nutrition and student performance at school. Journal of School Health, 75(6), 199-213.

The International Journal of Health Planning and ManagementLeurs, M. (2008). A collaborative approach to tailored whole-school health promotion. The SchoolBeat study. Maastricht.

Trudeau, F., \& Shephard, R. J. (2008). Physical education, school physical activity, school sports and academic performance. International Journal of Behavioral Nutrition and Physical Activity, 5(10). doi:10.1186/1479-5868-5-10

Trudeau, F., \& Shephard, R. J. (2010). Relationships of Physical Activity to Brain Health and the Academic Performance of Schoolchildren. American Journal of Lifestyle Medicine, 4, 138-150. 
Warner, M., \& Gould, N. (2009). Integrating Health in All Policies at the Local Level: Using Network Governance to Create 'Virtual Reorganization by Design'. In I. Kickbusch (Ed.), Policy Innovation for Health (pp. 125-163): Springer.

WHO. (1995). Improving School Health Programs: Barriers and Strategies to improve School Health Programs Promoting Health Through Schools. Report of the WHO Expert Committe on Comprehensive Education and Promotion (pp. 1-27). Geneva: WHO.

WHO. (2014). Health 2020: education and early development. Regional Office for Europe.

WHO. (2015). School and youth health. Retrieved 14 april 2015, from http://www.who.int/ school_youth_health/en/.

Wholey, J. S. (1996). Formative and Sumative Evaluations: Related Issues in Performance Measurement. Evaluation Practice, 17(2), 145-149.

Zins, J. E., Weissberg, R. P., Wang, M. C., \& Walberg, H. J. (2004). Building academic success on social and emotional learning. New York: Teachers College Press. 



\section{Part I}

Benefits of health promotion for the educational sector 



\section{Chapter 2 Systematic review: School health promotion interventions targeting physical activity and nutrition can improve academic performance in primary- and middle school children}

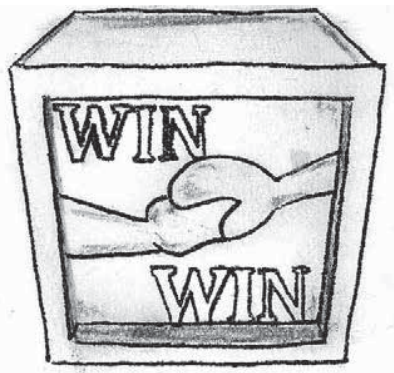

Based on:

Pucher, K.K., Boot, N.M.W.M., \& De Vries, N.K. (2013). Systematic review: School health promotion interventions targeting physical activity and nutrition can improve academic performance in primaryand middle school children. Health Education, 113( 5), 372-391. 


\section{Abstract}

Purpose: A systematic review of effects and mediators was conducted to determine whether school health promotion interventions (SHPIs) can enhance children's academic performance (AP).

Methodology: Only interventions targeting the maintenance of energy balance (physical activity (PA) and nutrition) in primary school and middle school children met the methodological criteria of this review.

Findings: SHPIs targeting the maintenance of energy balance can have small to large positive effects on AP; no negative effects were reported. Effects of different kinds of interventions vary across academic domains. One PA intervention reported large effects of vigorous activity on mathematics; another PA intervention had small to medium impact on language scores. Small to medium effects were found for interventions combining nutrition and PA elements; one affected mathematics and another both mathematics and language scores. Slight improvements in language scores were observed for breakfast provision in schools.

Limitations: The small number of interventions, little homogeneity in intervention components (content, length and measurement instruments), reporting bias and some inconsistent results should be considered when interpreting our results. Our review did not allow definite conclusions concerning mechanisms responsible for effects of SHPIs on AP.

Practical implications: Planned development of SHP will need to be based on evidence. Measures of AP should be included in evaluations of SHPIs. Schools and health professionals should be made aware of the importance of these measures.

Value: We provide evidence that SHPIs promoting energy balance can affect AP, also if they do not target children at risk or with specific symptoms, nor employ elements directly connected to school education.

Keywords: schools; health; promotion; exercise; nutrition; academic; learning 


\section{Introduction}

School health promotion interventions (SHPIs) are effective in improving the health status of school-aged children (St Leger \& Nutbeam, 2000; Stewart-Brown, 2006). These programs teach children about health and its determinants and enable them to develop skills to make healthy choices in their lives. Such efforts can be embedded in a broader framework, such as the Health Promoting School (HPS) approach which also targets the physical and social environments in and around school supported by community activities and health services. Broader frameworks to school health promotion are supposed to generate even greater health improvements in children (Lister-Sharp et al., 1999; St Leger, 1999; Stewart-Brown, 2006).

In the last decades a huge growth could be observed in the availability of SHPIs (ListerSharp et al., 1999; Stewart-Brown, 2006) and initiatives to implement school-based interventions (Boot et al., 2010a; Deschesnes et al., 2003). This was accompanied by ample evidence for a positive relation between students' health status and their academic performance (AP) (Davis \& Cooke, 2007; Resnick et al., 1997). This relation can partly be explained by several common determinants of health and education on the micro (e.g. socioeconomic status, gender), meso (e.g. geographical location, friends' habits) and macro level (e.g. health and education related policies and programs) (Suhrcke \& de Paz Nieves, 2011). The direct and causal relation between effects of general health promotion interventions and $\mathrm{AP}$ is much less clear.

Direct positive effects of mental health promotion and social and emotional learning interventions on AP have been shown (DeSocio \& Hootman, 2004; Greenberg et al., 2003b). DeSocio \& Hootman (2004) explain these effects from the direct impact of mental health symptoms (e.g. poor concentration, distractibility, sleepiness, etc.) on children's learning ability. Zins et al. (2004) point at the impact of social relations and emotions on what and how children learn. Most mental health and social and emotional learning interventions are designed for specific risk groups or students with evident symptoms, rather than the general school population.

More general lifestyle interventions, e.g. those targeting physical activity (PA) levels and healthy diet, have a less obvious connection to learning and teaching. Nevertheless, several mediating processes have been suggested for a relation between AP and PA (Trudeau \& Shephard, 2010) and nutrition (Taras, 2005). A review of school-based PA interventions (1966-2007) showed that increased opportunities for PA at school can enhance children's AP (Trudeau \& Shephard, 2008).

These findings provide preliminary evidence that SHPIs may enhance children's AP, even when they are not specifically designed for children at risk or children with evident symptoms, or when they do not employ elements directly connected to school education. 
These findings also suggest that mechanisms relating to children's healthier lifestyle might mediate the effects of school-based interventions on AP. However, some studies in the above reviews were methodologically weak, the outcome measures of AP varied widely, and some studies focused on groups at risk rather than the general school population.

\section{Aims of this paper}

The objective of the present review was to expand the available preliminary evidence by combining studies focusing on general health domains and restricting ourselves to methodologically sound designs (randomized controlled trials, cross-over controlled trials, quasi-experimental designs with pre- and posttest) using standardized measures of AP (e.g. grade-point averages or end-of-year marks) to increase comparability between studies. To maximize the applicability of the interventions effects, we only included studies addressing general school populations. The second objective of the present review was to report on the explanations authors of original studies suggest for the observed effects, to improve our understanding of the process that links lifestyle interventions to AP. Also, we were interested in whether employing a broad and comprehensive framework to SHPIs, such as the concept of Health Promoting Schools (HPS), would make any difference in observed effects on AP when compared to single issue health promotion interventions, such as a nutrition education program.

\section{Methods}

The literature search included two main strategies: an electronic search of the PubMed and PsycINFO databases and inspection of all reference lists of (selected) articles, reviews and dissertations generated from the databases. The electronic search was conducted on June 7, $2010^{1}$. A basic search was performed, first. Based on the results of the basic search, the search query was specified for a second search. The search query included different descriptions of the outcome measure, encompassing most general synonyms of AP, such as academic success and academic achievement (basic search), a diversity of school grades, such as math grade, science grade and the grade-point average (GPA) (basic search and advanced search), and different titles of national examination tests (advanced search), such as Californian Achievement Test and Comprehensive Achievement Test. Secondary search terms related to the research population (e.g. children, adolescents, pupils) and intervention setting (e.g. primary prevention intervention, school health promotion). No specific time frame and

\footnotetext{
${ }^{1}$ The electronic search was repeated on January 18, 2012. No other SHPIs met our inclusion criteria. A protocol for a randomized trial of a free-breakfast program to determine the effects in AP was found (Ni Mhurchu et al., 2010).
} 
geographical scope was specified for this search. The entire search query is included in Appendix 1 of this dissertation.

The selection process included two steps: titles and abstracts of articles were scanned for school-based health promotion interventions and full texts of relevant studies were evaluated with a standard form on final eligibility criteria (Figure 2.1). During the full text examination, studies were excluded from the review if they did not report on a randomized controlled trial (RCT), quasi-experimental design, pretest-posttest controlled trial or crossover control trial, or if they did not include individual school grades, results of national test examinations or grade-point-averages (GPAs) as an outcome measure.

\section{0 results}

- 951 results from electronic databases

-89 results from examined articles, reviews and dissertations

230 articles selected for full text examination

\section{0 titles and abstracts excluded}

- no school-based health promotion intervention

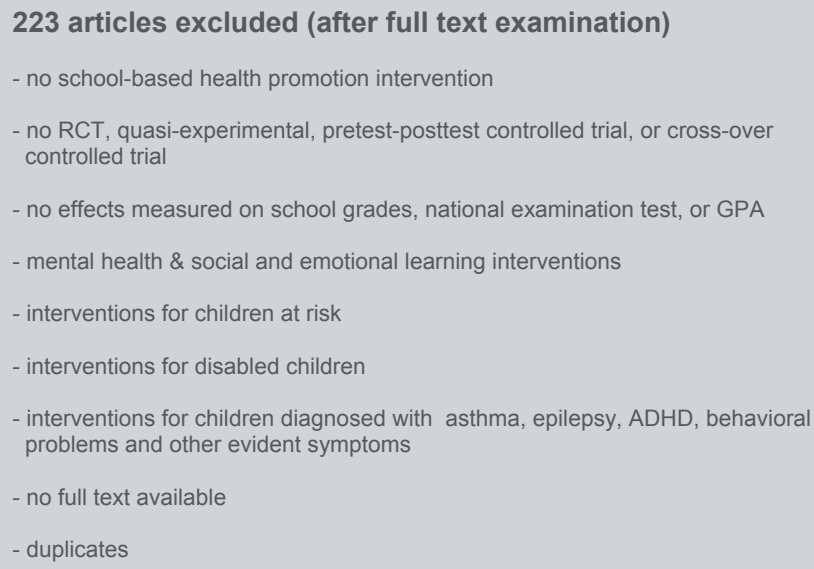

7 studies included in review

Figure 2.1: Selection process

Articles were also excluded when they reported on mental health interventions, social and emotional learning interventions which address determinants associated with children's learning ability or interventions designed for specific target groups (e.g. children at risk, disabled children, children diagnosed with asthma, epilepsy, ADHD, with behavioral problems, or other evident symptoms) rather than the general school population. We also excluded 
articles for which no full text was available (e.g. dissertation abstracts or book chapters despite our requests to the authors (Fourestier, 1962; Shephard et al., 1984)) or repeated reports of interventions reporting identical outcomes, with identical measures on the same population. The selection process was independently conducted by the first author and a research assistant. Disagreement was resolved by discussion.

Three types of studies were identified: PA interventions, interventions which combined PA and nutrition elements and school breakfast programs (SBP). No studies targeting other health behaviors fulfilled our selection criteria. Information for the study description was extracted from the original article: the country where the study was conducted, the main purpose of the intervention, research design, sample size, intervention, outcome measure, effects on AP measures, and components of the HPS (school health policies, physical environment, social environment, school/community relationship, personal health skills, and school health services, infrastructure support). We operationalized use of the HPS approach by coding for the presence of each of these elements, using the definition of IUHPE: 'School health policies are clearly defined policies in documents or accepted practices that promote health and well-being. Physical environment refers to the buildings, grounds and equipment in and surrounding the school. The social environment of the school is a combination of the quality of the relationship among and between staff and students. Community relationship presumes a connection between the school and key local groups and individuals. The individual health skills and action competencies include the formal and informal curriculum and associated activities, where students gain age-related knowledge, understanding, skills experiences, which enable them to build competencies in taking action to improve the health and well-being of themselves and others in their community, which enhances their learning outcomes. School health services refer to local and regional schoolbased and school-linked services, which have a responsibility for child and adolescents health care promotion, through the provision of direct services to students' (IUHPE, 2009; St Leger, 1999). Effects on other outcome measures than AP are reported when they were used by authors of original studies to explain observed effects.

Cohen's d effect sizes were calculated to indicate the magnitude of intervention effects. Effect sizes were calculated for each AP variable, using the reported means and standard deviations of the outcome measure at pre- and posttest and the sample size of the experimental group and the control group. If these data were not supplied, alternative methods were applied. Effect sizes were only calculated when there were significant differences between conditions in terms of AP measures. The effect sizes were interpreted based on Cohen's suggestion that $r=.10, r=.30$ and $r=.50$ represent small, medium, and large effects, respectively (Cohen, 1992; Cohen, 1995).

Below, we first report the effects of the reviewed SHPIs on AP, then report the explanations authors of original studies offered for observed effects. 


\section{Results}

The search resulted in a total of 7 studies (1989-2010) which exclusively addressed primary school children and children in middle school, targeted the maintenance of energy balance, and originated from North-America. The findings for the three categories of studies are described separately: PA interventions, interventions which combined PA and nutrition elements and school breakfast programs.

\section{Effects of physical activity interventions on academic performance}

Table 2.1 lists the following studies investigating the effects of PA on AP: Trois Riviéres (Shephard, 1996); Sports, Play, and Activity Recreation for Kinds (SPARK) (Sallis et al., 1999); Action Schools! British Columbia (AS!BC) (Ahamed et al., 2007); and Physical Education (PE) Program (Coe, Pivarnik, Womack, Reeves, \& Malina, 2006). The first three were delivered in the primary school setting and the last one in middle school.

Trois Riviéres experiment: In the six-year Trois Riviéres experiment, Shephard (1996) investigated the effects on AP of 60 minutes of daily physical education (PE) provided by a PE specialist at the expense of regular academic instruction, by comparing it to 40 minutes a week of usual PE classes by classroom teachers (control group). Although students spent 33 minutes a week less on instructions in mathematics, and no time was taken from English courses, the Trois Riviéres experiment had large positive effects $(E S=0.75)$ on students' Province Wide Examination (PWE) scores in mathematics, whereas controls were favored in terms of PWE scores in English. Results also showed a highly significant gender-program interaction for end of the year grades, with girls improving more on end of the year grades than boys in all grades (no exhaustive description provided). According to Shephard (1996) the available data suggest that the rate of learning per unit of class time is enhanced in physically active students and that lack of curricular time is not a valid reason for avoiding daily PA.' (p. S35).

Authors' explanations: Shephard (1996) found that improvements in AP in the early stages of the Trois Riviéres experiment could be attributed to gains in cognitive and psychomotor functioning, but not those in the later stages when controls had compensated for their disadvantage in psychomotor functioning. Instead, Shephard (1996) suggests immediate arousal and relief from boredom, resulting in more attention at the end of the school day, as possible mediators between PA and AP.

Sports, Play, and Activity Recreation for Kinds (SPARK): In the two-year SPARK study, Sallis et al. (1999) investigated the effects on AP of 3 times 30 minutes of PE a week and 30 minutes of self-management training, at the expense of other regular subjects (56-76 hours over a two- 
year span), provided by a trained teacher or a PE specialist, as compared with usual PE classes (control group). Effects were assessed by using a norm-referenced Comprehensive Test of Basic Skills (CTBS): the Metropolitan Achievement Test version 6 and 7 (MAT 6/7) for reading, mathematics and language. Participating schools were located in an affluent district with high baseline achievement scores. Pupils in the specialist condition had the lowest baseline scores on SES and achievement measures. The actual times spent on PE classes during an intervention week were 38, 65, 80 minutes in the control, trained teacher and specialist conditions, respectively. Decreases in AP over time were observed across all conditions. However, four of eight statistical comparisons showed an advantage for students in the experimental conditions, while only one of eight statistical comparisons favored the controls. MAT6 and later MAT7 reading, language and total battery scores (sum score of language, reading and mathematics scores) decreased less in the experimental conditions than in the control condition. The trained teacher condition performed better on more scales than the specialist condition (6:2), but positive effects were observed on different scales in different cohorts. No gender-program interactions were found. Sallis et al. (1999) concluded that 'devoting substantially increased school time to health-related PE does not have detrimental effects on students' AP' (p. 134)

Authors' explanations: Sallis et al. (1999) concluded that PA is unlikely to be responsible for the smaller decrease in AP in the experimental conditions (trained teacher condition; PE specialist condition) since the largest effects were not found in the most physically active condition (PE specialist condition). Instead, they proposed the training that the teachers had received as a possible explanation for the larger effects in the less active group (trained teacher condition). This training might have taught teachers how to manage children in the PE setting and increased teachers' confidence in teaching PE. Both increased competence and confidence may have transferred to the teaching of other subjects. The authors attributed the overall decrease in AP across conditions to the high SES at the schools and high achievement scores at baseline. They also suggested that baseline differences in SES between experimental conditions might impact on the observed effects.

Action Schools! British Columbia (AS!BC): In the two-year AS!BC study, Ahamed et al. (2007) examined the effects on AP of 15 minutes of daily classroom PA, administered by classroom teachers, in addition to a weekly 80 minutes of usual PE, compared with usual PE classes only (control group). Teachers spent only 10 of the intended 15 minutes on classroom PA. This intervention did not change AP significantly, but the intervention group caught up with the controls who had an initial advantage. No SES-program interaction was found. The authors concluded that AS!BC increased PA but did not harm AP, and therefore may 'be an attractive alternative for government and school administrators who aim to promote a school-based physical activity model' ( p. 376). 
Authors' explanations: Although the authors did not report on mediating processes, they did comment on SES, just like Sallis et al. (1999). They criticized the indirect assessment of SES through estimates of annual parental income in their own study, since SES can be an important marker of the academic standing of a school (cf. Alexander, Entwisle, \& Olson, 2001)

Physical Education Intervention: In the PE intervention, Coe et al. (2006) investigated the effects of 55 minutes of daily PE classes provided during one semester by trained school teachers, comparing it with controls who received art and computer classes instead (controls group). Effects of habitual moderate ( $\geq 3.0-5.99 \mathrm{METs}$ ) and vigorous PA ( $\geq$ 6.0 METs were also assessed. Habitual PA assessed PA outside of school. Additional PE, including an average of 19 minutes of moderate to vigorous activity, did not significantly compromise students' AP. Standardized test scores were $10 \%$ higher in the condition which was concurrently enrolled in the intervention (cross-over control trial). Increases in AP were associated with habitual vigorous PA, not with habitual moderate PA. The authors suggest that 'a potential role may exist for vigorous activity in physical education classes' (p.1519).

Authors' explanations: The authors presumed that the levels of moderate and vigorous PA during PE classes did not meet the necessary threshold to induce immediate arousal levels, improve motor skills or change body build. Just as arousal levels can increase attention and thereby facilitate learning, improvements in motor skills and changes in body build are positively linked to self-esteem, which has been shown to lead to better classroom behavior and the desire to learn (cf. Schendel, 1965; Schurr \& Brookover, 1970; Shephard, 1996; Teasdale, Sorensen, \& Stunkard, 1992). The authors also commented on SES, which was not assessed in their study. Previous research had shown that SES is related to higher levels of PA and more sports participation in youth (cf. Raudsepp \& Vira, 2000; Santos, Esculcus, \& Mota, 2004). SES may have acted as a major cause of AP, with PA acting as a mediator in this relationship. 
Table 2.1: Studies that assessed effects on academic achievement

\begin{tabular}{lllll}
\hline Study & Country & Design & Sample & Intervention \\
\hline $\begin{array}{l}\text { Shephard et } \\
\text { al. (1996) }\end{array}$ & $\begin{array}{l}\text { Québec, } \\
\text { Canada }\end{array}$ & $\begin{array}{l}\text { Pretest, } \\
\text { posttest, } \\
\text { controlled } \\
\text { trial }\end{array}$ & $\begin{array}{l}546 \text { 1st- 6th } \\
\text { graders from } \\
\text { one urban } \\
\text { primary } \\
\text { school and } \\
\text { one rural } \\
\text { primary } \\
\text { school }\end{array}$ & $\begin{array}{l}\text { Trois Riviéres experiment: A PE specialist provided one hour per day of PE } \\
\text { classes, emphasizing the learning of motor skills in the first two years, } \\
\text { dears, and the introduction of a variety of sports in the last two years. } \\
\text { Thaintained students' heart rates at a sufficient level to induce cardiovascular } \\
\text { training through the entire PE class. In the control group, teachers continued } \\
\text { teaching PE for } 40 \text { minutes a week. }\end{array}$
\end{tabular}

Sallis et al. Southern Quasi- 754 4th SPARK: In the PE program, students received $3 * 30$ min of additional PE a week (1999) California experimental, graders of randomizatio two of cardiovascular endurance and on strengthening of abdominal and upper stratification years of 7 body through 13 activities, and 15 minutes of skill fitness, which included 9 of schools elementary sports, promoting cardiovascular fitness and PA in children's community. In the based on schools weekly 30 min self-management program, students were taught skills to ethnicity; maintain a regular PA lifestyle. Methods used were topic-related presentations,

Ahamed et British al. (2007) Columbia, Canada
Quasiexperimental; 5 th graders Stratification of 10 of schools by elementary size and schools geographic location; Randomizati on

$\begin{array}{ll}\text { Coe et al. } & \text { Western } \\ \text { (2006) } & \text { Michigan, } \\ & \text { USA }\end{array}$

$\begin{array}{ll}\text { Randomized } & 2146 \text { th } \\ \text { cross-over } & \text { grade } \\ \text { controlled } & \text { students } \\ \text { trial } & \text { from 1 } \\ & \text { public } \\ & \text { middle } \\ & \text { school }\end{array}$

\begin{abstract}
goal-setting and creation of a reward system encouraging family participation. In 11 teacher training sessions, teachers were taught class management and instruction skills. PE specialists fulfilled an advisory role in coordinating space and equipment use and assisting with class scheduling etc.. during 2 years, either provided by a certified PE specialist or a trained teacher, including 15 min of health fitness activities, which focused on the development to
\end{abstract}

\begin{abstract}
AS!BC: Trained teachers provided 15 min daily of classroom physical activities in addition to $80 \mathrm{~min}$ of regular PE classes a week. Children were exposed throughout the school day to a variety of activities including skipping, chair aerobics, hip hop dancing, playground circuits, and resistance exercise with exercise band. These activities were performed in the classroom, hallway or school playground. Parents were informed by school newsletter inserts. Teachers were taught during a 1-day course how to implement classroom activities. A AS!BC support team provided schools with resources such as written materials, classroom action bins etc. The AS!BC facilitator provided support on a weekly basis. Classroom physical activities made up one of six zones in the AS!BC program in which schools can integrate physical activities. The model is consistent with the concept of health promoting schools. The classroom physical activity was the most consistently implemented activity at schools.
\end{abstract}

PE Intervention: Part of the sample receoived 55 minutes of physical education during the 1st semester by physical education teachers, while the others received no physical education classes but were enrolled in alternative classes (e.g.: art, computer). The conditions were reversed in the second semester. Students' activity levels during PE classes were recorded by the System for Observing Instruction Time (SOFIT) and students' habitual physical activity by a 3-day physical activity recall.

$c=$ control, $\exp =$ experimental group

${ }_{2}^{1}$ no exhaustive description of results provided in article. ES are taken from a review (Trudeau \& Shephard. 2007)

${ }^{2} \mathrm{c}=$ control, $\mathrm{t}=$ trained teacher condition, $\mathrm{s}=$ specialist condition

MAT6/7 = Metropolitan Achievement Test; CAT3 = Californian Achievement Test 
(continued on next page)

Outcome Measure

Province-wide examinations administered at the end of 6th grade: French, Mathematics, English; End of the year grades of 1 st through 6th grades: French, mathematics, English, natural science, combined score

Cohort1:

MAT6 administered in the $2 \mathrm{nd}$ and 5 th grades: reading, mathematics, language, full battery score

Cohort2:

MAT6 administered in 2nd grade and MAT7 administered in the 6th grade: Reading, mathematics, language, full battery score

CAT 3 administered in 4th and 5th grades (pretest) and 5 th and 6 th (posttest) grades: total standardized score for mathematics, reading, language / writing components
Effects Effect Size

Enhanced province-wide examination Mathematics: 0.75 exp. $>c^{2}$;

scores in mathematics, but lower scores English language: $0.80 \exp .<c^{2}$; in English for the experimental group.
Cohort 1:

Enhanced language scores for the specialist intervention group and enhanced reading scores for the teacher trained intervention group.

Cohort 2:

Enhanced reading and total battery score but decreased language score for the trained teacher intervention. Greater increase of reading and total battery scores but lower increase in language score for the trained teacher intervention group than for the specialist intervention group

Baseline differences between $\exp .=c$ intervention group and controls, with controls having better total standardized scores, were diminished at follow-up
TerraNova achievement test administered in the 2 nd semester of the 6 th grade: reading, language, arts, mathematics, science and social studies;

standardized test score of individual semester grades in 6 th grade in four subjects: mathematics, science, English, combined score of individual grades world studies performance as a function of physical activity in either the Terranova achievement test nor the combined test scores of individual grades in both semesters; however, habitual vigorous physical activity was associated with
No significant differences in academic

$\exp .=c$
Cohort $^{2}$ :

Language: $0.28 \mathrm{t}>\mathrm{c}$; Reading: $0.36 \mathrm{~s}>\mathrm{c} 4$

Language: $0.28 \mathrm{~s}<\mathrm{c} \& 0.39 \mathrm{~s}>\mathrm{t}$; Reading: $0.25 \mathrm{t}>\mathrm{c} \& 0.22 \mathrm{~s}>\mathrm{t}$; Total battery: $0.29 \mathrm{t}>\mathrm{c} \& 0.35 \mathrm{~s}<\mathrm{t}$; 
Table 2.1: Studies that assessed effects on academic achievement

\begin{tabular}{|c|c|c|c|c|}
\hline Study & Country & Design & Sample & Intervention \\
\hline $\begin{array}{l}\text { Shilts et al. } \\
\text { (2009) }\end{array}$ & $\begin{array}{l}\text { Central } \\
\text { Valley, } \\
\text { California }\end{array}$ & $\begin{array}{l}\text { Experimental } \\
\text { cross-over } \\
\text { controlled } \\
\text { trial }\end{array}$ & $\begin{array}{l}84 \text { th } \\
\text { graders } \\
\text { clustered in } \\
3 \text { classrooms } \\
\text { of an } \\
\text { elementary } \\
\text { school }\end{array}$ & $\begin{array}{l}\text { EatFit: The 5-week nutrition education intervention was developed based on } \\
\text { Social Cognitive Theory (SCT) and intended to influence SCT constructs } \\
\text { addressed during } 9 \text { experimental lessons accompanied by a magazine-style } \\
\text { EatFit workbook, including the following topics: dietary and physical activity } \\
\text { goal setting, reading food labels, eating at fast food outlets, learning physical } \\
\text { activities and understanding media influence. Methods used in the lessons were } \\
\text { teaching skills, goal performance feedback, behavior practice, motivation. } \\
\text { Strategies included e.g. barrier-counseling and -modelling, social support } \\
\text { (parents, friend) and environmental/reciprocal determinism (community, } \\
\text { school environment). Students completed a dietary and physical activity web- } \\
\text { based assessment each week. Dietary analysis for example included 24-hour } \\
\text { diet record, personalized dietary feedback, goal setting and contract. Raffle } \\
\text { tickets and prizes were used to motivate students. }\end{array}$ \\
\hline $\begin{array}{l}\text { Hollar et al. } \\
\text { (2010) }\end{array}$ & Florida, USA & $\begin{array}{l}\text { Pretest, } \\
\text { posttest, } \\
\text { controlled } \\
\text { trial }\end{array}$ & $\begin{array}{l}1197,6-13 \\
\text { year-old } \\
\text { children } \\
\text { from } 5 \\
\text { elementary } \\
\text { schools } \\
\text { qualifying for } \\
\text { free or } \\
\text { reduced- } \\
\text { price lunch }\end{array}$ & $\begin{array}{l}\text { HOPS: The dietary component included the modification of school-provided } \\
\text { breakfast, lunches and day snacks. Low-fiber items, high-glycemic items and } \\
\text { items with high amounts of total saturated fats and trans fats were substituted } \\
\text { by healthier options. The curriculum component included a nutrition and } \\
\text { healthy lifestyle management program that intended to teach children, parents } \\
\text { and school staff about good nutrition and benefits of physical activity. Teachers } \\
\text { were equipped with the Organ Wise Guys curriculum, which included print } \\
\text { books, print activity posters and physical activity programs, to facilitate the } \\
\text { integration of healthy lifestyle topics in the curriculum. The PA component } \\
\text { (WISERCISE) included } 10-15 \text { min of desk-side physical activities daily. The } \\
\text { activities were tailored to the core courses so that teachers could continue their } \\
\text { instructional lessons. Beyond this, schools were asked to implement physical } \\
\text { activity opportunities during school breaks and encourage children, parents and } \\
\text { school staff to be physically active every day. }\end{array}$ \\
\hline $\begin{array}{l}\text { Meyers et al. } \\
\text { (1989) }\end{array}$ & $\begin{array}{l}\text { Massa- } \\
\text { chusetts, } \\
\text { USA }\end{array}$ & $\begin{array}{l}\text { Pretest, } \\
\text { posttest, } \\
\text { controlled } \\
\text { trial }\end{array}$ & $\begin{array}{l}1023 \text { 3rd - } \\
\text { 6th graders } \\
\text { of } 6 \\
\text { elementary } \\
\text { schools } \\
\text { qualifying for } \\
\text { free and } \\
\text { reduced- } \\
\text { price meals }\end{array}$ & $\begin{array}{l}\text { SBF: In } 1986 \text { the Commonwealth of Massachusetts enacted legislation } \\
\text { mandating the implementation of SBP in those schools which were not offering } \\
\text { SBP and in which } 40 \% \text { or more of school lunches were served for free or at } \\
\text { reduced price. }\end{array}$ \\
\hline
\end{tabular}

$\mathrm{c}=$ control, $\exp =$ experimental group

${ }^{1}$ no exhaustive description of results provided in article. ES are taken from a review (Trudeau \& Shephard, 2007)

${ }^{2} \mathrm{c}=$ control, $\mathrm{t}$ = trained teacher condition, $\mathrm{s}=$ specialist condition

STAR = Standardized Reporting and Testing Program; FCAT = Florida Comprehensive Assessment Test; CTBS = Comprehensive Test of Basic Skills 
(continued from last page)

Outcome Measure

STAR Contents Standards revised administered in 6th grade (pre-, posttest): Language (listening, speaking), Mathematics (Algebra \& Functions 2.2/2.3, Statistics 1.1, Mathematical Reasoning 1.1),

Combined score
Effects Effect Size

Enhanced language score and scores for Mathematical reasoning 1.1: 0.29 the components algebra \& functions exp.>c;

2.3 and mathematical reasoning 1.1 for Algebra \& Functions 2.3: 0.45 exp.>c; the intervention group Listening \&speaking: 0.57 exp.>c; Combined score: 0.33 exp.>c
FCAT administered in 3rd grade and at 1 Enhanced math scores were found in year and 2 year posttest: reading, mathematics. the intervention group.Positive trends were visble for reading scores in the intervention schools
Pre-test post-test:

Mathematics: 0.08 exp.>c; Pre-test follow-up:

Mathematics: 0.46 exp.>c
CTBS administered in 3rd through 6th grades and at 3 month follow-up: language, reading, mathematics, combined score
Enhanced language and combined scores for students participating in the School Breakfast Program. Positive trends were observed in CTBS change scores for reading and mathematics in SBP-participants
Language: 0.19 exp.>c;

Total battery: 0.24 exp. $>c$ 
Overall conclusion: Additional PA is not likely to affect AP negatively, even when provided at the expense of regular academic instructions, and regardless of whether it is employed as a class-room activity or as additional PE at high or low activity levels. Positive effects on AP have been demonstrated and are more likely when PE is delivered at vigorous levels targeting cardiovascular endurance and fitness and employed either by a trained teacher or a trained physical education specialist. Effects of the different PA interventions vary across academic domains. Inconsistent information is provided about possible gender-program interaction. One intervention related to the HPS, however no effects on AP resulted (Ahamed et al., 2007). The authors report that only one intervention element, the classroom activities (personal skill development), was compulsory for schools. It remains unclear if and which other elements of the approach were in place at the moment of evaluation. None of the effective PA interventions related their program to the key components of the HPS, though these interventions have the following HPS-elements in common: strengthening cardiovascular fitness and endurance, teaching of sport activities children can engage outside school (personal skill development) and provision of the program by a PE-specialist or a trained and supported teacher (infrastructure support). The proposed mediating processes for PA interventions on AP are improvements in psychomotor functioning, induced immediate arousal levels, long-term effects on self-esteem and transfer of teachers' competencies learned during the training that teachers had received to other subjects. SES is also proposed as a possible moderator of the relation between AP and PA.

\section{Effects of interventions combining physical activity and nutrition elements on academic performance}

Table 2.1 lists studies investigating the effects on AP of a nutrition education program and an obesity prevention intervention, viz. the Eatfit intervention (Shilts, Lamp, Horowitz, \& Townsend, 2009) and the Healthier Options for Public Schoolchildren (HOPS) (Hollar et al., 2010) program, both delivered in the primary school setting.

Eatfit intervention: Shilts et al. (2009b) assessed the impact of 5 weeks of nutrition education, consisting of 9 educational lessons assisted by webbased assessment of dietary and PA behavior. In addition, 58\% of the respondents were eligible for free or reduced-price lunches. Effects were assessed by using the Standardized Reporting Testing Program (STAR) which statewide measures students' achievement of academic standards in language and mathematics. The EatFit intervention had large positive effects on content standards in English and almost medium to almost large positive effects on content standards in mathematics. A medium-sized effect was observed on the total score of all content standards. The class with the highest academic scores at baseline improved least. No gender-program interaction was found. Shilts et al. (2009b) concluded that the nutrition education 
intervention positively affects educational and health outcomes (Shilts, Horowitz, \& Townsend, 2009), 'thus serving a dual purpose for public schools' (p.130).

Author's explanations: Shilts et al. (2009b) did not report on mediators.

Healthier Options for Public Schoolchildren (HOPS): In the HOPS intervention, Hollar et al. (2010) examined the effects of an obesity prevention program (including dietary, PA and curriculum components) on AP and healthy weight, one and two years after the intervention was implemented. Effects were assessed by using a norm-referenced Comprehensive Test of Basic Skills (CTBS): the Florida Comprehensive Assessment Test (FCAT) for reading and mathematics. Data for 350 of the 1197 children eligible for free or reduced-price lunch were available in the repeated-measure analysis of AP, against data for 645 children in the repeated-measure analysis of BMI. Children in intervention schools achieved higher FCAT math scores than controls at both measurements. A considerably larger effect on FCAT math scores was observed at two-year follow-up than at one-year follow-up, indicating that effects can express themselves after some time. Reading scores showed a positive trend in the intervention schools. HOPS also positively affected children's BMI, with more intervention children than controls remaining within normal BMI percentiles over the two years. Given that HOPS improved educational and health outcomes among children eligible for free or reduced-priced meals, the authors concluded that 'these findings are particularly encouraging given that many children from low-income backgrounds receive a significant proportion of their daily nutrition requirements at schools' in the USA (p. 652)

Authors' explanations: The authors did not report on mediating processes.

Overall conclusion: There is strong evidence that nutrition education interventions and obesity prevention programs targeting dietary behavior and PA levels can positively affect the AP of primary school children. Even dual effects, on mathematics and language, are possible. Since the study samples mainly included children eligible for free or reduced-priced lunches, results can be generalized to children from low-income background. One study reports the absence of differences between gender groups in outcomes. Although both interventions did not directly relate to the HPS-elements, practicing nutrition- and healthy lifestyle choices in real life situations, thereby using a diversity of methods, and involving children's direct physical and social environments as well as providing infrastructure support in the implementation of the programs may be important ingredients to achieve benefits on AP.

\section{Effects of free breakfast provision on academic performance}

Table 2.1 lists one School Breakfast Program (SBP) (Meyers, Sampson, Weitzman, Rogers, \& Kayne, 1989), which was delivered to primary school children. 
School Breakfast Program (SBP): In the SBP study, Meyers et al. (1989) examined effects on AP by comparing change scores of 335 SBP participants who attended breakfast on at least $60 \%$ of the days at school with change scores of 668 SPB non-participants who did not attend school breakfast on any day in the three months after SBP was introduced (control group). Effects were assessed on a norm-referenced Comprehensive Test of Basic Skills (CTBS) in language, readings and mathematics (no exhaustive description provided of which CTBS was exactly used). SBP participants' gains in the CTBS total battery (sum score of language, reading and mathematics scores) and CTBS language scores were greater than those of non-SBP participants. Positive trends were observed in CTBS change scores for reading and mathematics among SBP participants. The authors concluded that if these results can be confirmed by prospective controlled trials, SBP should be implemented on a larger scale.

Authors' explanations: The authors suggested immediate effects of morning meals eaten at the start of the school day, more long-term benefits relating to improved 24-hour dietary intake, or a combination of both, as possible explanations for academic improvements.

Overall conclusion: Breakfast interventions can slightly enhance AP. In this case improvements in AP were the result of legislation mandating SBP at schools and contributed to the admission of SBP in the school (health) policy. However, only one SBP was found. This makes conclusions about the generalizability of the observed effects impossible, also to children from low SES background. Effects in this study might relate to immediate effects of meal intake or to long-term effects of 24-hour improvements in nutritional status.

\section{Discussion}

We reviewed the evidence for effects of general lifestyle interventions on children's AP and the mechanisms researchers have proposed to account for these effects. We specifically focused on the effects on standardized measures of AP found in methodologically sound studies of interventions addressing healthy lifestyles in the general school populations. Although we initially found a large number of studies evaluating effects of SHPIs on AP, very few met these criteria. The remaining studies exclusively addressed primary school children and children in middle school, targeted the maintenance of energy balance, and originated from North-America.

The reviewed SHPIs showed that interventions targeting energy balance obviously can have small to large effects on AP (range of effect sizes: 0.19-0.75). Effects of different kinds of interventions varied in size and across academic domains, as mathematics and language scores. Also positive effects were observed in subjects from which time was taken for the intervention, e.g. for additional PE. No negative effects occurred, although some inconsistent 
results were reported. Two PA-studies resulted in no effects on AP. In one of these studies SES was suggested as possible explanation for no effects. Although most authors suggest SES and gender are important moderators of health and AP, only a minority report on these variables. Studies on PA interventions did not measure SES-intervention interactions at all. Interventions combining PA and nutrition or targeting nutrition only were mostly directed at children from low SES-backgrounds (most of the children were eligible for free- or reducedpriced meals at schools). Contradicting results were reported for gender-intervention interactions in PA intervention, while no gender-intervention interaction were measured in the other two intervention domains. No studies referred to SES as a mediator, although there are studies outside the intervention field which see SES as possible mediator of the relationship between health behavior and academic performance (Datar, Sturm, \& Magnabosco, 2004): in this study, the relation between obesity and academic achievement disappears when controlling for the positive relation of learning with SES.

Since our review only included studies from North-America, it remains unclear whether the same effect on AP would be found in SHPIs from other countries and continents. Possibly, different grading systems are used in other countries, which are more or less responsive to changes in children's academic performance. Suhrcke and Paz Nieves (2011) state that there seems to be a general lack of information on the impact of health and health behaviors on AP in countries belonging to the Organization for Economic Co-operation and Development (OECD). It might be that evaluations on AP using standardized testing are more common in North America. In the U.S. for example most schools complete at least one annual achievement test battery (MAT 6/7 or CAT 3). Alternatively, standardized test may be more accessible for research purpose in North America than in other countries. For instance, within the Netherlands standardized test scores are only available on school level not on individual pupil level. Further, central tests are not identical in different grades.

The second objective of this review was to report on the mediators that authors suggested for the observed effects; regretfully, little evidence for possible mediators was provided. Instead, authors based hypothetical assumptions on previous studies in experimental settings. Mediators were proposed for PA interventions and the school breakfast program. These were mechanisms directly related to physical, neurohormonal and cognitive conditions, such as improved psychomotor skills, inducement of arousal levels, improved self-esteem and nutritional balance. As regards indirect mechanisms, Sallis et al. (1999) suggested improved teaching practices, which might have transferred from teaching of PE to teaching of other subjects, such as English lessons. For example, in this study the school health promotion interventions might have enhanced teachers' confidence and competence in teaching in general (no matter what their topic) and thereby increased children's AP.

We were interested whether we could find any differences in outcomes between the studies that used a broad framework to school health promotion, such as the HPS initiative, 
and studies that used a more limited approach. The only intervention that referred to a broader framework had no effects on AP. However we cannot exclude underreporting of HPS elements in the reviewed studies.

\section{Strengths and limitations}

The findings of this review support previous work by Trudeau and Shephard (2008) who conclude that general interventions targeting physical health may lead to improved AP. With this review we extend this conclusion by providing additional evidence for interventions simultaneously targeting healthy diets and PA levels and a school breakfast program. This again indicates that school health promotion does not necessarily have to target children at risk or with specific symptoms in order to generate effects on AP. Also, interventions do not necessarily have to employ elements related to school education per se to produce academic gains, although it is likely that effects on AP might even be larger in those interventions.

The strength of this review is that we only report on the effects of methodologically sound evaluation studies. This limited the number of studies included but also allowed for strong inferences with a high degree of intern validity about intervention effects. Another strength of this review is that we assessed the effects on standardized measures of AP, ensuring maximum construct validity. Although the interventions were limited to the domain of energy balance, a third strength is that we examined the evidence of studies focusing on PA levels, studies combining nutrition and PA elements and studies involving daily breakfast provision at school, and calculated the effect sizes for each intervention type. This gave us the opportunity to compare the effects between different lifestyle interventions.

The most important limitation of this review is that we end up with a very small sample of interventions in three intervention domains from the use of strict inclusion criteria. This, and the lack of homogeneity between intervention elements (content, length of elements and measurement instruments) in these three domains, forces us to be extremely cautious with conclusions about generalizability of our results. For example, in the PA domain, two PA-interventions targeted cardiovascular endurance and fitness (Sallis et al., 1999; Shephard, 1996), one daily classroom activities (Ahamed et al., 2007) and one daily PA lessons (Coe et al., 2006). We also have to be cautious with generalizations of these results to other countries than North-America, because of the limited geographical scope of the reviewed interventions. Another limitation of our review is that many of the excluded studies reported positive effects on the determinants of AP (e.g. Wide Range Achievement Test, Digit Span Test, Wechsler Intelligence Test for Children, school attendance and behavior), rather than AP per se. It seems likely that where improvements on determinants of AP are possible, improvements in AP might be feasible too; although the relevant data were lacking in these studies. A further limitation of our review is that our findings are partly based on cross-over controlled trials. Cross-over control trials are prone to maturation and testing biases and 
background learning. However, none of the reports on cross-over trials considered their results to be seriously threatened by these biases. Also, one of our studies dates from 1989. Possible changes in statistical methods and measurement instruments should be considered when comparing the results of the Meyers et al. study from 1989 with the more recent studies (1996-2010). Finally, because of the nature of the reviewed studies we were not able to answer our third question, therefore whether employing a broad framework to SHPIs would make any difference in observed effects on AP when compared to single issue health promotion interventions remains unanswered.

\section{Implications for research and practice}

Despite these limitations, this review shows that school health promotion targeting healthy lifestyles can positively affect AP in the general school population. More studies are needed among secondary school children, studies in European- and OECD-countries and in other domains than personal skill development, such as school health policies, physical environment, social environment, school/community relationship, school health services and infrastructure support. The review of Murray et al. (2007) might provide good examples of possible studies in this field for Europe.

We also conclude that future studies should pay more attention to factors mediating the effects of health promoting interventions on AP. Similarly, interventions should use outcome measures that allow better understanding of the contributions of individual intervention elements (e.g. practical strategies and HPS-elements) to educational outcomes. Moreover, gender- en SES-intervention interactions should be considered. The effect on AP might differ between children from different SES-backgrounds and between boys and girls. Also, our review suggests that longitudinal changes in the observed effects (sleeper effects) possibly occur. This warrants long-term evaluations of school-based health promotion interventions. Finally, academic outcomes are of utmost importance but also the determinants of AP are extremely relevant. They can provide additional evidence for the beneficial effects of school-based interventions on AP. We strongly encourage that effects on such outcomes are systematically reviewed.

To conclude, the planned development of school health promotion will need to be based on evidence. Our practical implications for the implementation of measures of AP in school health promotion are as follows:

- Measures of AP should be included in process- and effect evaluations of SHPIs.

- Schools and health professionals should be made aware of the importance of these measures. 


\section{References}

Ahamed, Y., Macdonald, H., Reed, K., Naylor, P. J., Liu-Ambrose, T., \& McKay, H. (2007). School-based physical activity does not compromise children's academic performance. Medicine and Science in Sports and Exercise, 39(2), 371-376.

Alexander, K. L., Entwisle, D. R., \& Olson, L. S. (2001). Schools, Achievement, and Inequality: A Seasonal Perspective. Educational Evaluation and Policy Analysis, 23(2), 171-191.

Boot, N. M. W. M., van Assema, P., Hesdahl, B., \& de Vries, N. K. (2010). Professional assistance in implementing school health policies. Health Education, 110(4), 294-308.

Coe, D. P., Pivarnik, J. M., Womack, C. J., Reeves, M. J., \& Malina, R. M. (2006). Effect of physical education and activity levels on academic achievement in children. Medicine and Science in Sports and Exercise, 38(8), 1515-1519.

Cohen, J. (1992). A power primer. Psychological Bulletin, 112(1), 155-159.

Cohen, J. (1995). Statistical power analysis for the behavioral sciences (2nd edition). Hillsdale, New Jersey: Erlbaum.

Datar, A., Sturm, R., \& Magnabosco, J. L. (2004). Childhood overweight and academic performance: national study of kindergartners and first-graders. Obesity Reserach, 12(1), 58-68.

Davis, J. M., \& Cooke, S. M. (2007). Educating for a healthy, sustainable world: an argument for integrating Health Promoting Schools and Sustainable Schools. Health Promotion International, 22(4), 346-353.

Deschesnes, M., Martin, C., \& Hill, A. J. (2003). Comprehensive approaches to school health promotion: how to achieve broader implementation? Health Promotion International, 18(4), 387-396.

DeSocio, J., \& Hootman, J. (2004). Chilrden's Mental Health and School Success. The Journal of School Nursing, 20(4), 188-196.

Fourestier, M. (1962). Les expériences scolaires de Vanves International Review of Education, 8, 81-85.

Greenberg, M. T., Weissberg, R. P., O'Brien, M. U., Zins, J. E., Fredericks, L., Resnik, H., \& Elias, M. J. (2003). Enhancing school-based prevention and youth development through coordinated social, emotional, and academic learning. American Psychologist, 58(6), 466-474.

Hollar, D., Messiah, S. E., Lopez-Mitnik, G., Hollar, T. L., Almon, M., \& Agatston, A. S. (2010). Effect of a two-year obesity prevention intervention on percentile changes in body mass index and academic performance in low-income elementary school children. American Journal of Public Health, 100(4), 646-653.

IUHPE. (2009). Achieving Health Promoting Schools: Guidelines for Promoting Health in Schools. Retrieved 15 January 2015, from 
http://www.dhhs.tas.gov.au/_data/assets/pdf_file/0011/115895/guidelines_for_heal th_promoting_schools1.pdf.

Lister-Sharp, D., Chapman, S., Stewart-Brown, S., \& Sowden, A. (1999). Health promoting schools and health promotion in schools: two systematic reviews. Health Technology Assessment, 3(22), 1-207.

Meyers, A. F., Sampson, A. E., Weitzman, M., Rogers, B. L., \& Kayne, H. (1989). School Breakfast Program and school performance. American Journal of Diseases of Children, 143(10), 1234-1239.

Murray, N. G., Low, B. J., Hollis, C., Cross, A. W., \& Davis, S. M. (2007). Coordinated School Health Programs and Academic Achievement: A Systematic Review of the Literature. Journal of School Health, 77, 589-600.

Raudsepp, L., \& Vira, R. (2000). Sociocultural correlates of physical activity in adolescents. Pediatric Exercise Sience, 12, 51-60.

Resnick, M. D., Bearman, P. S., Blum, R. W., Bauman, K. E., Harris, K. M., Jones, J., Tabor, J., Beuhring, T., Sieving, R. E., Shew, M., Ireland, M., Bearinger, L. H., \& Udry, J. R. (1997). Protecting adolescents from harm: Findings From the National Longitudinal Study on Adolescent Health. Journal of the American Medical Association, 278(10), 823-832. doi: 10.1001/jama.1997.03550100049038

Sallis, J. F., McKenzie, T. L., Kolody, B., Lewis, M., Marshall, S., \& Rosengard, P. (1999). Effects of health-related physical education on academic achievement: project SPARK. Research Quarterly for Exercise and Sport, 70(2), 127-134.

Santos, M. P., Esculcus, C., \& Mota, J. (2004). The relationship between socioeconomic status and adolescents' organized and nonorganized physical activities. Pediatric Exercise Science, 16, 210-218.

Schendel, J. (1965). Psychological differences between athletes and non-participants in atheletics at three educational levels. Research Quarterly, 36, 52-67.

Schurr, T., \& Brookover, W. (1970). Athletes, academic self-concept and achievement. Medicine and Science in Sports and Exercise, 2(2), 96-99.

Shephard, R. J. (1996). Habitual physical activity and academic performance. Nutrition Reviews, 54(4 Pt 2), S32-36.

Shephard, R. J., Volle, M., Lavallée, H., LaBarre, R., Jéquier, J. C., \& Rajic, M. (1984). Required physical activity and academic grades: a controlled longitudinal study In IImarinen J. \& Valimaki I. (Eds.), Children and Sport. Berlin: Springer Verlag.

Shilts, M. K., Horowitz, M., \& Townsend, M. S. (2009). Guided goal setting: effectiveness in a dietary and physical activity intervention with low-income adolescents. International Journal of Adolescent Medicine and Health, 21(1), 111-122. 
Shilts, M. K., Lamp, C., Horowitz, M., \& Townsend, M. S. (2009). Pilot study: EatFit impacts sixth graders' academic performance on achievement of mathematics and english education standards. Journal of Nutrition Education and Behavior, 41(2), 127-131.

St Leger, L., \& Nutbeam, D. (2000). Research into Health Promoting Schools. Journal of School Health, 70(6), 257.

St Leger, L. H. (1999). The opportunities and effectiveness of the health promoting primary school in improving child health - a review of the claims and evidence. Health Education Reserach, 14(1), 51-69. doi: 10.1093/her/14.1.51

Stewart-Brown, S. (2006). What is the evidence on school health promotion in improving health or preventing disease and, specifically, what is the effectiveness of the health promoting schools approach? . Copenhagen: WHO Regional Office for Europe.

Suhrcke, M., \& de Paz Nieves, C. (2011). The impact of health and health behaviors on educational outcomes in high income countries: a review of the evidence. W.H.O. Regional Office for Europe, Copenhagen.

Taras, H. (2005). Nutrition and student performance at school. Journal of School Health, 75(6), 199-213.

Teasdale, T. W., Sorensen, T. I., \& Stunkard, A. J. (1992). Intelligence and educational level in relation to body mass index of adult males. Human Biology, 64(1), 99-106.

Trudeau, F., \& Shephard, R. J. (2008). Physical education, school physical activity, school sports and academic performance. International Journal of Behavioral Nutrition and Physical Activity, 5(10). doi: 10.1186/1479-5868-5-10

Trudeau, F., \& Shephard, R. J. (2010). Relationships of Physical Activity to Brain Health and the Academic Performance of Schoolchildren. American Journal of Lifestyle Medicine, 4, 138-150.

Zins, J. E., Weissberg, R. P., Wang, M. C., \& Walberg, H. J. (2004). Building academic success on social and emotional learning. New York: Teachers College Press. 
Part II

A systematic approach to the establishment of intersectoral collaboration in CSHP 



\section{Chapter 3}

\section{A multiple-case study of intersectoral collaboration in comprehensive school health promotion using the Diagnosis of Sustainable Collaboration (DISC) model}

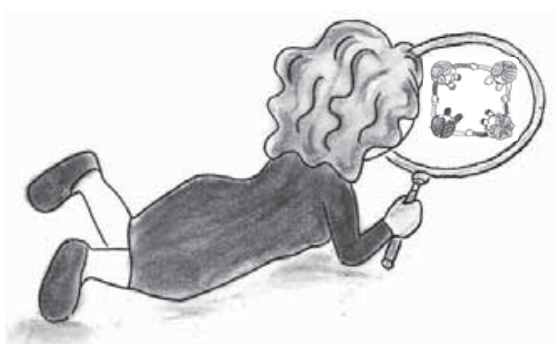

Based on:

Pucher, K.K., Candel, M.J.J.M., Boot, N.M.W.M, Van Raak, A., \& De Vries, N.K., (2015). A multiple-case study of intersectoral collaboration in the context of coordinated school health promotion using the Dlagnosis of Sustainable Collaboration (DISC) Model. Health Education, 115(3/4), 301-321. 


\section{Abstract}

Purpose: Intersectoral collaboration is often a prerequisite for effective interventions in public health. This study assessed the facilitating and hindering conditions regarding intersectoral collaboration between health authorities, public health services (PHSs), public services stakeholders (PPSs) and the education sector in comprehensive school health promotion (CSHP) in the Netherlands.

Methods: CSHP collaborations in five Dutch regions were studied using a questionnaire based on the Dlagnosis of Sustainable Collaboration (DISC) model, focusing on: change management; perceptions, intentions and actions of collaborating parties; project organization; and factors in the wider context. Univariate and multivariate analyses with bootstrapping were applied to 106 respondents (62\% response).

Findings: A similar pattern of facilitating and hindering conditions emerged for the five regions, showing positive perceptions, but fewer positive intentions and actions. An overall favorable internal and external context for collaboration was found, but limited by bureaucratic procedures and prioritizing stakeholders' own organizational goals. Change management was rarely applied. Some differences between sectors emerged, with greatest support for collaboration found among the coordinating organizations (PHSs) and least support among the financing organization (municipalities).

Limitations: The generalization of our findings is limited to the initial formation stage of collaboration, and may be affected by selection bias, small sample size and possible impact of interdepartmental collaboration within organizations.

Implications: We recommend establishing stronger change management to facilitate translation of positive perceptions into intentions and actions, and coordination of divergent organizational structures and orientations among collaborating parties.

Originality/value: Our results show that it is valuable for collaborating parties to conduct DISC analyses to improve intersectoral collaboration in CSHP.

Keywords: collaboration; management; public health; schools; health promotion; healthy schools 


\section{Introduction}

Intersectoral and interorganizational partnerships and collaborations have been recognized as crucial for a healthy public policy in terms of effectiveness (Jackson et al., 2006) and sustainability (Stirman et al., 2012), in addition to investments in local and national governments and social policy and the creation of legislation and regulations. Such intersectoral collaboration requires system change. Theories and principles of organizational change advocate a thorough analysis of factors and the development of appropriate strategies (Cummings \& Worley, 2001; Daft \& Noe, 2001; De Caluwé \& Vermaak, 2003). At the moment there is no uniform conceptual model for partnership development in public health, but there are numerous ideas grounded in specific comprehensive initiatives, all of which suggest consideration of the same range of factors (Clark et al., 2006; Crowley et al., 2000; Feinberg et al., 2004; Florin et al., 2000; Kegler \& Swan, 2011b). These factors relate to personal characteristics, attitudes, beliefs and behaviors of relevant stakeholders, the organizational context of parties involved and the external context of the collaboration. These factors clearly indicate the necessity of involving actors at various levels (individual level, organizational level, policy level), regardless of the setting (e.g. schools, community) in which the collaboration is established. That interconnected systems can accomplish their goals more easily through collaboration than through individual actions by individual stakeholders is also confirmed by the literature on complex adaptive systems (Dür, 2013; Plsek \& Greenhalgh, 2001; Plsek \& Wilson, 2001). The theory of complex adaptive systems relates to vertical interconnections between system levels as well as to horizontal interconnections between sectors and disciplines. In the literature on collaboration there is consensus that coalitions develop in stages (e.g. formation, maintenance, institutionalization) with frequent loops to earlier stages and with impact of different factors at each stage (Butterfoss, 2007). In addition, the theory on group development seems helpful to understand the group dynamics of aligning stakeholders and progressing to collaborative performance (McMorris, Gottlieb, \& Sneden, 2005; Tuckman, 1965).

Comprehensive school health promotion (CSHP) is one of the public health approaches which entails broad multisectoral stakeholder representation. CSHP has been recognized by the World Health Organization as an effective means of improving children's wellbeing and health, and is implemented worldwide (IUHPE, 2009). CSHP goes beyond teaching pupils about health and its determinants and enabling them to develop skills to make healthy choices in their lives. It also targets the physical and social environments in and around school through community activities and re-designing health services (Leurs et al., 2005a; Stewart-Brown, 2006). The key drivers for collaboration are to reduce fragmentation and overlap in school health promotion (Deschesnes et al., 2003; Leurs et al., 2005b; WHO, 1995) and to improve the effectiveness and efficiency of school health promotion in the long 
term (Lister-Sharp et al., 1999; St Leger, 1999; Stewart-Brown, 2006). The intersectoral collaboration needed for CSHP presents an opportunity to study the development of such collaboration.

The specific collaborative structure involving relevant stakeholders from the education sector, health authorities, public health services (PHSs) and public service stakeholders (PPSs) in CSHP has been studied by Leurs et al. (2008) in the southern parts of the Netherlands. The Dutch healthy school approach (HSA), which is equivalent to CSHP, targets demand-driven practice in school health promotion, with schools implementing only health promotion programs that fit its specific health problems. Such demand-driven practices require coordination of health promotion programs and collaboration between local and regional stakeholders. At the level of the schools, the implementation of HSA is professionally assisted by a 'healthy school advisor' who represents different public services and providers (e.g. from the welfare, health, prevention and safety sectors) in individual contacts (Buijs, 2005; Leurs et al., 2006; RIVM Centre for Healthy Living, 2010). At local and regional levels, the PHSs function as a linking pin (coordinator) between the education sector, health authorities and PSSs from mental health care, addiction care etc. The coordinating role derives from a legal responsibility for the implementation of local public health policy and youth health care financed by the municipality (Hirsch Ballin, 2008). The case-study by Leurs et al. (2008) included schools as clients of the HSA, municipalities as the main financers of the HSA and PSSs and PHSs as coordinators and providers of topic-specific expertise, educational materials and health promotion programs.

The work of Leurs et al. (2008) resulted in the Dlagnosis of Sustainable Collaboration (DISC) model, which summarizes the important predictors of intersectoral collaboration at the individual, organizational and policy levels in six main clusters: collaborative support, change management, project management, context, external factors and CSHP (Table 3.3). These clusters incorporate the above-mentioned concepts of organizational change theory. The DISC clusters are based on previous findings from Dutch case studies aimed at bringing together different health domains in integrated care (Van Raak, Mur-Veeman, \& Paulus, 1999) and on theories of interorganizational collaboration (Cummings \& Worley, 2001), planned organizational change (De Caluwé \& Vermaak, 2003) and organizational behavior (Daft \& Noe, 2001). The reference to sustainability in the name of the model refers to the gradual establishment of a long-lasting and stable collaboration instead of a project-bound coalition limited in time. Under the continuous influence of the collaborative process, an idea of the way CSHP should be organized is worked out and developed into formalized regular working routines. This transition into sustainable collaboration is captured in the sixth DISC cluster, 'CSHP'. The study by Leurs et al. (2008) found that different DISC factors (e.g. intention to commit, changes within the organization, change strategies, project management, openness to innovations) were associated with collaboration in the different 
sectors. The results of the analysis later became the basis for strategies to improve collaboration between these sectors.

\section{Aims of this paper}

Although the basis of the DISC model was developed through several consecutive case studies using the replication logic by Yin (2009), its application as a diagnostic instrument for advantageous and disadvantageous conditions for intersectoral collaboration has so far been limited to the case of the HSA in the Dutch Southern Limburg region. Broadening the scope of investigation from one coalition to a multiple-case study of partnerships in a variety of situations was intended to increase the generalizability of the DISC model to other partnerships in school health promotion and maybe even to other types of partnerships.

The current multiple-case study therefore used the DISC model to evaluate five HSA partnerships across the Netherlands, with different characteristics. The main research questions were as follows. What main facilitating and hindering DISC factors for intersectoral collaboration can be identified in five Dutch PHS regions? Can they be related to the specific characteristics of the coalitions and their starting situation in the regions? Are these factors different for stakeholders from different sectors (i.e. education, health authorities, PHSs, PSS)?

\section{Methods}

\section{Procedure}

In 2008/2009, cross-sectional quantitative data on DISC determinants were collected in five of the 30 Dutch PHS regions. Regional coordinators of the HSA working at the PHSs were asked to identify relevant stakeholders from the education sector, PHSs, PSSs and municipal authorities, and to announce the topic of our research to these persons. They then distributed materials for the survey (the questionnaire and a brief summary of the HSA). Data collection lasted for a total of eight weeks; reminders were sent after four weeks. In accordance with Dutch regulations, no ethical approval was required for this study.

\section{Participating PHS regions}

The number of existing HSA-collaboration is not registered in the Netherlands, but from the only report about this topic (Bos et al., 2010), we know that existing collaborations are as diverse as the five collaborations at hand. In order to examine a variety of situations, five examples of HSA collaboration were studied, which differed in several characteristics and starting situations. Table 3.1 depicts these for each of the five PHS regions, in ascending order of size. Important differences and similarities between the regions are described below. 
Table 3.1: Characteristics of the five PHS regions and their CSHP in 2008

\begin{tabular}{|c|c|c|c|c|c|}
\hline & PHS region 1 & PHS region 2 & PHS region 3 & PHS region 4 & PHS region 5 \\
\hline $\begin{array}{l}\text { Stakeholders } \\
\text { approached } \\
\text { from school } \\
\text { type }\end{array}$ & Primary education & $\begin{array}{l}\text { Secondary } \\
\text { education }\end{array}$ & $\begin{array}{l}\text { Secondary } \\
\text { education }\end{array}$ & $\begin{array}{l}\text { Secondary } \\
\text { education }\end{array}$ & Primary education \\
\hline Working area & $\begin{array}{l}12 \text { municipalities } \\
\text { (secondary } \\
\text { education: } \pm 324 \\
\text { schools) }\end{array}$ & $\begin{array}{l}13 \text { municipalities } \\
\text { (secondary } \\
\text { education: } \pm 12 \\
\text { schools at } 25\end{array}$ & $\begin{array}{l}20 \text { municipalities } \\
\text { (secondary } \\
\text { education: } \pm 16 \\
\text { school boards) }\end{array}$ & $\begin{array}{l}26 \text { municipalities } \\
\text { (secondary } \\
\text { education: } \pm 30 \\
\text { schools) }\end{array}$ & $\begin{array}{l}29 \text { municipalities } \\
\text { (primary education: } \\
\pm 450 \text { schools) }\end{array}$ \\
\hline $\begin{array}{l}\text { Year of CSHP } \\
\text { adoption }\end{array}$ & $\begin{array}{l}\text { Another variant } \\
\text { than HSA; primary } \\
\text { education: } 2007 \\
\text { secondary } \\
\text { education: } \\
2009\end{array}$ & $\begin{array}{l}\text { Primary education: } \\
2006 \\
\text { Secondary } \\
\text { education: } 2008\end{array}$ & $\begin{array}{l}\text { Primary education: } \\
2008 \\
\text { Secondary } \\
\text { education: } 2008\end{array}$ & no & $\begin{array}{l}\text { Primary education: } \\
2004 \\
\text { Secondary } \\
\text { education: } 2008\end{array}$ \\
\hline $\begin{array}{l}\text { Manpower for } \\
\text { CSHP at PHS }\end{array}$ & $\begin{array}{l}\text { Primary education: } \\
3 \text { health promoters }\end{array}$ & $\begin{array}{l}\text { Secondary } \\
\text { education: } 4 \text { health } \\
\text { promoters, } 2 \\
\text { epidemiologists }\end{array}$ & $\begin{array}{l}\text { Secondary } \\
\text { education: } 4 \text { health } \\
\text { professionals }\end{array}$ & $\begin{array}{l}\text { Secondary } \\
\text { education: } 2 \text { health } \\
\text { promoters, } 4 \text { youth } \\
\text { health professionals }\end{array}$ & $\begin{array}{l}\text { Primary education: } \\
12 \text { health } \\
\text { promoters, } \\
29 \text { youth health } \\
\text { care professionals, } 1 \\
\text { project assistant, } 3 \\
\text { epidemiologists }\end{array}$ \\
\hline CSHP delivery & $\begin{array}{l}\text { Primary education: } \\
\text { single service point }\end{array}$ & $\begin{array}{l}\text { Primary education: } \\
\text { newsletter }\end{array}$ & no & no & $\begin{array}{l}\text { Primary education: } \\
\text { healthy promoting } \\
\text { school advisors }\end{array}$ \\
\hline $\begin{array}{l}\text { Health } \\
\text { promoting } \\
\text { school advisor } \\
\text { in CSHP }\end{array}$ & no & $\begin{array}{l}\text { Health promoting } \\
\text { school advisors } \\
\text { from PHS, Youth } \\
\text { Care, Education } \\
\text { Support Service, } \\
\text { Mental Health Care }\end{array}$ & no & no & $\begin{array}{l}\text { Healthy promoting } \\
\text { school advisors } \\
\text { from PHS }\end{array}$ \\
\hline \multirow[t]{2}{*}{$\begin{array}{l}\text { Collaboration } \\
\text { with PSSs in } \\
\text { CSHP }\end{array}$} & $\begin{array}{l}\text { Previous variant: } \\
\text { Education Support } \\
\text { Service, Mental } \\
\text { Health, Youth Care, } \\
\text { Addiction Care, } \\
\text { Justice, Dietician, } \\
\text { Sports company }\end{array}$ & $\begin{array}{l}\text { Primary education: } \\
\text { Organizations of } \\
\text { health promoting } \\
\text { school advisors, } \\
\text { Addiction Care, } \\
\text { Welfare and YHC }\end{array}$ & $\begin{array}{l}\text { Previous projects: } \\
\text { Mental Health Care, } \\
\text { Justice and Welfare }\end{array}$ & no & $\begin{array}{l}\text { Primary education: } \\
\text { PE: Welfare, } \\
\text { Dietician, Sports } \\
\text { company, Addiction } \\
\text { Care }\end{array}$ \\
\hline & Meet once a year & $\begin{array}{l}\text { Meet six times a } \\
\text { year }\end{array}$ & & & \\
\hline $\begin{array}{l}\text { Collaboration } \\
\text { with } \\
\text { municipalities } \\
\text { in CSHP }\end{array}$ & no & $\begin{array}{l}\text { Primary education: } \\
\text { PHS informs about } \\
\text { the healthy school } \\
\text { approach via } \\
\text { general PHS-journal }\end{array}$ & no & no & no \\
\hline $\begin{array}{l}\text { Collaboration } \\
\text { with schools in } \\
\text { CSHP }\end{array}$ & $\begin{array}{l}\text { Primary education: } \\
\text { PHS informs schools } \\
\text { via single service } \\
\text { point at PHS }\end{array}$ & $\begin{array}{l}\text { Primary education: } \\
\text { PHS recruits schools } \\
\text { for the HSA }\end{array}$ & no & no & $\begin{array}{l}\text { Primary education: } \\
\text { PHS recruits schools } \\
\text { for the HSA }\end{array}$ \\
\hline
\end{tabular}


PHS region 1 used a single PHS-based service point for health promotion programs and expertise for schools, which had several linkages with PSSs, involving annual meetings. For the purpose of our study, the coordinator approached stakeholders for the HSA in primary education. PHS region 2 had just started extending the existing collaborative structure from primary education to secondary education, and this new collaboration was the focus of our study. PHS region 3 had just started the implementation of the HSA in both school types. There were plans to build on a previous collaboration (in another domain) with managers of some PSSs. In this region, stakeholders from secondary education were approached. PHS region 4 was in the post-merger phase (of two PHSs) without any uniform school health policy, and the coordinator also approached stakeholders from secondary education. PHS region 5 had some pilot projects in primary schools running, with the assistance of healthy school advisors, and had a single service point for health promotion programs and expertise at the PHS. There were no regular meetings with any external partners. The coordinator in PHS region 5 approached stakeholders from primary education. In short, all PHS regions were in the initial stages of intersectoral collaboration, with stakeholders from the relevant school type but with different starting situations. None of the PHS regions were actually delivering health promotion programs and expertise in a demand-driven fashion to schools as intended by the HSA.

\section{Stakeholders approached}

The regional coordinators contacted a total of 171 potential stakeholders from municipalities, PHSs, PSSs and schools (Table 3.2). The municipal civil servants ( $N=28)$ who were approached were responsible for youth health policy, education and welfare. The PHS professionals $(\mathrm{N}=43)$ included health promoters, epidemiologists, pediatricians and youth nurses. The PSSs $(\mathrm{N}=44)$ were working in the domains of addiction, mental health, social welfare, security and other services, like educational support services, dietician centers and sports companies. Stakeholders from the educational sector who were approached included pupil care coordinators and school managers $(\mathrm{N}=56)$.

\section{DISC questionnaire}

The DISC questionnaire developed by Leurs et al. (2008) measures the 27 DISC factors (divided over 6 clusters) using 1 to 5 items each, mostly on a 5-point scale (completely agree to completely disagree) with the additional option of 'unknown'. Examples of items used in the questionnaire are 'I think it is important that my organization participates in the HSA' and 'I think the HSA is of interest to my own organization' (collaborative support - perceptions importance). A summary of the operationalization of the main DISC constructs (collaborative 
support, change management, project management, context, external factors and CSHP) and their factors is presented in Table 3.3.

\section{Statistical analysis}

Statistical analyses were conducted using SPSS 20 and R.

During data cleaning, 5-point item response scales were first recoded into 3-point scales for the interpretation of facilitating and hindering conditions for intersectoral collaboration. The top two options of the answering scale indicated that a particular DISC factor was in place, and were recoded as positive (code 3); the midpoint of the answering scale was equivalent to a neutral evaluation of the DISC factor and recoded as neutral (code 2); and the bottom two answering options indicated the absence of a DISC factor and were recoded as negative (code 1 ). We also recoded the 'unknown' option as a value of ' 1 ' (negative) because it apparently indicated the absence of a particular DISC factor. Missing values for one item in scales with four or more items were replaced by the mean of the other items. Cronbach's alphas were calculated for the different scales operationalizing the DISC factors. These appeared to be lower than .60 for five of the 15 scales: perceptions of importance, perceptions of involvement, willingness to change, organizational characteristics and policy and regulations (Table 3.3). The items of these scales were therefore included separately in the analyses.

Analyses involving bootstrapping were used to avoid the erroneous assumption of normality and the resulting Type 1 and Type 2 errors. Bootstrap analyses were conducted with 5000 replications. The significance level for all tests was set at 0.05 . To assess facilitating and hindering factors for collaboration, overall means were tested against the midpoint of each scale. First, multivariate (one sample Hotellings $\mathrm{T}^{2}$ ) and univariate (one-sample t-test) bootstrapping analyses were conducted for each subset of DISC factors. When the multivariate test was significant, univariate one-sample t-tests with bootstrapping were conducted for each of the constituent factors.

To test whether facilitating and hindering factors differed between regions and sectors $^{1}$, multivariate (Pillai's test) and univariate (F-test) bootstrapping analyses were first conducted for each subset of factors with 'region' and 'sector' in one statistical model, followed, in case of significance, by t-tests (pairwise comparison with Fisher's Least Significant Method (LSD)) with bootstrapping to identify which regions and sectors differed from each other for each of the constituent determinants.

\footnotetext{
${ }^{1}$ In the first instance multivariate and univariate analyses were conducted with the two main effects of 'sector' and 'region' and an interaction term of 'region x sector'. As some region-sector combinations contained no data, tests on the 'region $x$ sector' interaction were inconclusive. We therefore do not report the results for the interaction term.
} 


\section{Results}

\section{Response}

Table 3.2 shows that of the 171 stakeholders who were approached in the five regions, 106 completed the DISC questionnaire (62\%). The response rates were comparable across sectors, but there was some variation between regions.

Table 3.2: Response to DISC questionnaire

\begin{tabular}{|c|c|c|c|c|c|c|}
\hline & Region 1 & Region 2 & Region 3 & Region 4 & Region 5 & Total \\
\hline Sector & Number of act & respondents & imber of resp & ents approa & $(\%)$ & \\
\hline PHS & $5 / 5$ & $8 / 9$ & $11 / 19$ & $1 / 3$ & $3 / 7$ & $28 / 43(65 \%)$ \\
\hline PSS & $5 / 7$ & $5 / 6$ & $10 / 15$ & $1 / 1$ & $3 / 15$ & $24 / 44(55 \%)$ \\
\hline Municipality & $7 / 12$ & $3 / 4$ & $8 / 11$ & - & $0 / 1$ & $18 / 28(64 \%)$ \\
\hline Education & $1 / 2$ & $3 / 3$ & $13 / 22$ & $5 / 12$ & $10 / 17$ & $32 / 56(57 \%)$ \\
\hline Unknown* & & $2 /$ & $1 /$ & 1/ & & 4/ \\
\hline Total & $18 / 26(69 \%)$ & $21 / 22(95 \%)$ & $43 / 67$ (64\%) & $8 / 16(50 \%)$ & $16 / 40(40 \%)$ & $106 / 171(62 \%)$ \\
\hline
\end{tabular}

PHS: public health service; PSS: public service stakeholders

* These respondents did not indicate their sectors, so they were only included in general analyses and not in uni/mutlivariate analyses with bootstrapping for differences between regions and sectors.

\section{Facilitating and hindering factors}

Facilitating factors are shown in bold-italic in Table 3.3 (see column marked total); hindering factors are shown bold and underlined. Since no differences were found between regions, only significant differences between sectors are indicated by different superscript letters in Table 3.3. Below we present the results for the six main categories of DISC determinants.

Collaborative support. A relatively large proportion of the facilitating factors relate to the perceptions of collaborative support. Respondents perceived the goals of the HSA as important (perceptions - goal) and of interest to their own organization (perceptions importance). According to the respondents, the HSA offers win-win situations for parties involved (perceptions - win-win) and the parties involved have common views about ways to realize the HSA (perceptions - ideological consensus). The only two hindering factors respondents perceived were the differences between involved parties (perceptions involvement) and the unclear boundaries between the spheres of activity of the various partners (perceptions - domain consensus). Participants reported few intentions and actions. The only facilitating factors mentioned in this category were a high degree of willingness to trust each other (intentions - trust) and a large investment of resources for the HSA (collaborative support-actions - resources). One hindering factor is apparently the extent to which respondents think that changes within their own organization are necessary for the HSA (collaborative support - intentions - change). 
Table 3.3: Operationalization of DISC model (adapted from Leurs, Mur-Veeman et al. (2008)), reliability, response, means, and results of multi/univariate test and t-tests with bootstrapping

Operationalization of DISC $\quad$ DISC indicators $\quad$ Cronbach's alpha Missings

The collaborative support can be assessed on the levels of perceptions, intentions and actions of the parties involved.

\section{- Perceptions}

Intersectoral collaboration evolves more smoothly when participating organizations share goals and interests, perceive positive outcomes supportive of their own goals, are able to reach consensus on the goal of the collaborative process and are of the opinion that the most relevant parties are involved in the collaborative process.

\section{- Intentions}

Parties involved should start with the intention to trust each other (if not present, this needs to be worked on first), the intention to commit themselves to the collaborative process and its subject and the intention to make changes within one's own organization, if needed, in favour of the collaborative process.

\section{- Actions}

The collaborative process may induce a wide variety of actions, varying from the implementation of small adaptations to major innovations within one's own organizations to the inclusion of relatively minor adaptations of regular procedures. The actions may involve a reallocation of resources as well. Whatever actions result from a collaborative process, it is important that these are formalized in order to enhance sustainability. The level of formalization needed depends mainly on the type of action itself.

\begin{tabular}{|c|c|c|c|}
\hline - Perceptions & & & \\
\hline Goals & 5 & .923 & $1,89 \%$ \\
\hline Importance & 3 & .590 & \\
\hline $\begin{array}{l}\text {-The HSA is effective } \\
\text { - It is important that my } \\
\text { organization participates in the }\end{array}$ & 1 & & $5,66 \%$ \\
\hline HSA & 1 & & $1,89 \%$ \\
\hline $\begin{array}{l}\text { - The HSA is important for the } \\
\text { realization of the goals of my } \\
\text { organization }\end{array}$ & 1 & & $2,83 \%$ \\
\hline Win-win & 1 & & $0,28 \%$ \\
\hline Ideological consensus & 4 & .825 & $4,95 \%$ \\
\hline Domain consensus & 1 & & $4,72 \%$ \\
\hline $\begin{array}{l}\text { Involvement } \\
\text { - Differences between } \\
\text { partners disturb effective }\end{array}$ & 2 & .543 & \\
\hline $\begin{array}{l}\text { collaboration } \\
\text { - Partners provide enough and }\end{array}$ & 1 & & $4,72 \%$ \\
\hline various support & 1 & & $4,72 \%$ \\
\hline - Intentions & & & \\
\hline Willingness to trust & 2 & .781 & $3,30 \%$ \\
\hline Willingness to commit & 2 & .621 & $2,83 \%$ \\
\hline Willingness to change & 2 & .389 & \\
\hline - Available room for change & & & $2,83 \%$ \\
\hline - Things to change & & & $2,83 \%$ \\
\hline - Actions & & & \\
\hline Changes & 1 & & $2,83 \%$ \\
\hline Resources & 2 & .665 & $2,83 \%$ \\
\hline Formalization & 1 & & $2,83 \%$ \\
\hline
\end{tabular}

PHS: public health service; PSS: public service stakeholders; $\mathrm{K}$ : number of items measuring a DISC indicator Multi/univariate tests: ${ }^{*} p \leq .05,{ }^{* *} p<.01,{ }^{* * *} p<.001$

Multiple comparison: means with the different superscripts are statistically different $(p<.05)$ 
(continued on next page)

\begin{tabular}{|c|c|c|c|c|c|}
\hline \multicolumn{6}{|c|}{ Bootstrap analysis } \\
\hline Total & Per sector & & & & \\
\hline & PHS & PSS & Municipalities & Education & Manova (N)/ \\
\hline$(N=106)$ & $(\mathrm{N}=28)$ & $(N=24)$ & $(N=18)$ & $(N=32)$ & Anova (N) \\
\hline Mean (SD) & Mean (SD) & Mean (SD) & Mean (SD) & Mean (SD) & (F) \\
\hline
\end{tabular}

\begin{tabular}{|c|c|c|c|c|c|}
\hline $2.75(0.51)$ & $2.83(.41)$ & $2.69(.62)$ & $2.54(.73)$ & $2.85(.34)$ & $\begin{array}{r}1,609 \\
(\mathrm{~N}=93)\end{array}$ \\
\hline $2.21(.61)$ & $2.32(.55)$ & $2.09(.67)$ & $2.07(.70)$ & $2.26(.58)$ & \\
\hline $2.76(.53)$ & $2.56(.62)$ & $2.61(.72)$ & $2.56(.62)$ & $2.88(.42)$ & \\
\hline $2.38(.729)$ & $2.71(.54)$ & $2.00(.85)$ & $2.35(.70)$ & $2.38(.71)$ & \\
\hline $2.65(.61)$ & $2.71(.53)$ & $2.35(.78)$ & $2.59(.71)$ & $2.84(.37)$ & \\
\hline $2.10(.69)$ & $2.13(.66)$ & $2.40(.60)$ & $1.74(.68)$ & $2.09(.71)$ & \\
\hline $1.71(.84)$ & $1.89(.79)$ & $2.00(.95)$ & $1.28(.57)$ & $1.60(.86)$ & \\
\hline$\underline{1.77(.87)}$ & $1.71(.85)$ & $2.00(.98)$ & $1.39(.70)$ & $1.81(.83)$ & \\
\hline $1.88(.88)$ & $2.11(.83)$ & $1.68(.84)$ & $1.44(.78)$ & $2.03(.91)$ & \\
\hline & & & & & $2.480^{* *}$ \\
\hline $2.18(.82)$ & $2.16(.75)^{a, b}$ & $2.35(.73)^{b}$ & $1.81(.89)^{\mathrm{a}}$ & $2.27(.86)^{b}$ & $(\mathrm{~N}=101)$ \\
\hline $1.90(.73)$ & $2.34(.67)^{\mathrm{a}}$ & $1.72(.56)^{b, c}$ & $1.36(.51)^{\mathrm{c}}$ & $1.98(.78)^{b}$ & \\
\hline $1.97(.89)$ & $2.04(.84)$ & $2.00(.95)$ & $1.61(.92)$ & $2.09(.86)$ & \\
\hline$\underline{1.55(.80)}$ & $1.64(.91)$ & $1.65(.88)$ & $1.61(.85)$ & $1.38(.61)$ & \\
\hline & & & & & $3.334 * * *$ \\
\hline $1.84(.92)$ & $2.46(.84)^{c}$ & $1.78(.90)^{b}$ & $1.28(.57)^{\mathrm{a}}$ & $1.72(0.89)^{b}$ & $(\mathrm{~N}=101)$ \\
\hline $2.24(.78)$ & $2.52(.74)^{b}$ & $2.37(.63)^{a, b}$ & $2.00(.79)^{a}$ & $2.02(0.84)^{\mathrm{a}}$ & \\
\hline $1.94(.86)$ & $2.07(.77)$ & $1.91(.95)$ & $1.78(.81)$ & $1.91(0.93)$ & \\
\hline
\end{tabular}


Table 3.3: Operationalization of DISC model (adapted from Leurs, Mur-Veeman et al. (2008)), reliability, response, means, and results of multi/univariate test and t-tests with bootstrapping

Operationalization of DISC $\quad$ DISC indicators $\quad$ Cronbach's alpha Missings

Change management

The intended change requires management by one or small group of leaders. In order to establish a successful collaboration, individual and collective leadership skills are necessary to guide the developmental process. Change management strategies should fit the chosen innovation perspective and be supportive of the health promotion subject. The most relevant actors are included, and where

$\begin{array}{llll}\text { Vision } & 3 & .792 & 2,83 \% \\ \text { Innovation perspective } & 4 & .604 & 3,30 \% \\ \text { Change strategy } & 4 & .632 & 2,83 \% \\ \text { Network development } & 1 & & 2,83 \%\end{array}$
any are missing, this will be addressed by extending the network of the leaders of the collaborative process.

\section{Project management}

Project management

During the development and initial implementation phase the collaborative process is dealt with as a project in a project management structure.

This includes deciding who are the actors in the project, what they need to do and how they operate (planning, procedures, evaluation, communication, etc.). This project management structure fades out when the subject of the collaborative process is being integrated (or about to be integrated) in the regular work and the alliance becomes self-supportive.

$\begin{array}{llll}\text { Actors, Tasks, communication } & 3 & .883 & 4,72 \%\end{array}$

Context

The collaborative process evolves in a context which can be influenced by the partners themselves.

When parties have more positive experiences with each other in previous collaborative processes, need less energy for internal changes, have more research power and feel more supported by policies which they can influence as well, they are more open to the sustainable collaborative process supporting inter-sectoral health promotion.

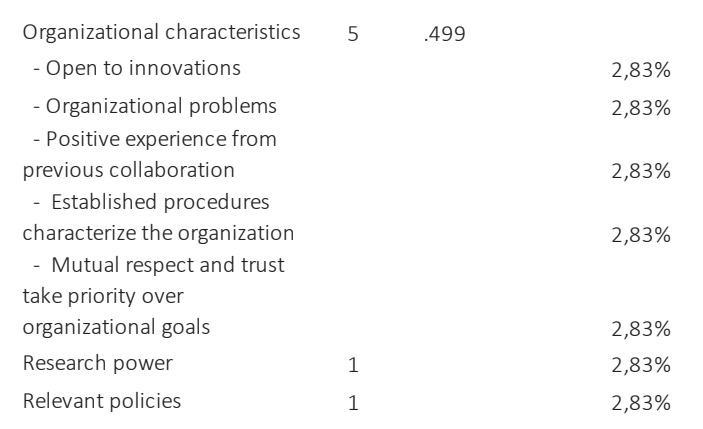

PHS: public health service; PSS: public service stakeholders; K: number of items measuring a DISC indicator Multi/univariate tests: ${ }^{*} p \leq .05,{ }^{* *} p<.01,{ }^{* * *} p<.001$

Multiple comparison: means with the different superscripts are statistically different ( $p<.05)$ 
(continued from last page)

\begin{tabular}{|c|c|c|c|c|c|}
\hline \\
\hline \multicolumn{6}{|c|}{$\frac{\text { Bootstrap analysis }}{\text { Total Per sector }}$} \\
\hline$(N=106)$ & $\begin{array}{c}\text { PHS } \\
(\mathrm{N}=28)\end{array}$ & $\begin{array}{c}\text { PSS } \\
(\mathrm{N}=24)\end{array}$ & $\begin{array}{c}\text { Municipalities } \\
\qquad(\mathrm{N}=18)\end{array}$ & $\begin{array}{l}\text { Education } \\
\qquad(\mathrm{N}=32)\end{array}$ & $\begin{array}{c}\text { Manova (N)/ } \\
\text { Anova (N) }\end{array}$ \\
\hline Mean (SD) & Mean (SD) & Mean (SD) & Mean (SD) & Mean (SD) & (F) \\
\hline & & & & & $2.127^{*}$ \\
\hline $2.44(.67)$ & $2.54(.56)$ & $2.48(.58)$ & $2.24(.78)$ & $2.42(.76)$ & $(\mathrm{N}=101)$ \\
\hline $1.99(.58)$ & $1.94(.50)$ & $1.90(.61)$ & $1.89(.64)$ & $2.16(.61)$ & \\
\hline $1.86(.59)$ & $1.96(.47)^{b}$ & $1.92(.66)^{a, b}$ & $1.54(.56)^{a, b}$ & $1.93(.62)^{b}$ & \\
\hline $2.05(.87)$ & $2.29(.76)^{b}$ & $2.30(.93)^{b}$ & $1.56(.78)^{\mathrm{a}}$ & $1.97(.86)^{\mathrm{a}, \mathrm{b}}$ & \\
\hline $1.72(.78)$ & $1.86(.74)^{b}$ & $2.12(.93)^{b}$ & $1.30(.52)^{\mathrm{a}}$ & $1.53(.69)^{\mathrm{a}, \mathrm{b}}$ & $\begin{array}{r}4.459^{* *} \\
(N=98)\end{array}$ \\
\hline & & & & & $4.164^{* * *}$ \\
\hline $2.79(.52)$ & $2.43(.74)^{a}$ & $2.96(.21)^{b, c}$ & $2.72(.57)^{a, c}$ & $3.00(.00)^{b}$ & $(\mathrm{~N}=101)$ \\
\hline $2.34(.77)$ & $2.18(.86)^{a}$ & $2.22(.90)^{a, b}$ & $2.33(.59)^{a, b}$ & $2.63(.61)^{b}$ & \\
\hline $2.65(.70)$ & $2.36(.83)^{\mathrm{a}}$ & $2.83(.58)^{b}$ & $2.83(.51)^{b}$ & $2.66(.70)^{a, b}$ & \\
\hline$\underline{1.54(.74)}$ & $1.57(.84)^{b}$ & $1.83(.83)^{b}$ & $1.22(.43)^{\mathrm{a}}$ & $1.53(.67)^{b}$ & \\
\hline$\underline{1.88(.78)}$ & $1.75(.84)^{\mathrm{a}}$ & $1.78(.67)^{\mathrm{a}}$ & $1.72(.67)^{\mathrm{a}}$ & $2.22(.79)^{b}$ & \\
\hline $2.36(.75)$ & $2.50(.69)$ & $2.39(.84)$ & $2.28(.67)$ & $2.22(.79)$ & \\
\hline $1.90(.83)$ & $2.43(.74)^{c}$ & $1.78(.80)^{\mathrm{b}}$ & $2.22(.81)^{b, c}$ & $1.31(.54)^{\mathrm{a}}$ & \\
\hline
\end{tabular}


Table 3.3: Operationalization of DISC model (adapted from Leurs, Mur-Veeman et al. (2008)), reliability, response, means, and results of multi/univariate test and t-tests with bootstrapping

Operationalization of DISC $\quad$ DISC-indicators $\quad$ Cronbach's alpha Missings

The collaborative process is influenced by a number of factors that are beyond the control or influence of the alliance itself:

\section{- Policy and regulations}

Clear, preferably inter-sectoral policies, laws and regulations providing challenging and sound goals for health promotion may enhance the collaborative process. Limiting factors may be diffuse borders between policy domains, contradicting policies of different public sectors and policies focusing on the transformation of public organizations into private enterprises.

\section{- Attitude of financing bodies}

Collaborative process is supported by an encouraging and accommodating attitude of financing bodies and commitment to provide the necessary funding over a longer period to prevent a brain drain from starting during the initial developmental phase.

\section{- Community notion}

Community notion can be regarded as an add-on to the individual interests of each party and can additionally stimulate organizations to work together on coordinated school health promotion. Incentives, policies and regulations can increase community notion for coordinated school health promotion, as can parents, school staff and collaborating parties who show social interest for coordinated school health promotion.

$\begin{array}{lccc}\begin{array}{l}\text { Policy and regulations } \\ \text { - fits in with public health } \\ \text { policy }\end{array} & 2 & .401 & \\ \begin{array}{l}\text { - fits in with school health } \\ \text { policy }\end{array} & 1 & & 3,77 \% \\ \end{array}$

Attitude of financing

1
Community notion 1

\section{Comprehensive School Health Promotion}

The collaborative process influences the development of the coordinated school health promotion and supports the move towards sustainability (goal):

Under the continuous influence of the collaborative process, an idea is elaborated and develops into regular working routines that are formalized. During this process the subject of the collaborative process evolves: it 'changes colour' under the influence of the collaborative process itself.

\section{organizations} 年

External factors
The collaborative process is influenced by a number of
factors that are beyond the control or influence of the
alliance itself:
- Policy and regulations
Clear, preferably inter-sectoral policies, laws and
regulations providing challenging and sound goals for
health promotion may enhance the collaborative proce
Limiting factors may be diffuse borders between policy
domains, contradicting policies of different public sectc
and policies focusing on the transformation of public
organizations into private enterprises.
- Attitude of financing bodies
Collaborative process is supported by an encouraging a
accommodating attitude of financing bodies and
commitment to provide the necessary funding over a
longer period to prevent a brain drain from starting duri
the initial developmental phase.
- Community notion
Community notion can be regarded as an add-on to the
individual interests of each party and can additionally
stimulate organizations to work together on coordinatec
school health promotion. Incentives, policies and
regulations can increase community notion for
coordinated school health promotion, as can parents,
school staff and collaborating parties who show social
interest for coordinated school health promotion.

\section{Comprehensive School Health Promotion}

PHS: public health service; PSS: public service stakeholders; K: number of items measuring a DISC-indicator

Multi/univariate tests: ${ }^{*} p \leq .05,{ }^{* *} p<.01,{ }^{* * *} p<.001$

Multiple comparison: means with the different superscripts are statistically different ( $p<.05)$ 
(continued from last page)

\begin{tabular}{|c|c|c|c|c|c|}
\hline \multicolumn{6}{|c|}{ Bootstrap analysis } \\
\hline Total & Per sector & & & & \\
\hline$(N=106)$ & $\begin{array}{c}\text { PHS } \\
(\mathrm{N}=28)\end{array}$ & $\begin{array}{c}\text { PSS } \\
(N=24)\end{array}$ & $\begin{array}{c}\text { Municipalities } \\
\quad(N=18)\end{array}$ & $\begin{array}{l}\text { Education } \\
\qquad(\mathrm{N}=32)\end{array}$ & $\begin{array}{c}\text { Manova (N)/ } \\
\text { Anova (N) }\end{array}$ \\
\hline Mean (SD) & Mean (SD) & Mean (SD) & Mean (SD) & Mean (SD) & (F) \\
\hline
\end{tabular}

$2.22(.92)$

$2.36(.83)$

$2.26(.92)$

$2.33(.91)$

$2.03(1.00)$

$2.03(.92)$

$1.79(.92)^{\mathrm{a}}$

$2.13(.92)^{b}$

$1.89(.90)^{\mathrm{a}, \mathrm{b}}$

$2.31(.90)^{b}$

$2.216^{*}$

( $N=100)$

$2.30(.87)$

$2.43(.69) \mathrm{a}$

2.67 (.69)a,b

$2.84(.52) \mathrm{b}$

$1.83(.99)$

$2.69(.64)^{b}$

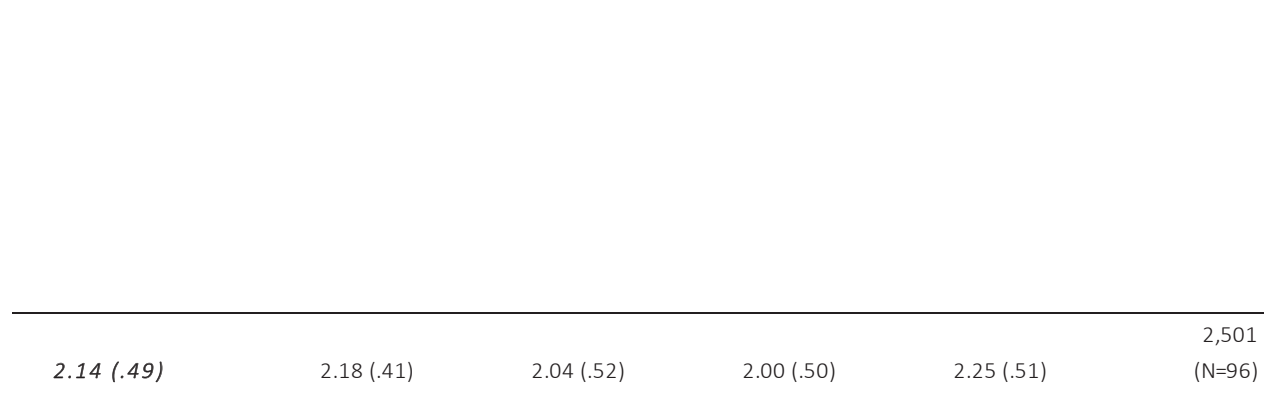


Differences between sectors were found for respondents' intentions $(F(12,276)=2.480, p<.01)$ and actions $(F(9,93)=3.334, p<.001$, Table 3.3). As regards the facilitating factor of 'willingness to trust', municipal civil servants scored significantly lower than the educational sector or the PSSs, who reported a definite intention to trust each other. As regards the facilitating factor of 'allocation of resources', municipal civil servants and the educational sector reported significantly less investments in the HSA than PHSs.

Change management. Not all principles of change management were in place yet, although respondents perceived a common vision which could be facilitating for collaboration. Project management. Respondents evaluated the project management as insufficient. A comparison between sectors regarding project management $(F(3,90)=4.459$, $p<.01$ ) shows that PSSs and PHSs perceived significantly better project management than the municipal civil servants. Nevertheless, scores on project management were low in all sectors.

Context. The internal context of the HSA seems to comply with many conditions necessary for proper implementation of an innovation within the different organizations. The answers showed openness to innovations, not many organizational problems, positive experiences with previous collaborations and enough expertise for research, although there were also some signs of bureaucracy (organization characteristics) which could hinder collaboration.

Some differences between sectors were found in perceived context $(F(21,267)=4.164$, $p<.001)$. Although all sectors scored high on the facilitating factors, the educational sectors differed significantly from the municipalities and PHSs, which showed the highest degree of openness to innovation and the fewest organizational problems. PSSs also reported significantly more openness to innovations than municipal civil servants and PHSs. Compared with the other sectors, the PHSs had the least positive experiences with previous collaborations. With regard to hindering factors, aspects of bureaucracy were reported by all sectors, with slight differences. Established procedures were most common in municipalities. PHSs, PSSs and municipalities gave organizational goals greater priority than trust and mutual respect. The opposite was true for the educational sector.

External factors. The HSA appeared to fit in with the school health policies and public health policies (policies and regulation) and was perceived favorably by the most important financer of the HSA (attitude of most important financer).

Sectors evaluated their external context differently $(F(12,273)=2.216, p<.05)$. All sectors were optimistic about the degree to which the HSA fitted in with local public health policy, but the educational sector was even more optimistic than the PHSs. The sectors showed greater differences regarding the degree to which the HSA fits in with school health policy. Schools perceived the best fit between the HSA and the school health policy, significantly more so than municipal civil servants and PSSs. Municipal civil servants perceived the poorest fit, significantly less than PHSs. 
Characteristics of the HSA. Finally, respondents gave positive overall scores to the characteristics of the HSA (e.g. planned health promotion, one health promotion offer, joint venture).

\section{Discussion}

Intersectoral collaboration is becoming increasingly important in public health. An example of this is CSHP, and this gave us the opportunity to study the development of such collaborations. According to the theory of organizational change, the necessary system change for intersectoral collaboration can best be established using a systematic approach, starting with an analysis of the status quo in terms of collaboration and the development of strategies tailored to this analysis. The study of collaborative processes requires an appropriate model. The DISC model has successfully been applied in a single-case study of intersectoral collaboration in CSHP (Leurs et al. 2008), but its applicability to other cases was as yet unclear. The purpose of this study was to assess the status quo regarding facilitating and hindering conditions for a type of intersectoral collaboration in CSHP in the Netherlands, viz. the HSA.

Our study showed that the DISC model can fruitfully be applied to other cases as well and be used to diagnose the strengths and difficulties in a collaboration as a whole and for each individual sector involved in the collaboration, as previously suggested by Leurs et al. (2008).

We also replicated Leurs et al.'s (2008) finding that different factors may be important in different sectors. In our study, the DISC diagnosis showed that five PHS regions across the Netherlands encountered similar facilitating and hindering factors for intersectoral collaboration. We found impressive positive perceptions about the HSA in the five PHS regions, but little of this had as yet been translated into positive intentions and actions. In addition, there was an overall favorable internal and external context for the implementation of the HSA, but it was also characterized by many established bureaucratic procedures and high aspirations for the respondents' own organizational goals. Finally, change management was modestly developed, and there was little or no project management. Some contrasts between sectors emerged for these factors. PHSs indicated the greatest collaborative support for the HSA, followed by PSSs and schools, while the municipal civil servants reported the least collaborative support. The highest degree of project management was perceived by the PSSs, and the most favorable context by the schools.

\section{Limitations}

We believe that our findings are relevant for other collaborations to implement the HSA in the Netherlands, since we studied collaboration in various situations and found that, despite 
their differences (e.g. size of district, type of participating school, organization of the CSHP and participating stakeholders), the same advantageous and disadvantageous conditions were reported across regions. However, this generalization also has several limitations.

Firstly, in view of the developmental stage of the collaborations we studied, generalization of our findings must be limited to the initial stage of collaboration. Leurs et al. (2008), for example, studied the collaborative structure one year after the collaboration had been established. Their results differ on some points from ours.

Secondly, despite being based on multiple cases, our analyses are limited by our small sample size. The nature of the collaboration implied that there were only a small number of possible stakeholders (Leurs et al., 2008). Therefore, we were not able to analyze interaction terms to see whether differences between sectors differed across regions.

Thirdly, our findings might have been affected by selection bias. Relevant stakeholders for CSHP were identified by the coordinators employed by the PHSs themselves, so the desire to achieve their own organizational goals (e.g. youth health, health promotion) might have influenced their choices. Most representatives came from the health sector, while there were fewer from the educational sector. For example, the schools inspectorate, which supervises the quality of education in schools, and the school board, which decides on the introduction of innovations in the curricula, were not represented in the study sample. Other sectors, such as the occupational health service responsible for teachers' health, were missing as well. An objective stakeholder analysis conducted prior to the DISC analysis could have prevented this bias.

Finally, recent insights suggest that it is not only intersectoral collaboration but also interdepartmental collaboration which impacts upon the realization of CSHP. Within the PHS alone, several departments can be distinguished which can fulfill a unique role within CSHP: health promotion, youth health care, epidemiology and policy. Although interdepartmental collaboration was not the focus of this study, it may, according to complexity theory (Plsek \& Greenhalgh, 2001; Plsek \& Wilson, 2001), have influenced the results for PHSs and should be considered in future research.

\section{Implications for practice}

Our study has important implications for future practice. The findings clearly indicate that intersectoral collaboration to implement the HSA in the Netherlands was still in its infancy in 2008/2009, and that some important steps still had to be made before it could develop its full capacity. Collaborating partners in our survey expressed very positive perceptions about the HSA, but hardly translated them into intentions and actions. These findings are in line with Tuckman's group developmental model (Tuckman, 1965) which explains the dynamics of group development processes. This model divides the group developmental process into four 
phases: forming, storming, norming and performing. In terms of this model, the HSA collaborations were in the forming stage, in which collaborating parties are brought together, have low involvement and low commitment. Also in line with the model, an important implication for practice is that the collaborating parties should carefully explore their possibilities and impossibilities regarding the allocation of resources and manpower in the future, before they can enter the performance stage. They will have to decide whether they are able to make concessions regarding their own organizations, for example in terms of changes and adaptations (storming). Only after conflicts have been resolved can the collaborating parties commit to ways to accomplish goals, and after they have agreed upon an appropriate communication structure (norming stage), they can concentrate on the accomplishment of their goals (performance stage) (Tuckman, 1965). Although the great enthusiasm we found for the concept of HSA might be atypical for the forming stage, this might be the result of the amount of attention it has been receiving from the Dutch authorities and others since 2002, which meant that the collaborating parties knew that the HSA was regarded as a solution to schools' reluctant implementation of health promotion programs (Boot et al., 2010a; Buijs et al., 2002; Buijs, 2005; Leurs et al., 2005a).

Our findings also clearly indicate that not every party occupies the same position within the HSA collaborations, which is reflected in the extent of collaborative support reported by the parties. In view of the high degree of interdependence between different systems in public health, it is important that every stakeholder involved provides collaborative support (Dür, 2013; Plsek \& Greenhalgh, 2001; Plsek \& Wilson, 2001). The differences between the sectors showed that the PHSs are taking the lead in the collaboration, which undoubtedly relates to their coordinating role, and explains the considerable investments in the initial stage. PSSs displayed a wait-and-see attitude that is typical of the forming stage. Conflicts of values, goals, and interest (storming stage) will still have to be resolved before full commitment can develop (norming stage) and action can be taken (performing stage) (Tuckman, 1965). Right change management will be of great importance here in order to guide the collaboration through these stages (Axelsson \& Axelsson, 2006; Van Raak et al., 1999). However, change management was as yet barely being utilized in the HSA collaboration, and project management, which did receive more attention, is less functional/effective in the initial stage of collaboration (Bohlmeijer, Ruland, Van Raak, \& MurVeeman, 2005). The municipality was the most passive actor in the collaboration, with the fewest actions, but also receiving the lowest level of attention from the coordinating organization. It purely fulfilled the role of financer, which may be not enough to develop the collaborative support that is needed for supportive policies and (financial) agreements between municipalities and PHSs (and eventually PSSs), and is necessary for demand-driven practices within school health promotion. Compared to municipalities, the schools showed little action, but they reported optimal preconditions for the implementation of the HSA. This 
seems somehow at odds with previous studies reporting CSHP to be difficult to implement at school level (Boot, De Jongh, Leurs, \& De Vries, 2011; Boot et al., 2010b). However, Deschesnes et al. (2013a) also emphasized that schools might be good at acquiring and assimilating knowledge, but not as effective in translating it into innovative practices. Therefore, integrative mechanisms (e.g. networking, professional development, active participation, joint work) might be necessary at different strategic levers (e.g. leadership, learning culture).

Building on the above interpretations, our results suggest that intersectoral collaboration is a new phenomenon for collaborating parties, demanding special managerial competencies which need to be further developed by the sectors involved. Our DISC analysis showed that it is especially the differences between professionals that are hampering collaboration and need to be resolved. For example, all sectors reported many established procedures, and PHSs, PSSs and municipalities reported high aspirations for their own organizational goals, which need to be managed. The high differentiation in orientation and structure between the organizations is typical, and can delay or even frustrate the creation of consensus (norming stage) and the necessary organizational change (performance stage) unless the collaboration is managed properly and collaborative support is created (Axelsson \& Axelsson, 2006; Van Raak et al., 1999). As regards the management of the HSA collaborations, our DISC diagnosis showed that project management, and especially change management, were only marginally utilized in the five PHSs regions. This indicates considerable potential in this area. Change management in particular seems highly important in the initial stages of collaboration (forming and storming), in order to involve and guide relevant stakeholders smoothly into the collaborative process. It is needed in situations characterized by a high level of uncertainty about collaborative goals (Plsek \& Wilson, 2001) and when change agents lack the formal authority and power to make firm decisions to facilitate strict project management (Bohlmeijer et al., 2005). In such situations, it helps to gradually develop a common vision which guides the collaboration through the developmental process and facilitates the necessary system change, facilitated by change strategies (e.g. persuasive communication, image building). By contrast, project management is a planned approach used to accomplish goals that are clearly defined and agreed upon by all parties (Bohlmeijer et al., 2005; Plsek \& Wilson, 2001) and is therefore more valuable in the later stages (norming and performing). It helps to formalize agreements about responsibilities and collaborative structure in plans and to monitor and evaluate goals. In practice, both types of management might seldom be implemented separately, because of repetition of and overlap between the stages in intersectoral collaboration (McMorris et al., 2005). For this reason, utilizing both types of management certainly demands special qualities from the parties involved, which have not been investigated in the context of coordinated school health promotion yet, though their importance has been acknowledged previously (Boot et al., 2010a). 


\section{Implications for research}

As regards the recommendations for future research, it would be of great interest to examine the impact of the DISC-determinants on sustainable collaboration, similar to Raak et al. (1999) who did that in another context. Since effects are possible, we will study these effects and report on them when analyses are available. It is also warranted to ascertain whether DISC analyses can be applied to other collaborations in public health and to find out whether our implications are also relevant for them. Finally the extent to which the DISC constructs 'context' and 'external factors' are operationalized limited us in the proper analysis of institutions (e.g. law, rules and regulations) that facilitate or hamper CSHP collaborations. The DISC model does not specify these institutions at different levels (e.g. EU, national, regional, local) nor their impact on the other DISC constructs. For example, EU policies such as the Health in All Polices concepts (Stahl et al., 2006) should be included here and their impact on the collaboration specified. In this context, further operationalization of these DISC constructs is necessary, as well as the study of the interrelations between the DISC constructs.

Concluding, our DISC analysis of main facilitating and hindering factors in intersectoral collaboration in five Dutch PHSs and in four sectors provided valuable insights into the opinions and perceptions of relevant stakeholders and the characteristics of their organization, which allowed us to explain current practices and formulate clear implications for future practice. Our findings were related to specific characteristics of the coalitions and their starting situation in the regions and depended on the particular sector. We studied intersectoral collaboration in CSHP when it was still in the forming stage, where PHSs run a head, the municipalities' role was limited to financing the HSA, PSSs were reactive rather than proactive, and schools were enthusiastic but not translating their enthusiasm into practice. Major steps remain to be taken by the collaborating parties if the collaboration is to proceed from the formation stage to collaborative performance. The employment of appropriate managerial principles offers considerable potential to enable the HSA collaboration to develop its full potential (research questions 1 and 2).

The insights from the present study were used in 2010 to write a supplement about collaboration to a support manual for health professionals working with the CSHP (RIVM Centre for Healthy Living, 2010). 


\section{References}

Axelsson, R., \& Axelsson, S. B. (2006). Integration and collaboration in public health - a conceptual framework. The International Journal of Health Planning and Management, 21(1), 75-88.

Bohlmeijer, E., Ruland, E., Van Raak, A., \& Mur-Veeman, I. M. (2005). Procesmanagement in public health - ontwerp, analyse \& verandering (Processmanagement in public health design, analysis \& change). Utrecht: Trimbos.

Boot, N. M. W. M., De Jongh, D., Leurs, M., \& De Vries, N. (2011). De Gezonde School als methode voor GGD'en bij de invoering van schoolgezondheidsbeleid (The Healthy School as method for Public Health Services to implement a school health policy). Tijdschrift voor Gezondheidswetenschappen, 89(4), 222-228.

Boot, N. M. W. M., van Assema, P., Hesdahl, B., \& de Vries, N. K. (2010a). Professional assistance in implementing school health policies. Health Education, 110(4), 294-308.

Boot, N. M. W. M., van Assema, P., Hesdahl, B., Leurs, M., \& de Vries, N. K. (2010b). Gezondheidsbevordering en voortgezet onderwijs: verstandshuwelijk of echte liefde? (Health promotion and secondary education: marriage of convenience or true love?) Tijdschrift voor Gezondheidswetenschappen, 88(3), 127-135.

Bos, V., De Jongh, D., \& Paulussen, T. (2010). Gezondheidsbevordering en preventie in het onderwijs. Stand van zaken, effectiviteit en ervaringen van GGD'en en scholen (Health promotion and prevention in schools. Current state of affairs, effectiveness and experiences from public health services and schools.). Bilthoven: RIVM.

Buijs, G., De Jong, A., Paulussen, T., \& Van Wijngaarden, J. (2002). Actieprogramma Schoolgezondheidsbeleid Nederland (National Action Program on School Health Policy). Woerden: National Instituut voor Gezondheidsbevordering en Ziektepreventie (Netherlands Institute for Health Promotion and Disease Prevention).

Buijs, G. J. (2005). Werkdocument. De Gezonde School Methode in Nederland. (Work document. The Healthy School Approach in the Netherlands. Woerden: National Instituut voor Gezondheidsbevordering en Ziektepreventie (Netherlands Institute for Health Promotion and Disease Prevention).

Butterfoss, F. D. (2007). Coalitions and Partnerships in Community Health. San Francisco: Jossey-Bass.

Clark, N., Doctor, L., Friedman, A., Lachance, L., Houle, C., Geng, X., \& Grisso, J. (2006). Community coalitions to control chronic disease: Allies against asthma as a model and case study. Health Promotion Practice, 7(2), 13S-22S.

Crowley, K., Yu, P., \& Kaftarian, S. (2000). Prevention actions and activities make a difference: A structural equation model of coalition building. Evaluation and Program Planning, 23(3), 381-388. 
Cummings, T. G., \& Worley, C. G. (2001). Organizational Development and Change (7th edition). Mason, Ohio: Southern-Western College Publishing.

Daft, R. L., \& Noe, R. A. (2001). Organizational behavior. Orlando: Hartcourt Inc.

De Caluwé, L., \& Vermaak, H. (2003). Learning to change: Thousand Oaks: Sage Publications.

Deschesnes, M., Drouin, N., \& Couturier, Y. (2013). Schools' absorptive capacity to innovate in health promotion. Journal of Health Organization and Management 27(1), 24-41.

Deschesnes, M., Martin, C., \& Hill, A. J. (2003). Comprehensive approaches to school health promotion: how to achieve broader implementation? Health Promotion International, 18(4), 387-396.

Dür, W. (2013). Applying system theory of organizational change to health promotion interventions in schools and their problems. In O. Samdal \& L. Rowling (Eds.), The Implementation of Health Promoting Schools. Exploring the theories of what, why and how (pp. 34-50). New York: Routledge Publishers.

Feinberg, M., Greenberg, M., \& Osgood, D. (2004). Readiness, functioning and perceived effectiveness in community prevention coalitions: A study of communities that care. American Journal of Community Psychology, 3/4(33), 163-176.

Florin, P., Mitchell, R., Stevenson, J., \& Klein, I. (2000). Predicting intermediate outcomes for prevention coalitions: A developmental perspective. Evaluation and Program Planning, 23(3), 341-346.

Hirsch Ballin, E. M. H. (2008). Wet Publieke Gezondheid (Public Health Act). Overheid.nl (Government.nl). Retrieved 14 April 2015, from http://wetten.overheid.nl/BWBR0024705/geldigheidsdatum_14-04-2015.

IUHPE. (2009). Achieving Health Promoting Schools: Guidelines for Promoting Health in Schools. Retrieved 15 January 2015, from

http://www.dhhs.tas.gov.au/_data/assets/pdf_file/0011/115895/guidelines_for_heal th_promoting_schools1.pdf.

Jackson, S. F., Perkins, F., Khandor, E., Cordwell, L., Hamann, S., \& Buasai, S. (2006). Integrated health promotion strategies: a contribution to tackling current and future health challenges. Health Promotion International, 21(suppl 1), 75-83. doi: 10.1093/ heapro/dal054

Kegler, M. C., \& Swan, D. W. (2011). An initial attempt at operationalizing and testing the Community Coalition Action Theory. Health Education \& Behavior, 38(3), 261-270.

Leurs, M., Jansen, M., Schaalma, H., Mur-Veeman, I., \& De Vries, N. (2005a). The Tailored SchoolBeat-approach: new concepts for health promotion in schools In S. Clift \& B. B. Jensen (Eds.), The Health Promoting School: International Advances in Theory, Evaluation and Practice (pp. 87 - 105). Copenhagen: Danish University of Education Press. 
Leurs, M., Mur-Veeman, I., van der Sar, R., Schaalma, H., \& de Vries, N. (2008). Diagnosis of sustainable collaboration in health promotion - a case study. BMC Public Health, 8(382). doi: 10.1186/1471-2458-8-382

Leurs, M., Schaalma, H., Jansen, M., Mur-Veeman, I., St. Leger, L., \& De Vries, N. (2005b). Development of a collaborative model to improve school health promotion in the Netherlands. Health Promotion International, 20, 296 - 305.

Leurs, M., Steenbakkers, M., \& Jansen, M. (2006). Het schoolSlag-praktijkboek: samen werken aan preventie op maat in het onderwijs (The SchoolBeat manual: working together towards tailored prevention in education). Maastricht: GGD Zuid Limburg.

Lister-Sharp, D., Chapman, S., Stewart-Brown, S., \& Sowden, A. (1999). Health promoting schools and health promotion in schools: two systematic reviews. Health Technology Assessment, 3(22), 1-207.

McMorris, L. E., Gottlieb, N. H., \& Sneden, G. G. (2005). Developmental Stages in Public Health Partnerships: A Practical Perspective. Health Promotion Practice, 6(2), 219-226. doi: $10.1177 / 1524839903260647$

Plsek, P., \& Greenhalgh, T. (2001). The challenge of complexity in health care. British Medical Journal, 323(7313), 625.

Plsek, P., \& Wilson, T. (2001). Complexity, leadership, and management in healthcare organisations. British Medical Journal, 323, 746 - 749.

RIVM Centre for Healthy Living. (2010). Handleiding Gezonde School (Healthy School Guide). Bilthoven: National Institute for Public Health and the Environment - Centre for Healthy Living.

St Leger, L. H. (1999). The opportunities and effectiveness of the health promoting primary school in improving child health - a review of the claims and evidence. Health Education Reserach, 14(1), 51-69. doi: 10.1093/her/14.1.51

Stahl, T., Wismar, M., Ollila, E., Lahtinen, E., \& Leppo, K. (2006). Health in All Policies. Prospects and potentials. Finland: Ministry of Social Affairs and Health.

Stewart-Brown, S. (2006). What is the evidence on school health promotion in improving health or preventing disease and, specifically, what is the effectiveness of the health promoting schools approach? . Copenhagen: WHO Regional Office for Europe.

Stirman, S. W., Kimberly, J., Cook, N., Calloway, A., Castro, F., \& Charns, M. (2012). The sustainability of new programs and innovations: a review of the empirical literature and recommendations for future research. Implementation Science, 7(17).

Tuckman, B. W. (1965). Developmental sequence in small groups. Psychological Bulletin, 63(6), 384-399. doi: 10.1037/h0022100

Van Raak, A., Mur-Veeman, I., \& Paulus, A. (1999). Understanding the feasibility of integrated care: a rival viewpoint on the influence of actions and the institutional context. The International Journal of Health Planning and Management, 14(3), 235-248. 
WHO. (1995). Improving School Health Programs: Barriers and Strategies to improve School Health Programs Promoting Health Through Schools. Report of the WHO Expert Committe on Comprehensive Education and Promotion (pp. 1-27). Geneva: WHO.

Yin, R. K. (2009). Case Stuy Research: Design and Methods. Califormia: Sage Publications. 



\section{Chapter 4}

\section{Effectiveness of a systematic approach to promote intersectoral collaboration in comprehensive school health promotion - a multiple-case study using quantitative and qualitative data}

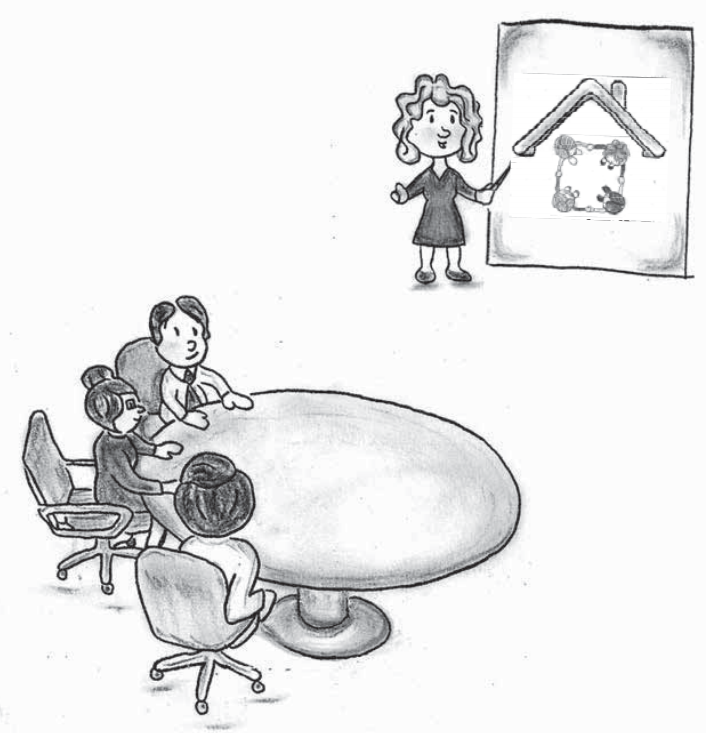

Based on:

Pucher, K.K., Candel, M.J.J.M., Krumeich, A., Boot, N.M.W.M, \& De Vries, N.K., (2015). Effectiveness of a systematic approach to promote intersectoral collaboration in comprehensive school health promotion - a multiple-case study using quantitative and qualitative data. BMC Public Health, 15(613). 


\section{Abstract}

Background: We report on the longitudinal quantitative and qualitative data resulting from a two-year trajectory (2008-2011) based on the Diagnosis of Sustainable Collaboration (DISC) model. This trajectory aimed to support regional coordinators of comprehensive school health promotion (CSHP) in systematically developing change management and project management to establish intersectoral collaboration.

Methods: Multilevel analyses of quantitative data on the determinants of collaborations according to the DISC model were done, with 90 respondents (response 57\%) at pretest and 69 respondents (52\%) at posttest. Nvivo analyses of the qualitative data collected during the trajectory included minutes of monthly/bimonthly personal/telephone interviews $(N=65)$ with regional coordinators, and documents they produced about their activities.

Results: Quantitative data showed major improvements in change management and project management. There were also improvements in consensus development, commitment formation, formalization of the CSHP, and alignment of policies, although organizational problems within the collaboration increased. Content analyses of qualitative data identified five main management styles, including (1) facilitating active involvement of relevant parties; (2) informing collaborating parties; (3) controlling and (4) supporting their task accomplishment; and (5) coordinating the collaborative processes.

Conclusions: We have contributed to the fundamental understanding of the development of intersectoral collaboration by combining qualitative and quantitative data. Our results support a systematic approach to intersectoral collaboration using the DISC model. They also suggest five main management styles to improve intersectoral collaboration in the initial stage. The outcomes are useful for health professionals involved in similar ventures.

Keywords: collaboration; implementation; health promoting schools 


\section{Background}

Comprehensive school health promotion (CSHP) is endorsed by the WHO because of its broad perspective on children's health, involving social and physical environments in and around school, community activity and redesigning health services. Moreover, it has been recognized as an effective means to improve children's health and well-being (IUHPE, 2009; Lister-Sharp et al., 1999; St Leger, 1999; Stewart-Brown, 2006).

The Dutch equivalent of CHSP is the Dutch Healthy School Approach (HSA). Basically, HSA targets demand-driven practices in school health promotion based on the epidemiological data of the school community, a prioritization of school needs, an assessment of important and modifiable determinants, the drafting and implementation of a multi-year school health plan, and its evaluation. All this is done jointly with multiple stakeholders who provide different expertise and fulfill different tasks (Buijs, 2005; Leurs et al., 2006; RIVM Centre for Healthy Living, 2010). At school level, the implementation of the HSA is professionally assisted by a 'health promoting school advisor', who represents various public services and providers (e.g. from the welfare, health, prevention and safety sectors) in individual contacts with schools. At local and regional levels, the public health services (PHSs) function as a linking pin (coordinator) between the education sector, health authorities and public services stakeholders (PSSs). Their coordinating role derives from a legal responsibility for the implementation of local public health policy and youth health care financed by the municipality (Hirsch Ballin, 2008).

While the popularity of the HSA and its adoption in Dutch regions is growing (Bos et al., 2010), its implementation remains complex (Boot et al., 2010a; Boot et al., 2010b). The establishment of a functional structure for the collaboration between the sectors involved poses important challenges in practice (Leurs, Mur-Veeman, Schaalma, \& De Vries, 2003; Leurs et al., 2008). The necessity of partnerships and networking and related challenges are not unique for the Dutch context, but are also acknowledged by studies in other countries in and outside Europe (Dadaczynski \& Paulus, 2013; Inchley, Guggelberger, \& Young, 2013; Noble \& Toft, 2013; Rowling \& Legder, 2013). The increasing understanding of public health schools as social adaptive systems stimulates the study of intersectoral collaboration in CSHP. This perspective puts an emphasis on the need of joint work between relevant actors at different levels (individual, organizational, policy level) and from various sectors (health, education and authorities) to successfully implement CSHP (Keshavarz, Nutbeam, Rowling, \& Khavarpour, 2010; Pucher et al., 2015a).

In the study at hand we investigated a systematic approach to the development of intersectoral collaborations based on a thorough analysis of facilitating and impeding factors and the use of appropriate change strategies. We studied the impact of this systematic approach quantitatively in a two-year trajectory supporting health professionals in its 
implementation. We also aimed to open up the 'black box' of collaborative processes, since collaboration research has found that these interactive processes are generally not very well understood (Thomson \& Perry, 2006; Wood \& Gray, 1991). We therefore explored qualitatively if, and if so which, managerial activities were induced by the systematic approach. The benefits of a mixed methods approach (including qualitative and quantitative data) over qualitative or quantitative research alone have been acknowledged in inquiries evaluating health promotion in schools (Pommier, Guével, \& Jourdan, 2010) and studying collaboration in public health (El Ansari, Phillips, \& Hammick, 2001). In our case, presenting both types of results in one paper helps to understand whether a systematic approach positively influences intersectoral collaboration in the HSA.

\section{Conceptual framework}

The specific collaborative structure involving relevant stakeholders from the education sector, health authorities, PHSs, and PSSs in HSA has been studied by Leurs et al. (2008). Inspired by the Integrated Care model, which is rooted in organizational theories (Cummings \& Worley, 2001; Daft \& Noe, 2001; De Caluwé \& Vermaak, 2003) and which advocates a systematic approach to intersectoral collaboration in integrated health care (De Leeuw, 1999; Van Raak et al., 1999), Leurs et al. (2003; 2008) developed a diagnostic framework for intersectoral collaboration in the HSA, called the Diagnosis of Sustainable Collaboration (DISC) model. Using the DISC questionnaire as an assessment tool and semi-structured interviews to triangulate the results of the DISC questionnaire, Leurs et al. (2008) diagnosed the collaborative structure for HSA in the southern parts of the Netherlands. Their study firstly validated the importance of the DISC factors and secondly suggested that DISC analysis can be leading in the implementation of strategies to strengthen collaboration between the sectors involved. This practice orientation makes the model very promising for the study of a systematic approach to intersectoral collaboration in CSHP.

The DISC model summarizes important factors into six main clusters that impact on the intended change and its sustainability: collaborative support (including the perceptions, intentions, and actions subclusters), change management, project management, context, external factors and sustainability (called 'CSHP' in original model). In the DISC model, stakeholders' collaborative support refers to the extent to which major stakeholders agree on the problems that need to be solved and to the degree of consensus on the actions to be taken, outcomes to be achieved and boundaries to be established between the domains of various partners. In addition, it refers to stakeholders' level of commitment to and trust in each other's intentions to effectuate actual change (allocation of resources and manpower, adaptations to ensure sustainability, etc.) within the organization they represent (rather than acting out of self-interest only). 
Change management refers to the need to gradually develop a common vision of the innovation which then guides and facilitates the selection of a change perspective and change strategies, and, when necessary, the extension of the network with new actors required for the desired system change. Four perspectives for change and related change strategies have been suggested (Barnhoorn \& Walda, 1992; De Leeuw, 1999; Saan \& De Haes, 2005).

In the developmental and implementation phase, a project management structure is needed to steer the actors involved towards the accomplishment of the goals. This structure becomes self-supportive as soon as collaboration becomes formalized in the work routines of the parties involved.

The DISC model further assumes that the context of the stakeholders involved and several external factors influence the collaborative process, while especially the later factor itself is difficult to influence. The context supports the collaborative process when the actors involved have positive experiences with previous collaborations, have enough research power, interest and expertise in the relevant field, and recognize relevant policies which they can also influence. External factors include intersectoral policies, laws, and regulations at different levels (EU, local, regional, and national) relevant to HSA, encouraging attitudes of financing bodies and positive community notions and public interest in CSHP. The sixth cluster, sustainability, addresses the HSA itself and refers to its sustainability, with "sustainability" defined as the gradual establishment of a stable collaboration.

\section{Aims of this study}

The relation between the DISC constructs is based on preliminary assumptions from Leurs et al.'s (2008) single case study and relevant literature. Which managerial principles induce improvements on specific DISC factors has not yet been established. Using this conceptual framework, we have studied the effectiveness and managerial processes of a systematic approach based on the DISC model in the two-year DISC-based trajectory.

\section{Methods}

\section{The DISC-based trajectory}

The trajectory started with DISC analyses, offering a thorough analysis of facilitating and impeding factors in five regional HSA collaborations spread across the Netherlands. The analyses showed that stakeholders' positive perceptions about the HSA needed to be more fully translated into positive intentions and real actions and that change management and project management were hardly applied, even though they were considered crucial for this transition (Pucher et al., 2015a). Based on these diagnoses, we advised the regional coordinators of the five HSA collaborations to focus on the development of effective change management and project management. In addition, and in accordance with the 
operationalization of the DISC model, we supported them for the period of one year in accomplishing the following steps: (1) bringing the different partners together; (2) developing a common vision; (3) identifying the possibilities and impossibilities for each collaborating partner based on the DISC analysis; (4) determining the desired collaborative structure; (5) developing a task distribution based on the information; (6) discussing the choices at the management and executive levels. Support included monthly personal/telephone contacts with the central facilitator involved in the trajectory. This facilitator was a health educator working at the PHS where the Dutch HSA and the DISC model had been developed and who was specialized in the implementation of the HSA. The facilitator provided support which basically comprised critical reflection on the collaborative process using a standard interview protocol, exchange of expertise between regions, with the facilitator as intermediary between them, and occasional peer-review of produced documents. In addition, one joint training session for regional coordinators was organized which addressed the regional coordinator's role as process facilitators within the HSA ${ }^{1}$. After support had ended, the collaborative process was monitored for an additional year using the same standard interview protocol during bi-monthly phone calls with regional coordinators. These calls were made by a researcher affiliated to Maastricht University who had also conducted the DISC analyses in the regions. The monitoring data were later used for the analysis of managerial activities induced by the systematic approach. After the one-year follow-up period, the DISC-based trajectory ended with a second round of DISC analyses which, together with the results of the first round, were used for the purpose of effect evaluation.

\section{Procedure and data collection instruments}

Longitudinal quantitative data on the DISC factors and qualitative data on the managerial activities were collected in five of 30 (in 2008) Dutch PHS regions, from 2008 to 2011. Inclusion criterion was the ability (e.g. resources, other priorities) and willingness to start with the DISC-based trajectory at the end of 2008.

For the quantitative data collection, coordinators of the HSA working at the PHSs were asked to identify relevant stakeholders from the education sector, municipal authorities, PHSs and other PSSs. The coordinators introduced the topic of research to these persons and distributed materials for the survey (the questionnaire and a brief summary of the HSA) at the end of 2008. Data collection lasted for a total of eight weeks. Reminders were sent after an additional 4 weeks. The procedure was repeated in 2011 as a posttest.

The longitudinal quantitative data were collected using the DISC questionnaire (adapted from Leurs et al. (2008)) which measures the 26 DISC factors of the 6 clusters

\footnotetext{
${ }^{1}$ The training was based on a national supportive manual for health professionals involved in the HSA (RIVM Centrum Gezond Leven, 2010) and co-organized by the Netherlands School of Public and Occupation Health.
} 
(collaborative support [including the perceptions, intentions, and actions subclusters], change management, project management, context, external factors, and sustainability), with 1 to 5 items each, mostly on a 5-point scale (completely disagree: 1 to completely agree: 5) with the additional option of 'unknown'. Examples of items used in the questionnaire are 'I think it is important that my organization participates in the HSA' and 'I think the HSA is of interest to my own organization' (collaborative support - perceptions). Table 4.3 presents a brief description of the DISC clusters.

In the early months of 2009, the results of the quantitative pretest and the resulting recommendations (i.e. the six predefined steps) were presented to the regional coordinators in a regional report, followed by a personal meeting for further clarification between each of the regional coordinators and the facilitator and researcher. At these meetings, all regional coordinators independently indicated that priority should be given to correctly situating the HSA within their own organization and positioning it together with PSSs in the region. Consequently, managerial activities carried out during the trajectory mainly targeted the representatives of PHSs and PSSs, so only quantitative and qualitative data concerning these stakeholders are included in the current paper.

During the one-year period of support (mid 2009-mid 2010) and the one-year followup period (mid 2010-mid 2011), qualitative data on the collaborative process were collected using a standard interview protocol including the following questions: Which activities have been conducted for the purpose of collaboration? Which activities are planned for the purpose of collaboration? Have any documents been produced in relation to the collaboration? Are there any other developments influencing the collaborative process? Minutes were made of these interviews and sent to regional coordinators for approval. Relevant documents such as project proposals and project plans (multiyear plans and work plans) were collected. Nvivo analysis was used to extract managerial activities from the interview minutes and the collected documents, in order to open up the black box of collaborative processes in the DISC-based trajectory.

By the end of 2011, after the second round of DISC analyses, the regional coordinators received a final report with the regional results.

In accordance with Dutch regulations, no ethical approval was required for this study.

\section{Participating PHS regions}

Five cases of HSA collaboration were studied, with different characteristics and starting situations. Table 4.1 lists these for each of the five PHS regions, in ascending order of size. We decided to study intersectoral collaboration in a variety of situations, to be able to collect more data than would have been possible in a single case study, and to enhance the generalizability of the study results. 
Table 4.1: Characteristics of the five PHS regions and their CSHP at pretest

\begin{tabular}{|c|c|c|c|c|c|}
\hline & PHS region 1 & PHS region 2 & PHS region 3 & PHS region 4 & PHS region 5 \\
\hline $\begin{array}{l}\text { Stakeholders } \\
\text { approached } \\
\text { from school }\end{array}$ & Primary education & $\begin{array}{l}\text { Secondary } \\
\text { education }\end{array}$ & Primary education & $\begin{array}{l}\text { Secondary } \\
\text { education }\end{array}$ & $\begin{array}{l}\text { Secondary } \\
\text { education }\end{array}$ \\
\hline Working area & $\begin{array}{l}12 \text { municipalities } \\
\text { (primary education: } \\
\pm 324 \text { schools) }\end{array}$ & $\begin{array}{l}13 \text { municipalities } \\
\text { (secondary } \\
\text { education: } \pm 12 \\
\text { schools on } 25\end{array}$ & $\begin{array}{l}14 \text { municipalities } \\
\text { (primary } \\
\text { education: } \pm 214 \text { ) }\end{array}$ & $\begin{array}{l}20 \text { municipalities } \\
\text { (secondary } \\
\text { education: } \pm 16 \\
\text { school boards) }\end{array}$ & $\begin{array}{l}26 \text { municipalities } \\
\text { (secondary } \\
\text { education: } \pm 30 \\
\text { schools) }\end{array}$ \\
\hline $\begin{array}{l}\text { Year of CSHP } \\
\text { adoption }\end{array}$ & $\begin{array}{l}\text { Primary and } \\
\text { secondary: } \\
2009\end{array}$ & $\begin{array}{l}\text { Primary education: } \\
2006 \\
\text { Secondary } \\
\text { education: } 2008\end{array}$ & $\begin{array}{l}\text { Primary education: } \\
2009 \\
\text { Secondary }\end{array}$ & $\begin{array}{l}\text { Primary education: } \\
2008 \\
\text { Secondary } \\
\text { education: } 2008\end{array}$ & $\begin{array}{l}\text { Primary education: } \\
2009 \\
\text { Secondary } \\
\text { education: } 2009\end{array}$ \\
\hline $\begin{array}{l}\text { Manpower for } \\
\text { CSHP at PHS }\end{array}$ & $\begin{array}{l}\text { Primary education: } \\
3 \text { health promoters }\end{array}$ & $\begin{array}{l}\text { Secondary } \\
\text { education: } 4 \text { health } \\
\text { promoters, } 2 \\
\text { epidemiologists }\end{array}$ & $\begin{array}{l}\text { Primary education: } \\
5 \text { health promoters, } \\
\qquad 2 \text { youth } \\
\text { health care } \\
\text { professionals }\end{array}$ & $\begin{array}{l}\text { Secondary } \\
\text { education: } 4 \text { health } \\
\text { professionals }\end{array}$ & $\begin{array}{l}\text { Secondary } \\
\text { education: } 2 \text { health } \\
\text { promoters, } 4 \text { youth } \\
\text { health professionals }\end{array}$ \\
\hline CSHP delivery & Primary education: & Primary education: & no & no & no \\
\hline $\begin{array}{l}\text { Health } \\
\text { promoting } \\
\text { school advisor } \\
\text { in CSHP }\end{array}$ & no & $\begin{array}{l}\text { Health promoting } \\
\text { school advisors } \\
\text { from PHS, Youth } \\
\text { Care, Education } \\
\text { Support Service, } \\
\text { Mental Health Care }\end{array}$ & no & no & no \\
\hline $\begin{array}{l}\text { Collaboration } \\
\text { with PSSs in } \\
\text { CSHP }\end{array}$ & $\begin{array}{l}\text { Primary education: } \\
\text { Education Support } \\
\text { Service, Mental } \\
\text { Health Youth Care, } \\
\text { Addiction Care, } \\
\text { Justice, Dietician, } \\
\text { Sports company } \\
\text { Meet once a year }\end{array}$ & $\begin{array}{l}\text { Primary education: } \\
\text { Organizations of } \\
\text { health promoting } \\
\text { school advisors, } \\
\text { Addiction Care, } \\
\text { Welfare and YHC } \\
\text { Meet six times a } \\
\text { year }\end{array}$ & no & $\begin{array}{l}\text { Previous projects: } \\
\text { Mental Health Care, } \\
\text { Justice and Welfare }\end{array}$ & no \\
\hline $\begin{array}{l}\text { Collaboration } \\
\text { with } \\
\text { municipalities } \\
\text { in CSHP }\end{array}$ & no & $\begin{array}{l}\text { Primary education: } \\
\text { PHS informs about } \\
\text { the healthy school } \\
\text { approach via } \\
\text { general PHS-journal }\end{array}$ & no & no & no \\
\hline $\begin{array}{l}\text { Collaboration } \\
\text { with schools } \\
\text { in CSHP }\end{array}$ & $\begin{array}{l}\text { Primary education: } \\
\text { PHS informs } \\
\text { schools via single } \\
\text { service point at PHS }\end{array}$ & $\begin{array}{l}\text { Primary education: } \\
\text { PHS recruits } \\
\text { schools for the HSA }\end{array}$ & $\begin{array}{l}\text { Primary education: } \\
\text { PHS recruits } \\
\text { schools for the HSA }\end{array}$ & no & no \\
\hline
\end{tabular}

PHS: Public Health Service; PSS: Public Service Stakeholders 


\section{Participants}

A total of 158 stakeholders at pretest and 132 potential stakeholders at posttest were approached by the regional coordinators for the DISC questionnaire (Table 4.2). Contacted PHS professionals included health promoters, epidemiologists, pediatricians, and youth nurses. PSSs came from the domains of addiction, mental health, social welfare, and security, and other services like educational support services, dietician centers, and sports companies. The five regional coordinators who were followed and interviewed during the advice trajectory all worked at PHSs. All of them were health promoters.

\section{Quantitative data analyses}

During data cleaning, the 'unknown' option was recoded to ' 1 ' (negative value) as it apparently indicated the absence of a particular DISC factor. Missing values for one item in scales with four or more items were replaced by the mean of the other items.

Cronbach's alphas were calculated for the different scales operationalizing the DISC factors. These appeared to be lower than .60 for three of the 13 multi-item scales: willingness to change, organizational characteristics, and characteristics of CSHP. The items of these scales were therefore included separately in the analyses. Descriptive statistics were used to establish the mean values for the DISC factors at both measurements.

Multi-level analyses with linear mixed regression including a random intercept were performed for the five HSA collaborations to analyze changes in staff and organizations that occurred between pretest and posttest. The random intercept model enabled us to include in the analyses both respondents with complete data and respondents who participated at pretest or posttest only. This allowed for a more reliable estimation of the general trend than an analysis based only on complete cases.

To test whether relevant measures had improved significantly at posttest, multi-level analyses (F-test) were conducted with time of measurement (pretest versus posttest) as the fixed factor and one of the DISC factors as dependent variable. We corrected for multiple testing using Holm's method, by first ranking the p-values of the analyses by magnitude and then multiplying them by their rank number (where the largest p-value gets the lowest rank and the smallest $p$-value gets the highest

rank). Ranking was performed for all factors within a cluster (e.g. change management). In the case of subclusters, ranking was performed for all factors within a subcluster (e.g. stakeholder's perceptions).

In addition we calculated effect sizes based on the intercept and the error variances for each measure, in order to weight the effects. The effect sizes were interpreted according to Cohen's (1998) categorization, in which $d=0.20,0.50$ and 0.80 represent small, medium, and large effects, respectively. Statistical analyses were conducted using SPSS 20. 


\section{Qualitative data analyses}

Document analysis included 65 minutes of the standard protocol interviews with the regional coordinators, 39 of which were held by the facilitator and 26 by the researcher, and the project proposals and project plans regarding the HSA from each region. Document analysis with Nvivo 9 was independently performed by two researchers, the researcher who conducted the DISC analyses and a research assistant with expertise on the topic. Ambiguities of coding were resolved by discussion. Data from documents were mainly used to verify regional coordinators' self-reports on managerial activities. Initial coding focused on the identification of managerial activities. Several iterations of analyses resulted in a classification scheme of managerial activities.

We triangulated our data by studying information from various types of sources (qualitative and quantitative data) and by having the coding of the qualitative data done by two independent researchers (Yin, 2009).

\section{Quantitative results}

\section{Response}

Of the total of 158 stakeholders who were approached at pretest and 132 at posttest, 90 (57\%) and 69 (52\%), respectively, were included in the analyses. There were various reasons for dropping out. Organizational tasks of collaborating parties changed in response to mergers, reorganizations, government cutbacks and changing policies. Also, collaborative goals became more specific as collaboration progressed, which led to a poorer fit between the agenda of some organizations and the collaborative agenda. Table 4.2 indicates that the regional coordinators had set slightly different priorities within the collaboration, since the numbers of representatives from the two sectors who were approached varied between regions.

Table 4.2: Response DISC-questionnaire and included number of respondents in analyses

\begin{tabular}{|c|c|c|c|c|c|c|}
\hline & PHS Region 1 & PHS Region 2 & PHS Region 3 & PHS Region 4 & PHS Region 5 & Total \\
\hline Pre measure- & PHS: $5 / 5$ & PHS:9/9 & PHS:25/32 & PHS:11/19 & PHS:20/64 & PHS:70/129 (54\%) \\
\hline \multirow[t]{2}{*}{ ment } & PSS: $5 / 7$ & PSS: $5 / 6$ & PSS: - & PSS: $10 / 16$ & PSS: - & - PSS: 20/29 (69 \%) \\
\hline & Total:10/12 & Total:14/15 & Total:25/32 & Total:21/35 & Total:20/64 & $90 / 158(57 \%)$ \\
\hline Post measure- & PHS: $6 / 9$ & PHS:7/7 & PHS:20/36 & PHS:8/8 & PHS:10/48 & PHS:51/108 (47\%) \\
\hline \multirow[t]{2}{*}{ ment } & PSS: $5 / 7$ & PSS: $3 / 3$ & PSS: - & PSS: $9 / 12$ & PSS: $1 / 2$ & PSS: 18/24 (75\%) \\
\hline & Total:11/16 & Total:10/10 & Total:20/36 & Total:17/20 & Total:11/50 & 69/132 (52\%) \\
\hline
\end{tabular}

PHS: public health service; PSS: public service stakeholders 


\section{What are the pretest-posttest differences regarding the DISC factors?}

Our results indicate significant differences between pretest and posttest in all six DISC categories (Table 4.3).

Collaborative support. Significant differences between pretest and posttest were found, with medium effect size. At posttest, the parties involved had more shared views about ways to realize the HSA (perception of ideological consensus), had greater intentions to commit to the collaborative goal (intention to commit) and reported more formalization of the HSA within their organizational policies (action of formalization).

Change management. Change management improved significantly, with gains of almost medium effect size, specifically regarding the presence of a clear and systematically developed vision, the innovative perspectives pursued and the change strategies employed.

Project management. Respondents evaluated the project management more favorably at posttest than at pretest. Gains were small, though almost of medium magnitude. Further exploration of project management showed that it was especially the awareness among stakeholders involved and their responsibilities which had increased.

External factors. Significant improvements of medium size were found for the external context. According to the respondents, the HSA appeared to fit in with school health policies and public health policies (policies and regulations).

Context. The internal context for the implementation of the HSA, however, had deteriorated at posttest. The number of problems within their own organization increased, an effect of medium magnitude.

Sustainability. Finally, respondents evaluated CSHP significantly better at posttest than at pretest. At posttest, they perceived the HSA more as practical and less as research (ES > $0.50)$ or as theory $(E S<0.20)$. Furthermore, the HSA was evaluated more as permanent and less as ad-hoc (ES < 0.20). In addition, respondents perceived less fragmentation of school health promotion and were more aware of the existence of a single service point at PHSs for health promotion programs and expertise. This effect was almost of medium effect. 
Table 4.3: Description of DISC model (adapted from Leurs, Mur-Veeman et al. (2008)), reliability, response, and linear mixed model regression

\section{Description of DISC clusters and DISC subclusters}

DISC factors

(based on single-item or

multi-item scales)
Cronbach's alpha

Number

of items

(N)

alpha
Collaborative support

The collaborative support can be assessed at the levels of perceptions, intentions and actions of the parties involved.

\section{- Perceptions}

Intersectoral collaboration evolves more smoothly when participating organizations share goals and interests, perceive positive outcomes supportive of their own goals, are able to reach consensus on the goal of the collaborative process and are of the opinion that the most relevant parties are involved in the collaborative process.

\section{- Intentions}

Parties involved should start with the intention to trust each other (if not present, this needs to be worked on first), the intention to commit themselves to the collaborative process and its subject and the intention to make changes within their own organization, if needed, in favor of the collaborative process.

\section{- Actions}

The collaborative process may induce a wide variety of actions, ranging from the implementation of major innovations within one's own organizations to the inclusion of relatively minor adaptations of regular procedures. The actions may involve a reallocation of resources as well. Whatever actions result from a collaborative process, it is important that these are formalized in order to enhance sustainability. The level of formalization needed depends mainly on the type of action itself.
Collaborative support

$\begin{array}{lll}\text { - Perceptions } & & \\ \text { Goals } & 5 & .876 \\ \text { Importance } & 3 & .721 \\ \text { Win-win } & 1 & \\ \text { Ideological consensus } & 4 & .859 \\ \text { Domain consensus } & 1 & \\ \text { Involvement } & 2 & .662\end{array}$

\section{- Intentions}

Willingness to trust $\quad 1$

Willingness to commit $\quad 1$

Willingness to change 2

- Available room for change

- Things have to change

\section{- Actions}

Changes

1

Resources

2

\section{6}

21

Formalization

a-values corrected according to Holm procedure: ${ }^{*} p \leq .05,{ }^{* *} p<.01,{ }^{* * *} p<.001$ 
(continued on next page)

\begin{tabular}{|c|c|c|c|c|c|c|c|c|}
\hline \multicolumn{4}{|c|}{ Means } & \multirow{2}{*}{\multicolumn{4}{|c|}{ Linear mixed model of regression analysis }} & \multirow[t]{2}{*}{ Effect size } \\
\hline & Irement & Post & urement & & & & & \\
\hline $\mathrm{N}$ & $M(S D)$ & $\mathrm{N}$ & $M(S D)$ & b & $S E(b)$ & $\mathrm{F}$ & $\begin{array}{c}\text { corrected } \\
\mathrm{p} \text {-value }\end{array}$ & Cohen's d \\
\hline
\end{tabular}

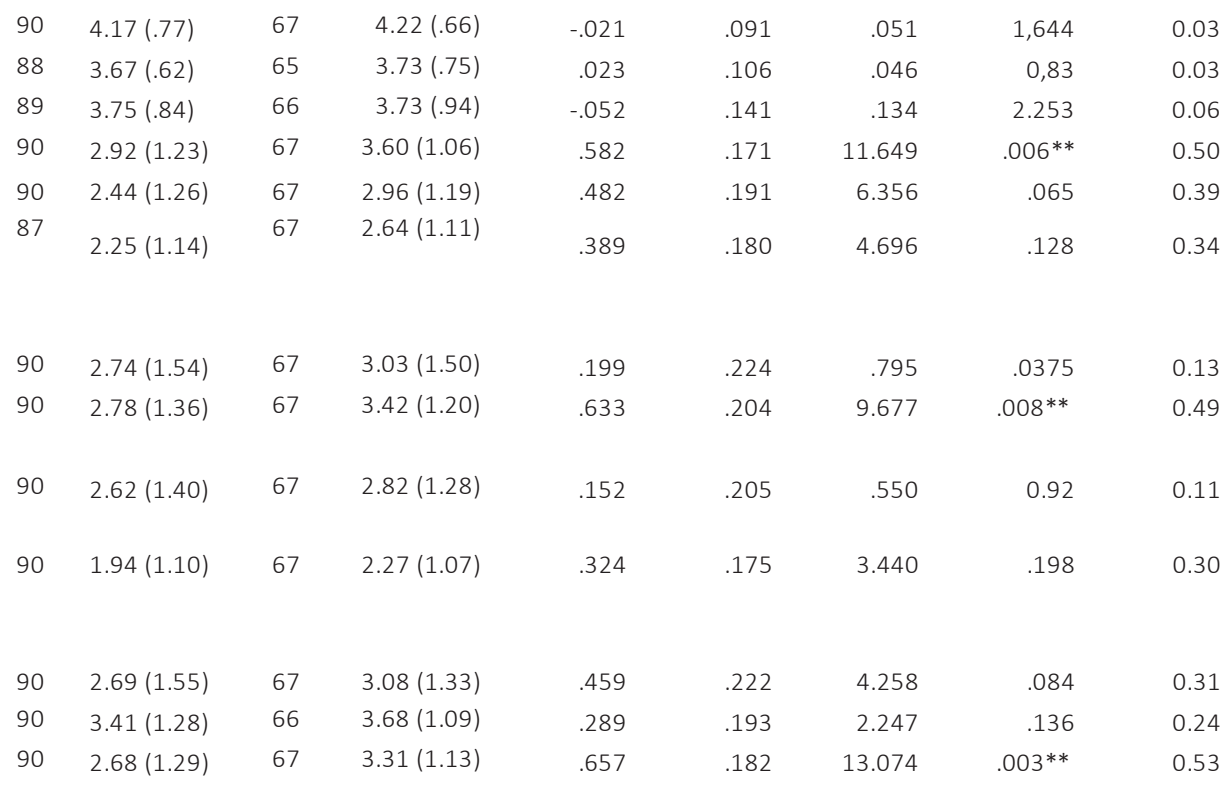


Table 4.3: Description of DISC model (adapted from Leurs, Mur-Veeman et al. (2008)), reliability, response, and linear mixed model regression

\section{Description of DISC clusters and DISC subclusters}

DISC factors

(based on single-item or

multi-item scales)
Cronbach's alpha

Number

of items

(N)

\section{Change management}

The aspired change requires management by one or a small group of leaders. Establishing a successful collaboration requires individual and collective leadership skills to guide the developmental process. Change management strategies should fit the chosen innovation perspective and be supportive of the health promotion subject. The most relevant actors are included. and where missing. this is accomplished by extending the network of the leaders of the collaborative process.
Change management

$\begin{array}{lll}\text { Vision } & 3 & .866 \\ \text { Innovation perspective } & 4 & .694 \\ \text { Change strategy } & 4 & .714 \\ \text { Network development } & 1 & \end{array}$

\section{Project management}

\section{Project management}

During the development and initial implementation phase, the collaborative process is dealt with as a project in a project management structure.

This includes deciding who are the actors in the project. what they need to do and how they operate (planning. procedures, evaluation, communication, etc.). This project management structure fades out when the subject of the collaborative process is being integrated (or close to being inetgrated) in regular work and the alliance becomes selfsupportive.

\section{Context}

The collaborative process evolves in a context which can be influenced by the partners themselves When parties have had positive experiences with each other in previous collaborative processes, need less energy for internal changes, have more research power and feel more supported by policies which they can influence as well, they will be more open to sustainable collaborative processes supporting intersectoral health
Actors. Tasks. Communication.

3

\section{Context}

$\begin{array}{lll}\text { Organizational characteristics } & 3 & .489 \\ \text { - Open to innovations } & & \\ \text { - Organizational problems } & \\ \text { - Positive experience with } & \\ \text { previous collaboration }^{c} & \\ \text { Research power } & 1 \\ \text { Relevant policies } & 1 \\ \end{array}$

${ }^{\mathrm{d}} \mathrm{p}$-values corrected according to Holm procedure: ${ }^{*} \mathrm{p} \leq .05,{ }^{* *} \mathrm{p}<.01,{ }^{* * *} \mathrm{p}<.001$ 
(continued from last page)

\begin{tabular}{|c|c|c|c|c|c|c|c|c|}
\hline \multicolumn{4}{|c|}{ Means } & \multicolumn{4}{|c|}{ Linear mixed model of regression analysis } & \multirow[t]{2}{*}{ Effect size } \\
\hline \multicolumn{2}{|c|}{$\underline{\text { Pre measurement }}$} & \multicolumn{2}{|c|}{ Post measurement } & & & & & \\
\hline $\mathrm{N}$ & $\mathrm{M}(\mathrm{SD})$ & $\mathrm{N}$ & $\mathrm{M}(\mathrm{SD})$ & $b$ & $\mathrm{SE}(\mathrm{b})$ & $\mathrm{F}$ & $\begin{array}{r}\text { corrected } \\
\text { p-value }\end{array}$ & Cohen's d \\
\hline 89 & $3.40(1.15)$ & 67 & $3.91(1.02)$ & .495 & .154 & 10.359 & $.008^{* *}$ & 0.45 \\
\hline 89 & $2.55(.97)$ & 67 & $3.05(.91)$ & .430 & .139 & 9.534 & $.009 * *$ & 0.45 \\
\hline 89 & $2.36(.99)$ & 67 & $2.84(.94)$ & .433 & .147 & 8.688 & $.008^{* *}$ & 0.44 \\
\hline 89 & $2.43(1.40)$ & 67 & $2.39(1.11)$ & -.039 & .208 & .035 & .852 & 0.03 \\
\hline
\end{tabular}

\begin{tabular}{cccccccccc}
\hline 89 & $2.44(1.26)$ & 66 & $2.97(1.10)$ & .507 & .180 & 7.962 & $.006^{* *}$ & 0.44 \\
89 & $2.43(1.41)$ & 67 & $3.04(1.38)$ & .621 & .221 & 7.887 & $.006^{* *}$ & 0.44 \\
90 & $2.44(1.26)$ & 67 & $2.96(1.19)$ & .482 & .191 & 6.356 & $.026^{*}$ & 0.39 \\
90 & $2.46(1.33)$ & 66 & $2.86(1.36)$ & .351 & .205 & 2.919 & .180 & 0.26
\end{tabular}

\begin{tabular}{rrrrrrrrr}
\hline 89 & $3.80(1.04)$ & 67 & $3.96(.96)$ & .160 & .158 & 1.020 & .942 & 0.16 \\
89 & $2.78(1.32)$ & 67 & $1.94(1.03)$ & -.788 & .188 & 17.609 & $.00^{* *}$ & -0.66 \\
89 & $3.16(1.45)$ & 67 & $3.61(1.35)$ & .455 & .228 & 3.980 & .192 & 0.32 \\
& & & & & & & & \\
89 & $3.38(1.20)$ & 67 & $3.46(1.20)$ & .092 & .194 & .225 & .636 & 0.08 \\
89 & $3.15(1.35)$ & 67 & $3.33(1.20)$ & .182 & .208 & .764 & .636 & 0.14 \\
\hline
\end{tabular}


Table 4.3: Description of DISC model (adapted from Leurs, Mur-Veeman et al. (2008)), reliability, response, and linear mixed model regression

\section{Description DISC clusters and DISC subclusters}

DISC factors

(based on single-item or

multi-item scales)
Cronbach's alpha

Number

of items

(N)

\section{External factors}

External factors

The collaborative process is influenced by a number of factors that are beyond the control or influence of the alliance itself:

\section{- Policy and regulations}

Clear, preferably intersectoral policies, laws and

regulations providing challenging and sound goals for health promotion, may enhance the collaborative process. Limiting factors may be poorly defined boundaries between policy domains, contradictory policies of different public sectors and policies focusing on the transformation of public organizations into private enterprises.

\section{- Attitude of financing bodies}

Attitude of financing

An encouraging and accommodating attitude on the part of financing bodies and commitment to provide the necessary funding over a longer period to prevent brain drain during the initial developmental phase supports the

\section{- Community notion}

Community notion can be regarded as an added value for organizations the individual interests of each party and can additionally stimulate organizations to work together on coordinated school health promotion. Incentives, policies and regulations can increase community notion for coordinated school health promotion, as can parents, school staff and collaborating parties who show social interest in coordinated school health promotion.

\section{Sustainability}

The collaborative process influences the development of the coordinated (school) health promotion and supports the move towards sustainability (goal):

Under the continuous influence of the collaborative process. an idea is elaborated and is formalized into regular working routine. During this process the subject of the collaborative process evolves: it 'changes colour' under the influence of the collaborative process itself.
Sustainability

Characteristics of HSA

6 .548

- Project vs. regular work

- Network support vs. individual actions

- Research vs. practical

- Systematic vs. ad-hoc

- Practical vs. theoretical

- Single service point vs.

fragmentation

p-values corrected according to Holm procedure: ${ }^{*} p \leq .05,{ }^{* *} p<.01,{ }^{* * *} p<.001$ 
(continued from last page)

\begin{tabular}{|c|c|c|c|c|c|c|c|c|}
\hline \multicolumn{4}{|c|}{ Means } & \multirow{2}{*}{\multicolumn{4}{|c|}{ Linear mixed model of regression analysis }} & \multirow{3}{*}{$\begin{array}{l}\text { Effect size } \\
\text { Cohen's d }\end{array}$} \\
\hline Pren & asurement & Post & asurement & & & & & \\
\hline $\mathrm{N}$ & $M(S D)$ & $\mathrm{N}$ & $M(S D)$ & b & $\operatorname{SE}(b)$ & $\mathrm{F}$ & $p$-value ${ }^{a}$ & \\
\hline 90 & $3.29(1.08)$ & 67 & $3.83(.90)$ & .552 & .154 & 12,922 & $.000^{* * *}$ & 0.55 \\
\hline 89 & $2.64(1.53)$ & 67 & $2.73(1.55)$ & .091 & .250 & .133 & .716 & 0.04 \\
\hline 90 & $2.50(1.38)$ & 67 & $3.00(1.37)$ & .362 & .211 & 2.938 & 1.80 & 0.26 \\
\hline 84 & $2.14(1.16)$ & 65 & $2.55(1.26)$ & .429 & .183 & 5.256 & .072 & .36 \\
\hline 82 & $2.91(1.20)$ & 66 & $3.20(.98)$ & .282 & .135 & 2.380 & .125 & .26 \\
\hline 83 & $3.37(.95)$ & 64 & $3.80(.78)$ & .522 & .161 & 15.065 & $.000^{* * *}$ & .59 \\
\hline 81 & $3.38(1.06)$ & 66 & $3.74(.93)$ & .389 & .136 & 5.816 & $.010 *$ & .39 \\
\hline 82 & $3.20(.90)$ & 66 & $3.41(.80)$ & .212 & .166 & 2.422 & $.020^{*}$ & .25 \\
\hline 80 & $2.85(1.11)$ & 66 & $3.29(.97)$ & .487 & .089 & 8.525 & $.030 *$ & .46 \\
\hline
\end{tabular}




\section{Qualitative results}

\section{How was the DISC-based trajectory operationalized by the regional coordinators?}

We identified a great variety of working methods and instruments that the regional coordinators applied in response to the DISC-based advice, which clustered into five main management styles (Figure 4.2). Below we summarize how these management styles were used in practice.

Involving. Regional coordinators created spaces for negotiation between stakeholders about a common vision, a possible collaborative structure and a suitable division of tasks. They used different working methods and instruments to induce people to think about these aspects and to give everybody a voice in the decision-making process. They involved stakeholders through discussions and brainstorm sessions, and encouraged their involvement by means of prepared agendas, short questionnaires, DISC results or assignments. An example of an assignment used for the systematic development of a common vision is shown in Figure 4.1. Based on the results of the individual assignments that had been completed by each stakeholder, the regional coordinators came up with a proposal for a common vision.

1. Describe the mission of your organization/department towards health in education.

2. Describe the added value of the HSA for your own organization/department.

3. Describe the contribution your organization/department can provide to the HSA.

4. Describe the preconditions for your organization/department for any contribution to the HSA.

Figure 4.1: Work assignment: creating a common vision

Comparable assignments were used to compare financing systems and policy cycles between collaborating parties. Additionally, they stimulated active participation by making collaborating partners responsible for certain tasks through the formation of steering groups and working groups. They also created moments for feedback on minutes, proposals, predefined formats/scenarios, and plans, to create a common perspective and commitment, and they tailored agreements to the possibilities and impossibilities of collaborating parties to facilitate alignment of policies. For example, when stakeholders were unable to commit to long-term agreements, then short-term agreements about investments and task distributions were made instead.

Informing. Regional coordinators shared plans with distal stakeholders (i.e. municipal authorities, PSS managers), raised awareness of HSA among 'potential' stakeholders and provided everybody who worked with the HSA (distal and proximal stakeholders) with relevant updates and tools. For example, regional coordinators informed stakeholders at local and regional levels through newsletters and websites. In addition, they networked with relevant informants during conferences and symposia. They held presentations during 
persuasive and information meetings for potential partners and municipalities. They also assigned stakeholders to be responsible for the distribution of information in their organization and their networks. Finally, they used minutes of meetings as a source of commitment and progress tracking for closely involved stakeholders.

Controlling. Planning and control systems were set up to inform the collaboration about whether the plans that had been made would bring about the desired effects, whether the resources allocated (e.g. staff, time) were realistic, but also to identify deviations at operational level and to intervene in time. The regional coordinators employed different systems at different levels. For example, at operational level, they used available registration systems to monitor and evaluate activities (e.g. the number of schools visits performed by the health promoting school advisors, the time they dedicated to school visits) and worked with action lists which they used as checklists during meetings. At tactical level, the coordinators used different types of evaluations (e.g. end-of-year evaluations) to check whether the intended outcomes and budgets were met.

Supporting. The coordinators organized different types of support. At operational level, they used monitoring in combination with active coaching. For the monitoring part, they used information from the registration system, from action lists and different types of evaluations. For active coaching, they used tools from the 2010 practitioner guide (RIVM Centre for Healthy Living, 2010), including predefined formats and scenarios for discussions with particular stakeholders, and provided these on a platform that was easily accessible to health professionals. The regional coordinators also encouraged participation in training courses and discussion of group norms to strengthen the team spirit (e.g. supporting each other in the attainment of the goals established). At local level, regional coordinators facilitated demand-driven practices among collaborating parties by establishing appropriate financial and other arrangements with municipalities (and possibly PSSs). At managerial level, the regional coordinators created clearly defined agreements about responsibilities and manpower, to prevent resistance and fears among the representatives involved.

More active forms of control and supportive behaviors were used in collaborations between organizations that fall under one umbrella organization, with clear agreements on resources and manpower and one management (e.g. youth health care and public health officials working at PHSs).

Coordinating. Coordinating activities were central to all other management activities. Coordination included an interactive, integrative process of collecting information, interpreting it, determining knowledge requirements, outlining the next steps and elaborating ways in which results could best be presented to the parties involved (e.g. proposals, predefined formats), followed by formalization of final decisions (e.g. multi-year plans). 


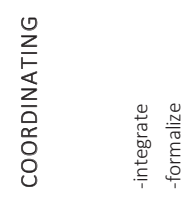

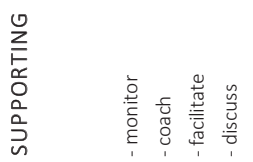

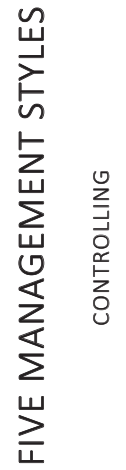

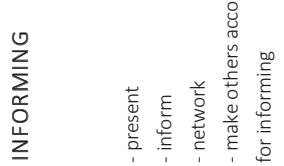

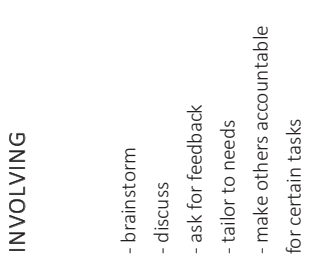

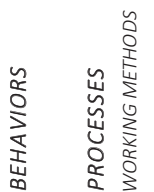

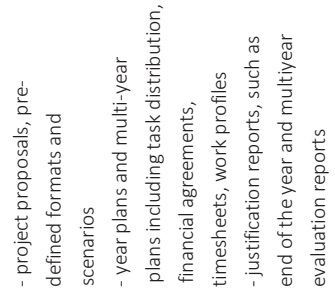

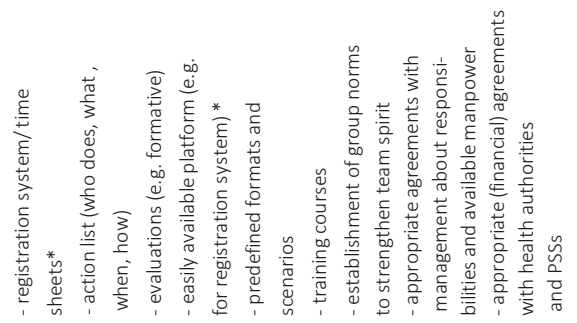

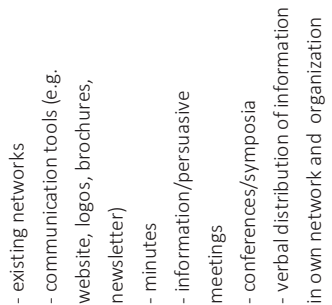

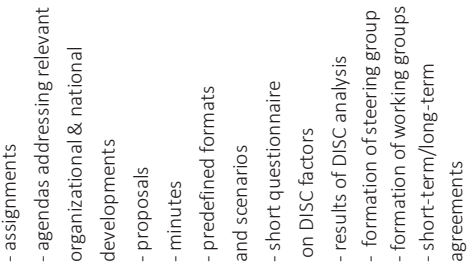




\section{Discussion}

The current study had two aims: first to investigate the effectiveness of a systematic approach to the development of intersectoral collaboration in CSHP and second to open up the 'black box' of the collaborative processes involved. These aspects were investigated using the data from a two-year DISC-based trajectory. We examined longitudinal quantitative data from the trajectory to find out whether collaboration had improved in terms of the DISC factors after participation in the DISC-based trajectory (research question 1), and studied the longitudinal qualitative data to assess whether managerial activities were employed by regional coordinators in response to the trajectory, and if so which ones (research question 2). Presenting both results, quantitative and qualitative, in one paper provides additional understanding of the origins of the observed effects.

As regards our first research question, the quantitative data showed remarkable improvement (of almost medium effect size) in change management and project management. In addition, gains of medium magnitude were found on the three subclusters of collaborative support (i.e. perceived consensus, intention to commit, and formalization), as well as on one measure of external factors (i.e. perceived alignment between policies), and on four measures of sustainability (i.e. theoretical vs. practical, research vs. practical, ad-hoc vs. systematic, fragmentation vs. single service point). These improvements were found despite an increase in organizational problems reported by stakeholders involved (due to e.g. mergers, reorganization, financial cutbacks). As regards our second research question, our qualitative data showed that regional coordinators undertook different activities in response to the DISC-based trajectory, activities which clustered into five managerial styles and basically addressed (1) involving stakeholders in the decision-making process, (2) informing them about decisions and progress made, (3) controlling and (4) supporting their task accomplishment, (5) and coordinating the collaborative process.

The improvements that we found in terms of change management, project management, and collaborative support seem to be the result of having encouraged regional coordinators to identify common grounds with the stakeholders regarding several aspects. These aspects included the establishment of a common vision, a common collaborative structure, and a suitable task distribution, while considering stakeholders' individual interests. In this respect our qualitative data provide some indications that regional coordinators have created the necessary opportunities for stakeholders to freely voice their suggestions, doubts, and wishes regarding these aspects (the involving management style). Similar findings have been reported by others, who found that creating spaces for negotiation (e.g. brainstorming, discussion) can enhance the consensus on collaborative goals and necessary actions, and thereby promote the formulation of commitments in collaborations (Bohlmeijer et al., 2005; Gray, 1989; Thomson \& Perry, 2006). 
The same reasoning seems to apply to the increased degree of formalization we have found at posttest. We advised regional coordinators to discuss choices at the management and executive levels. The qualitative data indeed indicate that regions consolidated agreements in documents at different levels (the coordinating management style). Bohlmeijer et al. (2005) reported that written documents can be regarded as the visible results of the negotiations and are an important indicator of formalization. Koelen et al. (2012) showed that such formalization builds employees' accountability, which acts as an important driving force for action in Dutch health organizations.

As an adverse development, we have observed that the internal context of the parties involved deteriorated. It is conceivable that this result is related to the internal developments (e.g. mergers, reorganizations) that the organizations were going through during the trajectory, in response to government cutbacks due to the financial crisis in the Netherlands. In addition, it could be the consequence of the new four-year public health policy cycle which organizations had entered in 2011 and which obliged them to translate new national health promotion objectives into concrete strategies to improve health at local level. We observed that these dynamics often forced collaborating parties to make choices which were not in interest of the collaboration. Time and staff were mainly dedicated to the reorientation. Legislation changed, as did organizational tasks. Some PSSs left the collaboration, others reduced their investments. The reconciliation of collective and individual interests has been reported by others as a recurring dilemma in collaborations. While stakeholders achieve collaborative goals, they also have to fulfil the individual organization's mission and respond to organizational developments and problems (Bardach, 1998; Huxham \& Vangen, 1996; Koelen et al., 2012; Thomson \& Perry, 2006; Van de Ven, Emmett, \& Koenig Jr., 1975; Vangen \& Huxham, 2003; Warner \& Gould, 2009; Wood \& Gray, 1991). This finding may explain the state of the collaboration after three years, where collaboration shows no improvements in terms of collaborative actions as yet. Even if agreements were reached, this seemed to require much more time.

Next to the effort to reconcile individual and collective interests, our qualitative and quantitative data strongly suggest that regional coordinators recognized relevant policies for intersectoral collaboration and tried to influence them to promote collaboration. Regional coordinators used the 'windows of opportunity' (Kingdon, 1995) that emerged from the dynamic context for this purpose. They placed the HSA and the collaborative structure on the agenda of meaningful internal and external meetings (the informing management style). They made connections and opportunities visible to relevant actors (the coordinating management style). They developed supporting policies and financial agreements between municipal authorities and PHSs (the supporting management style). Our quantitative data confirm greater alignment between health policies, school policies, and the HSA after the trajectory (external factors). De Leeuw (1999) reported comparable skills by 'social entrepreneurs' who 
were able to influence policy agendas. These social entrepreneurs had the abilities to obtain an overall view of the various perspectives of stakeholders, to broker commitments of stakeholders into networks and to reflect on their own position and that of the stakeholders. They influenced the policy agenda by bringing problems, solutions, and the right stakeholders together.

By contrast, our study shows that directive behaviors, which focus on task performance, such as planning and control systems (the controlling management style) were less commonly employed, and when they were used, it was mostly in organizations that fall under one umbrella organization. This probably indicates the difficulty of employing this type of behavior in collaborations lacking formal authority (Bohlmeijer et al., 2005; Vangen \& Huxham, 2003).

Finally, it is encouraging to find that stakeholders expressed more favorable judgments about the sustainability of the collaboration at posttest (i.e. more systematic, more practical, more demand-driven practices). Although the absence of comparable studies makes it difficult to compare our findings, there are studies that support the view that a systematic, step-wise approach to change can give direction and transparency (Bohlmeijer et al., 2005; Deschesnes et al., 2003; Gajda, 2004; Mur-Veeman \& Van Raak, 1994). A study involving the provision of professional support for school staff to implement the CSHP acknowledged that professional support can enhance the acquisition of organizational knowledge and its translation into practice (Deschesnes, Tessier, Couturier, \& Martin, 2013b). Lastly, the finding that school health promotion developed from fragmentation towards a single service point for health promotion (i.e. demand-driven practices) provides additional evidence that collaborative efforts start to pay off and contribute to collaborative goals.

\section{Strengths, limitations and implications}

Based on the above interpretations, it is plausible to postulate that regional coordinators employed managerial activities in response to the DISC-based trajectory, which have contributed to the observed improvements in terms of the DISC factors. In this respect the combination of the qualitative and quantitative data was an important strength of our study. It allowed data triangulation and a combined study of effects and processes. This in turn provided important insights into the causes of the observed effects. This strength partly offsets the weakness of the quantitative results based on a pretest-posttest design, which as such limited the opportunities to draw causal inferences due to possible history and maturation biases and Hawthorne effects (Isaac \& Michael, 1995). In addition, data source and investigator triangulation, as well as the member check of analyzed minutes contributed to the objectivity (i.e. confirmability) and credibility of our findings. Furthermore, studying multiple cases gave us the opportunity to collect qualitative data from various cases, which differed in several characteristics and staring situations, and thereby increased the transferability of our conclusions. Finally, we tried to enhance readers' judgments about the 
dependability of qualitative findings through a thorough description of the inquiry process and interpretation of findings against the context of the studied collaboration (Anney, 2014; Denzin \& Lincoln, 2005). Nevertheless, some limitations to our study should be considered. Despite being based on multiple cases, our quantitative research suffered from a small sample size, due to the small number of stakeholders involved. In addition, drop-out affected our sample size, though we minimized its detrimental effects by applying suitable analysis techniques (i.e. including all available cases in the analysis). Furthermore, selection bias may have affected our data because of the voluntary participation of PHS regions in the DISCbased trajectory and because the stakeholders were not randomly selected. In addition, regional coordinators decided to give priority to a particular sector in the collaboration. The desire to achieve their own organizational goals (e.g. youth health promotion) may have led their choices. Finally, the data gathered for the purpose of support may not necessarily capture all managerial activities that the regional coordinators employed, so our overview might not be exhaustive and might need further elaboration. In addition, the stage of the collaboration limited the number of managerial activities that could be studied, activities which can help manage the transition from formalization to collaborative action. These activities will thus need special attention in follow-up studies.

To conclude, our study provides preliminary evidence for the effectiveness of a systematic approach to intersectoral collaboration based on the DISC model. In addition, it offers important insights into the black box of managerial processes related to this kind of approach. Our findings suggest that when collaboration is to be established in a systematic way, a thorough analysis of facilitating and impeding factors can help to formulate an appropriate strategy. In addition, it seems to indicate that each step of this strategy should provide enough space for negotiation and be concluded with formalized agreements, so that employees are made accountable for collaborative actions. Support for this process can probably be provided by partnership managers who can devise creative working methods and instruments to manage the collaboration, and who have the skills to function as social entrepreneurs in dynamic contexts. The byproducts of our study are a strategy to improve the change and project management in intersectoral collaboration and a large repertoire of managerial working methods and instruments. Both might inspire health professionals engaged in comparable partnership endeavors. Assistance on demand might be necessary to support them in the acquisition, assimilation, and application of the new knowledge. 


\section{References}

Anney, V. N. (2014). Ensuring the quality of the findings of qualitative research: looking at Trustworthiness Criteria. Journal of Emerging Trends in Educational Research and Policy Studies, 5(2), 272-281.

Axelsson, R., \& Axelsson, S. B. (2006). Integration and collaboration in public health - a conceptual framework. The International Journal of Health Planning and Management, 21(1), 75-88.

Bardach, E. (1998). Getting Agencies to work Together: the Practice and Theory of Managerial Craftsmanship. Washington: Brookings Institution Press.

Barnhoorn, H., \& Walda, R. (1992). De eerste lijn op spitzen. Assen: Van Gorcum.

Bohlmeijer, E., Ruland, E., Van Raak, A., \& Mur-Veeman, I. M. (2005). Procesmanagement in public health - ontwerp, analyse \& verandering (Processmanagement in public health design, analysis \& change). Utrecht: Trimbos.

Boot, N. M. W. M., van Assema, P., Hesdahl, B., \& de Vries, N. K. (2010). Professional assistance in implementing school health policies. Health Education, 110(4), 294-308.

Boot, N. M. W. M., van Assema, P., Hesdahl, B., Leurs, M., \& de Vries, N. K. (2010). Gezondheidsbevordering en voortgezet onderwijs: verstandshuwelijk of echte liefde? (Health promotion and secondary education: marriage of convenience or true love?) Tijdschrift voor Gezondheidswetenschappen, 88(3), 127-135.

Bos, V., De Jongh, D., \& Paulussen, T. (2010). Gezondheidsbevordering en preventie in het onderwijs. Stand van zaken, effectiviteit en ervaringen van GGD'en en scholen (Health promotion and prevention in schools. Current state of affairs, effectiveness and experiences from public health services and schools.). Bilthoven: RIVM.

Buijs, G. J. (2005). Werkdocument. De Gezonde School Methode in Nederland. (Work document. The Healthy School Approach in the Netherlands. Woerden: National Instituut voor Gezondheidsbevordering en Ziekte preventie (Netherlands Institute for Health Promotion and Disease Prevention).

Cummings, T. G., \& Worley, C. G. (2001). Organizational Development and Change (7th ed.). Mason, Ohio: Southern-Western College Publishing.

Dadaczynski, K., \& Paulus, P. (2013). Germany, Anschub.de-Alliance for sustainable school health and education. In O. Samdal \& L. Rowling (Eds.), Implementing Health promoting schools: exploing the what, why and how (pp. 139-142). London: Routledge.

Daft, R. L., \& Noe, R. A. (2001). Organizational behavior. Orlando: Hartcourt Inc.

De Caluwé, L., \& Vermaak, H. (2003). Learning to change: Thousand Oaks: Sage Publications.

De Leeuw, E. (1999). Healthy Cities: urban social entrepreneurship for health. Health Promotion International, 14(3), 261-269. 
Denzin, N. K., \& Lincoln, Y. S. E. (2005). The sage handbook of qualitative research. Thousands Oaks, CA: Sage.

Deschesnes, M., Martin, C., \& Hill, A. J. (2003). Comprehensive approaches to school health promotion: how to achieve broader implementation? Health Promotion International, 18(4), 387-396.

Deschesnes, M., Tessier, C., Couturier, Y., \& Martin, C. (2013). Professional development in the context of Healthy Schools in Quebec. Health Promotion International, (e-pub ahead of print). doi: 10.1093/heapro/dat043

Dür, W. (2013). Applying system theory of organizational change to health promotion interventions in schools and their problems. In O. Samdal \& L. Rowling (Eds.), The Implementation of Health Promoting Schools. Exploring the theories of what, why and how (pp. 34-50). New York: Routledge Publishers.

El Ansari, W., Phillips, C. J., \& Hammick, M. (2001). Collaboration and partnerships: developing the evidence base. Health and Social Care in the Community, 9(4), 215-227.

Gajda, R. (2004). Utilizing Collaboration Theory to Evaluate Strategic Alliances. American Journal of Evaluation, 25(1), 65-77.

Gray, B. (1989). Collaborating: Finding Common Ground for Multiparty Problems. San Francisco: Jossey Bass.

Hirsch Ballin, E. M. H. (2008). Wet Publieke Gezondheid (Public Health Act). Overheid.nl (Government.nl). Retrieved 14 April 2015, from http://wetten.overheid.nl/BWBR0024705/geldigheidsdatum_14-04-2015.

Huxham, C., \& Vangen, S. (1996). Working together. International Journal of Public Sector Management, 9(7), 5-17. doi: 10.1108/09513559610153863

Inchley, J., Guggelberger, L., \& Young, I. (2013). From health to education: the journey towards health promoting school implementation in Scotland. In O. Samdal \& L. Rowling (Eds.), Implementing health promoting schools: the what, why and how (pp. 142-146). London: Routledge.

Isaac, S., \& Michael, W. B. (1995). Handbook in research and evaluation. A collection of principles, methods and strategies useful in the planning, design and evaluation of studies for education and the behavioral sciences (3rd edition). San Diego, California: EdiTS.

IUHPE. (2009). Achieving Health Promoting Schools: Guidelines for Promoting Health in Schools. Retrieved 15 January 2015, from http://www.iuhpe.org/uploaded/Publications/Books_Reports/HPS_Guidelinesll_2009 _English.pdf.

Keshavarz, N., Nutbeam, D., Rowling, L., \& Khavarpour, F. (2010). Schools as social complex systems: a new way to understand the challenges of introducing the health promoting school concept. Social Science and Medicine, 70(10), 1467-1474. 
Kingdon, J. W. (1995). Agendas, Alternatives and Public Policies ((2nd Ed) ed.). New York: Harper Collins College Publishers.

Koelen, M. A., Vaandrager, L., \& Wagemakers, A. (2012). The Healthy ALLiances (HALL) framework: prerequisites for success. Family Practice, 29(suppl 1), i132-i138. doi: 10.1093/fampra/cmr088

Leurs, M., Mur-Veeman, I., Schaalma, H., \& De Vries, N. (2003). Integrale samenwerking gaat verder dan de samenwerking tussen professionals: introductie van het DISC-model (Integrated collaboration continues beyond professional collaboration: introduction of the DISC-model). TSG, 81, 369 - 372.

Leurs, M., Mur-Veeman, I., van der Sar, R., Schaalma, H., \& de Vries, N. (2008). Diagnosis of sustainable collaboration in health promotion - a case study. BMC Public Health, 8(382). doi: 10.1186/1471-2458-8-382

Leurs, M., Steenbakkers, M., \& Jansen, M. (2006). Het schoolSlag-praktijkboek: samen werken aan preventie op maat in het onderwijs (The schoolBeat manual: working together towards tailored prevention in education). Maastricht: GGD Zuid Limburg.

Lister-Sharp, D., Chapman, S., Stewart-Brown, S., \& Sowden, A. (1999). Health promoting schools and health promotion in schools: two systematic reviews. Health Technology Assessment, 3(22), 1-207.

McMorris, L. E., Gottlieb, N. H., \& Sneden, G. G. (2005). Developmental Stages in Public Health Partnerships: A Practical Perspective. Health Promotion Practice, 6(2), 219-226. doi: 10.1177/1524839903260647

Mur-Veeman, I., \& Van Raak, A. (1994). Inter-organizational networks on the Dutch home health care market. The International Journal of Health Planning and Management, 9(3), 245-258.

National Institute for Public Health and the Environment Centre of Healthy Living. (2010). Handleiding Gezonde School (Healthy School Guide). Bilthoven.

Noble, C., \& Toft, M. (2013). The English National Healthy School Programme 1999-2011. In O. Samdal \& L. Rowling (Eds.), Implementation of Health promoting Schools: exploring the theories of what, why and how (pp. 112-116). London: Routledge.

Plsek, P., \& Greenhalgh, T. (2001). The challenge of complexity in health care. British Medical Journal, 323(7313), 625.

Plsek, P., \& Wilson, T. (2001). Complexity, leadership, and management in healthcare organisations. British Medical Journal, 323, 746 - 749.

Pommier, J., Guével, M., \& Jourdan, D. (2010). Evaluation of health in schools: a realistic evaluation approach using mixed methods. BMC Public Health, 10(43). doi: 10.1186/1471-2458-1110-1143

Pucher, K. K., Candel, M. J. J. M., Boot, N. M. W. M., Van Raak, A., \& De Vries, N. K. (2015). A multiple-case study of intersectoral collaboration in the context of coordinated school 
health promotion using the Dlagnosis of Sustainable Collaboration (DISC) Model Health Education, 115(3/4), 301-321.

Rowling, L., \& Legder, E. (2013). Australia: The role of intermediary organisations in the development of health promoting schools. In O. Samdal \& L. Rowling (Eds.), Implementation of Health Promoting Schools: exploring the theories of what, why and how (pp. 116-120). London: Routledge.

Saan, H., \& De Haes, W. (2005). Gezond effect bevorderen. Het organiseren van effectieve gezondheidsbevordering (Promotion of healthy effects. The organization of effective health promotion.). Woerden: NIGZ.

St Leger, L. H. (1999). The opportunities and effectiveness of the health promoting primary school in improving child health - a review of the claims and evidence. Health Education Reserach, 14(1), 51-69. doi: 10.1093/her/14.1.51

Stewart-Brown, S. (2006). What is the evidence on school health promotion in improving health or preventing disease and, specifically, what is the effectiveness of the health promoting schools approach? . Copenhagen: WHO Regional Office for Europe.

The International Journal of Health Planning and ManagementLeurs, M. (2008). A collaborative approach to tailored whole-school health promotion. The schoolBeat study. Maastricht.

Thomson, A. M., \& Perry, J. L. (2006). Collaboration Processes: Inside the Black Box. Public Administration Review, 66(S1), 20-32. doi: 10.1111/j.1540-6210.2006.00663.x

Tuckman, B. W. (1965). Developmental sequence in small groups. Psychological Bulletin, 63(6), 384-399. doi: 10.1037/h0022100

Van de Ven, A. H., Emmett, D. C., \& Koenig Jr., R. (1975). Theoretical and Conceptual Issues in Inter-Organizational Theory. In A. R. Negandhi (Ed.), Inter-Organizational Theory (pp. 19-38). Kent, Ohio: Kent State University Press.

Van Raak, A., Mur-Veeman, I., \& Paulus, A. (1999). Understanding the feasibility of integrated care: a rival viewpoint on the influence of actions and the institutional context. The International Journal of Health Planning and Management, 14(3), 235-248.

Vangen, S., \& Huxham, C. (2003). Enacting Leadership for Collaborative Advantage: Dilemmas of Ideology and Pragmatism in the Activities of Partnership Managers. British Journal of Management, 14, S61-S76.

Warner, M., \& Gould, N. (2009). Integrating Health in All Policies at the Local Level: Using Network Governance to Create 'Virtual Reorganization by Design'. In I. Kickbusch (Ed.), Policy Innovation for Health (pp. 125-163): Springer.

Wood, D. J., \& Gray, B. (1991). Toward a Comprehensive Theory of Collaboration. The Journal of Applied Behavioral Science, 27(2), 139-162. doi: 10.1177/0021886391272001

Yin, R. K. (2009). Case Stuy Research: Design and Methods. Califormia: Sage Publications. 


\section{Chapter 5 \\ Predictors and mediators of sustainable collaboration and implementation in comprehensive school health promotion}

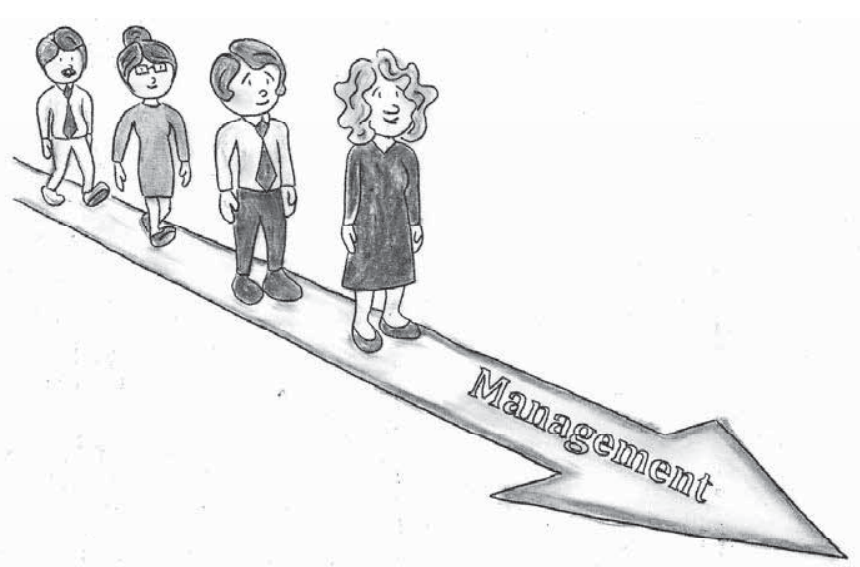

Based on:

Pucher, K.K., Candel, M.J.J.M., Boot, N.M.W.M, \& De Vries, N.K. (submitted). Predictors and mediators of sustainable collaboration and implementation in comprehensive school health promotion. Health Education. 


\section{Abstract}

Purpose: The Diagnosis of Sustainable Collaboration (DISC) model (Leurs et al., 2008) specifies five factors (i.e. project management, change management, context, external factors, stakeholders' support) which predict whether a collaborative structure becomes strong and stable. We studied the dynamics of these factors in a study of multiple partnerships in comprehensive school health promotion (CSHP).

Method: A Dutch two-year DISC-based intervention to support coordinators of five CSHP partnerships in the systematic development of intersectoral collaboration was studied in a pretest-posttest design. To uncover the determinants of sustainable collaboration and implementation of CSHP and to find possible mediators, we carried out multilevel path analyses of data on the DISC factors obtained from 90 respondents (response of approached respondents 57\%) at pretest and 69 respondents (52\%) at posttest. Mediation mechanisms were assessed using joint significance tests.

Results: The five DISC factors were important predictors of implementation of CSHP (explained variance: 26\%) and sustainable collaboration (19\%). For both outcomes, stakeholders' support proved to be the most important factor. Regarding sustainable collaboration, mediation analysis showed that stakeholders' support fully mediated the effects of change management, project management, external factors and context. This indicates that the extent of stakeholders' support determines whether collaboration becomes sustainable. We also found that the extent of stakeholders' support in turn depends upon a well-functioning project management structure, the employment of change management principles a favourable organizational context and external context. For the actual implementation of CSHP, partial mediation by the support factor was found. There was a direct positive effect of change management indicating that organizational knowledge is also necessary to implement CSHP, and a direct negative effect of project management, probably pointing to the negative effects of too much negotiation in the collaboration.

Limitations: A design lacking a control group, a small sample and a relatively early assessment after implementation support stopped limit the generalizability of our results.

Implications: Strategies targeting the DISC factors can enhance stakeholders' support and thereby promote sustainable intersectoral collaboration and the implementation of CSHP.

Added value: The DISC model provides a fruitful conceptual framework for the study of predictors and processes in public health partnerships. The importance of stakeholders' support and other factors in the model are demonstrated.

Keywords: collaboration; implementation; health promoting schools 


\section{Introduction}

Intersectoral collaboration plays an increasingly important role in public health (Barry et al., 2012; Stahl et al., 2006; Warner \& Gould, 2009). Health problems are often multifactorial and can best be solved by combining effective interventions implemented with the support of different sectors. Such multi-strategic approaches to health problems are complex and difficult to implement, however. One of the challenges to their implementation is the establishment of a functional collaborative structure between stakeholders. The ultimate goal is often to develop a stable, long-term and self-supporting collaboration.

Conceptual models of partnership development in public health list factors that are responsible for successful collaboration. These include personal characteristics, attitudes, beliefs and behaviors of relevant stakeholders, the organizational context of the parties involved and the external context of the collaboration (Clark et al., 2006; Crowley et al., 2000; Feinberg et al., 2004; Florin et al., 2000; Kegler \& Swan, 2011b). Where previous research paid much attention to the determinants and to the outcomes of intersectoral collaboration, the interactive processes in between these two have been less studied. This particular lack of knowledge has been called the 'black box' of collaborative processes (Thomson \& Perry, 2006; Wood \& Gray, 1991).. In the current study we explored the dynamics within collaborations in a quantitative way. We investigated the relations between determinants of collaboration by using a quantitative approach including path analyses, previously applied by (Kegler \& Swan, 2011a; Kegler \& Swan, 2011b) to study associations between coalition factors included in the Community Coalition Theory (Butterfoss, 2007). For the purpose of this study, we used the longitudinal data from a multiple-case study on comprehensive school health promotion (CSHP) conducted in the Netherlands between the end of 2008 and the end of 2011. In further work we opened up this 'black box' by presenting qualitative data on the managerial processes facilitating the systematic development of intersectoral collaboration (Pucher et al., 2015b)

CSHP is endorsed by the World Health Organization and has been implemented in different forms worldwide (IUHPE, 2009; Leurs et al., 2005a; Stewart-Brown, 2006). The Dutch equivalent of CSHP, called the Healthy School Approach (HSA), basically includes the following steps: (1) creating a supportive infrastructure for the HSA, (2) using demand-driven practices in school health promotion based on the epidemiological data of the school community, (3) prioritizing school needs, (4) compiling a multiyear school health plan, (5) executing the plan, (6) evaluating the activities, (7) and creating an education care continuum by linking available care structures in schools with the necessary structures for prevention. Multi-stakeholder engagement is needed to put the HSA into practice (Buijs, 2005; Leurs et al., 2006; RIVM Centre for Healthy Living, 2010). 
Since in the Netherlands schools have no legal obligations to implement health promotion programs and policies, its implementation is stimulated by public health services (PHSs). In the HSA, PHSs function as a linking pin (coordinator) between the education sector, health authorities and public service stakeholders (PSSs). As illustrated in Figure 5.1, they shape demand-driven practices in school health promotion by matching the available health promotion offer to the health demands of schools. In addition, PHSs fulfill an advisory role to the municipality, to ensure financial and policy support for the HSA. Their activities are based on a legal responsibility for the implementation of local public health policy and youth health care, financed by the municipality (Hirsch Ballin, 2008). Furthermore, at the school level, the implementation of the HSA is professionally assisted by a 'health promoting school advisor', who represents different public services and providers (e.g. from the welfare, health, prevention and safety sectors). This can be either a representative from the PHSs or a representative from another public service. The contacts with PSSs are maintained by the HSA coordinator itself. The organization of the HSA (e.g. task distribution, contacts) can vary between Dutch regions (Pucher et al., 2015).

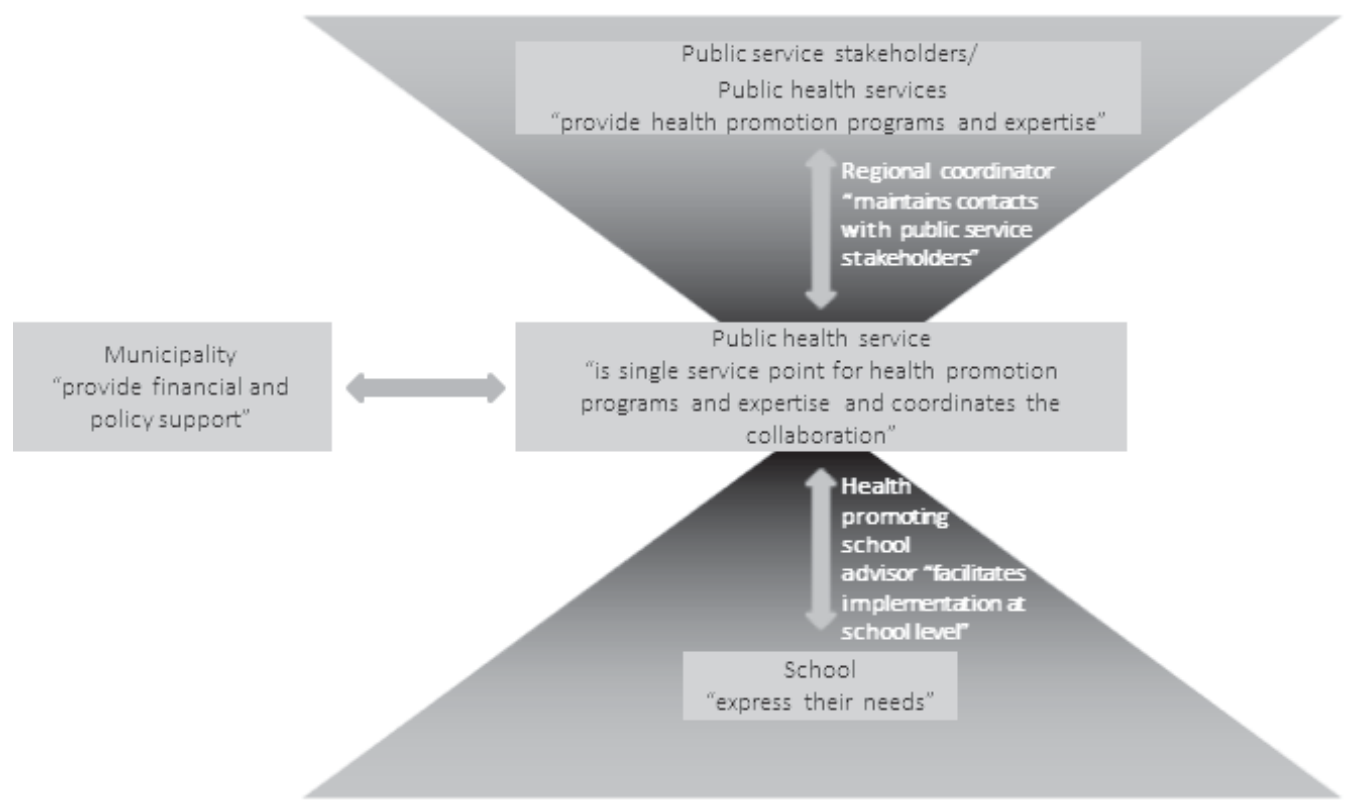

Figure 5.1: Collaborative structure in the HSA

The first attempt to establish a functional collaborative structure between these stakeholders was managed by using the practice-oriented Dlagnosis of Sustainable Collaboration (DISC) model (Leurs et al. 2008). The DISC model originates from Dutch multiple-case studies aimed at bringing different health domains together in integrated care (Van Raak et al., 1999) and is based on organizational change theory (Cummings \& Worley, 2001; Daft \& Noe, 2001; De 
Caluwé \& Vermaak, 2003). Its validity in the context of the HSA has been established in a single case study (Leurs et al., 2008) and its application as a diagnostic instrument further confirmed in a study of multiple partnerships (Pucher et al., 2015a). The results of DISC analyses showed to be useful to guide future actions in HSA partnerships. The DISC model includes five factors that predict sustainable collaboration: change management, stakeholders' support, project management, context and external factors. Each factor can be assessed on the basis of a set of subfactors. tThe main assumption of the model is that stakeholders' support, which can be assessed at the level of perceptions (i.e. importance, mutual benefits or win-wins), intentions (i.e. intention to trust, to commit, and to innovate) and actions (i.e. innovations, investments of resources and personal, and formalization) of the parties involved, determines the progress within the partnership. The collaboration makes progress when stakeholders succeed to translate their positive perceptions into positive intentions and actions. The collaboration stagnates when it fails to enter the action stage. The collaborative process is also affected by factors in the wider context. On the one hand, there are contextual factors (i.e. characteristics of organizations, research power, and relevant policies) which exert influence on the collaboration and can be influenced by the partners themselves. On the other hand, there are external factors (e.g. rules and regulations, financers' attitudes and community notions), which are rather beyond the control of the alliance itself. Furthermore, the model assumes that the collaborative structure varies over phases. During the developmental and initial implementation phase, the collaborative process is dealt with in a project management structure (i.e. who, what, when). This project management structure fades out when the subject of the collaborative process is integrated into regular work of the partner organizations, and the alliance becomes a self-supportive initiative. The transition from incidental, project bound collaboration (i.e. a project with a project-management structure) to joint work embedded in organizational routines (a selfsupported coalition without strict project management but embedded in normal routines) is indicated by the shading in Figure 5.2. This integration in organizational policies is captured in the factors of sustainable collaboration. The process of integration is facilitated by one leader or a small group of leaders enacting the principles of change management (i.e. vision, change perspectives, change strategies and network development). Finally the model assumes that the subject of the collaboration (i.e. HSA) is further developed under the influence of the partnership. For instance, the HSA is adapted to the characteristics of a region and the stakeholders involved. In other words, there is a clear interdependence between the HSA and the collaboration: when the collaboration is sustained also the implementation of the HSA continues.

Sustainable collaboration, as defined in the DISC model clearly resembles the understanding of this concept as suggested by Steckler and Goodman (1989) and Yin (1979). Those authors emphasize the institutionalization of the subject of collaboration within 
organizational policies after withdrawal of implementation support, e.g. in terms of funding. Other existing perspectives not included in the DISC conceptualization, feature sustainability as maintenance of health benefits over time (for example achieved through partnerships) or view it as capacity-building by relevant actors (for example through development of problemsolving capacities that enable the building of relationships and their maintenance) (ShediacRizkallah \& Bone, 1998). Although it can be assumed that all three can contribute to the sustainability of collaboration, or even that the one can reinforce the effects of the other (Sridharan \& Gillespie, 2004), the DISC model in particular focuses on the institutionalization aspect in organizational policies.

The precise relationship between the DISC factors is not yet clear. So far, preliminary data (Leurs et al., 2008; Pucher et al., 2015b) only suggest that the DISC factors of change management, project management, context and external factors can have positive effects on stakeholders' support and that stakeholders' support partially mediates the effects of these factors on sustainable collaboration (Figure 5.2).

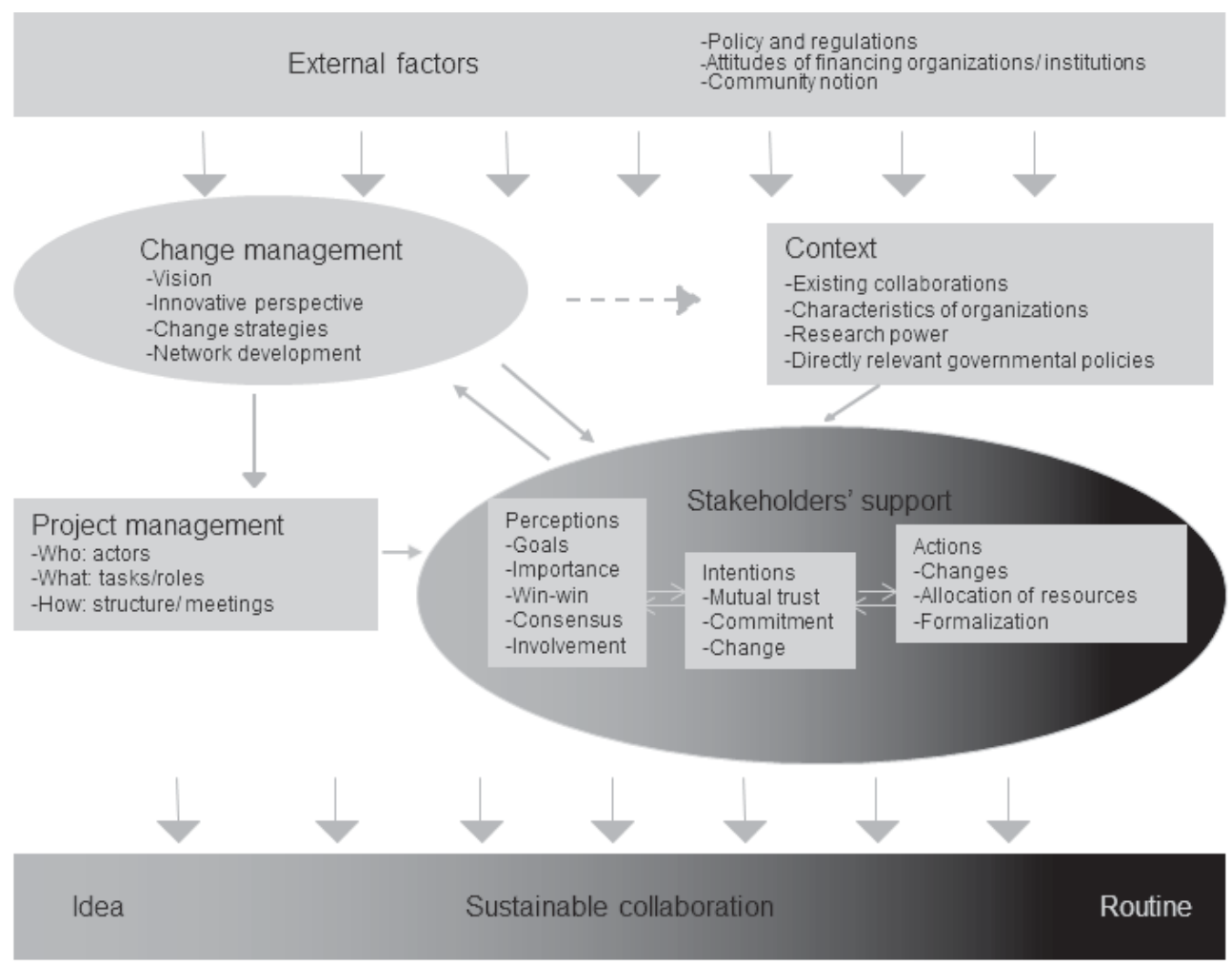

Figure 5.2: The Diagnosis of Sustainable Collaboration (DISC) model (adapted from Leurs et al. (2008)) 


\section{The aims of this paper}

However, this mediation has not yet been quantitatively assessed. In addition, previous studies provide some indications for a direct impact of the DISC factors on the implementation of the HSA in schools (Boot \& De Vries, 2012; Boot et al., 2010a). In 20082011, the DISC model and results of DISC questionnaires were used to support five Dutch regions in the systematic development of intersectoral collaboration in a two-year trajectory. The five HSA collaborations were diagnosed by means of a survey among the relevant stakeholders from health services, PHSs and municipal authorities (Pucher et al., 2015a). Based on the results, recommendations were made to improve the collaborative structure, followed by a one-year period of support for its implementation. The DISC recommendations concerned improvements in the management of the collaboration, which were summarized in the following DISC-based strategy: 1) bringing different stakeholders together, 2) developing a common vison, 3) identifying the possibilities and impossibilities for each collaborating partner based on the DISC analysis, 4) determining the desired collaborative structure, 5) developing a task distribution based on the information, 6) and discussing the choices at the management and the executive levels. After one year of support, the collaborative process was followed up for an extra year and then ended with an additional assessment of the current state of the collaboration. The longitudinal quantitative data from the DISC survey offered the opportunity to study previous assumptions regarding: (1) the processes connecting DISC factors to the sustainability of the collaboration, including the mediation by stakeholders' support, and (2) the effects of DISC factors on the actual implementation of the HSA in schools.

\section{Methods}

\section{Procedure}

Quantitative data on DISC factors were collected in five (of 30) Dutch PHS regions in 2008/2009. Table 5.1 gives an overview of the characteristics of the five regions. Regional coordinators of the HSA in those regions were located at the PHSs and were the central contact persons for this study. To participate in the DISC-based trajectory, PHS regions had to meet several inclusion criteria. Regional coordinators had to indicate that they had sufficient personnel and time to participate in the DISC-based trajectory. They also had to agree to give priority to intersectoral collaboration in their work with the HSA and to start with the DISCbased trajectory by the end of 2008.

The regional coordinators of the HSA working at PHSs identified relevant stakeholders from the education sector, municipal authorities, PHSs and other PSSs. They announced the topic of research to these persons and distributed materials for the survey (the questionnaire and a brief summary of the HSA). Data collection lasted eight weeks. Reminders were sent 
after an additional four weeks. The procedure was repeated in 2011 for the posttest measurement.

Coordinators independently indicated that adequately situating the HSA within their own organization and positioning it in the region together with PSSs should get priority. For this reason, the DISC recommendations targeted representatives of the PSSs and PHSs, and only data from these stakeholders were included in the current study.

\section{Participants}

A total of 158 potential stakeholders at the pretest and 132 potential stakeholders at the posttest were approached by regional coordinators to complete the DISC questionnaire. These included health promoters, epidemiologists, pediatricians and youth care nurses. PSSs came from the domains of addiction, mental health, social welfare, security and other services like educational support services, dietician centers and sports companies. Coordinators approached more PHS representatives than PSSs. At pretest 129 PHS representatives and 29 PSSs were approached. At posttest 108 PHS representatives and 24 PSSs were asked to complete the questionnaire.

\section{DISC questionnaire}

The DISC questionnaire (adapted from Leurs et al. (2008)) relates to 26 subfactors that can be grouped into 6 DISC factors (change management, project management, context, external factors, stakeholders' support, sustainable collaboration) with 1 to 5 items each, mostly on a 5-point scale (completely disagree: 1 to completely agree: 5) with the additional option 'don't know'. Stakeholders' support is measured at the level of stakeholders' perceptions, intentions and actions. Examples of the items used in the questionnaire to assess stakeholders' perceptions asked whether they appreciated the goals of the HSA ('I think demand-driven practices in school health promotion are important for the educational sector') and whether they thought that working together for the HSA was of interest for their own organization ('I think it is important that my organizations participates in the HSA'). Example items to assess stakeholders' intentions related to the subfactors of willingness to trust ('I think that the HSA partners can be trusted') and willingness to commit ('I think that the development of the HSA is the task of my organization'). Stakeholders' actions were assessed by items such as 'My organization implemented changes for the HSA' (belonging to the subfactor changes) and 'My organization invests in the HSA though allocation of personnel' (belonging to the subfactor resources). Example items for the factor of change management are 'The HSA goals are clear' (subfactor vision) and 'The HSA is accepted because of good PR' (subfactor change strategies). To assess project management items were used like 'There is a clear task distribution' (subfactor task distribution) and 'There is a clear communication structure' (subfactor 
communication). The context of the HSA was assessed by items like 'My organization is open to innovations' (subfactor organizational characteristics) and 'My organizations can influence health policy' (subfactor relevant policies). Example items to measure external factors were 'The HSA fits into the health policy' (subfactor policies and regulations) and 'The most important financer appreciates the idea of the HSA' (subfactor attitude of most important financier).

The main outcome measure of our study was the DISC factor of sustainable collaboration, which was assessed with six contrasts evaluating the extent of institutionalization of CSHP and the collaborative structure: project-bound (i.e. a project with a project-management structure) versus regular work (i.e. a self-supported coalition without strict project management but embedded in normal routines), network support versus individual actions, research versus practical, systematic versus ad-hoc, practical versus theoretical, single service point at PHS for health promotion programs for schools (i.e. the linking-pin function of the PHSs described earlier) versus fragmented health promotion programs for schools (i.e. uncoordinated overload of schools with school-based programs). Coalition members were asked to indicate for each contrast, on a 5-point scale 'How do you characterize the HSA in your region?' The contrast 'project-bound versus regular work' refers to the transition indicated by the shading in Figure 5.2. The contrast 'single service point at PHS for health promotion programs for schools versus fragmented health promotion programs for schools' refers to the linking pin function of PHSs between the education sector, health authorities and health services (Figure 5.1). At the PHSs health promotion programs from different health services are collected and provided to schools tailored to the school health needs. Such demand-driven practice aims to reduce fragmentation in school health promotion.

A second important outcome measure was the degree to which HSA was implemented in schools. This construct was assessed by measuring the execution of the different HSA activities: (1) creating stakeholders' support, (2) assessing the school health situation, (3) prioritizing school needs, (4) compiling a school health plan, (5) executing the plan, (6) evaluating health promotion activities and (7) linking available infrastructure for care at schools with prevention. The specific instruction for coalition partners was to indicate on a 3-point scale (1: no, 2: somewhat, 3: yes) whether their own organization performed these activities. The last activity 'linking available infrastructure for care in schools with prevention' is specific to the organizational structure for school health in the Netherlands (Leurs et al., 2005b). 


\section{Statistical analyses}

The scores for specific subfactors of each DISC factor were combined into a mean score. The same was done with the scores on items measuring the HSA activities. The DISC subfactors and items for HSA activities were considered formative indicators and satisfied the criteria proposed by Diamantopoulos and Winkelhofer (2001) for averaging the scores on such indicators.

The determinants of stakeholders' support, sustainable collaboration and implementation of HSA activities were examined using path analyses. The relations between pretest-posttest difference scores as obtained for each of the stakeholders for the several DISC factors were analyzed. As a specific example, when examining whether change management was a determinant of sustainable collaboration, changes in sustainable collaboration between pre- and postmeasurement were related to changes in change management. This was done in a multilevel analysis, where time points were considered to be nested within stakeholders, and in addition to measurements on change management at preand posttest, a time factor (indicating pre- versus posttest) and measurements on other DISC factors at pre- and posttest (such as project management, context) were included as predictors. The latter allowed for correcting the influence of change management on sustainable collaboration for a set of possibly confounding covariates. In these analyses the effect of the time factor was considered to reflect the effect of the DISC based trajectory.

The multilevel analysis was performed through linear mixed regression modeling involving a random intercept that varied across stakeholders. This allowed to include in the analyses both respondents with complete data and those who participated only in the pretest or posttest. Compared to an analysis based on complete cases only (that participated in both pretest and posttest), the present procedure enabled a more reliable estimation and test of the effects of the determinants of sustainable collaboration and executed HSA activities and associated mediation mechanisms.

Joint significance tests, as described by Preacher and Hayes (2004) and MacKinnon et al., (2002), were used to assess possible mediation effects of stakeholders' support in these pathways. Stakeholders' support was a full mediator when (1) it was significantly predicted by a DISC factor, (2) it significantly predicted sustainable collaboration and (3) sustainable collaboration was not significantly predicted directly by a DISC factor. When the third condition was not satisfied, we concluded that stakeholders' support partially mediated the effect of the DISC factor.

Cohen's $d$ effect sizes (ES) were calculated for significant relationships between binary and continuous variables and were interpreted based on Cohen's (1998) categorization, in which ES $=0.20,0.50$ and 0.80 represent small, medium and large effects, respectively. Cohen's $f^{2}$ effect sizes were calculated for significant relationships between continuous 
variables and were also interpreted based on Cohen's (1988) categorization, in which ES = $0.02,0.15$ and 0.35 represent small, medium and large effects respectively.

Finally, the power of the DISC model to predict sustainable collaboration and the execution of the HSA activities was calculated based on the amount of explained variance in these outcome measures (Snijders \& Bosker, 1999).

Statistical analyses were conducted using SPSS 20.

\section{Results}

\section{Response}

Of the 158 stakeholders who were approached for the pretest and the 132 approached for the posttest, 90 (57\%) and 69 (52\%) respectively could be included in the analyses. The sample comprised 70 PHS representatives (78\% of actual respondents) and 20 PSSs (22\%) at pretest and 51 PHS representatives (74\%) and 18 PSSs (26\%) at posttest. Drop-out was due to changes in organizational tasks of collaborating parties in response to organizational developments (i.e. mergers, reorganizations, government cutbacks) and changing policies, but also to the more specific collaborative goals, as collaboration progressed, leading to a poorer fit between the agendas of some organizations and the collaborative agenda.

\section{Which collaborative processes predict sustainable collaboration?}

Path analyses for the outcome measure sustainable collaboration (Figure 5.3) show that stakeholders' support is the strongest predictor of this measure (ES=.07). There was no direct impact of change management, project management, context and external factors on sustainable collaboration. Instead, the joint significance tests suggest that the effects of change management, project management, contextual and external factors were fully mediated by stakeholders' support, with change management having the greatest effect on stakeholders' support (ES=.18) and the other DISC factors having smaller effects (ES=.02-.08). The amount of variance of sustainable collaboration explained by the DISC factors was $19.2 \%$.

\section{Which collaborative processes predict the implementation of the HSA?}

The importance of the stakeholders' support was also found for the implementation of HSA. Stakeholders' support was the strongest predictor of the implementation of the HSA (ES=.10; Figure 5.3). However, different from the outcome of sustainable collaboration, stakeholders' support only partially mediated the effects of the DISC factors on the execution of the HSA. Change management and project management directly influenced the implementation of the $H S A$, too: change management had a small positive direct influence $(E S=.02)$ on the execution of the HSA activities, whereas project management had a small negative direct effect (ES=.02) on their implementation. The DISC factors explained $26.3 \%$ of the implementation of the HSA. 
Further exploration of the DISC factor project management which includes the subfactors awareness of actors, clear task distribution and communication, showed that the communication subfactor directly and negatively predicted the execution of the HSA activities $(-0.14, p<.10 ; E S=.02)$. Our analysis to find out which of the seven HSA activities was negatively influenced by communication showed a direct negative effect of communication on the execution of health promotion activities $(-0.16, p<.05$; ES:.03).

\section{What are the effects of the DISC-based trajectory on the DISC factors and both outcome measures?}

The DISC-based trajectory positively influenced all DISC factors with the exception of the context factor, which was unaffected. The largest effects were found on stakeholders' support $(\mathrm{ES}=.47)$, project management $(\mathrm{ES}=.44)$ and change management $(\mathrm{ES}=.39)$, followed by effects on the external factors ( $E S=.37$; see Figures 5.3 and 5.4 ). The joint significance test suggests that the effects of the DISC-based trajectory on stakeholders' support were fully mediated by the other DISC factors, with change management being the strongest predictor of stakeholders' support (ES=.18), though the direct impact of the trajectory on stakeholders' support was close to significance $(p=.051)$.

When the DISC factors were not considered as covariates in the analyses, results showed that the overall impact of the DISC-based trajectory on stakeholders' support (ES=.51) and sustainable collaboration (ES=.66) was of medium size. The effects of the trajectory on the implementation of the HSA activities were small $(E S=.34)$ and almost significant $(p<0.10)$.

A summary of the results can be found in Appendix 2 of this dissertation. 
Predictors and mediators of sustainable collaboration and implementation
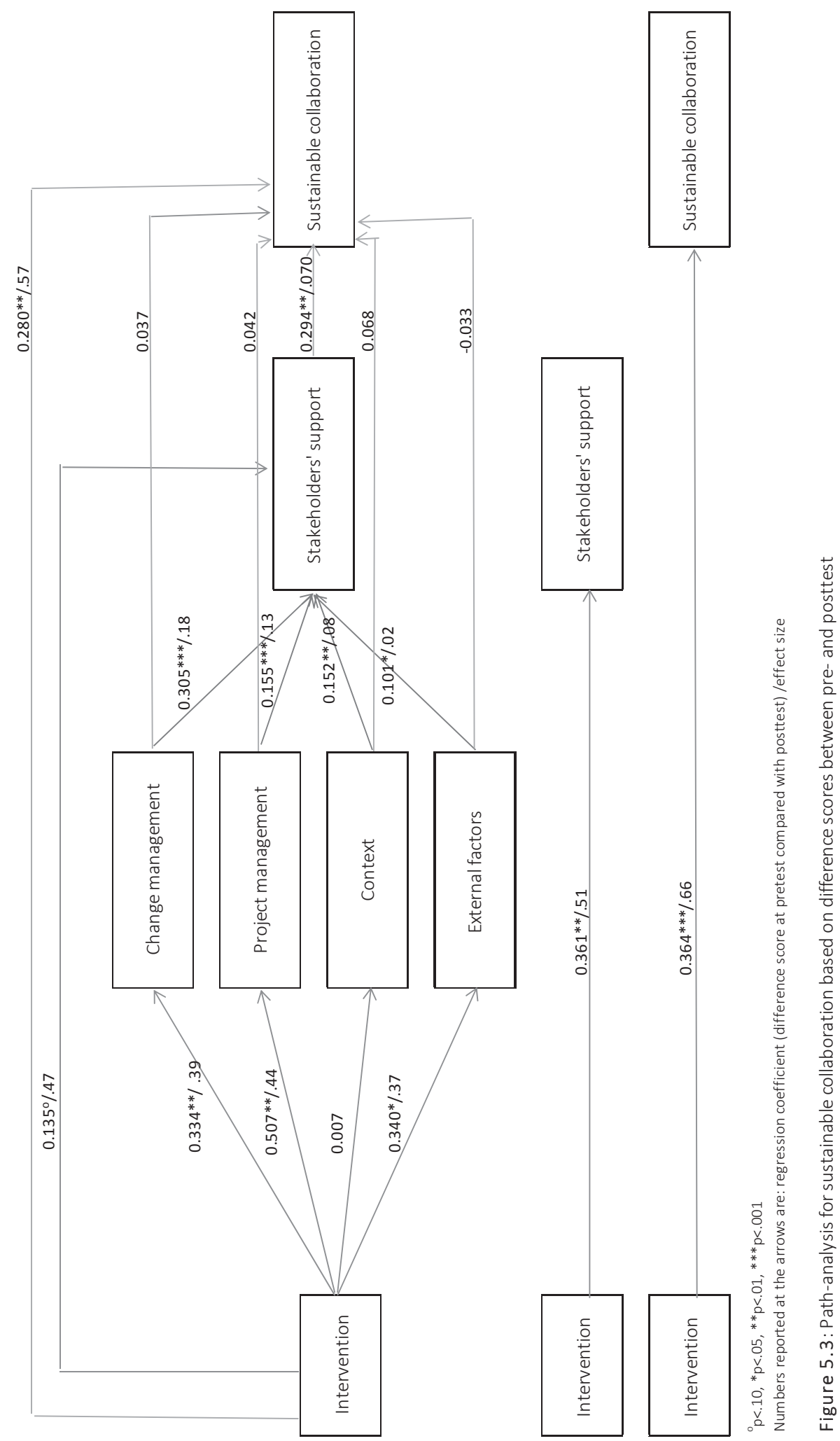


\section{Chapter 5}

5
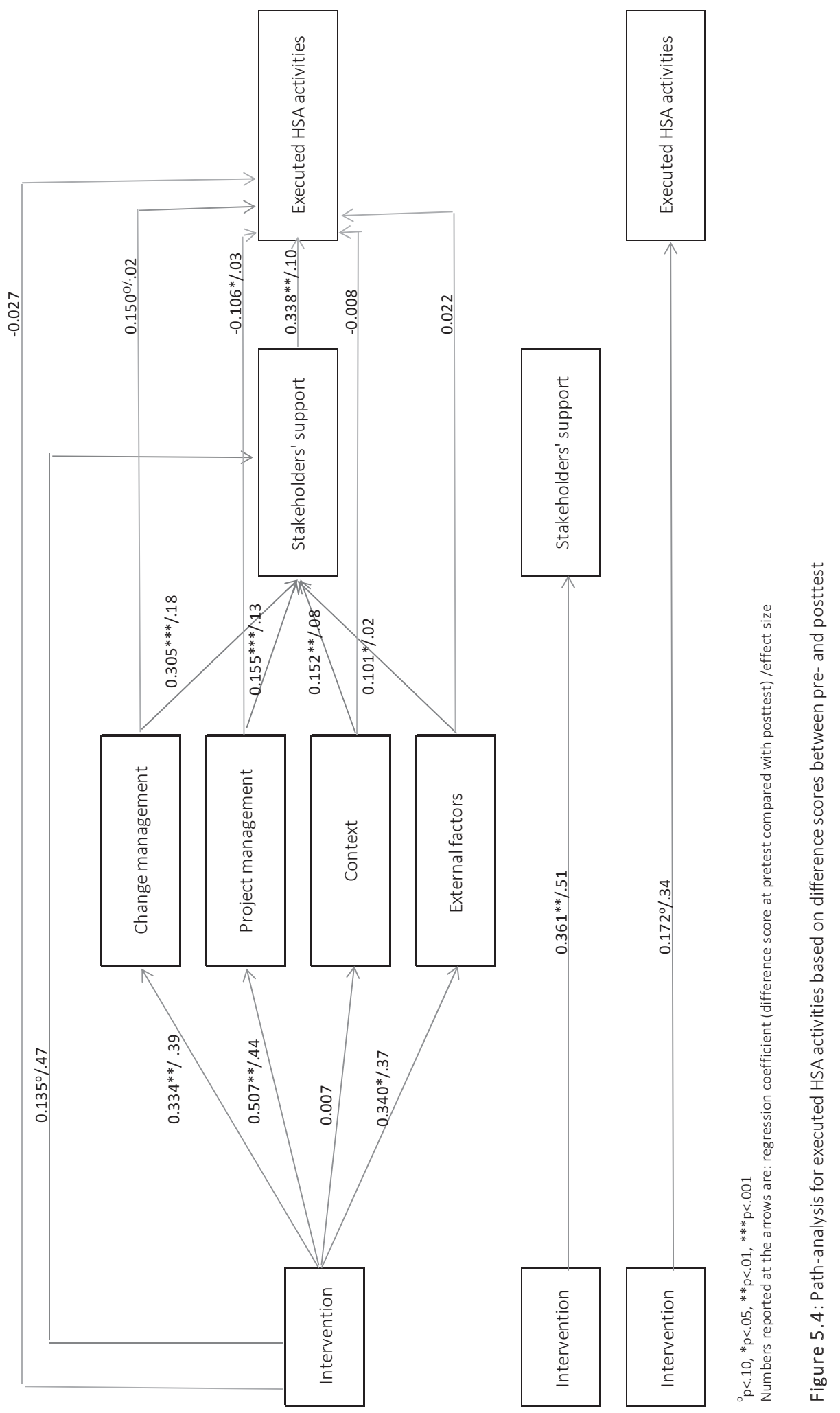


\section{Discussion}

This study attempted to open up the 'black box' of collaborative processes by which sustainable collaboration evolves and CSHP is implemented, using mediation analyses based on the DISC model. It used longitudinal data from the two-year DISC-based trajectory, which targeted the systematic development of intersectoral collaboration in CSHP. The systematic approach included the assessment of facilitating and hindering conditions for collaboration which set the basis for strategic planning. Targets to be accomplished were better change management and project management (DISC-based strategy) to enhance stakeholders' support. Professional support was delivered to attain these targets. Our results show the relevance of the DISC factors for predicting both outcome measures: the sustainability of collaboration and the implementation of HSA activities. Stakeholders' support proved the most important. In addition, the results of the joint significance analyses showed that the influences of the DISC factors were to a large extent mediated by the support factor. These findings demonstrate on the one hand the necessity of stakeholders' support to integrate joint implementation of the HSA into organization policies of relevant parties. On the other hand, these results indicate that a well-functioning collaborative structure, using change management principles and having a favorable organizational (e.g. openness to innovations and positive experience with previous collaborations) and external context (e.g. positive attitudes of financing bodies and supporting health and educational policies) can positively influence this support. These results are consistent with the relationship between the DISC constructs suggested by Leurs et al. (2008) and support the conclusions of other scholars in this area (Boot et al., 2010a; Deschesnes, Couturier, Laberge, \& Campeau, 2010) and other fields (Mur-Veeman \& Van Raak, 1994; Van Raak, Mur-Veeman, Hardy, Steenbergen, \& Paulus, 2003).

For example, Leurs et al. (2010) and Deschesnes et al. (2010) reported that consensual understanding concerning the CSHP goals and the way to disseminate a comprehensive approach to schools has to be developed, between the health sector and the educational sector, to implement CSHP (both, goals and consensus, are subfactors of the stakeholders' support factor). Leurs et al. (2008) also found that competitive feelings (i.e. lack of trust within the stakeholders' support factor) between the stakeholders from different sectors were destructive for sustainability of the collaboration. Others showed that the levels of commitment among stakeholders can be influenced by partnership managers when they cleverly adapt to the stakeholders' circumstances, requiring skillful communication and knowledge about the goals, interest and circumstances of coalition partners (Mur-Veeman \& Van Raak, 1994; Van Raak et al., 2003). In the DISC-based trajectory, stakeholders' support was enhanced by change management targeting the establishment of a common vision, consensual commitment about the HSA concept, and project management tailored to the 
possibilities of involved organizations. How these activities can be realized in practice is described elsewhere (Pucher et al., 2015b).

Further, our study showed that there was a direct link between change management and the implementation of the HSA, showing that employing change management principles (e.g. creating a common vision and employing change strategies to enhance trust, consensus and commitment) had a direct positive influence on the implementation of the HSA. Knowledge and competencies relating to change management are probably necessary to develop and implement the HSA in schools (Boot \& De Vries, 2012; Boot et al., 2010a; Deschesnes et al., 2013a; Flaschberger, Gugglberger, \& Dietscher, 2013; Teutsch, Gugglberger, \& Dür, 2014). Previous studies showed that a lack of professional knowledge to promote change in schools (Boot et al., 2010a; Teutsch et al., 2014) and to create leadership in the school community (Boot \& De Vries, 2012), as well as a limited ability to translate knowledge into innovative practices (Deschesnes et al., 2013a; Flaschberger et al., 2013) form important barriers to the implementation of comprehensive approaches in schools. It is conceivable that the knowledge and skills that coordinators acquired to improve the collaboration during the DISC-based trajectory were also used for the implementation of the HSA at school level.

Nevertheless, despite the positive impact of stakeholders' support and change management, the improvements in the implementation of the HSA at the end of the trajectory were only small and only close to significance. It might be that change management, which basically included negotiation to create a common vision and to gain consensus and commitment (Pucher et al., 2015b), was effective as regards establishing stakeholders' support for the HSA activities, but less effective in terms of getting things done (step 5 of HSA). In fact, our results suggest that ongoing negotiations could have slowed down the implementation of the HSA in schools, since communication (a subfactor of project management) had a negative effect on the implementation of the HSA. Probably final decisions on particular issues were difficult to made due to the context of organizations involved. Collaborating organizations were going through mergers, reorganizations, were affected by the financial crisis and were searching for a new position on the market, which did not allow them to enter into final and long-term agreements about their contributions. In addition, collaborations entered a new public health policy cycle, which caused additional workload. 'Collaborative inertia', which refers to the lack of progress or small successes which require a lot effort, has also been observed in other collaborations (Huxham \& Vangen, 1996, 2000; Vangen \& Huxham, 2003). One possible explanation for collaborative inertia that has been suggested is the desire to obtain full commitment from stakeholders, which can result in endless negotiation. Collaborative advantage (the opposite of collaborative inertia) on the other hand has been related to the acceptance that full commitment might not be possible because of different organizational agendas, and the decision to focus on task 
accomplishment instead. However, the latter approach is perceived as difficult to implement by leaders (e.g. regional coordinators) because these leaders lack formal authority in interorganizational work. Our further study also suggested that regional coordinators preferred not to act in a directive manner when working together with other organizations (Pucher et al., 2015b).

Our study further seems to suggest that the DISC-based trajectory had an important impact on the collaborative process. Compared with the situation at the beginning of the trajectory, where stakeholders' perceptions (e.g. about the HSA goals and win-win situations) had as yet barely been translated into positive intentions (e.g. willingness to implement innovations and changes within the own organization for the HSA) and actions (e.g. actual changes and allocation of personnel and manpower for the HSA), and where change management (e.g. implementation of change strategies) and project management (e.g. a clear communication structure and task distribution) necessary for this transition were only modestly or not developed (Pucher et al., 2015a), the collaboration was characterized three years later by better change management practices and project management structure. The external context for the implementation of the HSA had also improved (e.g. better fit of the HSA with school and health policies). How these improvements relate to the DISC-based trajectory is explained in more detail elsewhere (Pucher et al., 2015b).

\section{Strengths, limitations and implications}

Our attempt to understand collaborative processes responsible for the sustainability of collaboration and the implementation of the HSA in schools seems to confirm that stakeholders' support is necessary for joint implementation of the HSA and the maintenance of joint practices. It also suggests further application of path analyses to discover strategies for intersectoral collaboration in public health. The current results propose that strategies targeting the DISC factors can be used to enhance stakeholders' support in CSHP, which is an important precondition for the sustainability of the collaboration and the implementation of the HSA.

However, several limitations should be considered, such as the specific context of our findings. The collaborative processes are the results of the particular emphasis on the DISC factors of change management and project management in the trajectory. It is therefore not surprising that change management was the most important predictor of stakeholders' support. It is conceivable that interventions based on alternative models and probably with different perspective on sustainable collaboration (such as development of stakeholders' capacity) could reveal other collaborative processes which also generate the desired outcomes. Further, the path analyses were conducted at the level of factors, which in turn are constituted of several indicators. Path analyses at these lower-level indicators (e.g. consensus, commitment, formalization) could provide more insights into the collaborative processes, and 
also into the distinct character of collaboration in CSHP compared to other domains in public health, or the general management literature and theory (Smith Ring \& Van De Ven, 1994; Thomson \& Perry, 2006; Vangen \& Huxham, 2003; Wood \& Gray, 1991). The study sample was too small to generate sufficient statistical power for these analyses, however. Further, due to the small sample size, we were not able to study results per sector, nor partnership. An analysis comparing sectors could reveal that different sectors are sensitive to different strategies. The uneven representation of PHS stakeholders and PSSs in the study may also limit the generalizability of our findings.

In addition, the pretest-posttest design without a control group makes our results vulnerable to maturation bias and history bias, limiting the possibility to draw causal inferences. Our study also suffered from drop-out. We minimized the detrimental effects of drop-out by applying specific analysis techniques (i.e. linear mixed regression models with random intercept) which enabled more reliable estimations and tests of effects compared to analyses based only on complete cases. However, we cannot fully exclude the effects of selective drop-out. Finally, the collaborative agenda may have been affected by selection bias, as regional coordinators identified relevant stakeholders. It might be that the desire to achieve their own organizational goals (e.g. youth health, health promotion) guided their choice. Conducting an objective stakeholder analysis might be valuable in this respect.

To conclude, this study is one of the few which have used longitudinal, quantitative data to study collaborative processes, including the mediating role of stakeholders' support. Despite its limitations, it provides important insights for health professionals involved in establishing a collaborative structure for CSHP and in implementing CSHP. Our findings suggest that strengthening stakeholders' support should be an important task for these health professionals. When the main aim is to establish sustainable collaboration, strategies should aim at effective change management and project management, as well as factors in the wider context (i.e. context, external factors) which can create important opportunities for collaboration. However, health professionals should be reminded that whereas negotiation may be a necessary strategy to get stakeholders' consensus and commitment to enhance stakeholders' support, it could be less effective in terms of getting things done, or at least this is what our study suggests. However, especially as regards the latter, further replication of the findings will be needed before final implications can be formulated for practice. 


\section{References}

Barry, M. M., Battel-Kirk, B., Davison, H., Dempsey, C., Parish, R., Schipperen M., Speller, V., Van der Zanden, G., \& Zilnyk, A. (2012). The CompHP Project Handbooks. International Union for Health Promotion and Education (IUHPE). Paris.

Boot, N. M. W. M., \& De Vries, N. K. (2012). Implementation of school health promotion: consequences for professional assistance. Health Education, 112(5), 436-447.

Boot, N. M. W. M., van Assema, P., Hesdahl, B., \& de Vries, N. K. (2010). Professional assistance in implementing school health policies. Health Education, 110(4), 294-308.

Buijs, G. J. (2005). Werkdocument. De Gezonde School Methode in Nederland. (Work document. The Healthy School Approach in the Netherlands. Woerden: National Instituut voor Gezondheidsbevordering en Ziektepreventie (Netherlands Institute for Health Promotion and Disease Prevention).

Butterfoss, F. D. (2007). Coalitions and Partnerships in Community Health. San Francisco: Jossey-Bass.

Clark, N., Doctor, L., Friedman, A., Lachance, L., Houle, C., Geng, X., \& Grisso, J. (2006). Community coalitions to control chronic disease: Allies against asthma as a model and case study. Health Promotion Practice, 7(2), 13S-22S.

Cohen, J. (1988). Statistical Power Analysis for the Behavioral Sciences (second ed.). New York: Lawrence Erlbaum Associates.

Cohen, J. (1998). Statistical Power Analysis for the Behavioral Sciences second edition. : Lawrence Erlbaum Associates Publishers.

Crowley, K., Yu, P., \& Kaftarian, S. (2000). Prevention actions and activities make a difference: A structural equation model of coalition building. Evaluation and Program Planning, 23(3), 381-388.

Cummings, T. G., \& Worley, C. G. (2001). Organizational Development and Change (7th edition). Mason, Ohio: Southern-Western College Publishing.

Daft, R. L., \& Noe, R. A. (2001). Organizational behavior. Orlando: Hartcourt Inc.

De Caluwé, L., \& Vermaak, H. (2003). Learning to change: Thousand Oaks: Sage Publications.

Deschesnes, M., Couturier, Y., Laberge, S., \& Campeau, L. (2010). How divergent conceptions among health and education stakeholders influence the dissemination of healthy schools in Quebec. Health Promotion International, 25(4), 435-443. doi: 10.1093/heapro/daq040

Deschesnes, M., Drouin, N., \& Couturier, Y. (2013). Schools' absorptive capacity to innovate in health promotion. Journal of Health Organization and Management 27(1), 24-41.

Diamantopoulos, A., \& Winklhofer, H. M. (2001). Index Construction with Formative Indicators: An Alternative to Scale Development. Journal of Marketing Research, 38(2), 269-277. doi: 10.2307/1558630 
Feinberg, M., Greenberg, M., \& Osgood, D. (2004). Readiness, functioning and perceived effectiveness in community prevention coalitions: A study of communities that care. American Journal of Community Psychology, 3/4(33), 163-176.

Flaschberger, E., Gugglberger, L., \& Dietscher, C. (2013). Learning in networks: individual teacher learning versus organizational learning in a regional health-promoting schools network. Health Educ Res, 28(6), 993-1003. doi:10.1093/her/cyt079

Florin, P., Mitchell, R., Stevenson, J., \& Klein, I. (2000). Predicting intermediate outcomes for prevention coalitions: A developmental perspective. Evaluation and Program Planning, 23(3), 341-346.

Hirsch Ballin, E. M. H. (2008). Wet Publieke Gezondheid (Public Health Act). Overheid.nl (Government.nl). Retrieved 14 April 2015, from

http://wetten.overheid.nl/BWBR0024705/geldigheidsdatum_14-04-2015

Huxham, C., \& Vangen, S. (1996). Working together. International Journal of Public Sector Management, 9(7), 5-17. doi: 10.1108/09513559610153863

Huxham, C., \& Vangen, S. (2000). Leadership In The Shaping And Implementation Of Collaboration Agendas: How Things Happen In A (Not Quite) Joined-Up World. Academy of Management Journal, 43(6), 1159-1175. doi: 10.2307/1556343

IUHPE. (2009). Achieving Health Promoting Schools: Guidelines for Promoting Health in Schools. Retrieved 15 January 2015, from http://www.dhhs.tas.gov.au/_data/assets/pdf_file/0011/115895/guidelines_for_heal th_promoting_schools1.pdf.

Kegler, M. C., \& Swan, D. W. (2011a). Advancing coalition theory: the effect of coalition factors on community capacity mediated by member engagement. Health Education Research, 27(4), 572-584. doi: 10.1093/her/cyr083

Kegler, M. C., \& Swan, D. W. (2011b). An initial attempt at operationalizing and testing the Community Coalition Action Theory. Health Education \& Behavior, 38(3), 261-270.

Leurs, M., Jansen, M., Schaalma, H., Mur-Veeman, I., \& De Vries, N. (2005a). The Tailored SchoolBeat-approach: new concepts for health promotion in schools In S. Clift \& B. B. Jensen (Eds.), The Health Promoting School: International Advances in Theory, Evaluation and Practice (pp. 87 - 105). Copenhagen: Danish University of Education Press.

Leurs, M., Mur-Veeman, I., van der Sar, R., Schaalma, H., \& de Vries, N. (2008). Diagnosis of sustainable collaboration in health promotion - a case study. BMC Public Health, 8(382). doi: 10.1186/1471-2458-8-382

Leurs, M., Schaalma, H., Jansen, M., Mur-Veeman, I., St. Leger, L., \& De Vries, N. (2005b). Development of a collaborative model to improve school health promotion in the Netherlands. Health Promotion International, 20, 296 - 305. 
Leurs, M., Steenbakkers, M., \& Jansen, M. (2006). Het schoolSlag-praktijkboek: samen werken aan preventie op maat in het onderwijs (The SchoolBeat manual: working together towards tailored prevention in education). Maastricht: GGD Zuid Limburg.

MacKinnon, D. P., Lockwood, C. M., Hoffman, J. M., West, S. G., \& Sheets, V. (2002). A comparison of methods to test mediation and other intervening variable effects. Psychological Methods, 7(1), 83-104. doi: 10.1037/1082-989X.7.1.83

Mur-Veeman, I., \& Van Raak, A. (1994). Inter-organizational networks on the Dutch home health care market. The International Journal of Health Planning and Management, 9(3), 245-258.

Preacher, K. J., \& Hayes, A. F. (2004). SPSS and SAS procedures for estimating indirect effects in simple mediation models. Behavior Research Methods, Instruments, and Computers, 36, 717-731.

Pucher, K. K., Candel, M. J. J. M., Boot, N. M. W. M., Van Raak, A., \& De Vries, N. K. (2015a). A multiple-case study of intersectoral collaboration in the context of coordinated school health promotion using the Dlagnosis of Sustainable Collaboration (DISC) Model Health Education, 115(3/4), 301-321.

Pucher, K. K., Candel, M. J. J. M., Krumeich, A., Boot, N. M. W. M., \& De Vries, N. K. (2015b). Effectiveness of a systematic approach to promote intersectoral collaboration in comprehensive school health promotion-a multiple-case study using quantitative and qualitative data. BMC Public Health, 15(613), 1-14.

RIVM Centre for Healthy Living. (2010). Handleiding Gezonde School (Healthy School Guide). Bilthoven: National Institute for Public Health and the Environment - Centre for Healthy Living,

Shediac-Rizkallah, M. C., \& Bone, L. R. (1998). Planning for the sustainability of communitybased health programs: conceptual frameworks and future directions for research, practice and policy. Health Education Research, 13(1), 87-108.

Smith Ring, P., \& Van De Ven, A. H. (1994). Developmental processes of cooperative interorganizational relationships. Academy of Management Review, 19(1), 901-118.

Snijders, T., \& Bosker, R. (1999). Multilevel analysis. An introduction to basic and advanced multilevel Modelling. London, New Delphi: Thausand Oaks.

Sridharan, S., \& Gillespie, D. (2004). Sustaining problem-solving capacity in collaborative networks. Criminology \& Public Policy, 3(2), 221-250.

Stahl, T., Wismar, M., Ollila, E., Lahtinen, E., \& Leppo, K. (2006). Health in All Policies. Prospects and potentials. Finland: Ministry of Social Affairs and Health.

Steckler, A., \& Goodman, R. M. (1989). How to institutionalize health promotion programs. American Journal of Health Promotion, 3(4), 34-43. doi: 10.4278/0890-1171-3.4.34 
Stewart-Brown, S. (2006). What is the evidence on school health promotion in improving health or preventing disease and, specifically, what is the effectiveness of the health promoting schools approach?. Copenhagen: WHO Regional Office for Europe.

Teutsch, F., Gugglberger, L., \& Dür, W. (2015). School health promotion providers' roles in practice and theory: Results from a case study. Health Policy, 119(1), 82-87. doi:10.1016/j.healthpol.2014.09.004

Thomson, A. M., \& Perry, J. L. (2006). Collaboration Processes: Inside the Black Box. Public Administration Review, 66(S1), 20-32. doi: 10.1111/j.1540-6210.2006.00663.x

Van Raak, A., Mur-Veeman, I., Hardy, B., Steenbergen, M., \& Paulus, A. (2003). Integrated Care In Europe - Description And Comparison Of Integrated Care In Six EU Countries. Maarssen: Elzevier Gezondheidszorg.

Van Raak, A., Mur-Veeman, I., \& Paulus, A. (1999). Understanding the feasibility of integrated care: a rival viewpoint on the influence of actions and the institutional context. The International Journal of Health Planning and Management, 14(3), 235-248.

Vangen, S., \& Huxham, C. (2003). Enacting Leadership for Collaborative Advantage: Dilemmas of Ideology and Pragmatism in the Activities of Partnership Managers. British Journal of Management, 14, S61-S76.

Warner, M., \& Gould, N. (2009). Integrating Health in All Policies at the Local Level: Using Network Governance to Create 'Virtual Reorganization by Design'. In I. Kickbusch (Ed.), Policy Innovation for Health (pp. 125-163): Springer.

Wood, D. J., \& Gray, B. (1991). Toward a Comprehensive Theory of Collaboration. The Journal of Applied Behavioral Science, 27(2), 139-162. doi: 10.1177/0021886391272001

Yin, R. K. (1979). Changing Urban Bureaucracies: How New Practices Become Routinized. Lenxington, MA: Lenxington Books. 
Chapter 6 General discussion

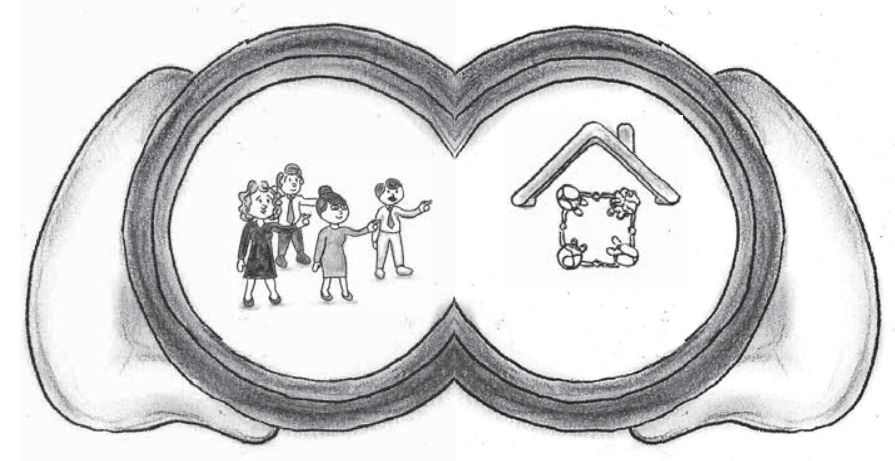



This dissertation has two aims. The first is to evaluate the possible gains of school health promotion for the educational sector. To attain this goal we have conducted a systematic review studying the effects of school health promotion interventions on students' academic performance and possible mediators of this relationship (Part I of the dissertation). The second aim is to report on an investigation of the processes and effects of systematic development of intersectoral collaboration in comprehensive school health promotion (CSHP) in the Netherlands regarding different aspects of the quality of collaboration (Part II of the dissertation). The intersectoral collaboration we studied concerns the joint work of public service stakeholders (PSSs) and funding, policy-making (i.e. municipal authorities) and executing bodies (i.e. public health services (PHSs)). We have conducted a longitudinal pretest-posttest study in six Dutch regions, only five of which participated from the beginning to the end of the study. The study included a survey to assess conditions facilitating and hampering collaboration in CSHP (pretest), the formulation of an appropriate strategy based on the survey results and professional support for the implementation of this strategy. In the course of two years, one year of professional support and one year of follow-up, the collaborative process was monitored by monthly/bimonthly interviews with regional coordinators and by inspecting relevant documents produced by the regions. At the end of the follow-up period, the study was completed with another assessment of the current state of the collaboration, to assess the effects of this systematic approach (posttest). The conceptual framework for this study was provided by the Dlagnosis of Sustainable Collaboration (DISC) model (Leurs et al., 2008). The DISC model categorizes 26 determinants of collaboration into 6 main clusters (change management, project management, collaborative support, context and external factors), all of which were considered in our study. This model formed the basis for the analyses of the condition of the collaborations (pretest and posttest), the recommendations derived from the analyses, and the advisory trajectory.

This general discussion chapter first presents the main findings of our studies and then discusses our considerations regarding these findings. Finally, it discusses implications for research and practice. The discussion chapter is divided into two parts, reflecting the two aims of the dissertation. 



\section{Part I Benefits of health promotion for the educational sector}





\section{Main findings}

The literature on the effects and mediators of school health promotion interventions regarding academic performance was systematically reviewed. Intervention studies were included when they had methodologically sound designs, targeted general school populations, and did not include elements directly related to the school's normal teaching program. Additionally, academic grades had to be used as the outcome measure. Only studies on interventions targeting the maintenance of energy balance in $1-6^{\text {th }}$ graders met the inclusion criteria. The results of our systematic review indicated that school health promotion programs targeting physical activity and nutrition can improve academic performance in American primary and middle school children. School health promotion interventions targeting energy balance (i.e. either nutrition or physical activity, or a combination of both) had small to large effects on performance in various academic domains. Moreover, no negative effects were reported on academic subjects from which time was taken away for the intervention. However, the small number of studies (7), their geographical origin (all were from North America) and the fact that one publication was rather old (dates from 1989) limited the generalizability of the findings. Another limitation was that the studies we reviewed paid too little attention to moderators, such as gender and socioeconomic status (SES), which are known to influence health and academic performance. We were therefore not able to identify group-specific effects. Some groups had probably benefited more from the health promotion interventions than others. The authors did suggest some mediators of the relationship they had studied. Reported mechanisms directly related to physical, neuro-hormonal and cognitive conditions, or included indirect mechanisms related to teaching practices. However, these suggestions were mainly based on hypothetical assumptions partly confirmed by previous studies in experimental settings, so they do not allow final conclusions. Finally, our systematic review addressed whether a comprehensive approach to health promotion in schools could generate even greater effects on students' academic performance than school health promotion programs targeting single health issues. Since only one of the reviewed studies referred to such a comprehensive approach, it was hardly feasible to answer this research question.

Our systematic review provides preliminary, but promising evidence: to produce academic gains, school health promotion interventions do not necessarily have to target children at risk or those with symptoms, nor include elements directly related to school subjects. Health promotion interventions targeting the general school population can enhance children's academic success. The evidence found in our review probably provides additional arguments to implement health promotion in the educational sector.

\section{Methodological and practical considerations}

This section discusses the inclusion criteria for our review and compares the results of the systematic review with those of later empirical studies, which investigated more or less the same relationship between school health promotion and academic performance (Busch et al., 2014; Dadaczynski, 2012; Langford et al., 2014). These studies generally support our findings and implications. Implications are formulated for future practice and research. 


\section{Strict versus lenient inclusion criteria}

Where earlier reviews were comprehensive in the presentation of the available literature on the relationship between school-based interventions and academic performance (DeSocio \& Hootman, 2004; Greenberg et al., 2003a; Trudeau \& Shephard, 2008; Zins et al., 2004), they were also lenient in their inclusion criteria. These reviews included some studies with weak methodology (e.g. cross-sectional) and a wide variety of outcome measures (e.g. abstinence rates, school performance), and some focused on groups with evident symptoms or at-risk groups. Additionally, some reviews included interventions linked to normal learning and teaching (e.g. teaching practices supporting learning). The broad inclusion criteria limited the possibility to compare intervention effects, as well as the possibility to infer causal relationships concerning school-based interventions and academic performance, and the generalizability of intervention effects to general populations. Nevertheless they present valuable evidence suggesting a positive relationship between school-based interventions and academic performance. Our systematic review used strict inclusion criteria, in order to include only the most valuable evidence for the educational sector. We only included studies with methodologically sound designs (randomized controlled trials, quasi-experimental designs with pretest-posttest designs, and cross-over controlled trials) to increase our ability to draw causal inferences. We focused on the effects on academic grades, as they are obviously the most persuasive argument for the educational sector. We also optimized the construct validity of the outcome measure by including only standardized academic grades (e.g. grade-point averages (GPA) or end of year marks) as outcome measure, but excluding determinants of academic performance (such as school attachment, school satisfaction, school climate, and cognitive performance) and cognitive tests as outcomes. Finally, our strict inclusion criteria implied that we addressed the general school population and omitted health promotion interventions with an obvious link to normal learning and teaching. This enabled us to partly exclude some third variables (moderators and mediators) that may obscure the relation between school health promotion interventions and academic performance, such as specific symptoms, risk factors, teaching practices, etc. Using these strict criteria ensured that we only assessed the specific effects of general health promotion interventions on standardized measures of academic performance. We found that general school health promotion interventions could lead to improved academic success among school-aged children. These specific effects offer opportunities for generalization. It is reasonable to assume that when a positive relation between school-based interventions and academic performance was found in general health domains, the positive relation will even be stronger for health promotion interventions including elements with an obvious relation to normal learning and teaching, or targeting children at risk or with evident symptoms.

Overall, our findings support the results of previous reviews (DeSocio \& Hootman, 2004; Greenberg et al., 2003a; Trudeau \& Shephard, 2008; Zins et al., 2004) and find further 
confirmation in later empirical studies (Busch et al., 2014; Dadaczynski, 2012; Langford et al., 2014), which are discussed in the following paragraphs.

\section{Effects of school-based interventions and (un)healthy lifestyles on academic performance}

Our review showed that school health promotion interventions targeting physical activity, nutrition, or a combination of both had small to large effects on performance in varying academic domains. Review studies that were published since have further supported this finding. Busch et al. (2014) studied the relationship between health behaviors and academic performance (i.e. academic grades) in many different health domains, including alcohol and marijuana use, smoking, nutrition, physical activity, sexual intercourse, bullying, and screen time exposure (television, internet and video games). Dadaczynski et al. (2012) also reviewed international studies with regard to the same relationship. In addition to academic performance itself, Dadaczynski et al. (2012) also included some determinants of academic performance (absenteeism, graduation from higher education) as outcome variables, but focused only on studies in three domains: nutrition, physical activity, and mental health. Langford et al. (2014) conducted a Cochrane review in which they focused on the effects of CSHP on academic performance and its determinants. Besides educational outcomes, Langford et al. (2014) were also interested in the effects of CSHP on students' well-being and health status, and like Busch et al. (2014), they studied a broad range of health behaviors. Busch et al. (2014) mainly, and Dadaczynski et al. (2012) exclusively, included prospective and retrospective cohort studies. Dadaczynski et al. (2012) found that overweight, obesity, and reduced physical activity had a negative impact over time on school grades and some determinants of academic performance. In addition, physical fitness and intensive physical activity five or more times a week had positive impacts on school grades. Busch et al. (2014) reported that healthy nutrition and team sports favorably influenced academic grades. The reviews by Busch et al. (2014) and Dadaczynski et al. (2012) provide additional support for a positive relationship between energy-balance related behaviors and academic performance, suggesting that interventions targeting those behaviors can also have effects on academic performance. Langford et al. (2014) included only cluster-randomized trials, which are regarded as the most reliable form of evidence for effects of CSHP interventions (Green et al., 2011). They did not identify new studies evaluating the effects of a comprehensive approach on academic grades matching the criteria of our review. However, they reported that other interventions than those targeting energy balance also impact on academic performance and related determinants, referring to studies on interventions targeting social-emotional wellbeing, multiple risks, bullying, and violence. Some of these convincingly show positive effects on educational measures (Beets et al., 2008; Bond et al., 2004; Kärnä et al., 2013; Li et al., 2011; Sawyer et al., 2010). Those studies were excluded from the systematic review presented in this dissertation, either because of the outcome measure (i.e. determinants of 
academic performance) or the direct link with children's learning abilities and teachers' teaching practices. The review by Langford et al. (2014) increases the awareness that interventions targeting other health behaviors and behavioral problems can also be beneficial for the educational sector.

Concluding, although recent reviews indirectly confirm the findings of the review presented in this dissertation, there have not yet been enough studies investigating the effects of school-based interventions (whether employed as part of a broad or a limited approach) on academic performance. This gap should definitely be addressed in future research.

\section{Moderators of the effects of school-based interventions and (un)healthy lifestyles on academic performance}

In line with our own conclusions, the three recent reviews (Busch et al., 2014; Dadaczynski, 2012; Langford et al., 2014) suggest that some third variables (e.g. gender and SES) influence the relationship. An important limitation of our own review was that only a minority of the included studies reported on these variables. Only three of the studies we reviewed assessed a possible gender-program interaction, one of which, a physical activity intervention, found that girls improved their academic performance more than boys (Shephard, 1996). None of the intervention studies in our review analyzed effects for different SES groups. On the other hand, several studies reported in Dadaczynski et al. (2012) investigated the effects on educational outcomes for different SES and gender groups. For instance, they found an inverse relationship between overweight/obesity and academic performance for girls, but not for boys (Crosnoe, 2007; Datar \& Sturm, 2006; Sabia, 2007) and reported a stronger relationship between physical fitness/physical activity and academic performance for girls than for boys (Carlson et al., 2008; London \& Castrechini, 2011). As regards moderation by SES, high SES was reported to function as a buffer in the relationship between physical fitness and academic performance: children with a high SES background did better in terms of educational outcomes despite being less physically fit than children from low SES backgrounds (Carlson et al., 2008). Busch et al. (2014) also reported that study outcomes related to energy balance were affected by third variables, including SES and gender. In the review by Langford et al. (2014), none of the CSHP intervention studies that assessed educational outcomes analyzed data for different SES groups.

Because of the striking evidence with regard to SES and gender presented in Busch et al. (2014) and Dadaczynski et al. (2012), but also the disappointingly high number of studies still not considering these measures (Langford et al., 2014), it is important to assess these variables in future research. The magnitude of effects of school-based interventions on educational outcomes could vary across children from different SES backgrounds and 
between girls and boys. Reliable conclusions about possible effects would be enhanced by considering these moderators in the analyses.

\section{Mediators of the effects of school-based interventions and (un)healthy lifestyles on academic performance}

The mechanisms suggested in the studies in our review were mainly based on hypothetical assumptions partly confirmed in previous studies. Suggested mediators of the relation between school-based interventions and educational outcomes included physiological, neurohormonal and cognitive conditions, such as students 'psychomotor skills, arousal levels, selfesteem, and nutrition balance. In addition, teachers' competencies and self-esteem, which can impact teaching practices, were suggested as indirect mechanisms. Dadaczynski et al. (2012) and Busch et al. (2012) identified additional mechanisms that could mediate the effects of health behaviors on educational outcomes, which also may offer relevant explanations for the effects we observed from our school-based intervention. Some cohort studies in Busch et al. (2014) suggest that socialization aspects mediated the effects of participation in team sports and school sports on academic performance. These studies found positive effects on academic performance of participation in group sports, whereas individual sports did not show these effects and were even associated with poorer school grades. The authors hypothesized that exercising could have negatively affected academic performance by taking up time that could be spent on learning, while the socialization aspect of groups sport may compensate for these negative effects. Suggested socialization aspects are: the bond with school personnel, increased social status, entry into elite groups and raised aspirations for entering university (Crosnoe, 2002; McNulty Eitle \& Eitle, 2002). Studies in our own review also found positive effects on academic performance, despite time being taken away from regular subjects to carry out the intervention. Socialization aspects may have functioned as a mediator here as well. Dadaczynski et al. (2012) also found support for 'school bonding' as a working mechanism. In addition, some studies included in the review by Busch et al. (2014) reported that a number of social factors, e.g. expectations about school achievement and its meaning for the future, a supportive family environment, and perceived norms, mediated the relationship between health behaviors and academic performance. Although the social factors were found to be important mediators specifically in studies targeting the health behaviors of sexual intercourse, smoking, and alcohol use, it could be that the same are relevant for studies promoting energy balance (Datar et al., 2004).

The additional mechanisms suggested in both of these reviews strongly support the effects of students' immediate environment (e.g. family, friends, and parents) on health promotion activities. The healthy school ethos which is characterized by strong engagement of students, parents, and staff is a crucial element of CSHP. Consequently, school-based 
interventions provided in the context of a broader framework like the CSHP could contribute to healthy socialization and thereby increase scholastic success.

\section{Comprehensive approach versus single issue approach}

Although it seems a reasonable assumption, the nature of the interventions included in our review prevented us from finding out whether CSHP offers added value in terms of educational outcomes (e.g. on mathematics or language) compared to a limited approach to school health promotion (i.e. targeting only one or two components of the CSHP framework). Only one of the studies in our review explicitly examined the effects of such a comprehensive framework (Ahamed et al., 2007). This study compared a comprehensive framework to promote physical activity with schools that continued their existing practice. No effects were found for this intervention, but it had no negative effects on academic performance either, even though the daily 15 minutes of physical activity were provided at the expense of regular school subjects. Stronger effects of interventions embedded in a holistic approach compared to limited approaches seem plausible, due to the integration of multiple components in CSHP, each with its unique contribution to health and cognitive performance. In addition it is plausible that the effects of individual elements reinforce each other (see also Figure 1.1 of this dissertation). In their Cochrane review, Langford et al. (2014) confirmed that only a small number of studies $(n=11)$ had assessed the effects of CSHP on outcomes related to academic performance (Beets et al., 2008; Bond et al., 2004; Bowen et al., 2007; Fekkes, Pijpers, \& Verloove-Vanhorick, 2006; Kärnä et al., 2013; Li et al., 2011; McVey, Tweed, \& Blackmore, 2004; Sahota et al., 2001; Sawyer et al., 2010; Simons-Morton, Haynie, Saylor, Crump, \& Chen, 2005; Talaat et al., 2011). Most of them compared a broad framework with schools that implemented no intervention or that continued with their existing practice. Only two of these had assessed the effects on academic grades (Beets et al., 2008; Li et al., 2011). Most of the CSHP studies included social-emotional learning elements (Beets et al., 2008; Bond et al., 2004; Bowen et al., 2007; Li et al., 2011; Sawyer et al., 2010; Simons-Morton et al., 2005). Although we chose to exclude these studies because of their direct link with the normal teaching and learning program, it is only in this domain that an indirect comparison between a limited and comprehensive approach seems feasible at the moment, and only when the outcome measure is extended to include the determinants of academic performance (such as school climate, well-being at school, teachers' perception of students' satisfaction, motivation and performance, attendance data).

In the future, comparison studies are needed to find out whether the educational sector can benefit more in terms of educational outcomes from comprehensive approaches to school health promotion than from single issue interventions. 


\section{Implications for future practice}

The above synthesis of the most recent evidence confirms the implications for future practice and future research that were formulated in our review. The evidence calls for more evaluation studies including academic outcomes and related measures in evaluation protocols. Program effects and processes are not usually evaluated in the Netherlands. It seems that school staff, school management, health promoting school advisors and providers of school-based programs can play a crucial role in such evaluations. To this end, they first need to be made aware of the importance of these measures, why they are meaningful to them, and how they could use them to meet their own goals. Second, they should recognize the crucial role they can play in the collection of these data. School managers could see it as their responsibility that every health promotion program which is implemented in their schools is also evaluated in terms of health effects and effects on academic success. Together with the school staff they could ensure access to and utilization of the relevant data for evaluation, either by school staff themselves or external evaluators.

In the past, Dutch schools have been inundated with health promotion programs, and they often found it difficult to make choices concerning the implementation of particular programs (Boot et al., 2010a). The inundation in the past and related problems could additionally motivate schools to conduct independent evaluations of school-based programs. Such evaluations would enhance schools' capacity to independently (without support of external institutions) decide whether to implement certain programs or not. Professional assistance could be organized to provide schools with the knowledge and skills necessary for program evaluation (Deschesnes et al., 2013b). When a school is assisted by a 'health promoting school advisor', this advisor could play a crucial role in this respect. An additional task of this advisor would be to ensure continuity of program evaluation, by having the evaluation protocol included in the school health plan, which is a fundamental part of the Dutch version of the CSHP. For schools not assisted by a 'health promoting school advisor', it would be important that providers of school-based programs use intervention evaluation protocols which contain academic performance as an outcome measure.

\section{Implications for future research}

The evidence presented in the above synthesis also reminds us of the gaps that remain to be filled by future research. In line with more recent work by Langford et al. (2014), it indicates that the effects of school-based health promotion interventions on academic performance are under-investigated especially in European and OECD countries. Studies in different contexts might produce different outcomes, for instance due to different educational systems. Similarly, more well-designed studies are needed comparing school-based interventions embedded in a comprehensive approach (such as CSHP) with those targeting 
single behaviors. CSHP has been endorsed by the WHO as an effective strategy for school health promotion. Evidence supporting the added value of CSHP over limited approaches with respect to academic performance could enhance the implementation of CSHP. Perhaps existing cohort data collected on a regular basis could also be used for this purpose. Such (anonymized) data may be easier to obtain for research studies (Langford et al., 2014). This type of data on school health promotion and its effects on health is being collected in the Health Behavior in School-Aged Children (HBSC) initiative. Comparable datasets may exist for academic outcomes, for instance the Programme for International Student Assessment (PISA). Any opportunity to integrate both assessments for a sample of schools could be considered. The use of international data could overcome the limitations due to the small number of schools working with CSHP and the different subcategories of programs generally used to compare intervention effects (e.g. physical activity programs, nutrition programs, programs combining physical activity and nutrition). The HBSC and PISA data are both being collected internationally.

Another issue that deserves particular attention in future research is the synthesis of evidence on the effects of school-based intervention on academic performance in children from different SES backgrounds and in girls and boys. Therefore, gender and SES interactions should be considered in the future. Attention should also be paid to other common determinants of health and education, such as geographical locations, friends' habits, and health and education related policies (Resnick et al., 1997). Insights into the mechanisms mediating the effects of health behaviors and school-based interventions are also valuable and should be more extensively investigated.

Another question that needs to be raised is which methodologies should be used for these evaluations. Evaluation approaches have been subject to debate in the field of health promotion. In 1998 the World Health Organization (WHO) concluded that the use of randomized control trials to evaluate health promotion initiatives is in most cases inappropriate, misleading and unnecessarily expensive' (WHO Regional Office for Europe, 1998). However, in the review by Langford et al. (2014), which was coauthored by the WHO, the use of a randomized (or cluster-randomized) controlled trial was an inclusion criterion. This ambiguity raises new questions instead of providing direction for future research. The complexity of the relations between different intervention components (e.g. those targeting different health domains) focusing on different target groups (e.g. teachers, parents, community), as given in CSHP, may require a creative combination of methodologies to assess intervention effects. Maybe the most suitable approaches to study the effects of schoolbased programs are not only quasi-experimental designs, but also best-case versus worst-case scenarios (Boot \& De Vries, 2012) and mixed methods approaches, combining several types of data (e.g. process and effect data) and data collection methods (Pommier et al., 2010). 
Part II

A systematic approach to the establishment of intersectoral collaboration in CSHP 



\section{Main findings}

The second aim of the current dissertation was to support health professionals in the systematic establishment of intersectoral collaboration for comprehensive school health promotion (CSHP) among schools, public service stakeholders (PSSs) and funding, policymaking (i.e. municipal authorities) and executing bodies (i.e. public health service (PHSs)). For this purpose, a two-year advisory trajectory was developed and implemented in six PHS regions (five of which completed the trajectory). The trajectory included diagnosing the state of the collaborations, formulating recommendations to improve the collaborations based on the results of the diagnosis, and professional support for the implementation of the recommendations. The trajectory was specifically designed for the regional CHSP

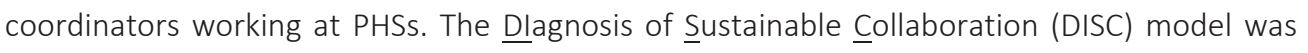
used as a conceptual framework for the trajectory. The DISC model categorizes the determinants of collaboration into six clusters: stakeholders' collaborative support, project management, change management, context, external factors, and sustainable collaboration. At the same time, the model served as an evaluation framework to study the effects of the systematic approach and related collaborative processes.

The first step of the trajectory involved diagnosing the state of the collaborations (Chapter 3), using the DISC survey. The results of the survey identified the facilitators and barriers perceived by the stakeholders at the beginning of the trajectory. The results showed that all five collaborations were in their initial stage, experiencing the same facilitators and barriers, despite their different regional characteristics (e.g. size of catchment area) and starting conditions (e.g. level of collaboration already in place). The stakeholders from the five collaborations indicated having favorable perceptions of CSHP, but reported less positive intentions and even fewer actions to establish collaboration. They reported an overall favorable internal and external context for the implementation of CSHP, but also many existing bureaucratic procedures and high aspirations for their own organizational goals. Change management and project management were rarely applied. The similarities between regions in the DISC results were explained by the group dynamics involved in the early stage of the collaborations. The DISC results also showed some differences in facilitators and barriers across sectors. The coordinating organizations (i.e. the PHSs) reported the greatest support for collaboration, followed by PSSs and schools, while the funding bodies (i.e. municipal authorities) reported the least support. The differences between sectors were explained by the different roles they fulfilled in the newly established partnership. PHSs were taking the lead, which undoubtedly resulted from their coordinating role. PSSs displayed a reactive rather than proactive attitude, which is typical at the formation stage. Schools were enthusiastic about CSHP, but not able to translate their enthusiasm into practice. The role of 
the municipal authorities was limited to funding the CSHP; apart from that they were hardly involved in the collaborative process.

In the follow-up to the trajectory, the results of the DISC survey and initial recommendations to improve collaboration were fed back to the regional coordinators, followed by the formulation of a clear DISC-based strategy. This strategy advised regional coordinators to establish stronger change management and project management, in order to increase stakeholders' collaborative support. The DISC-based strategy included the following activities: (1) bringing different stakeholders together, (2) developing a common vison, (3) identifying the possibilities and impossibilities for each collaborating partner based on the DISC analysis, (4) determining the intended collaborative structure, (5) developing a task distribution based on the information, and (6) discussing the choices at the management and executive levels. The DISC-based strategy specifically had to target representatives of the PHSs and PSSs, since regional coordinators independently indicated that positioning CSHP in their own organization and with PSSs should get priority. Regional coordinators were supported in the implementation of the strategy for one year. During this year, and an additional year of follow-up, the collaborative process was monitored (through monthly/bimonthly interviews with regional coordinators and documents). After the followup period, a new diagnostic evaluation of the collaboration was performed, which, together with the baseline assessment, was used for the purpose of effect evaluation.

The longitudinal data from the DISC surveys and the monitoring was used to evaluate the effectiveness of the DISC-based trajectory and related collaborative processes, and their results were reported in a paper (Chapter 4). The monitoring data showed that the regional coordinators had employed a great variety of managerial activities to translate the DISC-based strategy into practice. These activities included processes and instruments which aimed to (1) involve stakeholders in the decision-making process regarding CSHP, (2) inform potential close and distant stakeholders about CSHP-related activities, (3) control and (4) support the collaborative process as soon as it entered the performance stage, and (5) coordinate collaborative activities, including the integration of information and formalization of decisions made (also referred to as the five managerial styles). The longitudinal survey data showed that the change management and project management of the collaborations had considerably improved. In addition, we found increased stakeholder support for collaboration, including greater consensus and commitment to CSHP among stakeholders and greater degrees of formalization of CSHP within stakeholders' organizations. Moreover, the alignment of relevant policies (i.e. health policy, educational policy, and CSHP) had increased. Apart from the gains in the extent of formalization of the collaboration, however, no other collaborative actions were found. Presenting both types of results in one paper helped us to understand whether a systematic approach favorably influenced intersectoral collaboration for CSHP. The triangulation of the data confirmed the effectiveness of the systematic 
approach. We explained the limited improvements on collaborative actions from the dynamic context in which the collaborations operated, which was characterized by mergers and reorganizations of the institutions involved and the start of a new public health policy cycle. On the one hand, these developments may have delayed the collaborative process, but they also created windows of opportunity for collaboration, such as the establishment of more favorable agreements between municipal authorities and PHSs (and PSSs) on demand-driven practices.

The above findings were further supported by the study of predictors and mediators of sustainable collaboration and the implementation of CSHP (Chapter 5). Path analyses were conducted on the relations between the DISC-based trajectory, the DISC constructs and the desirable outcomes, viz. the implementation of CSHP and sustainable collaboration. These analyses were based on the longitudinal data from the DISC surveys, and supported the view that change management and project management, as well as the context and external factors, had favorably influenced stakeholder support. In addition, a positive relation was found between the DISC-based trajectory and the DISC factors. Besides supporting previous findings, this study also yielded insights into the collaborative process predicting sustainable collaboration and the implementation of CHSP. Path analyses showed that stakeholder support (i.e. stakeholders' perceptions, intentions, and actions towards the collaboration) was the strongest predictor of both outcome measures. Moreover, joint significance tests showed that the influences of the other DISC factors (change management, project management, external factors, and context) were to a large extent mediated by the support factor. When sustainable collaboration was used as the outcome measure, the effects of the other DISC factors (i.e. context, external factors, change management, project management) were fully mediated by the support factor. When the implementation of CSHP was used as the outcome measure, the effects of the DISC factors were partially mediated. Next to collaborative support, change management also directly and positively influenced the implementation of CSHP. By contrast, project management, especially the communication factor, negatively predicted the implementation of CSHP activities. The direct effects were explained by the fact that organizational knowledge is important for the implementation of organizational innovations, but because of the focus of change management on negotiation (i.e. communication) to create consensus and gain commitment, it is probably less effective as regards getting things done. The negative impact of communication even suggested that communication may have slowed down the implementation of CSHP.

The implications for practice were that strategies targeting the DISC factors can directly and indirectly provide collaborative support and thereby promote sustainable collaboration and the implementation of CSHP. We feel that our findings still need to be replicated in future studies, firstly because the finding of a negative impact of communication is surprising, and secondly because our pretest-posttest design lacked a control group. Causal 
inferences about predictors and mediators may be prone to several biases and should therefore be drawn with caution. Nevertheless, it should be noted that the findings from the previous study (Chapter 4) pointed in the same direction, namely, that a systematic approach based on the DISC model enhanced intersectoral collaboration for CSHP.

\section{Methodological considerations and implications}

A major strength of our studies was the process of inquiry. The action research approach allowed us to support health professionals in the systematic establishment of intersectoral collaboration contingent upon the situations that arose in practice. However, the inquiry process was also limited by aspects of study design, the sample size, drop-out, measurement instrument, and conceptual framework. These aspects are further discussed in this section, and implications are formulated.

\section{Process of inquiry}

As part of the inquiry process, the regional coordinator and the main advisor in the trajectory jointly progressed through the action research steps of observe/collect, reflect/review, plan and act (explained in Chapter 1). The action research approach offered several benefits for the attainment of the scientific and instrumental aims of the project (i.e. evaluating the effectiveness and collaborative processes of the systematic approach based on the DISC model and supporting health professionals in the implementation of the systematic approach). First, the inquiry generated process data collected on a regular basis (i.e. monthly in the first year and bimonthly in the second year), which had otherwise been difficult to obtain for research purposes. With these process data, we were able to interpret the quantitative results and obtain valuable insights into collaborative processes (e.g. how to create consensual commitment and organize a project management structure), which have so far been rather under-investigated (Thomson \& Perry, 2006; Wood \& Gray, 1991). Second, the iterative processes used in the approach gave us sufficient flexibility to meet the instrumental goal. It allowed us to respond to individual factors, organizational factors and factors in the wider context, which spontaneously evolved in the organizations and collaborations (Chapters 3, 4, and 5). This would not have been possible in a ready-made intervention in which the set of factors to be addressed and the strategies to be used are fixed beforehand. Third, frequent contacts enabled the main advisor in the trajectory to develop a relationship of trust with the regional coordinators, which was important for the acceptance of professional support (Boot et al., 2010a). At the end of the trajectory, regional coordinators had completed a brief evaluation of the DISC-based trajectory. Although trust was not measured directly, all coordinators indicated that they appreciated the advisory aspect. The willingness of regional coordinators to share perceptions seems to point to the 
existence of such relationships of trust between the regional coordinators and the main advisor in the trajectory.

\section{Study design}

The quantitative findings from our study derive from a pretest-posttest design without a control group. This design limited the possibility to draw causal inferences, due to a range of biases (Campbell \& Stanley, 1963; Isaac \& Michael, 1995). For instance, quantitative results may have been affected by history bias, which was introduced by the support manual for health professionals working with CSHP, which was edited in the early months of 2010 (RIVM Centre for Healthy Living, 2010). A randomized controlled trial (RCT) is a superior design which can enhance internal validity in evaluation studies (Campbell \& Stanley, 1963). However, such a design is hard to realize in the domain of intersectoral collaboration for several reasons (El Ansari et al., 2001; Roussos \& Fawcett, 2000; WHO, 2001). First of all, it can be extremely difficult to find an appropriate control group, due the diversity of partnerships and their contexts. Although randomization could avoid confounding introduced by group diversity, this can also be difficult to realize, as most participants prefer to be included in the intervention group, although a delayed or different intervention could be a good alternative. But even if an appropriate control group is found, a large sample size would be needed to avoid confounding in the randomization. Such a large sample size is difficult to obtain in partnerships which involve only a small number of stakeholders, such as in CSHP. In any case, the rapid movement and spread of ideas and information would make it difficult to protect against contamination between groups, especially in national programs like CSHP.

Alternative designs have been proposed to circumvent these limitations (Campbell \& Stanley, 1963; El Ansari et al., 2001; Roussos \& Fawcett, 2000), including designs using multiple methods and data sources, as was indeed done in our study. The benefits of such a mixed approach, compared to research using only one data source or method, have been acknowledged in inquiries of health promoting schools (Pommier et al., 2010) and studies of collaboration in public health (El Ansari et al., 2001). Choosing the methods and data sources carefully can lead to considerable levels of internal validity through triangulation (Pawson \& Tilley, 1997; Yin, 2009). However, despite the triangulation of our quantitative findings with qualitative results (Chapter 4) and further efforts to support this with results from the path analyses (Chapter 5), the fit between data sources and methods could have been better. This would have enhanced the internal validity of the findings on the causal relation between the DISC-based trajectory and the improvements observed. For instance, one of our studies used different frameworks for the two data sources, which had to do with the instrumental and research purposes of the study (Chapter 4). The qualitative data on the collaborative process were collected using a standard interview protocol including questions such as 'Which activities have been conducted for the purpose of collaboration?' and 'Which activities are 
planned for the purpose of collaboration?', and primarily served the instrumental goal (i.e. supporting health professionals in the implementation of the systematic approach). We used the DISC model as an evaluation framework to quantify the improvements in the collaborations for our research. The different frameworks used for data collection made the link between the findings coming from the two sources merely indicative, rather than absolute. Interviewing the target group about the impacts of the trajectory on the factors of the evaluation framework used for quantitative data collection could have strengthened the link between the data sources, and thereby the internal validity of our findings. In addition, the study of predictors and mediators supported the relations between the DISC-based trajectory and the observed improvements (Chapter 5). Here too, however, the coherence between the methods used could have been better. We conducted path analyses at the level of DISC constructs (e.g. collaborative support, change management), whereas the data derived from the study combining qualitative and quantitative results provided knowledge about the lower-level DISC factors (e.g. consensus, commitment, formalization). Path analyses at this lower level could have allowed a more direct link between the results from the two studies, and would have enhanced the internal validity of our findings. It was not possible to conduct these analyses due to lack of statistical power, caused by the small sample size of our study.

Concluding, despite the above-mentioned limitations, we were able to achieve a considerable degree of internal validity in our study by using a mixed methods approach. This approach seems to offer a valuable alternative to RCTs, which are difficult to realize in studies of intersectoral collaboration.

\section{Sample size}

We were not able to evaluate the effectiveness of the systematic approach (Chapter 4) and related processes (Chapter 5 ) per partnership or per sector. The sample size comprised too few stakeholders (pretest: $n=90$; posttest: $n=69$ ) to generate sufficient statistical power. In addition, since not all sectors were represented in the partnerships, we were not able to assess whether facilitators and barriers differed between sectors in the same way for each partnership (i.e. to examine the region-sector interaction; Chapter 3). Future research should study multiple partnerships, in which all sectors are represented by a sufficient number of stakeholders. Only then will it be possible to find out whether some partnerships are doing better than others and why, and which processes predict the success in different sectors. Another possibility to increase the sample size is to dedicate more time to the stakeholder analysis, advocacy of CSHP, and lobbying by relevant actors at the very beginning of the collaboration, in order to identify relevant decision-makers in each sector and to raise their interest in collaboration. In both cases, multi-level analyses will also be required to handle the 
hierarchical structure of the design, to accommodate possible dependencies between data resulting from stakeholders within the same partnership.

\section{Drop-out}

Of the total of 158 stakeholders who were approached at pretest and 132 stakeholders at posttest, 90 (a response of 57\%) and 69 (52\%), respectively, were included in the analyses. There were various reasons for dropping out, such as changes in organizational tasks of collaborating parties in response to mergers, reorganizations, governmental cutbacks and changing health policies. Also, goals became more specific as collaboration progressed, which led to a poorer fit between the stakeholders' own organizational agenda and the collaborative agenda (Chapter 4). We used statistical techniques which prevented detrimental losses of respondents because of drop-out. Linear mixed regression models with a random intercept enabled us to include in the analyses both respondents with complete data and those who participated at pretest or posttest only (Chapters 4 and 5). The random intercept model allows for a more reliable estimation of the general trend than an analysis based only on complete cases. This technique can be recommended for pretest-posttest studies of partnerships suffering from high drop-out rates. Furthermore, it is possible that informative drop-out (Schafer \& Graham, 2002) occurred, which probably led to an overestimation of the intervention effects. One of the reasons mentioned for drop-out points to this. Stakeholders left the collaboration when the collaborative agenda came to include fewer reference points for the goals of their own organization. These stakeholders would probably have rated the collaboration less favorably than those who remained involved. In future studies, informative drop-out can be prevented by ensuring data collection among stakeholders who decide to leave the collaboration.

\section{Measurement instrument}

The DISC-based questionnaire assessed stakeholder's perceptions, opinions and actions. Such measures are prone to desirable answers and to recall biases. In this respect, the strength of our study was that the DISC results were double-checked with the qualitative results and interpreted together with the regional coordinators during a face-to-face meeting. No significant discrepancies emerged from the discussion with the regional coordinators, nor from the qualitative data. However, the study suffered from a considerable number of missing values at pretest, because stakeholders were not familiar with the terminology of CSHP and collaboration used in the questionnaire. The DISC questionnaire was adapted at post-test, including definitions of concepts used ('Read "collaboration", "CSHP partners" as...') and short introductions for the set of items measuring a particular construct ('The following 
questions concern...'). Although the amount of missing values was reduced at posttest, the changes in the questionnaire may have introduced systematic biases.

\section{Conceptual framework}

The DISC model is specifically designed to examine the development of sustainable collaborative structures between relevant sectors, such as the school sector, the health sector and health authorities, for CSHP. It considers factors related to the attitudes, beliefs, and behaviors of relevant stakeholders, characteristics and policies of organizations involved, and relevant policies at local, regional, and national levels. Its eclectic nature makes it appropriate for diagnostic purposes in different situations, as has been shown in the single partnership study by Leurs et al. (2008) and was further confirmed by our own study (Chapter 3) of multiple partnerships with varying starting situations (e.g. regarding the number and type of participating stakeholders and sectors and the extent of support for CSHP within the stakeholders' own organization) and characteristics (e.g. size of working district). However, based on these studies, which both investigated partnerships in the initial stage of collaboration, it is unclear whether the model covers factors that are relevant in the later stages of collaboration. Different factors may play a role in different stages (Butterfoss, 2007; Kegler \& Swan, 2011b). Future studies should identify relevant factors per stage. Knowledge about the factors that affect collaboration in the various stages could be particularly useful to simplify the application of the model in practice. Partnership managers could consider a smaller set of factors in the DISC analysis, for instance. Tuckman's stage model (Tuckman, 1965) could be used for this purpose. In our study this model was found to be useful to assign the DISC results to a particular stage of collaboration (i.e. forming, storming, norming and performing; Chapter 3).

Future studies need to assess whether the DISC model covers all relevant factors. Although other conceptual models for partnership development in public health propose the same range of factors (Clark et al., 2006; Feinberg et al., 2004; Florin et al., 2000; Kegler \& Swan, 2011b), the predictive power of the DISC model (explained variance 19-26\%; Chapter 5) seems to suggest that there are also other factors that influence collaboration in CSHP.

Further, sustainable collaboration, as defined in the DISC model, clearly resembles the interpretation of this concept suggested by Steckler and Goodman (1989) and Yin (1979). These authors emphasize the institutionalization of the subject of collaboration within organization policies after withdrawal of implementation support. Researchers using the DISC model should be aware of the particular perspective of the model on sustainable collaboration, and be aware that other models with a different perspective (such as development of stakeholders' capacities) may include other determinants and reveal other collaborative processes. 
Finally, the DISC constructs of external factors and contexts appeared to be insufficiently operationalized with regard to rules, regulations and policies affecting the collaborations at EU, national, regional, and local levels. This limited the content validity of the diagnostic instrument. Items measuring these factors were too generic for proper diagnosis ('Does CSHP fit governmental policies at national, provincial, regional, and local levels', 'Does CSHP fit educational policies', and 'My organization has influence on the policies in their region'). The identification of effective and less effective policies at various levels should be a subject of further research. The studies presented in this dissertation suggest that at local level, supportive financial policies and agreements are necessary between municipalities and PHSs for demand-driven practices in CSHP. As for the national level, support for health professionals (e.g. practitioner guide, newsletter, and funding) provided by the national government proved to be useful, but there were no findings pointing to existing policies and regulations at EU level. Gugglberger and Inchley (2012), who described the phases of implementation of health promotion in the Scottish school system, suggested additional direction for promising policies at national level, such as shifting power to local authorities while providing external framing of options by the national government, or the provision of national direction, leadership, and support by a temporary Health Promoting School Unit with representatives from the educational sector and the health sector. More studies of this kind are needed. In addition, international comparisons are suitable for addressing the following questions: how is school health promotion shaped in different countries (ad-hoc school health promotion vs. systematic school health promotion)? Can the differences be explained by policies at national, regional, and local levels?

\section{Reflection on the effectiveness of the systematic approach based on the DISC model}

Our study of DISC analyses in multiple partnerships shows that the DISC model can be used to assess facilitators and barriers for collaboration. In addition, our studies of the effectiveness of the systematic approach and related collaborative processes suggest several core elements which seem to have contributed to the observed effects in terms of the DISC factors, the implementation of CSHP, and the sustainability of the collaboration. This section discusses the feasibility of the DISC model and these core elements.

\section{DISC analyses and the DISC-based strategy}

Our study of multiple partnerships showed that the DISC model can be used as a diagnostic instrument for collaborations with various starting situations and characteristics (Chapter 3). This study further showed that the DISC results could be interpreted and a DISC-based strategy formulated using the literature on organizational behavior and organizational change 
(Dür, 2013; Plsek \& Greenhalgh, 2001; Plsek \& Wilson, 2001), coalition building (Axelsson \& Axelsson, 2006; Bohlmeijer et al., 2005; Van Raak et al., 1999), and group dynamics (McMorris et al., 2005; Tuckman, 1965). We found that stakeholders still had to find common ground with respect to values, goals, and interests in the early collaborations, which are the driving forces for commitments and joint actions. We also found that the collaborations were characterized by lack of management, although it was management that was greatly needed. At first, change management was needed to facilitate the formulation of consensual goals and ways to achieve them. Later, a project management structure had to be developed and implemented (Bohlmeijer et al., 2005; Plsek \& Greenhalgh, 2001; Plsek \& Wilson, 2001). Consequently, the DISC-based strategy was formulated as follows: (1) bring the stakeholders together, (2) develop a common vision, (3) identify the possibilities and impossibilities for each collaborating partner based on the DISC analysis, (4) determine the intended collaborative structure, (5) develop a task distribution based on the information, (6) and discuss the choices at the management and executive levels. In our further studies, we were able to find support for the effectiveness of the DISC-based strategy. In our study of the effectiveness of the systematic approach, we found at several aspects a relation between the formulated DISC-based strategy and the managerial activities employed by regional coordinators on the one hand and observed improvements in the DISC factors on the other (Chapter 4). Our study of predictors and mediators further showed that the improvements regarding the DISC factors were positively related to the collaborative goals of implementing CSHP and increasing the sustainability of the collaboration (Chapter 5). Although the absence of studies of this kind makes it difficult to compare our findings, there have been studies supporting the view that a systematic, step-wise approach to change can give direction and transparency (Bohlmeijer et al., 2005; Deschesnes et al., 2003; Gajda, 2004; Mur-Veeman \& Van Raak, 1994)

\section{Professional support}

Professional support in the DISC-based trajectory was necessary to provide regional coordinators with the required knowledge and capabilities to systematically develop intersectoral collaboration in CSHP. In the DISC-based trajectory, regional coordinators received support to conduct DISC analyses, to interpret DISC results, and to formulate and implement the DISC-based strategy. In addition, multiple moments of reflection on the collaborative process were provided while following the action research steps in the trajectory. Other authors have acknowledged the potential of action research for the implementation of CSHP. At school level, action research helped educational staff to acquire new knowledge (Turunen, Tossavainen, \& Vertio, 2004). In addition, organizational knowledge and related skills that formed the basis of the trajectory have been found to facilitate the implementation process of CSHP in schools (Boot \& De Vries, 2012; Boot et al., 2010b; 
Deschesnes et al., 2013a; Deschesnes et al., 2013b; Senior, Joyce, \& Batras, 2015). From this, the concept of the 'critical friend' emerged, a role which can be compared with that of the main advisor in the DISC-based trajectory, except that the former pertains to assistance in the implementation of CSHP at schools. A 'critical friend' assists in building the capacity of the school and facilitates the process of organizational change (Bond, Glovers, Godfrey, Butler, \& Patton, 2001). He/she is a 'detached outsider' (Swaffield, 2007) who is in direct contact with a 'champion' (or a group of 'champions') from inside the school, who drives the changes forward. The similarity with the main advisor in the trajectory resides in the main activities of the 'critical friend': (1) conceptualizing the intervention as an ongoing process of change ('not a product to be done'), (2) facilitating the change process ('not just training and technical assistance'), (3) bringing in depth-understanding of educational context and health and wellbeing, and (4) assisting schools in integrating the work within the core business (Butler et al. (2001). Although we were only able to provide indirect evidence for a causal relation between professional support and the observed improvements in the collaborations, our studies suggest that professional support in the form of a critical friend is valuable for health professionals responsible for the implementation of intersectoral collaboration in CSHP. A few studies (Boot et al., 2010; Baker et al., 1991, Laughlin, 1990, Deschesnes et al., 2013) have acknowledged that external support by a 'critical friend' increases the chances of changing individuals and organizations for CHSP.

\section{Regional coordinators and managerial styles}

Senior et al.(2015) emphasize that the 'champion' (or a group of 'champions') is just as important for the facilitation of the process of change as the 'critical friend' acting from within the organizations. The champion takes the ideas (s)he has elaborated together with the main advisor back to the community in which the intervention is implemented. The studies presented in this dissertation showed that regional coordinators acted as such 'champions'. They implemented a wide range of managerial activities (utilizing particular collaborative processes and instruments) that clustered into five managerial styles, including (1) involving and (2) informing stakeholders, 3) controlling and (4) supporting collaborative performance, and (5) coordinating collaborative activities. Interestingly, we found that managing the collaborations required more instruments and processes than the options specified in the change management cluster of the DISC model (i.e. image building, power, positive feedback, and persuasive methods). More activities were needed to bring stakeholders' interests together, to stimulate them to formulate possible solutions and to ask for criticism. Additional activities were necessary to address the identification of 'windows of opportunity' that could enhance the visibility of CSHP, the building of facilitating policies, and the establishment of crucial connections with existing policies (Chapters 4 and 5). These findings are in line with 
the precursor variety of the DISC model (Bohlmeijer et al., 2005) which emphasizes the need for a partnership manager to act as a 'social entrepreneur' (De Leeuw, 1999; Kingdon, 1995).

\section{Reflection on the collaborative process in intersectoral collaboration for CSHP}

The collaborative processes we identified resemble the ideas reported in general management literature and theory. Smith Ring and Van Veen's (1994) conceptualization of the collaborative process involves an interaction between negotiated commitments, their implementation and evaluation, and new negotiations in case the commitments are not implemented. The notion of negotiated commitments resembles our findings concerning the spaces regional coordinators created for negotiation, included in the managerial 'involving' style. We have also observed Smith Ring and Van Veen's (1994) notion of evaluation of commitments and collaborative support (i.e. controlling and supportive managerial style) and renegotiation of commitments and collaborative support (i.e. controlling and supporting styles). In addition, Thomson and Perry (2006) identified 'governance' as a crucial dimension for collaborative processes, which is comparable to our coordinating styles. Their definition of 'governance' includes rules about the joint decision-making process, such as who participates in the negotiation processes, what is the process of commitment building, or how is the implementation of commitments monitored. This procedure is analogous to the ideas of participatory decision-making (McCaffrey, Faerman, \& Hart, 1995; Wood \& Gray, 1991), shared power arrangements (Clift, Veal, Holland, Johnson, \& McCarthy, 1995; Crosby \& Bryson, 2005), and problem solving (Hellriegel, Slocom, \& Woodman, 1989) in the literature on collaboration.

Our finding of more active forms of control and supportive behaviors being used in collaborations between organizations that fall under one management (e.g. municipal departments of health promotion and youth health care) finds support in the collaborative literature. In their grid of attributes of partnership coordinators, Wood and Gray (1991) suggested that various types of interventions and influences are used by coordinators, depending on the formal or informal authority they have. Formal authority results in more directive attributes being assigned to the regional coordinators, due to their legitimization or a mandate. Informal authority involved more facilitative and persuasive attributes being assigned.

Finally, our study of predictors and mediators of implementation and sustainable collaboration in CSHP (Chapter 5) suggests that the lack of directive behaviors can be problematic. It can lead to ongoing negations instead of getting things done. Vangen and Huxham (2003) also found that the partnership managers of 13 public health partnerships appreciated the use of directive behaviors to bring the collaborative agenda forward. Vangen 
and Huxham's (2003) conclude that engaging in facilitative and directive activities has to take place simultaneously.

Overall, the above comparisons suggest that concepts and processes described in the general management literature are also applicable to collaboration for CSHP. Future studies are needed to validate our findings.

\section{Generalizability of findings to other partnerships in public health}

Three questions regarding external validity are important: are our findings generalizable to other CHSP collaborations in the Netherlands? Are our findings generalizable to CHSP collaborations outside the Netherlands? Are the findings generalizable to collaborations outside the CSHP domain?

As regards the first question, the intent of our study was to investigate the collaboration between PSS, PHSs, schools, and municipal authorities. During the course of the study the range of represented sectors was narrowed to stakeholders mainly from the health sector. Although regional coordinators had approached all sectors for the assessment of facilitators and barriers in the collaboration, even then most representatives were working in the health sector. For the advisory part of the trajectory, regional coordinators had independently indicated that stakeholders from PHSs and health services should get priority. In this respect they formed the study sample for the longitudinal analysis. We suppose that the PHSs' own organizational goals guided these stakeholder choices. The PHS is responsible for health and related policies, so their most obvious partners come from the health sector (Pucher et al., 2015a). An alternative explanation is that regional coordinators were not aware of the decision structures in other sectors, and thus could not include the decision makers from these sectors from the start. This is in line with conclusions of other researchers (Vangen \& Huxham, 2003), who suggest that embracing the right kind of partners demands attention on a continuous basis. During the support trajectory we also observed that regional coordinators engaged in activities to identify new stakeholders, such as one regional coordinator who interviewed school staff to find out who were the decision makers at school level. It thus seems that the generalizability of our results is limited to CSHP collaborations with stakeholders from the health sector.

As regards the second question, structures relating to CSHP are organized differently in different countries. Whereas in the Netherlands, school health promotion is a task of the health sector and is part of youth health policies, in Scotland it is the responsibility of the educational sector and part of the general curriculum. Furthermore, youth health policies in the Netherlands have been devolved to municipalities, and PHSs have a legal obligation to implement youth health policies, either themselves or by delegating them to the right PSSs. Additionally, PHSs can advise municipal authorities in the development of public health 
policies. As a linking-pin between municipalities and PSSs, the PHS is an optimal actor to coordinate the work between the school sector, the health authorities and other PSSs. This structure is unique to the Netherlands. In the above, the importance is described of a 'champion' who brings the collaboration forwards from inside the network. In the Netherlands, once a PHS has decided to adopt CSHP, its role as coordinator/champion develops naturally from its legal obligations. Nationally, there is much attention for CSHP in the Netherlands. Several initiatives have been started to provide 'critical friends' to support PHSs in their work (see also Chapter 1). It is conceivable that in countries where school health promotion is not hosted by either sector and where natural and obvious structures are lacking and national attention and support is low, intersectoral collaboration will have to start with advocacy for CSHP and a systematic lobby among relevant partners. Our studies focused on the management of interorganizational work based in joint decision-making and the creation of facilitating policies for demand-driven practices, rather than on advocacy and lobbying and building the necessary infrastructure. Consequently, our findings seem to be generalizable to CHSP collaborations among stakeholders from the health sector outside the Netherlands that lack compulsory policies for school health promotion, but where support for CSHP is available from the health sector and facilitating structures at the local and national levels.

As regards the third question, it should be considered that the partnership being studied can be characterized by strong identities (e.g. stakeholders' own mission, own history, organizational structures) operating from various domains with different policies, rules, and regulations. The very dynamic context (involving e.g. reorganization, mergers, and new public health policies) in which the DISC-based trajectory took place also forced organizations to focus on their own organizations' missions, although it also created opportunities to influence relevant policies. Thus, the external and internal contexts played an important role in all studies. In addition, the partnerships were in the initial stage of collaboration, and intersectoral collaboration was a new phenomenon to them. This is why our initial analysis identified lack of change management and project management as impediments to the collaborations, and both were targets of the DISC-based strategy. Finally, the collaborations were characterized by limited formal authority, illustrating why the collaborative process was mainly based on shared-decision making. Concluding, our findings can be generalized to collaborations outside the CSHP domain that include parties from varies domains with high aspirations for their own organizational goals and operating in a highly dynamic context.

\section{Future directions for research into effective DISC-based strategies and managerial styles}

Our studies support the effectiveness of a particular DISC-based strategy and particular managerial styles, but also suggested that other DISC-based strategies may have potential. 
These strategies and their contingencies to enhance their generalizability should be studied. This section formulates the implications of our findings for further research.

\section{DISC-based strategies and managerial styles}

Our studies allow several suggestions to be made for research to identify further effective DISC-based strategies and managerial styles. Based on the study of the effectiveness of the systematic approach (Chapter 4), it seems plausible that strategies targeting the sequence of consensus-commitment-formalization (all factors of the collaborative support cluster) have potential. The study found improvements regarding exactly these DISC factors, but the impact of formalization on collaborative goals was not yet measured. Another subject of investigation could be the impact of the DISC constructs of project management, change management, and collaborative support on the context cluster. Apparently, it is especially during dynamic periods (e.g. mergers, reorganizations, new public health cycle) that contextual factors can be influenced through support from partnership managers and stakeholders (Chapters 4 and 5). A further relation that might deserve attention in future research is the link between a relationship of trust, commitment, and desired outcomes. Boot et al., (2010a) emphasized the importance of such a relationship to create the opportunity to support a community. A relationship of trust could possibly privilege partnership managers and permit them to engage in directive behaviors which seem relevant to the attainment of collaborative goals (Chapters 4 and 5). Finally, in line with the first part of this dissertation, which was devoted to the benefits of CSHP for the educational sector, there is a need to investigate the effects of creating win-win situations in CSHP on achieving the intended goals (e.g. DISC factors, implementation of CHSP, and sustainable collaboration). The proposed strategies could be studied in path analyses, as was done in our study of predictors and mediators (Chapter 5). The consequent managerial styles, their processes and instruments could be explored and their influence on the attainment of collaborative goals assessed.

\section{Contingencies of DISC-based strategies and managerial styles}

Enhancing the generalizability of DISC-based strategies, managerial styles, and their processes and instruments to other collaborative endeavors requires them to be validated, especially in different sectors and in collaborations with varying contexts (in terms of starting situation or regional characteristics). Others have suggested that such circumstances can affect collaboration. Kegler et al. (2011b) reported that certain characteristics of a coalition, like a large size and a large number of sectors involved, can positively influence stakeholders' investments. Koelen et al. (2012) emphasized the necessity of employees being made accountable for intersectoral collaboration, claiming a strong position for CSHP within the collaborating organizations. LaPaolombara (2001) emphasized that municipal authorities are 
highly dependent upon the political context and the efforts to achieve many goals. Their responsiveness to political environments and their multiple purposes probably make them more sensitive to contextual changes than PSSs and PHSs. The latter have to focus on a small set of goals fitting the organization's mission (which is rather stable over time). The capabilities required for collaboration (e.g. self-efficacy, leadership skills) are also addressed in collaborative models (Kegler \& Swan, 2011a; Koelen et al., 2012). Contingencies upon which the effectiveness of the strategies and managerial styles (including their processes and instruments) depend could be studied by using the expert knowledge of partnership managers, just by asking them why and how particular strategies and managerial options have worked (Pawson \& Tilley, 1997). Finally, the use of specific strategies and styles could be studied at various developmental stages to give direction to the managerial choices in the different stages.

\section{Future directions for the application of the DISC model in practice}

The practical goal of the DISC-based trajectory was to support regional coordinators in the systematic development of intersectoral collaboration. Based on our studies the following implications can be formulated for the use of the DISC model in practice.

First, a DISC analysis should be performed. DISC analysis provides valuable insights into the opinions of relevant stakeholders and the characteristics of their organizations, which allow current practices to be explained and clear implications for practice to be formulated. To take account of the busy agendas of partnership managers, regional coordinators could decide to evaluate all DISC factors only in the initial evaluation of the collaboration. Further evaluations could then be limited to the set of factors that relate to the key points on which the collaboration has been working.

Second, the results of the analysis should be used to formulate appropriate strategies to improve the collaboration. In this respect it is important that actors coordinating the collaboration have the right knowledge and capabilities. Actors should have knowledge about organizational change principles (e.g. development of a common vision, formulating change strategies), be able to function as social entrepreneurs in dynamic contexts, and be able to devise creative working methods and instruments to manage the collaboration. Since intersectoral collaboration is a relatively new phenomenon in the public health sector, some regional coordinators will need support to systematically develop such a collaboration. These regional coordinators would benefit from a 'critical friend' stimulating reflection on the collaborative processes. Coordinators should proactively seek to involve such a 'critical friend'. In the Netherlands, some support structures have been created at national level which can be used to provide professional assistance (Chapter 1). 
Third, our studies have yielded certain by-products, such as a strategy to improve change management and project management that can enhance collaborative support. They also provide a wide range of managerial processes and instruments that can be used to implement the DISC-based strategy. Regional coordinators are encouraged to use this strategy and managerial options to improve their partnerships.

Fourth, our study of collaborative process showed that the managerial activities we identified have enhanced stakeholders' collaborative support and thereby promoted the sustainability of the collaboration and the implementation of CSHP. However, it also seemed to indicate too much focus on negotiation. Although negotiation contributed to stakeholders' consensus and commitment, it seemed less effective in getting things done. Therefore when regional coordinators see that the collaboration is making little progress, they should search for a balance between task accomplishment and negotiation.

Fifth, we have acknowledged the relevance of devoting time to the involvement of potential stakeholders at the beginning of the collaboration. The more stakeholders and sectors are involved, the more investments (in terms of money and hours) can be expected in later stages of the collaboration (Kegler \& Swan, 2011b). Therefore, partnership managers of CSHP collaboration should not only ensure that all decision makers of the health and educational sectors are identified at the beginning of the collaboration, but also consider the involvement of other public and private stakeholders. For example, low health care costs are in the interest of insurances companies, and CSHP may lead to the decreases in health care costs in the long term, because of improved health status among school-aged children and improved skills to make healthy choices later in their lives. In addition, health insurance companies are increasingly starting up their own initiatives to improve health status. As such, they might be valuable co-financers of CHSP. Another sector with interest in CSHP might be the industry, which can provide healthy food options for CSHP while at the same time raising awareness for its brand products. Using the private sector to achieve public purpose is increasingly promoted by governments (Borins, 2000).

Finally, in 2010, the RIVM Centre for Healthy Living published a support manual for health professionals working with CSHP, which included a supplement on collaboration (RIVM Centre for Healthy Living, 2010), based, on the preliminary findings from our study. At the time, the effects and processes of the DISC-based trajectory still remained to be studied. The promising results of using the DISC model to establish intersectoral collaboration reported in the present dissertation should be disseminated to the health professionals working with CHSP. And our by-products, the DISC-based strategy to improve change management and project management and the related managerial options, should also be communicated to the target group. 


\section{General conclusions}

The first aim of this dissertation was to evaluate the possible gains that can be made by implementing health promotion in schools for the educational sector. We systematically reviewed the literature on studies investigating the effects of school health promotion interventions on students' academic performance and possible mediators of this relationship. We found promising but limited evidence for the relationship between interventions targeting energy balance and academic performance. The evidence for mechanisms explaining this relationship was limited to hypothetical assumptions from other studies. We were also interested in the net effects of a comprehensive approach to school health promotion compared with those of a limited approach. Since only one of the reviewed interventions was embedded in a comprehensive framework, we were not able to answer this research question. For the future close cooperation is recommended between practitioners and researchers to generate the evidence we need to identify the educational/academic gains achieved by school health promotion.

The second aim of this dissertation was to study the systematic development of intersectoral collaboration as part of a broader advisory trajectory designed for health professionals engaged in CSHP collaborations. This was examined using the Dlagnosis of Sustainable Collaboration (DISC) model. The effectiveness of the trajectory and related processes were studied in a pretest-posttest study with multiple sources of information and multiple research methods. All results of the comprehensive approach point in the same direction, suggesting that the DISC-based trajectory has contributed to the improvements regarding the DISC factors, the implementation of CSHP and the sustainability of the collaboration, even though we were not able to provide strong, direct evidence for a causal relation, due to the lack of a control group. Core elements of the trajectory were the DISC analysis, the formulation of a DISC-based strategy, the appointment of a champion (i.e. regional coordinator) who is accountable for the implementation of the strategy, and the support of a critical friend with expert knowledge of the domain (in our case the main advisor in the trajectory). The champion's ability to act as a social entrepreneur in a dynamic context was also found to be an essential asset. Further research is necessary to confirm our findings and to further improve the use of the DISC model in practice. Finally, our research yielded a strong message, namely that a systematic approach to intersectoral collaboration in CSHP seems effective and that the DISC model is an appropriate tool for this purpose. 


\section{References}

Ahamed, Y., Macdonald, H., Reed, K., Naylor, P. J., Liu-Ambrose, T., \& McKay, H. (2007). School-based physical activity does not compromise children's academic performance. Medicine and Science in Sports and Exercise, 39(2), 371-376.

Axelsson, R., \& Axelsson, S. B. (2006). Integration and collaboration in public health - a conceptual framework. The International Journal of Health Planning and Management, 21(1), 75-88.

Beets, M. W., Flay, B. R., Vuchinich, S., Acock, A. C., Li, K. K., \& Allred, C. (2008). School climate and teachers' beliefs and attitudes associated with implementation of the positive action program: a diffusion of innovations model. Prevention Science \& Government Report, 9(4), 264-275.

Bohlmeijer, E., Ruland, E., Van Raak, A., \& Mur-Veeman, I. M. (2005). Procesmanagement in public health - ontwerp, analyse \& verandering (Processmanagement in public health design, analysis \& change). Utrecht: Trimbos.

Bond, L., Glovers, S., Godfrey, C., Butler, H., \& Patton, G. (2001). Building capacity for systemlevel change in schools: lessons from the Gatehouse Project. Health Education and Behavior, 28(3), 368-383.

Bond, L., Patton, G., Glover, S., Carlin, J. B., Butler, H., Thomas, L., \& Bowes, G. (2004). The Gatehouse Project: can a multilevel school intervention affect emotional wellbeing and health risk behaviours? Journal of Epidemiology and Community Health, 58(12), 997-1003.

Boot, N. M. W. M., \& De Vries, N. K. (2012). Implementation of school health promotion: consequences for professional assistance. Health Education, 112(5), 436-447.

Boot, N. M. W. M., van Assema, P., Hesdahl, B., \& de Vries, N. K. (2010a). Professional assistance in implementing school health policies. Health Education, 110(4), 294-308.

Boot, N. M. W. M., van Assema, P., Hesdahl, B., Leurs, M., \& de Vries, N. K. (2010b). Gezondheidsbevordering en voortgezet onderwijs: verstandshuwelijk of echte liefde? (Health promotion and secondary education: marriage of convenience or true love?) Tijdschrift voor Gezondheidswetenschappen, 88(3), 127-135.

Borins, S. (2000). Loose Cannons and Rule Breakers, or Enterprising Leaders? Some Evidence About Innovative Public Managers. Public Administration Review, 60(6), 498-507.

Bowen, A., Ma, H., Ou, J., Billhimer, W., Long, T., Mintz, E., Hoekstra, R. M., \& Luby, S. (2007). A cluster-randomized controlled trial evaluating the effect of a handwashingpromotion program in Chinese primary schools. American Journal of Tropical Medicine and Hygiene, 76(6), 1166-1173.

Busch, V., Loyen, A., Lodder, M., Schrijvers, A. J. P., van Yperen, T. A., \& de Leeuw, J. R. J. (2014). The Effects of Adolescent Health-Related Behavior on Academic Performance: 
A Systematic Review of the Longitudinal Evidence. Review of Educational Research, 20(5), 1-30. doi: 10.3102/0034654313518441

Butterfoss, F. D. (2007). Coalitions and Partnerships in Community Health. San Francisco: Jossey-Bass.

Campbell, D. T., \& Stanley, J. C. (1963). Experimental and quasi-experimental designs for research. Boston: Houghton Miffelin Company

Carlson, S. A., Fulton, J. E., Lee, S. M., Maynard, L. M., Brown, D. R., Kohl, H. W., 3rd, \& Dietz, W. H. (2008). Physical education and academic achievement in elementary school: data from the early childhood longitudinal study. American Journal of Public Health, 98(4), 721-727.

Clark, N., Doctor, L., Friedman, A., Lachance, L., Houle, C., Geng, X., \& Grisso, J. (2006). Community coalitions to control chronic disease: Allies against asthma as a model and case study. Health Promotion Practice, 7(2), 13S-22S.

Clift, R. T., Veal, M. L., Holland, P., Johnson, M., \& McCarthy, J. (1995). Collaborative Leadership and Shared Decision Making: Teachers, principals, and university professors. New York: Teachers College Press.

Crosby, B. C., \& Bryson, J. M. (2005). Leadership for the Common Good: Tackling Public Problems in a Shared-Power World. San Francisco, CA: Jossey-Bass Publishers.

Crosnoe, R. (2002). Academic and health-related trajectories in adolescence: The intersection of gender and athletics. Journal of Health and Social Behavior, 43(3), 317-335.

Crosnoe, R. (2007). Gender, obesity, and education. Sociology of Education, 80, 241-260.

Dadaczynski, K. (2012). Stand der Forschung zum Zusammenhang von Gesundheit und Bildung: Überblick und Implikationen für die schulische Gesundheitsförderung. Zeitschrift für Gesundheitspsychologie, 20, 141-153.

Datar, A., \& Sturm, R. (2006). Childhood overweight and elementary school outcomes. . Internationl journal of Obesity, 30, 1449-1460.

Datar, A., Sturm, R., \& Magnabosco, J. L. (2004). Childhood overweight and academic performance: national study of kindergartners and first-graders. Obesity Reserach, 12(1), 58-68.

De Leeuw, E. (1999). Healthy Cities: urban social entrepreneurship for health. Health Promotion International, 14(3), 261-269.

Deschesnes, M., Drouin, N., \& Couturier, Y. (2013a). Schools' absorptive capacity to innovate in health promotion. Journal of Health Organization and Management 27(1), 24-41.

Deschesnes, M., Martin, C., \& Hill, A. J. (2003). Comprehensive approaches to school health promotion: how to achieve broader implementation? Health Promotion International, 18(4), 387-396. 
Deschesnes, M., Tessier, C., Couturier, Y., \& Martin, C. (2013b). Professional development in the context of Healthy Schools in Quebec. Health Promotion International, (e-pub ahead of print). doi: 10.1093/heapro/dat043

DeSocio, J., \& Hootman, J. (2004). Chilrden's Mental Health and School Success. The Journal of School Nursing, 20(4), 188-196.

Dür, W. (2013). Applying system theory of organizational change to health promotion interventions in schools and their problems. In O. Samdal \& L. Rowling (Eds.), The Implementation of Health Promoting Schools. Exploring the theories of what, why and how (pp. 34-50). New York: Routledge Publishers.

El Ansari, W., Phillips, C. J., \& Hammick, M. (2001). Collaboration and partnerships: developing the evidence base. Health and Social Care in the Community, 9(4), 215-227.

Feinberg, M., Greenberg, M., \& Osgood, D. (2004). Readiness, functioning and perceived effectiveness in community prevention coalitions: A study of communities that care. American Journal of Community Psychology, 3/4(33), 163-176.

Fekkes, M., Pijpers, F. I., \& Verloove-Vanhorick, S. P. (2006). Effects of antibullying school program on bullying and health complaints. Archives of Pediatrics and Adolescent Medicine, 160(6), 638-644.

Florin, P., Mitchell, R., Stevenson, J., \& Klein, I. (2000). Predicting intermediate outcomes for prevention coalitions: A developmental perspective. Evaluation and Program Planning, 23(3), 341-346.

Gajda, R. (2004). Utilizing Collaboration Theory to Evaluate Strategic Alliances. American Journal of Evaluation, 25(1), 65-77.

Green, S., Higgins, J., Alderson, P., Clarke, M., Mulrow, C., \& Oxman, A. (2011). Cochrane Handbook for Systematic Reviews of Interventions Version 5.1.0 [updated March 2011]: The Cochrane Collaboration.

Greenberg, M. T., Weissberg, R. P., O'Brien, M. U., Zins, J. E., Fredericks, L., Resnik, H., \& Elias, M. J. (2003). Enhancing school-based prevention and youth development through coordinated social, emotional, and academic learning. American Psychologist, 58(6-7), 466-474.

Gugglberger, L., \& Inchley, J. (2012). Phases of health promotion implementation into the Scottish school system. Health Promotion International, 29(2), 256-266. doi: 10.1093/heapro/das061

Hellriegel, D. S., Slocom, J. W., \& Woodman, R. W. (1989). Organisational Behavior. New York: West Publishing.

Isaac, S., \& Michael, W. B. (1995). Handbook in research and evaluation. A collection of principles, methods and strategies useful in the planning, design and evaluation of studies for education and the behavioral sciences (Third edition ed.). San Diego, California: EdiTS. 
Kärnä, A., Voeten, M., Little, T. D., Alanen, E., Poskiparta, E., \& Salmivalli, C. (2013). Effectiveness of the KiVa antibullying program: grades 1-3 and 7-9. Journal of Educational Psychology, 105(2), 535-551.

Kegler, M. C., \& Swan, D. W. (2011a). Advancing coalition theory: the effect of coalition factors on community capacity mediated by member engagement. Health Education Research, 27(4), 572-584. doi: 10.1093/her/cyr083

Kegler, M. C., \& Swan, D. W. (2011b). An initial attempt at operationalizing and testing the Community Coalition Action Theory. Health Education \& Behavior, 38(3), 261-270.

Kingdon, J. W. (1995). Agendas, Alternatives and Public Policies (2nd edition ed.). New York: Harper Collins College Publishers.

Koelen, M. A., Vaandrager, L., \& Wagemakers, A. (2012). The Healthy ALLiances (HALL) framework: prerequisites for success. Family Practice, 29(suppl 1), i132-i138. doi: 10.1093/fampra/cmr088

Langford, R., Bonell, C. P., Jones, H. E., Poliou, T., Murphy, S.M., Waters, E., K.A., K., Gibbs, L. F., Magnus, D., \& Campbell, R. (2014). The WHO Health Promoting School framework for improving the health and well-being of students and their academic achievement. Cochrane Database of Systematic Reviews(4).

doi: 10.1002/14651858.CD008958.pub2

LaPalombara, J. (2001). Power and Politics in Organizations: Public and Private Sector Comparisons. In M. Dierkes, A. Berthoin Antal, J. Child \& I. Nonaka (Eds.), Process of Organizational Learning. Oxford: Oxford University Press.

Leurs, M., Mur-Veeman, I., van der Sar, R., Schaalma, H., \& de Vries, N. (2008). Diagnosis of sustainable collaboration in health promotion - a case study. BMC Public Health, 8(382). doi: 10.1186/1471-2458-8-382

Li, K. K., Washburn, I., DuBois, D., Vuchinich, S., Ji, P., Brechling, V., Day, J., Beets, M. W., Acock, A. C., Berbaum, M., Snyder, F., \& B.R., F. (2011). Effects of the Positive Action programme on problem behaviours in elementary school students: a matched-pair randomised control trial in Chicago. Psychology and Health, 26(2), 187-204.

London, R. A., \& Castrechini, S. (2011). A longitudinal examinaton of the link between youth physical fitness and academic achievement. Journal of School Health, 81, 400-408.

McCaffrey, D. P., Faerman, S. R., \& Hart, D. W. (1995). The Appeal and Difficulties of Participative Systems. Organization Science, 6(6), 603-627.

McMorris, L. E., Gottlieb, N. H., \& Sneden, G. G. (2005). Developmental Stages in Public Health Partnerships: A Practical Perspective. Health Promotion Practice, 6(2), 219-226. doi: $10.1177 / 1524839903260647$

McNulty Eitle, T., \& Eitle, D. J. (2002). Race, cultural, capital, and the educational effects of participation in sports. Sociology and Education, 75, 123-146. 
McVey, G., Tweed, S., \& Blackmore, E. (2004). Healthy Schools-Healthy Kids: a controlled evaluation of a comprehensive universal eating disorder prevention program. Body Image, 4(2), 115-136.

Mur-Veeman, I., \& Van Raak, A. (1994). Inter-organizational networks on the Dutch home health care market. The International Journal of Health Planning and Management, 9(3), 245-258.

Pawson, R., \& Tilley, N. (1997). Realistic evaluation London: Sage Publications.

Plsek, P., \& Greenhalgh, T. (2001). The challenge of complexity in health care. British Medical Journal, 323(7313), 625.

Plsek, P., \& Wilson, T. (2001). Complexity, leadership, and management in healthcare organisations. British Medical Journal, 323, 746 - 749.

Pommier, J., Guével, M., \& Jourdan, D. (2010). Evaluation of health in schools: a realistic evaluation approach using mixed methods. BMC Public Health, 10(43). doi: 10.1186/1471-2458-1110-1143

Pucher, K. K., Candel, M. J. J. M., Boot, N. M. W. M., Van Raak, A., \& De Vries, N. K. (2015). A multiple-case study of intersectoral collaboration in the context of coordinated school health promotion using the Dlagnosis of Sustainable Collaboration (DISC) Model Health Education, 115(3/4), 301-321.

Resnick, M. D., Bearman, P. S., Blum, R. W., Bauman, K. E., Harris, K. M., Jones, J., Tabor, J., Beuhring, T., Sieving, R. E., Shew, M., Ireland, M., Bearinger, L. H., \& Udry, J. R. (1997). Protecting adolescents from harm: Findings From the National Longitudinal Study on Adolescent Health. Journal of the American Medical Association, 278(10), 823-832. doi: 10.1001/jama.1997.03550100049038

RIVM Centre for Healthy Living. (2010). Handleiding Gezonde School (Healthy School Guide). Bilthoven: National Institute for Public Health and the Environment - Centre for Healthy Living,.

Roussos, S. T., \& Fawcett, S. B. (2000). A review of collaborative partnerships as a strategy for improving community health. Annual Review of Public Health, 21, 369-340.

Sabia, J. J. (2007). The effect of body weight on adolescent academic performance. Southern Economic Journal, 73, 871-900.

Sahota, P., Rudolf, M. C. J., Dixey, R., Hill, A. J., Barth, J. H., \& Cade, J. (2001). Evaluation of implementation and effect of primary school based intervention to reduce risk factors for obesity. British Medical Journal, 323(7320), 1027-1029.

Sawyer, M. G., Harchak, T. F., Spence, S. H., Bond, L., Graetz, B., Kay, D., Patton, G., \& Sheffield, J. (2010). School-based prevention of depression: a 2-year follow-up of a randomized controlled trial of the beyondblue schools research initiative. Journal of Adolescent Health, 47(3), 297-304. 
Schafer, J. L., \& Graham, J. W. (2002). Missing data: Our view of the state of the art. Psychological Methods. Psychological Methods, 7(2), 147-177.

Senior, E., Joyce, A., \& Batras, D. (2015). Becoming a Health Promoting School: Using a 'Change Agent' to Influence School Structure, Ethos and Ensure Sustainability'. In V. Simovska \& P. Mannix-McNamara (Eds.), Schools for Health and Sustainability (pp. 131-152).

Shephard, R. J. (1996). Habitual physical activity and academic performance. Nutrition Reviews, 54(4 Pt 2), S32-36.

Simons-Morton, B., Haynie, D., Saylor, K., Crump, A. D., \& Chen, R. (2005). The effects of the going places program on early adolescent substance use and behavior. Prevention Science, 6(3), 187-197.

Smith Ring, P., \& Van De Ven, A. H. (1994). Developmental processes of cooperative interorganizational relationships. Academy of Management Review, 19(1), 901-118.

Steckler, A., \& Goodman, R. M. (1989). How to institutionalize health promotion programs. American Journal of Health Promotion, 3(4), 34-43. doi: 10.4278/0890-1171-3.4.34

Swaffield, S. (2007). Light touch critical friendship. Improving Schools, 10(3), 205-219. doi: 10.1177/1365480207077845

Talaat, M., Afifi, S., Dueger, E., El-Ashry, N., Marfin, A., Kandeel, A., Mohareb, E., \& El-Sayed, N. (2011). Effects of hand hygiene campaigns on incidence of laboratory-confirmed influenza and absenteeism in schoolchildren. Emerging Infectious Diseases, 17(4), 619-625.

Thomson, A. M., \& Perry, J. L. (2006). Collaboration Processes: Inside the Black Box. Public Administration Review, 66(S1), 20-32. doi: 10.1111/j.1540-6210.2006.00663.x

Trudeau, F., \& Shephard, R. J. (2008). Physical education, school physical activity, school sports and academic performance. International Journal of Behavioral Nutrition and Physical Activity, 5(10). doi:10.1186/1479-5868-5-10

Tuckman, B. W. (1965). Developmental sequence in small groups. Psychological Bulletin, 63(6), 384-399. doi: 10.1037/h0022100

Turunen, H., Tossavainen, K., \& Vertio, H. (2004). How can a critical incidents be used to describe health promotion in the Finish European Network of Health Promoting Schools? Health Promotion International, 19(4), 419-427.

Van Raak, A., Mur-Veeman, I., \& Paulus, A. (1999). Understanding the feasibility of integrated care: a rival viewpoint on the influence of actions and the institutional context. The International Journal of Health Planning and Management, 14(3), 235-248.

Vangen, S., \& Huxham, C. (2003). Enacting Leadership for Collaborative Advantage: Dilemmas of Ideology and Pragmatism in the Activities of Partnership Managers. British Journal of Management, 14, S61-S76. 
WHO. (2001). Evaluation in health promotion: Principles and perspectives. In I. Rootman, L. Goodstadt, L. Potvin, J. Springett, D. MCQueen \& E. Ziglio (Eds.), European Series. Copenhagen: WHO Regional Publications.

WHO Regional Office for Europe. (1998). Health promotion evaluation: recommendations to policy-makers. Copenhagen.

Wood, D. J., \& Gray, B. (1991). Toward a Comprehensive Theory of Collaboration. The Journal of Applied Behavioral Science, 27(2), 139-162. doi: 10.1177/0021886391272001

Yin, R. K. (1979). Changing Urban Bureaucracies: How New Practices Become Routinized. Lenxington, MA: Lenxington Books.

Yin, R. K. (2009). Case Stuy Research: Design and Methods. Califormia: Sage Publications.

Zins, J. E., Weissberg, R. P., Wang, M. C., \& Walberg, H. J. (2004). Building academic success on social and emotional learning. New York: Teachers College Press. 



\section{Valorization Addendum}

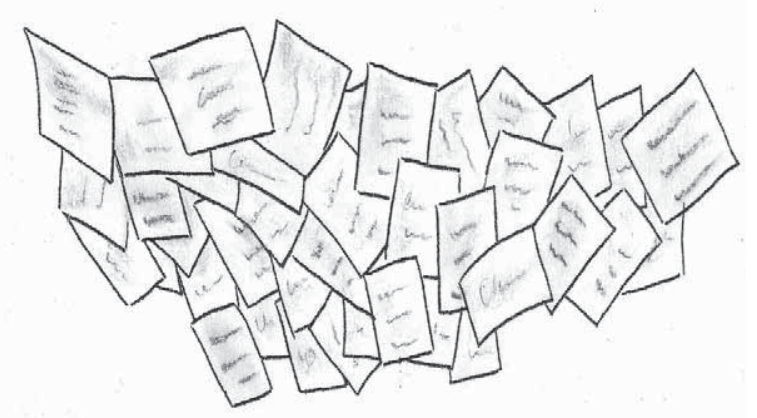





\section{Relevance}

Global health conferences have recognized the school as one of the settings where health is created and lived (WHO, 1986). They view comprehensive strategies as the most effective means to achieve health, and regard the school as an environment which offers plenty of opportunities for their implementation (WHO, 1997). Finally they urge the health sector to work across disciplines in order to implement such holistic approaches (WHO, 2005, 2009), an example of which is the approach discussed in this dissertation. These global health conferences provided the impetus for the development of various policies (IUHPE, 2009) and practices (Samdal \& Rowling, 2013) for comprehensive school health promotion (CSHP), even though the evidence base for its effectiveness so far still seems weak or lacking (Langford et al., 2014; Lister-Sharp, Chapman, Stewart-Brown, \& Sowden, 1999; Stewart-Brown, 2006). Samdal and Rowling (2013) reflected on the scarcity of evidence and related it to several implementation issues which need to be clarified, such as what should be implemented, why and how. In this respect, the studies presented in this dissertation fill important knowledge gaps and provide support for practices and policies promoted during the above-mentioned conferences.

The findings reported on in this dissertation support practices to encourage intersectoral collaboration for the implementation of CSHP, as well as identifying its success factors. They show that intersectoral collaboration enables opportunities for negotiation to be created between stakeholders involved in CSHP; this can enhance the formation of consensus on collaborative goals and necessary actions, and facilitate the formulation of commitments in the collaboration. Interaction between stakeholders can also lead to the identification of relevant policies for intersectoral collaboration, which can later be addressed. This dissertation also shows that such collaborative actions can improve the quality of the collaboration, as indicated by more favorable evaluations of the determinants of collaboration (Chapter 4, 5), and thereby contribute to further implementation of CSHP and to the sustainability of the collaboration (Chapter 5). In addition, this dissertation identifies several success factors of intersectoral collaboration. The success factors identified include a systematic approach, which holds the collaboration on track, and a full range of activities to manage the collaboration. This management comprises activities to involve and inform collaborating parties, to monitor and control the accomplishment of set tasks, and to enable the overall coordination of these tasks. These managerial behaviors were extracted from the full range of coordinators' management activities implemented during the trajectory. Instruments and processes used by coordinators to enact these behaviors were also identified. Another success factor identified is that of occasional professional assistance, including reflection on the planning, implementation and content of collaborative activities (Chapter 4, 5). 
Finally, this dissertation raises another issue, which is the subject of extensive debate. This concerns whether or not schools should feel responsible for the implementation of health promotion (WHO \& Regional Office for Europe, 2014). In the Netherlands, this debate is fueled by the fact that no legal obligation exists for schools to implement health promotion. When schools devote time to health education, they do so voluntarily (Boot, van Assema, Hesdahl, \& de Vries, 2010; Boot, van Assema, Hesdahl, Leurs, \& de Vries, 2010). It seems that providing them with a persuasive argument in line with their primary academic goals can induce the educational sector to feel more committed to implement health promotion.

Since comprehensive evidence on the causal relationship between school-based health promotion programs and children's academic performance was lacking when we became interested in this topic, the existing evidence on the above-mentioned causal relation has been systematically reviewed in this dissertation (Chapter 2). The evidence found in the systematic review suggests that health promotion interventions implemented in schools can enhance children's academic success. School-based programs targeting nutrition, physical activity or a combination of both were found to have small to large effects on academic performance across academic subjects. In addition, no negative effects were found, even when time from academic subjects was invested in the intervention. The evidence found provides additional arguments to implement health promotion in the educational sector.

\section{Target populations}

The results reported in this dissertation are relevant for actors shaping the context of CSHP implementation. In the Netherlands, school health promotion is initiated and promoted by the health sector. As shown in this dissertation, public health services (PHSs) can create region-wide support for CHSP among schools, municipal authorities and public service stakeholders (PSSs). Their task of functioning as a kind of linking pin between the sectors developed naturally from their legal obligations (Hirsch Ballin, 2008). Within PHSs, guiding collaborations is the job of CSHP coordinators. This dissertation offers concrete action perspectives for these coordinators, about which they should be informed, as well as trained and facilitated in their use. In this respect, the RIVM Centre of Healthy Living plays an important role. At the national level, it coordinates the development of CSHP by acting as a platform for knowledge exchange for health professionals and as an accreditation body certifying schools that employ CSHP (Ministry of Health of the Netherlands, 2013). The CSHP platform includes a website, a newsletter, network meetings, training courses, counseling opportunities and a support manual with a supplement on intersectoral collaboration, written in 2010, based on the preliminary results of the DISC study presented in this dissertation. This platform could be used to disseminate information from this dissertation. For instance, the supplement on intersectoral collaboration could be extended with action perspectives for 
regional coordinators. How to act as a social entrepreneur in dynamic contexts could be illustrated by management activities, related instruments and processes identified in the DISC study. In addition, the importance of change management in the early stage of collaborations could be emphasized more in the supplement, as well as the benefits of a 'critical friend' participating in the collaborative process. Furthermore, the RIVM Centre of Healthy Living could facilitate knowledge transfer and skills acquisition among CSHP coordinators through training courses and network meetings organized in collaboration with the Netherlands School of Public and Occupational Health. Finally, the RIVM Centre of Healthy Living could explore possibilities to increase the suitability of DISC analysis in practice, for instance by constructing a digital tool to quickly assess and analyze relevant data.

The results of this dissertation are also relevant for the educational sector. In the Netherlands, schools follow national educational policies established by the Ministry of Education. These policies specify primary educational goals for academic subjects, but unfortunately they do not include targets on health promotion. In addition, schools can implement other policies of their own choice. With regard to health promotion, desirable policies would be those that stimulate schools to attain a CHSP certificate. Other important actors shaping the educational agenda are the Inspectorate of Education, which supervises the quality of education in schools, the Education Council of the Netherlands, which promotes the interests of schools at national level, and school boards, which create the preconditions for schools to attain educational goals. It is important that the findings concerning the benefits of school health promotion to attain educational goals reach these actors, are discussed by them, and lead to new priorities for action. One priority should be to decide whether it is desirable to include health promotion in primary educational goals. Another priority should probably be to broaden the evidence base for the effectiveness of CSHP in terms of health and educational outcomes in cooperation with the health sectors. As discussed in this dissertation, it seems that close cooperation between the educational sector and the health sector is needed to strengthen the current evidence base.

Finally, the findings from the DISC study should encourage other countries to work with the DISC model to systematically develop intersectoral collaboration in CSHP. The Schools for Health in Europe (SHE) network could function as an intermediary for European countries in this respect. SHE is a network of national CSHP coordinators of 43 countries in Europe. It aims to support organizations and professionals in developing and sustaining school health promotion in each country (CBO, 2015). Furthermore, SHE could promote research initiatives in and among European countries, particularly on the following topics: (1) the effectiveness of school health promotion in terms of academic outcome - as this topic is underinvestigated in European countries compared with America - and (2) the net-benefits of CSHP compared to single-issue school-based programs - since international research seems promising to overcome limitations caused by the small number of schools working with CSHP 
and the different subcategories of programs generally used to compare intervention effects (e.g. physical activity programs, nutrition programs, and programs combining physical activity and nutrition). In this respect, SHE could also function as an intermediary between countries to explore any opportunities to use cohort data on health and academic performance collected on a regular basis, in order to study these outcomes. The Health Behavior in School Aged Children initiative and the Programme for International Student Assessment probably offer opportunities.

\section{Activities and products}

The main product of this dissertation was a two-year DISC-based trajectory for health professionals working with CSHP. The trajectory included an assessment of facilitators and barriers in six CSHP collaborations at baseline and at follow-up in five CHSP collaborations. To this end, the DISC questionnaire by Leurs et al. (2008), which was developed for the situation of CSHP in the southern parts of the Netherlands, had to be adapted to fit the situation in different Dutch regions. The trajectory resulted in regional reports at baseline and at followup, which were used to provide feedback to regional coordinators in the form of the results of the questionnaire, together with recommendations for each DISC factor. The content was further clarified in individual meetings with each of the coordinators. Finally, the trajectory resulted in the formulation of a DISC-based strategy to improve collaboration, and included professional assistance for regional coordinators in the implementation of the strategy. This support was provided monthly by telephone for the period of one year. A standardized interview protocol was developed, which was used during monthly phone calls for critical reflection on the collaborative process. Contacts also comprised the exchange of expertise between regions, occasional peer review of documents and a joint training session for regional coordinators. In addition, regions were informed about their progress in a newsletter published every four months. For the advisory part of the trajectory, an experienced facilitator was hired, who was an expert on CSHP implementation. The collaborative process was monitored for an additional follow-up period of one year using the same method, except that contacts took place bimonthly and that there was no provision of professional support.

Products for research purposes were a longitudinal dataset with quantitative information on determinants of intersectoral collaboration at the individual, organizational and policy levels, resulting from the DISC analyses. In addition, the monitoring program generated qualitative data on the management of the collaborative process. Research results were the strategies which were developed to analyze the data on intersectoral collaboration. The results of this study were documented in scientific journals and presented at national and international conferences to the relevant audience for CSHP implementation. Furthermore, a workshop was co-organized with the Netherlands School of Occupational and Public Health 
for Dutch health professionals who had not participated in the DISC study. Finally, the preliminary results of the DISC study were used to write the supplement on collaboration included in the practitioner guide published by RIVM Centre of Healthy Living.

\section{Innovation}

The innovative aspect of this study is the utilization of the DISC model to guide strategic decisions regarding intersectoral collaboration. The DISC model was specifically developed to diagnose facilitators and barriers in the collaborative structure for CSHP (Leurs, Mur-Veeman, van der Sar, Schaalma, \& de Vries, 2008). Leurs et al. (2008) suggested that the results of the diagnosis could also be used to determine strategies to further guide the collaboration, but this was never investigated before our project. This dissertation confirms that DISC analyses can give guidance to collaborations and thereby contribute to their success, their sustainability and the actual implementation of CSHP. Another innovative aspect of this study is that DISC analyses were successfully applied in six Dutch collaborations with various starting situations and characteristics. Before this, DISC analysis had only been used for one collaborative project in the southern parts of the Netherlands, the project for which the DISC model was developed (Leurs et al., 2008). This dissertation shows that DISC analyses are widely applicable to various types of collaborations in the educational domain. Extension to other fields seems well possible. Finally, as far as we know, no other study has investigated the effects and processes of a systematic approach to intersectoral collaboration in CSHP.

\section{Planning and realization}

It seems that external motivation is needed to encourage schools to strive for an objective such as health, in order to promote health and academic achievement among school-aged children. Therefore, the educational sector will probably need to include the attainment of a CSHP certificate in the primary educational goals. This dissertation shows how actors involved in CHSP can join forces by engaging PHSs, and though them extend CSHP to other stakeholders. It is now the task of the above-mentioned actors to work on this. 


\section{References}

Boot, N. M. W. M., van Assema, P., Hesdahl, B., \& de Vries, N. K. (2010). Professional assistance in implementing school health policies. Health Education, 110(4), 294-308.

Boot, N. M. W. M., van Assema, P., Hesdahl, B., Leurs, M., \& de Vries, N. K. (2010). Gezondheidsbevordering en voortgezet onderwijs: verstandshuwelijk of echte liefde? (Health promotion and secondary education: marriage of convenience or true love?) Tijdschrift voor Gezondheidswetenschappen, 88(3), 127-135.

Hirsch Ballin, E. M. H. (2008). Wet Publieke Gezondheid (Public Health Act). Overheid.nl (Government.nl). Retrieved 14 April 2015, from

http://wetten.overheid.nl/BWBR0024705/geldigheidsdatum_14-04-2015.

IUHPE. (2009). Achieving Health Promoting Schools: Guidelines for Promoting Health in Schools. Retrieved 15 January 2015, from http://www.dhhs.tas.gov.au/_data/assets/pdf_file/0011/115895/guidelines_for_heal th_promoting_schools1.pdf.

Langford, R., Bonell, C. P., Jones, H. E., Poliou, T., Murphy, S.M., Waters, E., K.A., K., Gibbs, L. F., Magnus, D., \& Campbell, R. (2014). The WHO Health Promoting School framework for improving the health and well-being of students and their academic achievement. Cochrane Database of Systematic Reviews(4). doi: 10.1002/14651858.CD008958.pub2

Leurs, M., Mur-Veeman, I., van der Sar, R., Schaalma, H., \& de Vries, N. (2008). Diagnosis of sustainable collaboration in health promotion - a case study. BMC Public Health, 8(382). doi: 10.1186/1471-2458-8-382

Lister-Sharp, D., Chapman, S., Stewart-Brown, S., \& Sowden, A. (1999). Health promoting schools and health promotion in schools: two systematic reviews. Health Technology Assessment, 3(22), 1-207.

Ministry of Health of the Netherlands. (2013). Good Practice in the Field of Health Promotion and Primary Prevention. The Netherlands Country Review. Retrieved 15 April 2015, from http://www.loketgezondleven.nl/object_binary/o21294_141105-TheNetherlands-Country-Review-PDF.pdf.

Samdal, O., \& Rowling, L. (2013). The Implementation of Health Promoting Schools. Exploring theories of what, why and how. Canada: Routledge.

Stewart-Brown, S. (2006). What is the evidence on school health promotion in improving health or preventing disease and, specifically, what is the effectiveness of the health promoting schools approach? . Copenhagen: WHO Regional Office for Europe.

WHO. (1986). The Ottawa Charter for Health promotion. Copenhagen: WHO Regional Office for Europe.

WHO. (1997). Jakarta Declaration on Health Promotion into the 21st Century. Geneva: WHO. 
WHO. (2005). Bangkok Charter for Health Promotion in a Globalized World. Geneva: WHO.

WHO. (2009). Nairobi Call to Action for Closing the Implementation Gap in Health Promotion. Geneva: WHO.

WHO, \& Regional Office for Europe. (2014). Education and early development. Synergy between sectors: Fostering better education and health outcomes. Health 2020. 

Appendices

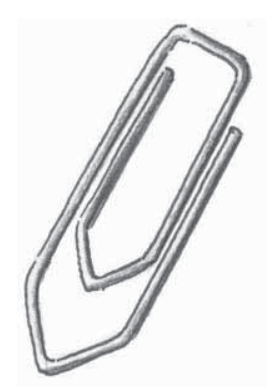





\section{Appendix 1}

\section{PubMed}

\section{Search queries}

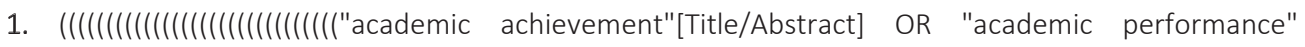
[Title/Abstract]) OR "academic functioning"[Title/Abstract]) OR "academic success"[Title/Abstract]) OR "academic grade"[Title/Abstract]) OR "school grade"[Title/Abstract]) OR "educational performance" [Title/Abstract]) OR "educational functioning"[Title/Abstract]) OR "educational achievement"[Title/ Abstract]) OR "learning performance"[Title/Abstract]) OR "learning achievement"[Title/Abstract]) OR "learning success"[Title/Abstract]) OR "scholastic performance" [Title/Abstract]) OR "scholastic achievement"[Title/Abstract]) OR "scholastic success"[Title/Abstract]) OR "academic growth" [Title/Abstract]) OR "vocabulary test"[Title/Abstract]) OR "test-scores"[Title/Abstract]) OR "examination mark"[Title/Abstract]) OR "test-score"[Title/Abstract]) OR "grade level"[Title/Abstract]) OR "grade point average"[Title/Abstract]) OR "GPA"[Title/Abstract]) OR "math achievement" [Title/Abstract]) OR "English achievement"[Title/Abstract]) OR "standardized reading"[Title/Abstract]) OR "class grade"[Title/Abstract]) OR "performance test"[Title/Abstract]) AND ("humans"[MeSH Terms] AND (English[lang] OR French[lang] OR German[lang] OR Italian[lang] OR Spanish[lang] OR Dutch[lang] OR Polish[lang]))) AND (((((("children"[Title/Abstract] OR "adolescent"[Title/Abstract]) OR "child" [Title/Abstract]) OR "pupil"[Title/Abstract]) OR "pupils"[Title/Abstract]) OR "student"[Title/Abstract]) OR "students"[Title/Abstract] AND ("humans"[MeSH Terms] AND (English[lang] OR French[lang] OR German[lang] OR Italian[lang] OR Spanish[lang] OR Dutch[lang] OR Polish[lang])))) AND ((()("intervention"[Title/Abstract] OR "school intervention"[Title/Abstract]) OR "school health promotion"[Title/Abstract]) OR "classroom health education"[Title/Abstract]) OR "prevention intervention"[Title/Abstract]) OR "health education"[Title/Abstract]) OR "health promotion"[Title/Abstract] AND ("humans"[MeSH Terms] AND (English[lang] OR French[lang] OR German[lang] OR Italian[lang] OR Spanish[lang] OR Dutch[lang] OR Polish[lang]))) AND ("humans"[MeSH Terms] AND Journal Article[ptyp] AND (English[lang] OR French[lang] OR German[lang] OR Italian[lang] OR Spanish[lang] OR Dutch[lang] OR Polish[lang]))

2. (()((()(intervention[Title/Abstract]) OR "school intervention"[Title/Abstract]) OR "school health promotion"[Title/Abstract]) OR classroom health education[Title/Abstract]) OR "primary prevention intervention"[Title/Abstract]) OR "health education"[Title/Abstract]) OR "health promotion" [Title/Abstract])) AND (((((adolescent[Title/Abstract]) OR pupil[Title/Abstract]) OR child[Title/Abstract]) OR children[Title/Abstract]) OR student[Title/Abstract])) AND ((((("performance test"[Title/Abstract]) OR "math grade"[Title/Abstract]) OR "science grade"[Title/Abstract]) OR "English grade"[Title/ Abstract]) OR "social study"[Title/Abstract]) OR mathematics[Title/Abstract]) AND (Journal Article[ptyp])

3. (()((()((intervention[Title/Abstract]) OR "school intervention"[Title/Abstract]) OR "school health promotion"[Title/Abstract]) OR classroom health education[Title/Abstract]) OR "primary prevention intervention"[Title/Abstract]) OR "health education"[Title/Abstract]) OR "health promotion" [Title/Abstract])) AND (((((adolescent[Title/Abstract]) OR pupil[Title/Abstract]) OR child[Title/Abstract])

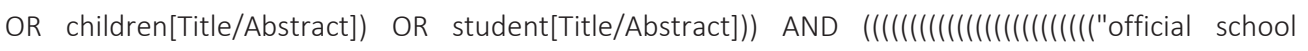


grade"[Title/Abstract]) OR "standardized national examination"[Title/Abstract]) OR "CAT"[Title/ Abstract]) OR "Californian achievement test"[Title/Abstract]) OR "comprehensive assessment test" [Title/Abstract]) OR FCAT[Title/Abstract]) OR "Florida comprehensive assessment test"[Title/Abstract]) OR "GCSE"[Title/Abstract]) OR "general certificate of secondary education"[Title/Abstract]) OR "STAR"[Title/Abstract]) OR "standardized testing and reporting"[Title/Abstract]) OR "province wide examination"[Title/Abstract]) OR "CTBS"[Title/Abstract]) OR "California test of basic skills" [Title/Abstract]) OR "SAT"[Title/Abstract]) OR "standard achievement test"[Title/Abstract]) OR "MAT6"[Title/Abstract]) OR "MAT7"[Title/Abstract]) OR "metropolitan achievement test"[Title/ Abstract]) OR "student assessment test"[Title/Abstract]) OR "Stanford achievement test"[Title/ Abstract]) OR "Terranova standardized test"[Title/Abstract]) OR "TERRANOVA"[Title/Abstract]) OR "EOG"[Title/Abstract]) OR "end-of-grade standardized test"[Title/Abstract]) AND (Journal Article[ptyp])

\section{PsyclNFO}

\section{Search queries}

1. Abstract ( (academic achievement) OR (academic performance) OR (academic functioning) OR (academic success) OR (academic grade) OR (academic test-score) OR (school grade) OR (educational performance) OR (educational functioning) OR (educational achievement) OR (learning performance) OR (learning functioning) OR (educational achievement) OR (learning performance) OR (learning functioning) OR (learning achievement) OR (learning success) OR (scholastic outcome) OR (scholastic outcomes) OR (scholastic achievement) OR (scholastic success) OR (academic growth) OR (vocabulary test) OR (academic competence learning capacity) OR (test-score) OR (examination mark) OR (student's overall GPA) OR (grade level) OR (GPA) OR (Grade-point average) OR (math achievement) OR (English achievement) OR (standardized reading) OR (class grade) OR (performance test)) and Abstract ( (intervention) OR (school intervention) OR (school health promotion) OR (classroom health education) OR (primary prevention intervention) OR (health education) OR (health promotion) ) and Abstract ( (children) OR (adolescent) OR (pupils) OR (student)) and health and Language: Dutch, English, German, Italian, Polish, Spanish; Age Groups: Childhood (birth-12 yrs), Preschool Age (2-5 yrs), School Age (6-12 yrs), Adolescence (13-17 yrs), Adulthood (18 yrs \& older), Young Adulthood (18-29 yrs); Population Group: Human, Male, Female

Limits: Language: Dutch, English, German, Italian, Polish, Spanish; Age Groups: Childhood (birth-12 yrs), Preschool Age (2-5 yrs), School Age (6-12 yrs), Adolescence (13-17 yrs), Adulthood (18 yrs \& older), Young Adulthood (18-29 yrs); Population Group: Human, Male, Female, Publication Type: All Journals

2. Abstract ( (("math grade") OR ("English grade") OR("science grade") OR ("mathematics") OR ("social study") OR ("performance test")) ) and Abstract ( ((intervention) OR ("school intervention") OR ("school health promotion") OR ("classroom health education") OR ("primary prevention intervention") OR ("health education") OR ("health promotion")) ) and Abstract ( (children) OR (adolescent) OR (pupil) OR (student) ) and Abstract health and Language: Dutch, English, German, 
Italian, Polish, Spanish; Age Groups: Childhood (birth-12 yrs), Preschool Age (2-5 yrs), School Age (6-12 yrs), Adolescence (13-17 yrs), Adulthood (18 yrs \& older), Young Adulthood (18-29 yrs); Population Group: Human, Male, Female

3. Abstract ( ("official school grade") OR ("standardized national examination") OR ("CAT") OR ("Californian achievement test") OR ("GCSE") OR ("general certificate of secondary education") OR ("CTBS") OR ("california test of basic skills") OR ("SAT") OR ("standard achievement test") OR ("MAT6") OR ("metropolitan achievement test") OR ("MAT7") OR ("student assessment test") OR ("Stanford achievement test") OR ("Terranova standardized test") OR ("TERRANOVA") OR ("EOG") OR ("End-ofgrade standardized test") ) and Abstract ( (intervention) OR ("school intervention") OR ("school health promotion") OR ("classroom health education") OR ("primary prevention intervention") OR ("health education") OR ("health promotion") ) and Abstract ( (children) OR (adolescent) OR (pupil) OR (student) ) and Language: Dutch, English, German, Italian, Polish, Spanish; Age Groups: Childhood (birth-12 yrs), Preschool Age (2-5 yrs), School Age (6-12 yrs), Adolescence (13-17 yrs), Adulthood (18 yrs \& older), Young Adulthood (18-29 yrs); Population Group: Human, Male, Female 


\section{Appendix 2}

Table A2.1: Path-analyses for sustainable collaboration, execution of the HSA activities and collaborative support based on difference scores between pre- and posttest

\section{Multi-level analysis Effect size}

Cohen's d /

b SE (b) F p-value

Cohen's $f^{2}$

Sustainable collaboration

Intervention

Collaborative support

Change management

Project management

Context

External factors

.280

.294

.037

.042

.068

$-.033$

.085

.093

.080

.047

.064

.054

10.913

10.058

.216

.804

1.131

.379

.57

.07

.643

.372

.289

.539

Execution of HSA activities

\begin{tabular}{|c|c|c|c|c|c|}
\hline Intervention & -.027 & .089 & .094 & .759 & \\
\hline Collaborative support & .338 & .096 & 12.446 & $.001^{* *}$ & .10 \\
\hline Change management & .150 & .079 & 3.632 & $.059^{\circ}$ & .02 \\
\hline Project management & -.106 & .048 & 4.926 & $.028^{*}$ & .03 \\
\hline Context & -.008 & .062 & .018 & .893 & \\
\hline External factors & .022 & .057 & .143 & .706 & \\
\hline \multicolumn{6}{|c|}{ Collaborative support } \\
\hline Intervention & .135 & .067 & 3.994 & $.051^{\circ}$ & .30 \\
\hline Change management & .305 & .061 & 24.753 & $.000 * *$ & .18 \\
\hline Project management & .155 & .038 & 16.289 & $.000^{* *}$ & .13 \\
\hline Context & .152 & .052 & 8.459 & $.004^{* *}$ & .08 \\
\hline External factors & .101 & .045 & 5.088 & $.026^{*}$ & .02 \\
\hline
\end{tabular}

${ }^{\circ} p<.10,{ }^{*} p<.05, * * p<.01, * * * p<.001$ 
Table A2.2: Influence of the DISC-based trajectory on the DISC factors, sustainable collaboration and execution of the HSA activities

\begin{tabular}{|c|c|c|c|c|c|}
\hline & \multicolumn{4}{|c|}{ Multi-level analysis } & \multirow{2}{*}{$\begin{array}{r}\text { Effect size } \\
\text { Cohen's d }\end{array}$} \\
\hline & $b$ & SE (b) & $\mathrm{F}$ & $p$-value & \\
\hline \multicolumn{6}{|l|}{ DISC factors } \\
\hline Collaborative support & .333 & .083 & 15.980 & $.000^{* * *}$ & .47 \\
\hline Change management & .334 & .129 & 6.709 & $.011^{* *}$ & .39 \\
\hline Project management & .507 & .180 & 7.962 & $.006^{* *}$ & .44 \\
\hline Context & .007 & .123 & 0.003 & .957 & .01 \\
\hline External factors & .340 & .143 & 5.616 & $.019 *$ & .37 \\
\hline \multicolumn{6}{|l|}{ Outcome measures } \\
\hline Collaborative support & -.360 & .114 & 9.974 & $.002^{* *}$ & .51 \\
\hline Sustainable collaboration & .364 & .891 & 16.678 & $.000^{* * *}$ & .66 \\
\hline Executed HSA activities & .172 & .092 & 3.485 & $.065^{\circ}$ & .34 \\
\hline
\end{tabular}

${ }^{0} p<.10,{ }^{*} p<.05,{ }^{* *} p<.01,{ }^{* * *} p<.001$ 


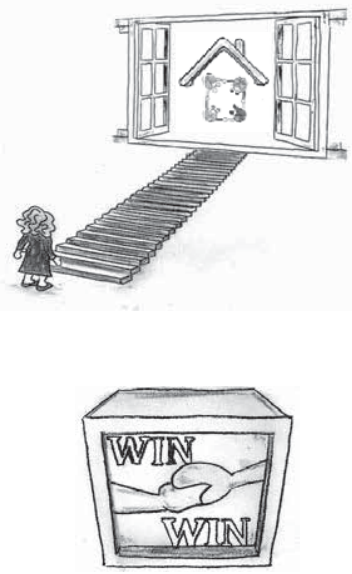

Summary
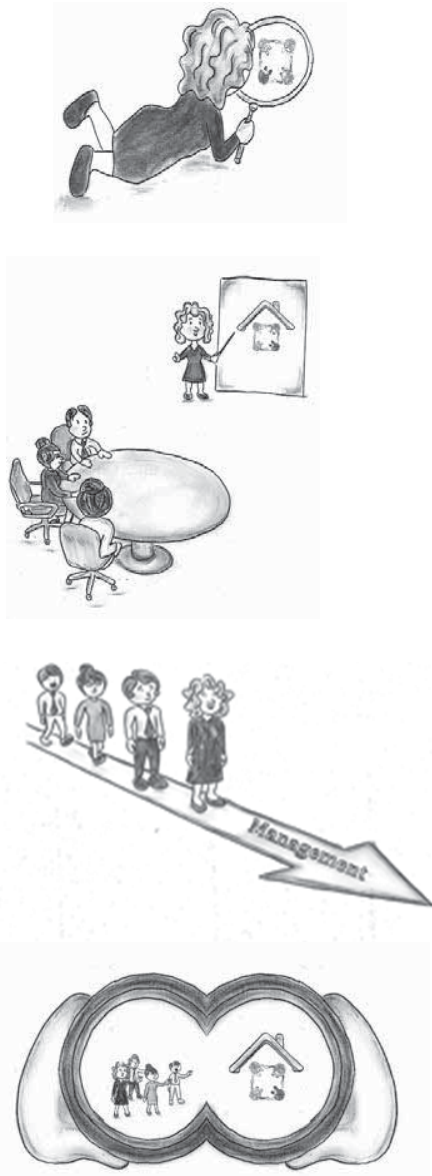

Comprehensive school health promotion (CSHP) is one of the comprehensive approaches to public health which requires collaboration between several sectors for its successful implementation. Although CSHP is endorsed by the World Health Organization (WHO) and regarded as an effective means to improve the health status of the school-age population, including teachers and school staff, its implementation needs to be further improved (IUHPE, 2009; Lister-Sharp et al., 1999; St Leger, 1999; Stewart-Brown, 2006). More effective collaboration is needed between the health sector and the educational sector, creating clear win-win situations for both sectors. In addition, a cooperative infrastructure is necessary which stimulates schools, public service stakeholders (PSSs) and funding, policy-making (e.g. municipal authorities) and executing bodies (i.e. public health services (PHSS)) to work together on the design, implementation, and future perspectives of school health promotion.

This dissertation aimed to elucidate benefits of school health promotion in terms of educational goals. A systematic review of published school-based health promotion interventions was conducted, to evaluate the effects of these interventions on students' academic success (Part I).The second aim of the dissertation was to evaluate a systematic approach based on the Dlagnosis of Sustainable Collaboration (DISC) model, to develop collaboration between schools, municipal authorities, PHSs and PSSs in CSHP in the Netherlands. During a two-year DISC-based trajectory, regional CSHP coordinators in six Dutch regions (five of which completed the trajectory) were supported in diagnosing the state of the CSHP collaboration and formulating strategies to improve the collaborations based on the diagnostic results. They were also advised about implementing appropriate strategies. The determinants of collaboration included in the conceptual framework - the DISC model - were addressed in the trajectory: project management, change management, collaborative support, context, external factors, and sustainable collaboration (Part II).

Chapter 1 introduces the topics of PART I and PART II of this dissertation. As regards Part I, it offers the rationale for the relation between school health promotion and academic performance. Recent work on this relation is discussed, as are existing gaps in the scientific literature. The objectives of the systematic review are presented. Concerning Part II, the chapter first describes the context of CSHP and intersectoral collaboration in the Netherlands, including the way CSHP is organized, the stakeholders and their tasks, and the history of CSHP implementation. Second, it presents an overview of the conceptual framework (i.e. the DISC model), the study design (pretest-posttest study) and the inquiry process (i.e. action research) that were used to systematically develop intersectoral collaboration in CSHP and to evaluate the effects and processes of this systematic approach. It also presents the objectives of the evaluation study. Finally, it outlines the contents of the dissertation. 


\section{Part I}

Chapter 2 presents the results of a systematic review which aimed to evaluate the benefits of school health promotion for the educational sector. The systematic review included studies on the effects and related mediators of school health promotion interventions on academic performance. We included methodologically sound studies (i.e. randomized controlled trials (RCTs), cross-over controlled trials and quasi-experimental designs with pre- and posttest) of school-based interventions targeting general school populations. The studies also had to assess the effects on standardized measures of academic performance and the interventions were not allowed to contain elements directly related to the normal teaching and learning program. These criteria were met by only seven studies (from an initially retrieved set of 1040) on interventions targeting physical activity, healthy diet, or a combination of both. Small to large effects on academic performance were found across academic subjects. No negative effects were found, even when time for the intervention was taken away from academic subjects. Mediators suggested by the authors of the reviewed studies included physiological, neuro-hormonal and cognitive conditions, such as students 'psychomotor skills, arousal levels, self-esteem, and nutrition balance. In addition, teachers' competencies and self-esteem, which can impact teaching practices, were suggested as indirect mechanisms. The review also compared broad versus limited approaches to school health promotion, with regard to their effects on academic performance. The comparison was hampered by the fact that only one reviewed intervention study referred to a broad approach. Despite some limitations, such as the small number of studies, all from the same geographical origin, one relatively old publication and limited or no assessment of important moderators (i.e. gender and SES), the results suggest that health promotion interventions can produce academic gains for the general school population. Consequently, we can postulate that school health promotion seems to offer benefits for the educational sector in terms of their primary goal: academic development. Implications for future research were formulated.

\section{Part II}

Chapter 3 shows the results of the diagnostic evaluation of facilitators and barriers conducted in five CSHP collaborations and four sectors (schools, municipalities, PSSs, and PHSs) which had just started the DISC-based trajectory. For this purpose, regional coordinators had to identify relevant stakeholders in the collaboration for CSHP and ask them to complete the DISC questionnaire. The results demonstrated that the five regions were in the initial stage of collaboration, characterized by impressive positive perceptions about the CSHP. These positive perceptions were as yet hardly translated into positive intentions (e.g. intentions to change and to commit) and actions (e.g. changes within their own organization to introduce CSHP). Overall, the internal organization (e.g. openness to innovations) and external context 
(e.g. whether CSHP fits in with public health) were favorable for the collaboration, apart from the many existing bureaucratic procedures and high aspirations for the stakeholders' own organizational goals, as reported by the parties involved. Less encouraging were the low scores on change management (e.g. change strategies and network development) and project management (e.g. clear task distribution and communication), which left much room for improvement. The coordinators of the collaborations were PHSs, which were proactive and offered much collaborative support. PSSs were reactive, undecided, and offered less collaborative support. Municipal authorities were least involved and reported the lowest degree of support for collaboration. Schools were found to represent the most favorable context for the implementation of CSHP, though it seemed that they were not able to translate their enthusiasm about CSHP into practice. Applying the literature on planned organizational change and organizational behavior (Dür, 2013; Plsek \& Greenhalgh, 2001; Plsek \& Wilson, 2001), coalition building (Axelsson \& Axelsson, 2006; Bohlmeijer et al., 2005; Van Raak et al., 1999), and group dynamics (McMorris et al., 2005; Tuckman, 1965) to the DISC results enabled realistic expectations about the further collaborative process and the formulation of recommendations for practice. Based on our results we can conclude that DISC analysis can be used to diagnose facilitators and barriers in different kinds of collaborations in their initial stage and in different sectors, though specific knowledge is required to interpret the results of the analysis.

In the follow-up to the trajectory, the DISC results and recommendations were fed back to the regional coordinators of the CSHP collaborations. This was followed by the formulation of a DISC-based strategy to enhance change management and project management: (1) bring the stakeholders together, (2) develop a common vision, (3) identify the possibilities and impossibilities for each collaborating partner based on the DISC analysis, (4) determine the intended collaborative structure, (5) develop a task distribution based on the information, and (6) discuss the choices at management and executive levels. Regional coordinators were advised to follow this strategy and were supported in its implementation for one year by experienced professionals. The collaborative process was monitored during this year and an additional one-year follow-up period. After the follow-up period, a new diagnostic evaluation of the collaboration was performed, and the results, together with the baseline measurement, were used for the purpose of effect evaluation.

In Chapter 4, the longitudinal data of the DISC analyses and of the monitoring process are used to evaluate the effectiveness and related collaborative processes of the two-year trajectory. The study of effects, which compared the results of the DISC analyses at the beginning and end of the trajectory, showed that the targets of the DISC-based strategy were met. Change management and project management had improved at one-year follow-up. There was also more support among stakeholders, including greater levels of consensus, commitment, and formalization of CSHP. In addition, the actors involved reported more 
alignment between policies. However, no improvement was found regarding other collaborative actions, such as changes to introduce CSHP within stakeholders' own organization or investments of resources. The monitoring data of the collaborative processes allowed five managerial styles to be identified: (1) involving stakeholders in the decisionmaking process regarding CSHP, (2) informing potential close and distant stakeholders about CSHP-related activities, (3) controlling and (4) supporting the collaborative process as soon as it has entered the performance stage, and (5) coordinating collaborative activities, including the integration of information and the formalization of decisions made. The qualitative data showed that collaborations were going through many internal developments (e.g. mergers, reorganizations) and had entered a new public health policy cycle. The types of managerial activities identified also indicated that regional coordinators used these dynamics to enhance the visibility of CSHP, to build facilitating policies and to establish crucial connections with existing policies. Presenting both types of results helped us find out whether the systematic approach had favorably influenced the collaborations. The triangulation of results indeed indicated at several aspects that the DISC-based strategy related to the managerial activities employed by regional coordinators and the observed improvements regarding the DISC factors, thus supporting the effectiveness of the systematic approach. In addition, the dynamic context of the collaborations seemed to offer a plausible explanation for the delays in collaborative actions. A longer follow-up period might have enabled us to identify further actions. Interesting by-products of this study for managers engaged in similar collaborations are the DISC-based strategy and the managerial options pertaining to the five managerial styles we identified.

In Chapter 5, the longitudinal data of the DISC analyses are used to quantitatively study the predictors and mediators of sustainable collaboration and CSHP implementation. Path analyses were conducted of the relation between the DISC-based trajectory, the DISC constructs, and the intended outcomes, i.e. implementing CSHP and ensuring the sustainability of the collaboration. The results of these analyses supported some of the findings of the previous study. Change management and project management had improved and together contributed to enhanced collaborative support among stakeholders. The evaluations of external factors had also improved and positively contributed to stakeholders' collaborative support. An additional finding to the previous study was that the five DISC constructs (i.e. change management, project management, external factors, context, and collaborative support) predicted a considerable proportion of the change that occurred in the outcome measures studied, viz. 19\% of the variance in the implementation of CSHP and 26\% of the variance in the sustainability of the collaboration. Path analyses showed that stakeholders' collaborative support was a direct predictor of the implementation of CSHP and the sustainability of the collaboration. More striking was that the influences of the other DISC factors on sustainable collaboration were fully mediated by the support factor. Partial 
mediation was demonstrated when the implementation of CSHP was used as the outcome. Not only collaborative support, but also change management directly and positively influenced the implementation of CSHP. Apparently, strategies targeting the use of change management principles (i.e. a common vision and change strategies) were necessary for the implementation of CSHP, too. Unexpectedly, project management had a direct negative influence on the implementation of CSHP. We explained this finding from the focus on negotiation to reach consensus and commitment in the trajectory. Too much focus on negotiation had probably prevented the collaboration from getting things done. The findings seem to suggest that strategies addressing the DISC factors can directly and indirectly enhance collaborative support and thereby promote the implementation of CSHP and the sustainability of collaboration.

Chapter 6 discusses the two objectives of the dissertation: (1) studying the benefits of school health promotion in line with the primary educational goals and (2) evaluating the effectiveness of a systematic approach based on the DISC model to establish intersectoral collaboration for CSHP. The main findings, methodological and practical considerations are discussed, as are the implications for research and practice. As regards the first objective, it is concluded that school health promotion interventions can create a win-win situation for the health and educational sectors. However, the limited evidence needs to be strengthened by collaborative research in which the collection, analysis, and utilization of data is facilitated by both sectors. Since our review was performed, more and corroborating evidence has been reported. As regards the second objective, it is concluded that the DISC model can be used as a diagnostic instrument in various kinds of collaborations. But the generalizability of this finding is limited to the initial stage of collaboration, in view of the developmental stage we have studied. It is also concluded that crucial elements in the systematic approach were the DISC analyses we employed, the DISC-based strategy we formulated, the regional coordinators acting as 'social entrepreneurs/champions' and the main advisor in the trajectory, who functioned as a 'critical friend'. Because of the study design - a pretestposttest design without a control group - we have to be very cautious about drawing conclusions regarding causal relations between these elements and the observed improvements at the three levels, viz. the determinants of collaboration (the DISC factors), the implementation of CSHP, and the sustainability of the collaboration. However, the mixed methods approach (i.e. multiple data sources and methods) strengthens our conclusions. Future research should focus on optimizing the DISC model for diagnostic purposes and identifying effective strategies, managerial options, and their contingencies for use in studies with high internal validity and sufficient sample size. Implications are presented for the use of the DISC model in practice. (see p. 210 for references) 



\section{Samenvatting}

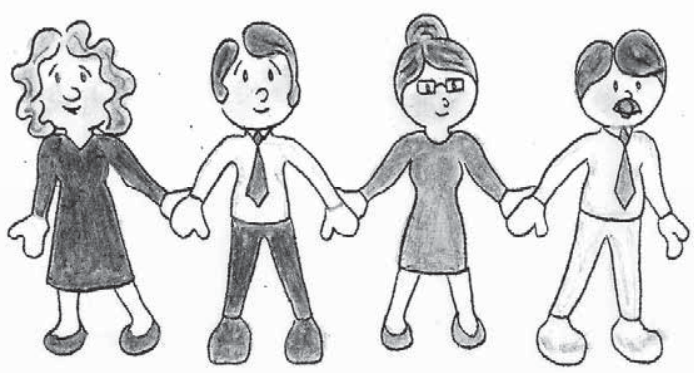



De "Gezonde School" - internationaal bekend als "Comprehensive School Health Promotion (CSHP)" - is een planmatige aanpak voor gezondheidsbevordering op scholen, waarin de gezondheid van schoolkinderen, hun ouders, docenten en de hele schoolgemeenschap centraal staat. Het is een voorbeeld van een initiatief in de public health met een integratieve benadering van gezondheid. De Gezonde School besteedt dus niet alleen aandacht aan factoren in het kind, die te maken kunnen hebben met een (on)gezonde leefstijl (bijv. gebrek aan kennis over wat een gezonde leefstijl is of juist de aanwezigheid daarvan), maar houdt tevens rekening met invloeden vanuit de sociale (bijv. docenten die een (on)gezonde leefstijl hebben) en fysieke omgeving (bijv. schoolpleinen die uitnodigen fysiek actief te zijn of juist niet) (Allensworth, Wyche, Lawson, \& Nicholson, 1995; IUHPE, 2009). Zodoende treffen we in een Gezonde School een combinatie van programma's aan, zoals educatieve lesprogramma's met als doel kennisoverdracht en aanleren van vaardigheden, gezondheidsprogramma's voor leerkrachten en schoolstaf, alsook interventies gericht op het schoolgebouw en plein. Alhoewel internationaal de Wereldgezondheids-organisatie (Engels: Word Health Organization; WHO) het gedachtegoed van de Gezonde School onderschrijft, en de werkwijze als de manier beschouwt om de gezondheidstoestand van scholieren effectief te verbeteren, verloopt de implementatie van de Gezonde School traag (IUHPE, 2009; Lister-Sharp, Chapman, Stewart-Brown, \& Sowden, 1999; St Leger, 1999; Stewart-Brown, 2006). Om het implementatieproces te verbeteren is, onder andere, meer samenwerking gewenst tussen de sector gezondheid en de sector onderwijs. In het bijzonder is winst te behalen door grotere duidelijkheid over de voordelen van de Gezonde School voor de sector onderwijs. Hierbij kan gedacht worden aan hoe de Gezonde School aansluit bij de kerndoelen van het onderwijs, waaronder taal-, reken- en schrijfvaardigheden. Bovendien dient een samenwerkingsstructuur ingericht te worden, die belangrijke partijen, zoals scholen, preventieorganisaties (bijv. welzijn en sport organisaties), financiers (gemeenten), beleidsmakers en uitvoerders (gemeentelijke gezondheidsdienst (GGD)) met elkaar verbindt en tegelijkertijd stimuleert om samen de Gezonde School verder te ontwikkelen, te implementeren en haalbare perspectieven voor de toekomst uit te werken.

Deze dissertatie had als eerste doel de voordelen van gezondheidsbevorderende en preventieve programma's op scholen voor de sector onderwijs inzichtelijk te maken, in het bijzonder met het oog op het behalen van de kerndoelen van het onderwijs. Hiervoor zijn aan de hand van een systematisch literatuuronderzoek bestaande schoolgezondheidsinterventies in kaart gebracht en beoordeeld in termen van hun effecten op de leerprestaties van scholieren (deel I). Een tweede doel van deze dissertatie betrof de evaluatie van een systematische aanpak die beoogde de samenwerking tussen scholen, gemeenten, GGD'en en preventieorganisaties ten behoeve van de Gezonde School te verbeteren. Hiervoor zijn de Gezonde School-coördinatoren van zes regio's, verspreid over Nederland, gedurende een tweejarig traject (vijf regio's hebben het hele traject doorlopen) ondersteund bij het 
uitvoeren van een sterke-zwakte-analyse van de bestaande samenwerking en het formuleren van passende strategieën om de samenwerking te verbeteren. Bovendien werden ze ondersteund bij het in praktijk brengen van de geformuleerde strategieën. De sterkte-zwakteanalyse werd gebaseerd op het Dlagnosis of Sustainable Collaboration (DISC) model dat de volgende determinanten van samenwerking omvat: projectmanagement, verandermanagement, draagvlak bij de samenwerkingspartners, context, externe factoren en duurzame samenwerking (deel II).

Hoofdstuk 1 introduceert de onderwerpen behandeld in deel I en deel II van deze dissertatie. Het hoofdstuk begint met de uiteenzetting van de relatie tussen gezondheidsbevordering en preventie op scholen enerzijds en academische prestaties van leerlingen anderzijds, gevolgd door een samenvatting van voorafgaand onderzoek en geïdentificeerde hiaten in de wetenschappelijke literatuur. De hieruit voortgekomen onderzoeksvragen voor het systematisch literatuuronderzoek dat in het kader van dit proefschrift is uitgevoerd, zijn vervolgens beschreven (deel I). Het hoofdstuk gaat verder met een beschrijving van de context waarin CSHP zich in Nederland afspeelt. De samenwerkende partijen en hun taken worden genoemd, alsook de activiteiten die in Nederland hebben plaatsgevonden om de Gezonde School een plek te geven in de dagelijkse praktijk. Daarna volgt een beschrijving van het conceptueel kader (het DISC model), het studiedesign (pretest-posttest design) en het proces van onderzoek (actiegericht onderzoek) waarmee is gewerkt om op een systematische manier de samenwerking tussen betrokkenen bij de Gezonde School te bestuderen en te bevorderen. Tevens worden hiermee de processen en effecten van de systematische aanpak geëvalueerd. Tot slot zijn de onderzoeksvragen die leidend waren voor het evaluatieonderzoek beschreven.

\section{Deel I}

Hoofdstuk 2 presenteert de resultaten uit het systematisch literatuuronderzoek. De effecten van schoolgezondheidsprogramma's op academische prestaties van scholieren zijn bekeken. Alleen methodologisch verantwoorde interventies (gerandomiseerde en gecontroleerde studies, cross-over gecontroleerde studies en quasi-experimentele studies met pretest en posttest), met als doelgroep de algemene schoolpopulatie, zijn geïncludeerd in het onderzoek. Daarnaast mochten deze interventies alleen gestandaardiseerde maten van academische prestaties gebruiken en geen elementen bevatten die leidden tot aanpassingen van reguliere onderwijspraktijken of de reguliere leerstof. Slechts zeven interventies (uitgaande van een verzameling van 1040 bekeken studies) voldeden aan deze criteria. Deze geïncludeerde studies bleken zich uitsluitend te richten op fysieke activiteit, gezonde voeding of een combinatie van beide. De gevonden effectgroottes voor leerprestaties varieerden van klein tot groot in verschillende vakken. Er werden geen negatieve effecten op leerprestaties 
gevonden, ondanks het feit dat een deel van de onderwijstijd werd gebruikt voor de interventie. Enkele verklarende variabelen voor het positief verband die door de auteurs van de beoordeelde studies genoemd werden, zijn verbeterde psychologische, neurohormonale en cognitieve condities van het kind. Zo nemen auteurs aan dat interventies gericht op fysieke activiteit de psychomotorische ontwikkeling van het kind, de mate van zijn/haar concentratie en zijn/haar zelfvertrouwen positief zouden kunnen hebben beïnvloed. Slechts de auteur van één voedingsinterventie gericht op het aanbieden van ontbijt op school, noemde mogelijke mechanismen waardoor de voedingsinterventie de leerprestaties van leerlingen zou kunnen hebben beïnvloed. De auteur stelde dat het ontbijt mogelijk een direct effect heeft gehad op de cognitie van leerlingen, maar hij sloot een mogelijke lange-termijn effect door een verbeterde 24 uur energie-inname of een combinatie van lange- en korte-termijn effecten niet uit. Bovendien zouden de interventies het zelfvertrouwen en competenties van docenten kunnen hebben versterkt, en daarmee hun lespraktijken hebben verbeterd. Zodoende zouden interventies via dit indirecte mechanisme de leerprestaties van kinderen kunnen hebben verbeterd. Tevens had het literatuuronderzoek tot doel om inzichtelijk te maken of kinderen die blootgesteld waren aan een integratief schoolprogramma, zoals nagestreefd in de Gezonde School, beter presteerden dan kinderen die deelnamen aan een programma waaraan geen integratieve benadering ten grondslag lag. Deze onderzoeksvraag kon onmogelijk worden beantwoord, doordat maar één studie naar een integratieve benadering werd gevonden. Ondanks de beperkingen, zoals het kleine aantal studies, alle van dezelfde geografische herkomst, een relatief oude publicatie en beperkte of geen bepaling van belangrijke moderatoren (bijv. geslacht en socio-economische status), laten de resultaten zien dat gezondheidsbevorderende programma's in het onderwijs positief kunnen uitpakken voor academische prestaties van leerlingen en dus bijdragen aan de kerndoelen van het onderwijs. Toekomstig onderzoek zou meer houvast aan de resultaten moeten bieden. Duidelijke implicaties zijn geformuleerd.

\section{Deel II}

Hoofdstuk 3 presenteert de bevindingen uit de sterkte-zwakte-analyse van de samenwerkingsverbanden ten behoeve van de Gezonde School in de GGD regio's gebaseerd op het DISC model. Aan het begin van het tweejarige traject is deze analyse uitgevoerd bij vertegenwoordigers van vier sectoren: scholen, gemeenten, preventieorganisaties en GGD'en. Hiervoor hebben de Gezonde School-coördinatoren relevante vertegenwoordigers geïdentificeerd en hen voor het invullen van de DISC vragenlijst benaderd. De resultaten laten zien dat de samenwerking zich in de beginfase bevond en zich kenmerkte door zeer positieve percepties over de Gezonde School, maar minder positieve intenties (bijv. commitment tot samenwerking) en weinig acties (bijv. veranderingen binnen de organisatie voor de Gezonde 
School) betreffende de samenwerking. Afgezien van bureaucratie en grote druk om de eigen organisatorische doelen te behalen, waren er volgens de respondenten zowel binnen hun eigen organisatie alsook daarbuiten goede voorwaarden voor samenwerking (bijv. openheid voor innovaties, faciliterende wet- en regelgeving). Minder positief waren hun evaluaties met betrekking tot verandermanagement (bijv. toepassing van veranderingsstrategieën en netwerkontwikkeling) en projectmanagement (bijv. een duidelijke taakverdeling en communicatie). Bovendien lieten de analyses verschillen per sector zien. GGD'en - de coördinerende organisaties - waren het meest proactief met het meeste draagvlak voor samenwerking. Preventieorganisaties vertoonden minder draagvlak, waren afwachtend en besluiteloos. Gemeenten waren nauwelijks betrokken bij het samenwerkingsproces en hadden daarvoor het minste draagvlak. Scholen evalueerden hun context grotendeels positief voor invoering van de Gezonde School, hoewel het nog haperde aan het vertalen van hun enthousiasme naar de praktijk. Aan de hand van de literatuur op het gebied van "planned organisational change" and "organizational behavior" (Dür, 2013; Plsek \& Greenhalgh, 2001; Plsek \& Wilson, 2001), "coalition building" (Axelsson \& Axelsson, 2006; Bohlmeijer, Ruland, Van Raak, \& Mur-Veeman, 2005; Van Raak, Mur-Veeman, \& Paulus, 1999) en "group dynamics" (McMorris, Gottlieb, \& Sneden, 2005; Tuckman, 1965) konden we de genoemde bevindingen interpreteren, en tot realistische verwachtingen over het verdere verloop van de samenwerking komen en ook passende adviezen voor de praktijk formuleren. Op basis van het onderzoek kunnen we concluderen dat een sterkte-zwakte-analyse gebaseerd op het DISC model goed inzetbaar is in het vroege stadium van verschillende soorten samenwerkingen en in diverse sectoren. $\mathrm{Er}$ is wel specifieke kennis nodig om de bevindingen uit de sterktezwakte-analyse adequaat te interpreteren.

$\mathrm{Na}$ de sterkte-zwakte-analyse werden de resultaten en adviezen naar de regiocoördinatoren teruggekoppeld en een strategie gebaseerd op het DISC model geformuleerd voor het verbeteren van het verander- en projectmanagement. De strategie bevatte de volgende stappen: (1) samenbrengen van samenwerkingspartners, (2) ontwikkelen van een gezamenlijke visie, (3) identificeren van de mogelijkheden en onmogelijkheden voor samenwerking met betrokkenen op basis van de sterkte-zwakte-analyse, (4) bepalen van de wenselijke samenwerkingsstructuur, (5) maken van een taakverdeling gebaseerd op de informatie (6) en bespreken van de gemaakte keuzes met het management en uitvoerders. De regiocoördinatoren werden gedurende een jaar ondersteund in de implementatie van de geformuleerde strategie door ervaren professionals. In dat jaar en de daarop volgende followup-periode van één jaar werd het implementatieproces gemonitord. Na afloop van de followup werd een nieuwe sterkte-zwakte-analyse uitgevoerd, welke samen met de eerste analyse ter evaluatie van het effect diende. 
In hoofdstuk 4 werden de longitudinale data van zowel de sterkte-zwakte-analyses alsook de monitoring gebruikt om het tweejarige DISC traject te evalueren in termen van effectiviteit en gerelateerde samenwerkingsprocessen. De effectstudie, waarin de eerste en de tweede sterkte-zwakte-analyse met elkaar werden vergeleken, liet zien dat de doelen gesteld in het traject waren behaald. Na afloop van de follow-up-periode waren verander- en projectmanagement verbeterd. Tevens werd meer draagvlak voor samenwerking bij de betrokkenen gevonden, waaronder meer consensus, commitment en formalisatie omtrent de samenwerking binnen de Gezonde School. Tevens rapporteerden de partners meer afstemming tussen beleidsterreinen, hoewel er geen verbetering werd gevonden op acties, zoals veranderingen binnen de eigen organisatie of investering van resources ten behoeve van de Gezonde School. Uit de monitoringdata konden vijf managementactiviteiten afgeleid worden, waaronder: (1) het betrekken van de samenwerkingspartners bij beslissingen rondom de Gezonde School, (2) het informeren van potentiële, nauw betrokken en ver afstaande partners, (3) het controleren (4) en ondersteunen van het samenwerkingsproces zodra dat de uitvoering inging en (5) het coördineren van samenwerkingsactiviteiten door de integratie van informatie en het formaliseren van gemaakte beslissingen. Tevens werden processen en instrumenten geïdentificeerd die door de coördinatoren werden gebruikt om de genoemde managementactiviteiten in de praktijk in te zetten. Bovendien lieten de monitoringdata zien dat betrokken organisaties gedurende het traject veel interne ontwikkelingen doorgemaakt hadden (bijv. fusies en reorganisaties) en een nieuwe beleidscyclus ingegaan waren. Deze dynamische context werd door regiocoördinatoren voor de samenwerking gebruikt door het vergroten van de zichtbaarheid van de Gezonde School, het ontwikkelen van faciliterend beleid en het bruggen bouwen tussen beleidsterreinen. De presentatie van zowel de resultaten uit de effectevaluatie alsook de procesevaluatie in één studie heeft ons geholpen te begrijpen of de systematische aanpak daadwerkelijk verantwoordelijk was voor de positieve ontwikkelingen in de samenwerkingen. De triangulatie van resultaten toonde op een aantal punten een samenhang tussen de geformuleerde DISC strategie, de managementactiviteiten toegepast door de coördinatoren en de geobserveerde verbeteringen op de DISC factoren aan. Hiermee werd de effectiviteit van de systematische aanpak ondersteund. Daarnaast bleek de dynamische context waarin de samenwerkingen verkeerden een plausibele verklaring voor vertraging in gezamenlijke acties. Met een langere follow-up-periode waren wellicht meer gezamenlijke acties gevonden. Interessante bijproducten voor managers in vergelijkbare samenwerkingen zijn de DISC strategie en de managementopties die de vijf gevonden managementactiviteiten karakteriseren.

In hoofdstuk 5 werden de longitudinale data van de sterkte-zwakte-analyses gebruikt om de voorspellers en mediatoren van een succesvolle samenwerking te onderzoeken. Hiervoor werden pad-analyses verricht voor de relatie tussen de interventie (het DISC traject), de DISC factoren en de nagestreefde doelen: de implementatie van de Gezonde School en het 
zekerstellen van de duurzaamheid van samenwerking. De resultaten uit de pad-analyses steunden de eerdere resultaten beschreven in hoofdstuk 4. Verandermanagement en projectmanagement waren verbeterd en droegen gezamenlijk bij aan het draagvlak voor samenwerking. Bovendien leidde de betere evaluatie van de externe factoren tot meer draagvlak. Aanvullend op de eerdere resultaten liet de analyse zien dat de vijf DISC factoren (te weten verandermanagement, projectmanagement, externe factoren, context en draagvlak) voor een groot deel de veranderingen op de bestudeerde uitkomstmaten voorspelden: de verklaarde variantie was $19 \%$ voor de implementatie van de Gezonde School en $26 \%$ voor de duurzaamheid van de samenwerking. Verder kwam uit het onderzoek naar voren dat draagvlak in directe relatie stond tot beide uitkomstmaten. Met betrekking tot de duurzaamheid van de samenwerking medieerde draagvlak zelfs volledig de invloeden van de overige DISC factoren. Voor de implementatie van de Gezonde School werd een gedeeltelijke mediatie gevonden. Niet alleen draagvlak, maar ook verandermanagement was een positieve voorspeller. Klaarblijkelijk was de toepassing van de principes van verandermanagement (bijv. het formuleren van een gemeenschappelijke visie) belangrijk voor de succesvolle implementatie van de Gezonde School. Onverwacht werd tevens een directe en negatieve relatie gevonden tussen projectmanagement en de implementatie van de Gezonde School. Dit resultaat werd verklaard door de focus in het DISC traject op het komen tot consensus en zekerstellen van commitment. Te veel focus op onderhandelen heeft wellicht de samenwerkingen ervan weerhouden om tot meer gezamenlijke actie te komen. Op basis van het onderzoek kan worden geconcludeerd dat strategieën die zich richten op de DISC factoren bevorderlijk kunnen zijn voor het creëren van draagvlak onder betrokkenen en daarmee aan zowel de implementatie van de Gezonde School alsook de duurzaamheid van de samenwerking kunnen bijdragen.

Hoofdstuk 6 bevat de algemene discussie van dit proefschrift. In de discussie wordt aandacht besteed aan belangrijke methodologische en praktische kwesties van het uitgevoerde onderzoek. Daarnaast worden er aanbevelingen voor toekomstig onderzoek en de praktijk geformuleerd. Met deel I van dit proefschrift werd nagestreefd de voordelen van schoolgezondheidsbevordering ten opzichte van de kerndoelen van het onderwijs inzichtelijk te maken. Deze voordelen hebben we kunnen aantonen in de systematische review die hiervoor is uitgevoerd. Echter, het aantal studies dat de relatie die in de literatuurstudie centraal stond heeft onderzocht, is nog beperkt. Om de empirische basis te versterken, moeten extra inspanningen door de sector onderwijs en gezondheid geleverd worden, zodat zowel de nodige data verzameld en geanalyseerd kunnen worden, alsook de resultaten toepassing in de praktijk vinden. Nieuw onderzoek verschenen sinds onze publicatie bevestigt deze bevindingen. Met deel II van dit proefschrift werd beoogd de effectiviteit van een systematische aanpak die gebaseerd was op het DISC model en tot doel had de samenwerking tussen betrokken sectoren in de Gezonde School te verbeteren, te evalueren. 
Op basis van het evaluatieonderzoek hebben we kunnen concluderen dat het DISC model schikt als diagnostisch instrument in een breed scala van samenwerkingen. De generalisatie van zijn toepassing blijft echter beperkt tot het vroege stadium, gezien het ontwikkelingsstadium van de onderzochte samenwerkingen zelf. Tevens werden er conclusies getrokken over de cruciale elementen van de systematische aanpak, waaronder de sterkte-zwakteanalyse, de geformuleerde DISC strategie, de regiocoördinatoren in hun rol als sociale ondernemers en "champions" en de hoofdadviseur in het traject, die als "critical friend" fungeerde. Gezien het design van het evaluatieonderzoek - een pretest-posttest onderzoek zonder controlegroep - is voorzichtigheid geboden bij uitspraken over de causale relatie tussen de genoemde elementen en de geobserveerde verbeteringen op de drie niveaus, te weten: de determinanten van samenwerking (de DISC factoren), de implementatie van de Gezonde School en de duurzaamheid van de samenwerking. Desalniettemin versterkt het mixed-methods design (gebruik van meerdere methoden en soorten data) onze conclusies. Toekomstig onderzoek zou zich moeten richten op het verbeteren van het DISC model voor diagnostische doeleinden en het identificeren van effectieve strategieën, managementopties en hun contingenties voor gebruik in studies met hoge interne validiteit en voldoende steekproefomvang. Implicaties zijn geformuleerd voor het gebruik van het DISC model in de praktijk. 


\section{References | Referenties}

Axelsson, R., \& Axelsson, S. B. (2006). Integration and collaboration in public health - a conceptual framework. The International Journal of Health Planning and Management, 21(1), 75-88.

Bohlmeijer, E., Ruland, E., Van Raak, A., \& Mur-Veeman, I. M. (2005). Procesmanagement in public health - ontwerp, analyse \& verandering (Processmanagement in public health design, analysis \& change). Utrecht: Trimbos.

Dür, W. (2013). Applying system theory of organizational change to health promotion interventions in schools and their problems. In O. Samdal \& L. Rowling (Eds.), The Implementation of Health Promoting Schools. Exploring the theories of what, why and how (pp. 34-50). New York: Routledge Publishers.

IUHPE. (2009). Achieving Health Promoting Schools: Guidelines for Promoting Health in Schools. Retrieved 15 January 2015, from

http://www.dhhs.tas.gov.au/_data/assets/pdf_file/0011/115895/guidelines_for_heal th_promoting_schools1.pdf.

Lister-Sharp, D., Chapman, S., Stewart-Brown, S., \& Sowden, A. (1999). Health promoting schools and health promotion in schools: two systematic reviews. Health Technology Assessment, 3(22), 1-207.

McMorris, L. E., Gottlieb, N. H., \& Sneden, G. G. (2005). Developmental Stages in Public Health Partnerships: A Practical Perspective. Health Promotion Practice, 6(2), 219-226. doi: 10.1177/1524839903260647

Plsek, P., \& Greenhalgh, T. (2001). The challenge of complexity in health care. British Medical Journal, 323(7313), 625.

Plsek, P., \& Wilson, T. (2001). Complexity, leadership, and management in healthcare organisations. British Medical Journal, 323, 746 - 749.

St Leger, L. H. (1999). The opportunities and effectiveness of the health promoting primary school in improving child health - a review of the claims and evidence. Health Education Reserach, 14(1), 51-69. doi: 10.1093/her/14.1.51

Stewart-Brown, S. (2006). What is the evidence on school health promotion in improving health or preventing disease and, specifically, what is the effectiveness of the health promoting schools approach? . Copenhagen: WHO Regional Office for Europe.

Tuckman, B. W. (1965). Developmental sequence in small groups. Psychological Bulletin, 63(6), 384-399. doi: 10.1037/h0022100

Van Raak, A., Mur-Veeman, I., \& Paulus, A. (1999). Understanding the feasibility of integrated care: a rival viewpoint on the influence of actions and the institutional context. The International Journal of Health Planning and Management, 14(3), 235-248. 
Curriculum Vitae

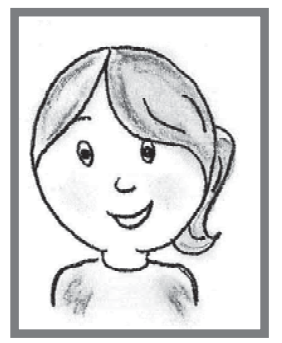



Katharina Pucher was born $4^{\text {th }}$ December 1984 in Poland. In 1990, her family emigrated to Germany, where she attended primary and secondary education. In 2004, she started studying Health Sciences at Maastricht University. After attaining the Bachelor's degree in General Health Sciences in 2007, she continued with the Master's program in Health Education and Health Promotion. She obtained her Master's degree in 2008, and started working as a PhD researcher at the Department of Health Promotion of Maastricht University. In her research project, which was practice-based, she worked closely together with health professionals from six public health services. From her position at the center of events, she studied the effects and processes of their collaboration with schools, municipalities and public service stakeholders in comprehensive school health promotion (CSHP). During her employment as a PhD researcher, she disseminated the study findings to relevant audiences at national and international conferences and at a network meeting for Dutch health professionals engaged in CSHP. Along with her employment as a PhD researcher, she fulfilled various teaching duties in the Bachelor's and Master's programs on Health Sciences and worked as a policy officer for educational matters at Maastricht University. Since October 2015, Katharina has been working as a postdoc researcher at Witten/Herdecke University. She is engaged in a European research project on the use of electronic decision support by general practitioners to reduce inappropriate medication and adverse drug events among elderly people with chronic diseases. 



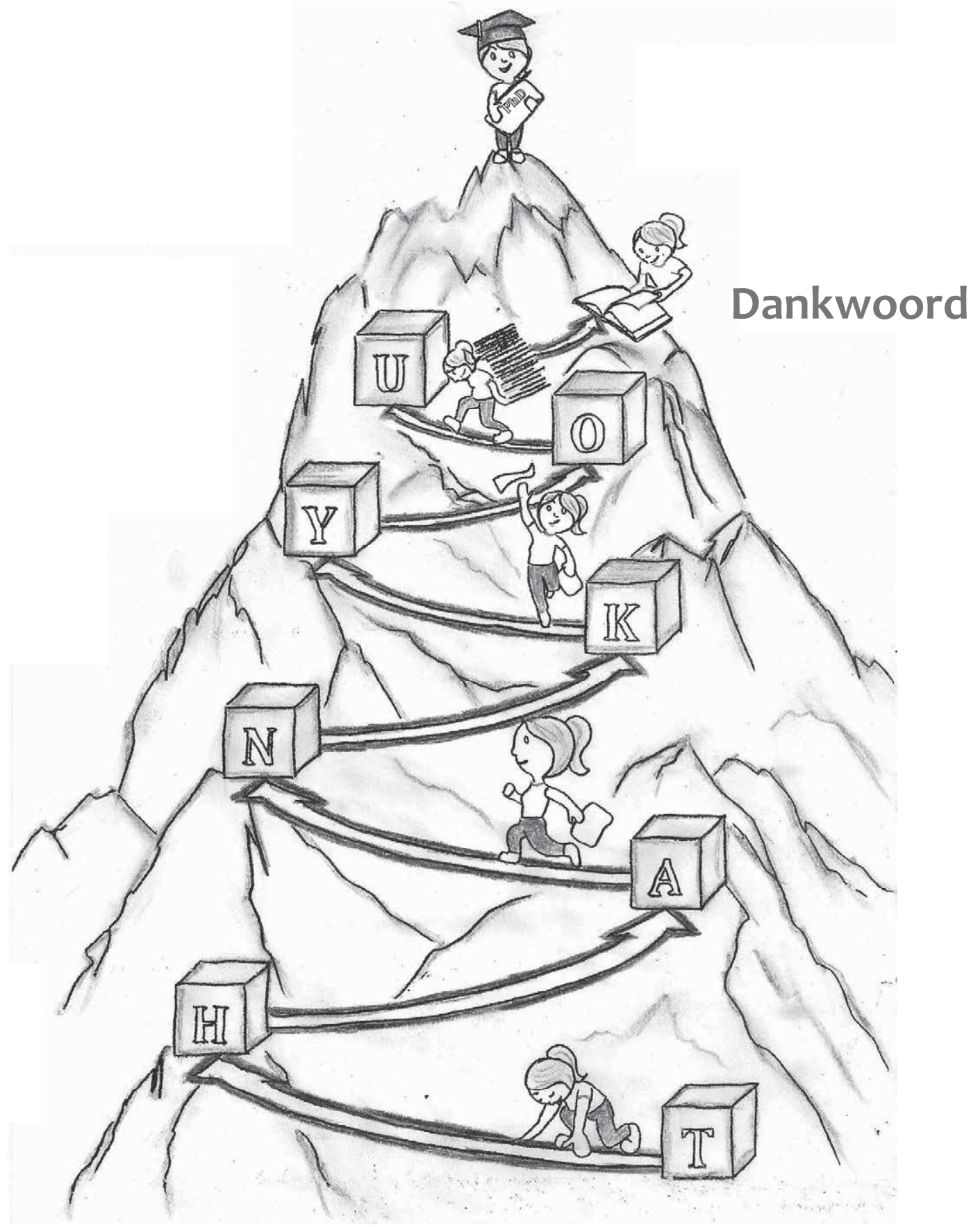



Graag wil ik iedereen bedanken die mij heeft begeleid en ondersteund bij het tot stand komen van dit proefschrift. Aan enkelen wil ik een bijzondere dank uitspreken.

Nanne, bedankt voor het delen van je expertise met mij en het vertrouwen dat je mij gegeven hebt!

Nicole, bedankt dat je voor mij en voor het onderzoek de deuren naar de praktijk hebt geopend.

Math, door de inbreng van uw expertise zijn nieuwe inzichten voor het analyseren van de onderzoeksgegevens ontstaan. Ik heb veel van u mogen leren over methodologie en statistiek. Bedankt voor uw toewijding.

Veel dank gaat naar de GGD'en die aan het onderzoek hebben deelgenomen. Twee jaar lang mochten we jullie dagelijks werk met scholen, preventieorganisaties en gemeenten volgen. Dank jullie wel voor jullie betrokkenheid.

Monique, Loes en Joris, bedankt voor jullie assistentie. Marja, bedankt voor het invallen als taalcorrector!

Beste collega's, maatjes om mee te sparren, kamer- en lunchgenootjes, bedankt voor de leerzame en gezellige tijd!

Lieve vrienden, wat fijn dat jullie er zijn! Jullie bieden mij altijd een luisterend oor en zorgen voor de nodige afwisseling. Daarmee hebben jullie me zeer geholpen bij het promoveren. Meine lieben Freunde, wie schön, dass es euch gibt! Ihr habt immer ein offenes Ohr für mich und sorgt für viel Abwechslung. Damit habt ihr mir beim Promovieren sehr geholfen.

Daniela und Saskia, es ist gut zu wissen, dass ihr mir bei meiner Verteidigung zur Seite stehen wollt. Während meiner Promotionszeit wart ihr mir in vielerlei Hinsicht eine fantastische Stütze. Danke dafür!

Meine liebe Familie, ihr habt mich unterstützt, wo(rin) und wann immer ihr konntet. Dafür und für das Verständnis, welches ihr mir und meiner Arbeit entgegengebracht habt, möchte ich mich bei euch ganz herzlich bedanken. Dziekuje babza ik wujek! Mum, dir danke ich besonders für deine unerschütterliche Zuversicht während dieser Zeit. 



\section{Publication list}

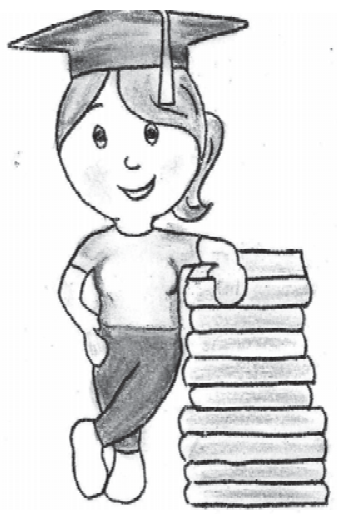





\section{Publications included in this dissertation}

Pucher, K.K., Boot, N.M.W.M., \& De Vries, N.K. (2013). Systematic review: School health promotion interventions targeting physical activity and nutrition can improve academic performance in primary- and middle school children. Health Education, 113( 5), 372-391.

Pucher, K.K., Candel, M., Boot, N.M.W.M, Van Raak, A., \& De Vries, N.K., (2015). A multiplecase study of intersectoral collaboration in the context of coordinated school health promotion using the Diagnosis of Sustainable Collaboration (DISC) Model. Health Education, 115(3/4), 301-321.

Pucher, K.K., Candel, M.J.J.M., Krumeich, A., Boot, N.M.W.M, \& De Vries, N.K., (2015). Effectiveness of a systematic approach to promote intersectoral collaboration in comprehensive school health promotion - a multiple-case study using quantitative and qualitative data. BMC Public Health, 15(613). doi: 10.1186/s12889-015-1911-2

\section{Submitted manuscripts included in this dissertation}

Pucher, K.K., Candel, M.J.J.M., Boot, N.M.W.M., De Vries, N.K. Predictors and mediators of sustainable collaboration and implementation in a two-year DISC-based trajectory - a longitudinal study in the context of comprehensive school health promotion. Health Education.

\section{Unpublished reports for public health services involved in the DISC-based trajectory}

Pucher, K.K., De Vries, N. K. (2009). Evaluation of school health promotion in the region MidHolland 2007-2008. A report on focus group interviews among stakeholders in comprehensive school health promotion.

Pucher, K.K., Boot, N.M.W.M., De Vries, N.K. (2008-2012). Intersectoral collaboration in comprehensive school health promotion-diagnosis and recommendations (13 DISC reports from the diagnoses at pretest, between measurements and posttests). 
